\title{
ORGANIC GROWTH: \\ BALANCING LIFEGIVING LEARNING PROCESSES \\ IN THE PROFESSION OF APPRECIATIVE INQUIRY PRACTITIONERS
}

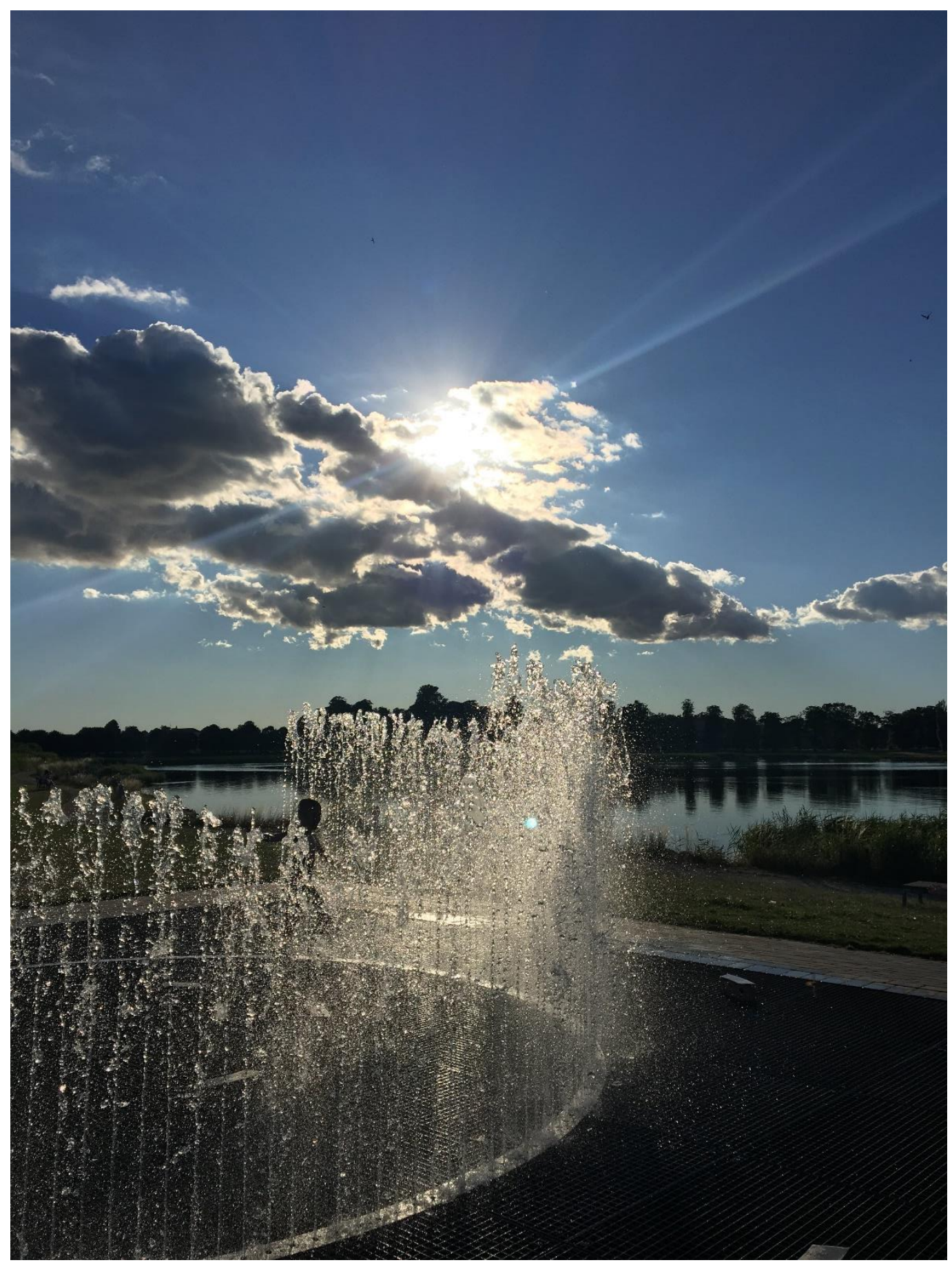

Mille Themsen Duvander 


\section{Graduation Committee:}

\section{Chairman and Secretary:}

Prof. dr. Th. A. J. Toonen, University of Twente

\section{Supervisors}

Prof. dr. C. P. M. Wilderom, University of Twente

Prof. dr. D. L. Cooperrider, Case Western Reserve University, USA

\section{Committee Members}

Prof. dr. E. T. Bohlmeijer, University of Twente

Prof. dr. M. D. T. Jong, University of Twente

dr. F. Lambrechts, Hasselt University, Belgium

Prof. dr. A. P. de Man, Vrije University, Amsterdam

Prof. dr. E. Todorova, University of National and World Economy, Bulgaria 


\section{ORGANIC GROWTH: \\ BALANCING LIFEGIVING LEARNING PROCESSES \\ IN THE PROFESSION OF APPRECIATIVE INQUIRY PRACTITIONERS}

\section{DISSERTATION}

to obtain

the degree of doctor at the University of Twente, on the authority of the rector magnificus,

Prof. dr. T. T. M. Palstra,

on account of the decision of the Doctorate Board,

to be publicly defended

on Friday, the $4^{\text {th }}$ of October, 2019 at $12: 45$ hrs.

by

Mille Themsen Duvander

born on the $27^{\text {th }}$ of January 1981

in Vordingborg, Denmark 
This PhD dissertation has been approved by:

Prof. dr. Celeste P. M. Wilderom (Supervisor)

Prof. dr. David L. Cooperrider (Supervisor)

Cover photography: Mille Themsen Duvander

Copyright (C 2019 Mille Themsen Duvander, Vordingborg, Denmark. All rights reserved. No part of this publication may be reproduced or utilized in any form or by any electronic, mechanical or by any means, now known or hereafter invented, including photocopying and recording without otherwise the prior written approval and permission of the author.

ISBN: $978-90-365-4861-8$

DOI: $10.3990 / 1.9789036548618$

URL: https://doi.org/10.3990/1.9789036548618 
Acknowledgements

I am forever grateful that I have been granted the opportunity to carry out this research. I would never had signed up for this challenge, if it was not on this subject and with these supervisors.

I would like to acknowledge the support of my supervisors Prof. Dr. Celeste Wilderom and Prof. Dr. David Cooperrider. I appreciate all the support they offered me, and I want to say special thanks for seeing the potential in me before I did.

The Al practitioners have been extremely kind and open; they generously shared the wisdom of their everyday professional lives. Thank you, all, for that. Thanks to my proofeditor Shelagh Aitken and my graphic designer Bjørn Nikolaj Lund Pedersen for your huge help and to Stine Lindegaard Hansen and Rikke Wriedt Klüver-Kristensen for healing help and wise guidance.

Many thanks go also to my workplace, the University College Absalon, for the time invested in the project, for every time they cheered me up and their professional support. Special thanks to Mikkel and to Neyah, Pernille, Geert, Mette, Gitte, Helle and Stine for valuable read-throughs and feedback and to Signe, Neyah and Nina for help in the research process. In Vordingborg, I have the most loving colleagues in the world.

A special thanks to the sisters, girlfriends, tribe sisters, dancing women and acquaintances I have felt a special connection with. May feminine power continue to be a worthy balancing partner to make the world a place for all of us.

My family is my world. For my parents: you are role models for many people and I will always cherish the way you created space for me to be me, to explore, to relate and to experience natural positive emotions. I wish for every child such a supportive environment, where no one takes away that pure curiosity.

My deepest appreciation and love for my husband, Jacob and our three sons Maurits, Julio and their baby brother, who have put up with a mother trying to be the most loving and present mother while mostly being the 'good enough' mother. I hope I succeed in creating loving space for you to be who you are, and space for the fun and endless happiness you bring to our lives. I love you.

Thank you to all those who helped me along the way but who have not been mentioned. We are all connected, and I could not have done this without everyone's support. Thank you. 
People are like stained glass windows - they sparkle when the sun is out, but when the darkness sets in, their true beauty is revealed only if there is a light within. Elizabeth Kübler-Ross.

There are only two ways to live your life: as though nothing is a miracle, or as though everything is a miracle. Albert Einstein.

Be the change you wish to see in the world. Mahatma Gandhi.

Be patient...try to love the questions themselves... Live the questions now. Perhaps you will then, gradually, without noticing it, live along some distant day into the answers. Rainer Maria Rilke.

I am going to do this. I am in an Al bootcamp, and I am going to be a Ninja. Interviewee.

Sometimes - the fastest way to get there is to go slow

And sometimes - if you want to hold on, you've got to let go. Tina Dickow, (singer-songwriter). 


\subsection{Abstract}

Appreciative Inquiry (AI) was conceived as a theory-building approach and at the same time a positive change method in organizational development. Since the 1980's, the approach has spread into several other arenas, and many people have learned to focus on "what gives life to a living system when it is most alive" (Cooperrider, Whitney \& Stavros, 2001, p. 3). But what about the people who profoundly apply the principles of appreciative inquiry in their personal and professional lives? What is important for appreciative inquiry practitioners' own development processes?

It has been said that human beings are living longer but suffer more, with stress, anxiety and depression widespread as diagnoses in today's Western cultures. The aim of this thesis is to discover what gives life to Al practitioners, with the purpose of learning from them to be inspired regarding greater wellbeing.

The study is an inquiry into the worldwide community of Al practitioners, who represent a unique context for studying human flourishing. The core phenomenon of organic growth developed in this study is based on grounded theory, in which concepts and theories emerge from the data. This process led to literature that helped give a context for the interpretation of the data; social learning theories, theories of flourishing, of consciousness development and of quantum physics. Fieldwork included twenty-four interviews and two interactive workshops with Al practitioners, as well as participant observations, and the fieldwork showed these Al practitioners' raised levels of human flourishing. The new idea this study brings is the introduction of the social learning conceptual model of organic growth, which is a model about how Al professionals can develop in flourishing ways.

The study shows that these Al practitioners actively prioritize finding balance in their work life, trust in a very significant way and enter states of flow when possible. They navigate via intuition and openness towards uplifted relational energy in shared processes, they take responsibility for their own healing of trauma and patterns, and they work and live from a quantum physics understanding of wholeness, which means that everything is connected. These six dimensions makes up the model of organic growth.

Organic growth provides a new theoretical approach towards the understanding of adult development. The dissertation concludes with a discussion of important implications that organic growth can have in educational and other organizational or institutional settings. 


\subsection{Abstract (Dutch)}

Appreciative Inquiry (AI) kwam tot stand als een theory-bouwende benadering en tegelijkertijd als een positieve veranderingsmethode in de sfeer van organisatie ontwikkeling (OD). Sinds de jaren tachtig van de vorige eeuw heeft Al zich verspreid in verschillende andere arena's, terwijl veel mensen hebben zich hebben leren focussen op "what gives life to a living system when it is most alive" ("wat geeft leven aan een levend systeem als deze het meest levendig is") (Cooperrider, Whitney \& Stavros, 2001, p. 3). Dit proefschrift stelt de vraag: Hoe zit het met de mensen die op diepzinnige wijze de principes van Al in hun eigen privé en professionele leven toepassen? Wat is belangrijk voor het eigen ontwikkelingsproces van de beoefenaars van Appreciative Inquiry? $\mathrm{Er}$ wordt tegenwoordig vaak gesteld dat mensen weliswaar langer leven, maar meer lijden o.a. via stress, angst en/of depressie als wijdverspreide diagnoses in de Westerse culturen. Het doel van dit proefschrift is om erachter te komen wat leven geeft aan professionele Al beoefenaars met als doel van hen te leren en inspiratie op te doen met betrekking tot een beter menselijk welzijn.

Dit proefschrift rapporteert een onderzoek naar de wereldwijde leefgemeenschap van professionele Al beoefenaars. Deze professionals werken doorgaans in complexe en unieke organisatiecontexten met als oogmerk om daarbinnen het menselijk floreren te stimuleren. Het kernfenomeen van organische groei, ontwikkeld in deze studie, is gebaseerd op grounded theory waarin concepten en theorieën uit de data exploratief naar voren kwamen. Dit proces leidde tot literatuur die hielp om een context te creëren voor de interpretatie van de data; social learning theorieën, theorieën over floreren, bewustzijn ontwikkeling en kwantumfysica. Het veldwerk behelsde vierentwintig interviews en ook twee interactieve workshops met Al beoefenaars als ook observaties van de deelnemers. Het veldwerk liet bij deze Al beoefenaars verhoogde niveaus van menselijk floreren zien. Het nieuwe idee wat door deze studie wordt voortgebracht is de introductie van de 'social learning' type conceptuele model of organische groei, wat een model is van hoe Al professionals zich kunnen ontwikkelen zodat ze op veel verschillende wijzen kunnen floreren.

De studie laat zien dat de Al beoefenaars op actieve wijze prioriteiten stellen bij het vinden van een balans in hun 'work-life' situatie, op een hele diepe wijze vertrouwen stellen en regelmatig zgn. 'flow states' ervaren. Ze navigeren intuïtief en met een openheid voor relationele energie in sociale processen. Daarnaast nemen ze verantwoordelijkheid voor hun eigen genezing van trauma en terugkerende onwenselijke patronen, en ze werken en leven vanuit een kwantum-fysisch begrip als 'wholeness' (alles is met elkaar verbonden). Het gepresenteerde model van organische groei wordt door deze zes dimensies bepaald.

Organische groei levert een nieuwe theoretische benadering op voor het inzicht in de ontwikkeling van volwassenen. Het proefschrift vind zijn conclusie in een discussie over belangrijke implicaties die organische groei kan hebben voor educatieve en andere organisatorische of institutionele (intermenselijke) verbanden. 


\subsection{Table of contents}

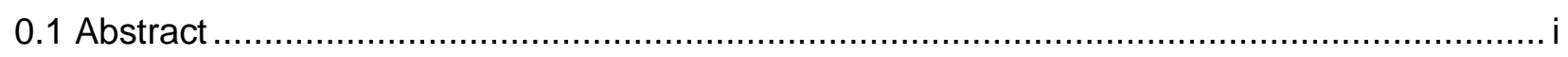

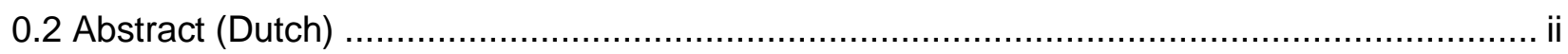

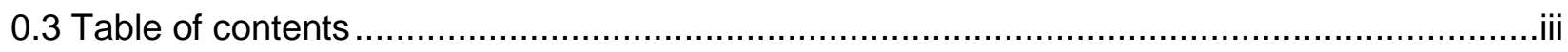

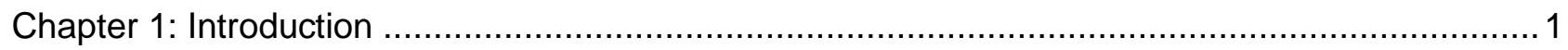

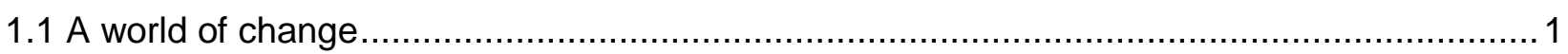

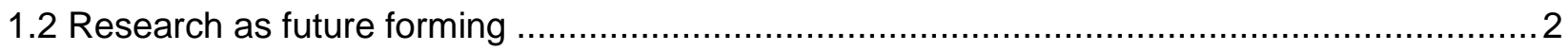

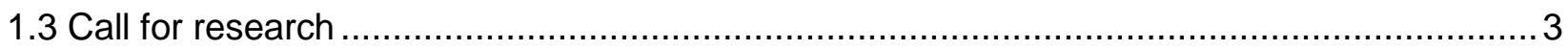

1.4 The characteristics of the group being researched ....................................................... 4

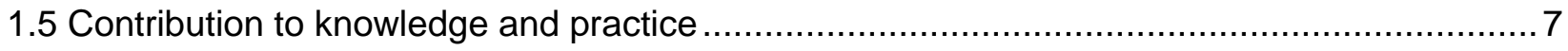

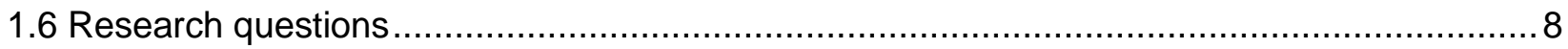

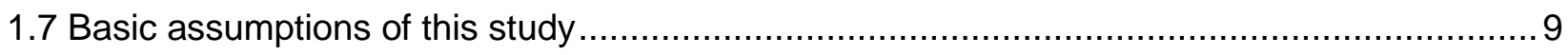

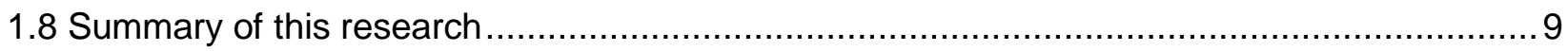

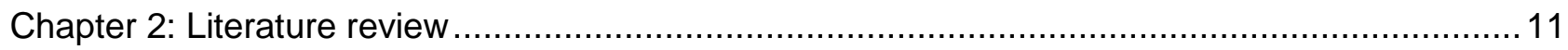

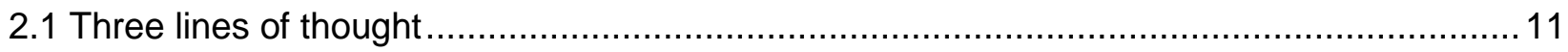

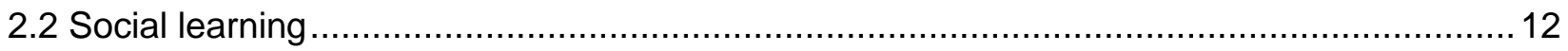

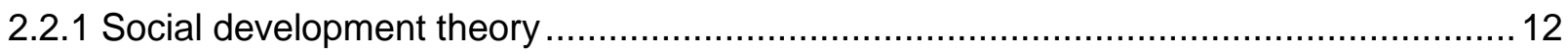

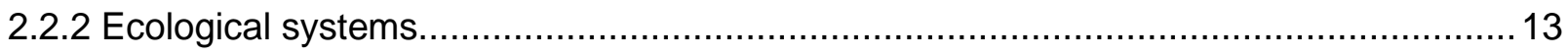

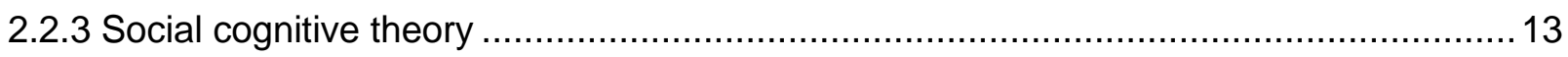

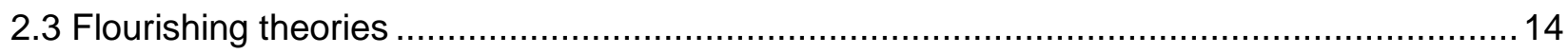

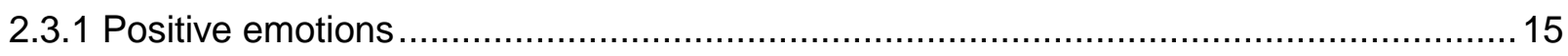

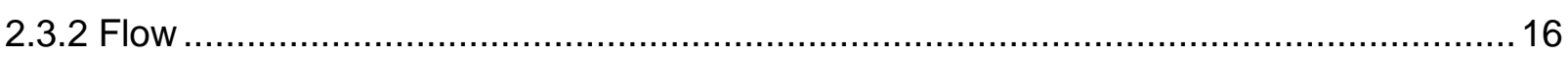

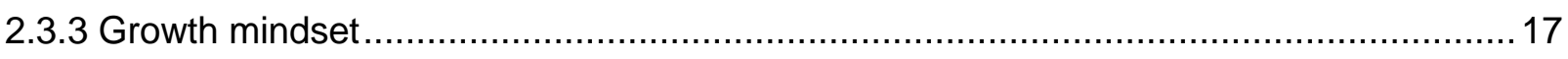

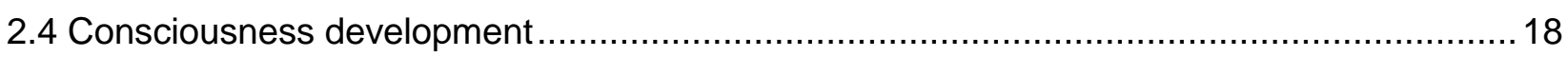

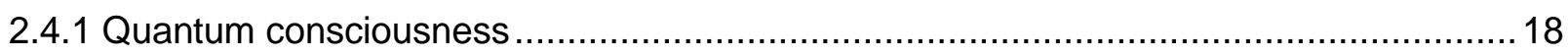

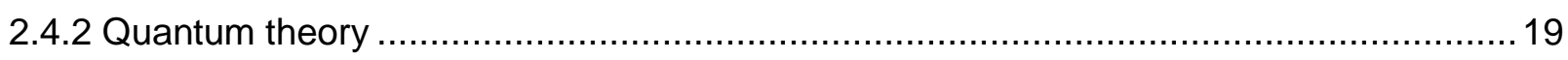

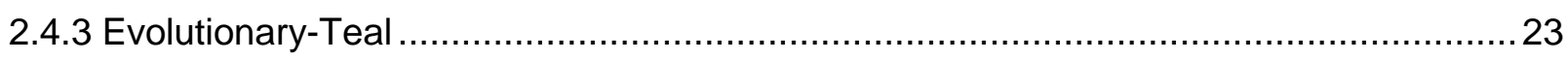

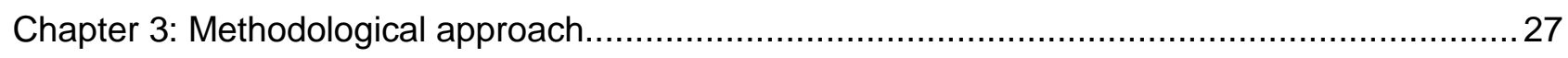

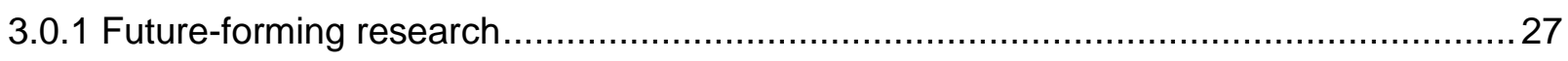

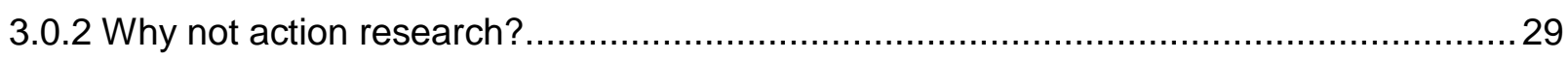

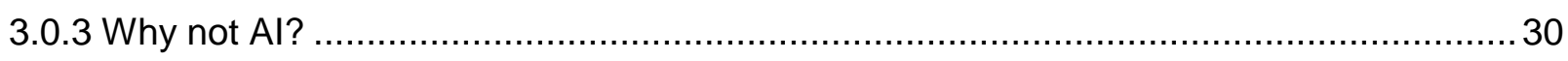

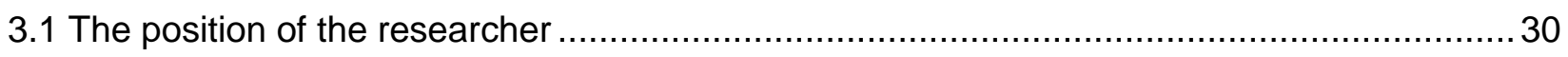


3.1.1 All research is autobiographical: Introducing the researcher's voice. 31

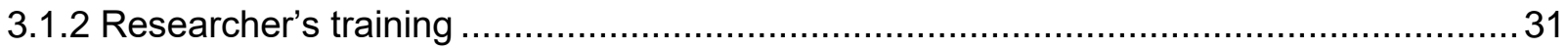

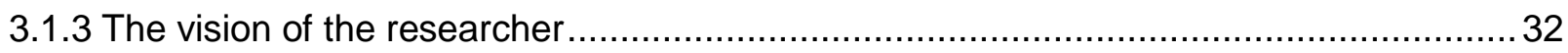

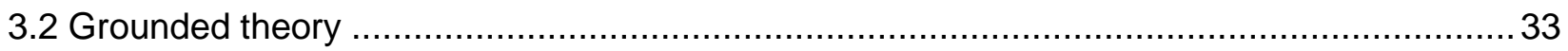

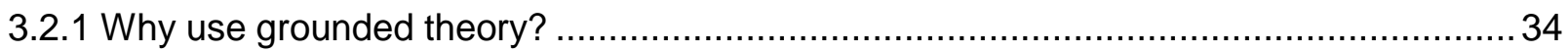

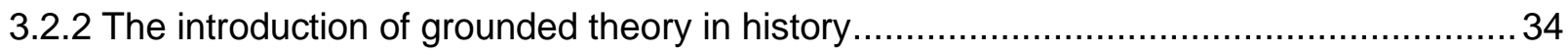

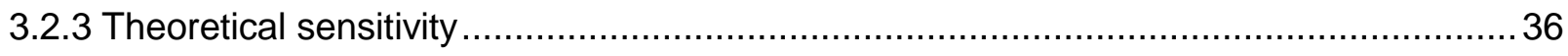

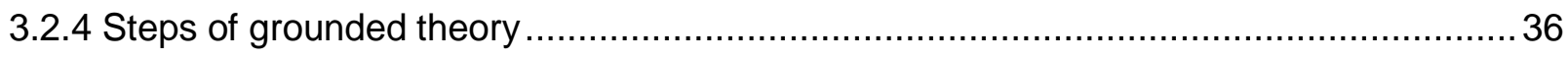

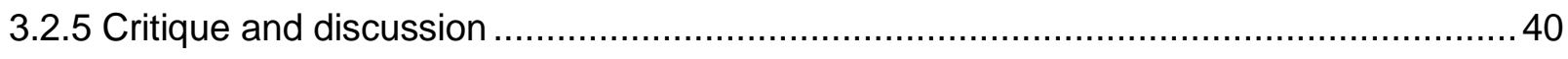

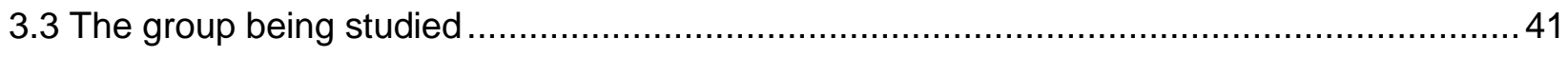

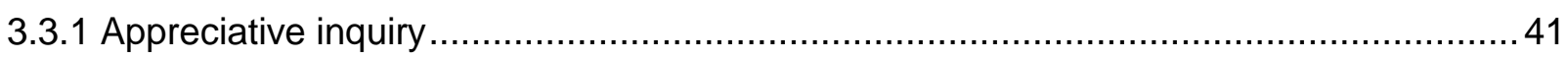

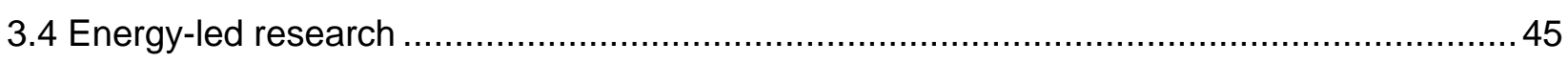

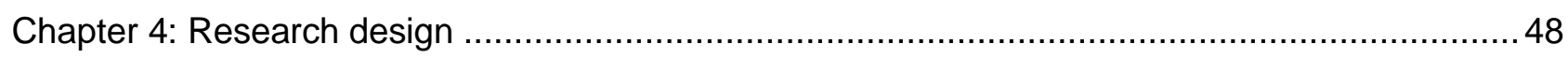

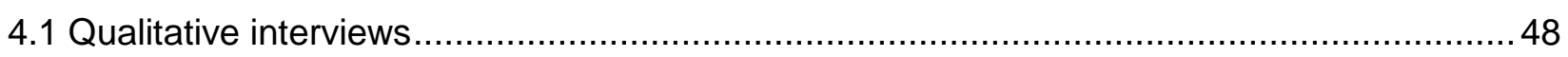

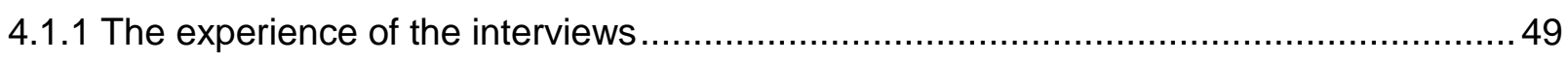

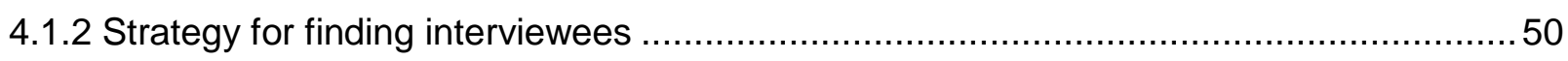

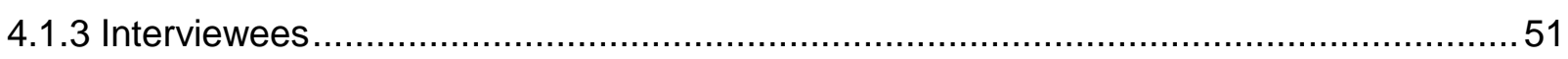

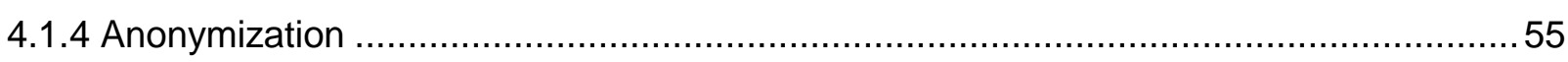

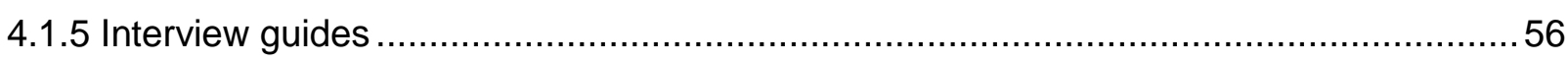

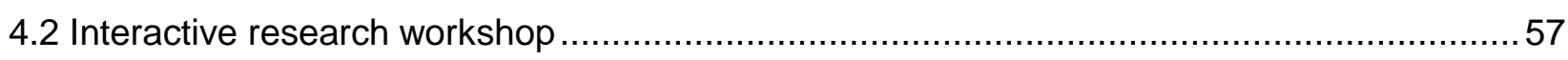

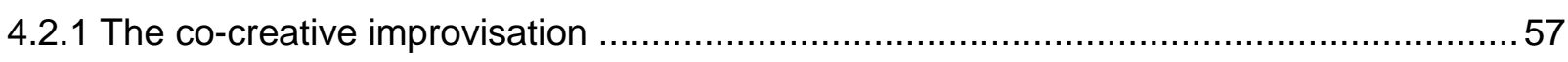

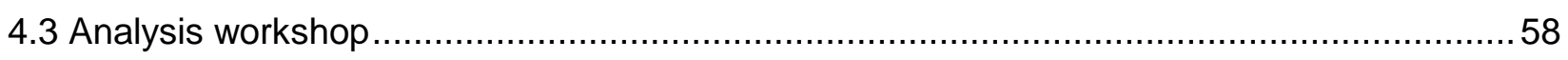

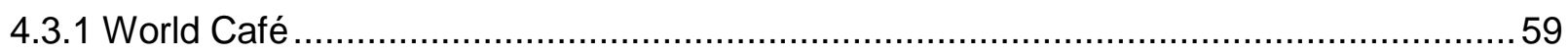

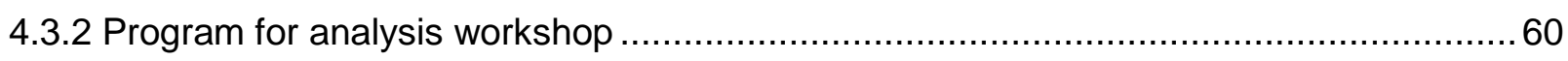

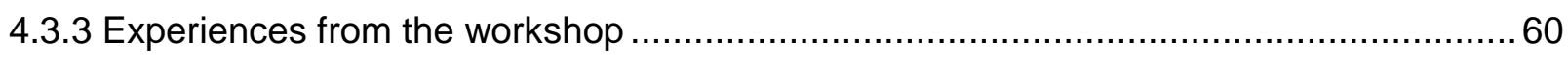

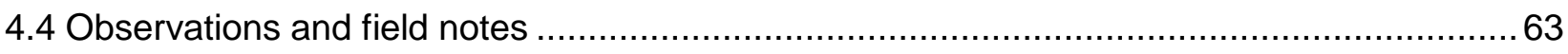

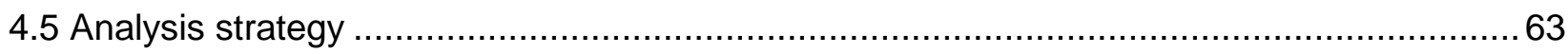

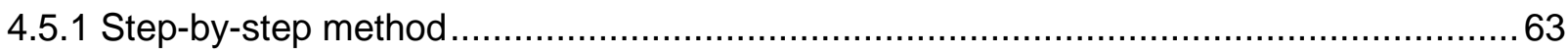

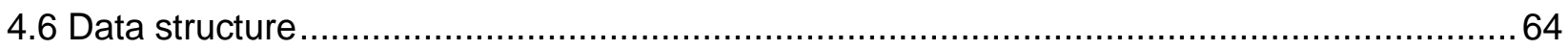

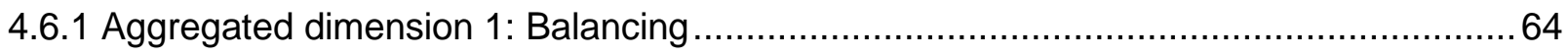

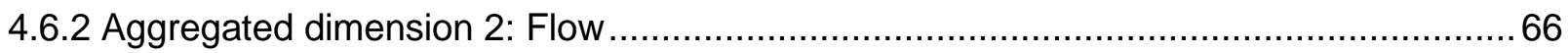

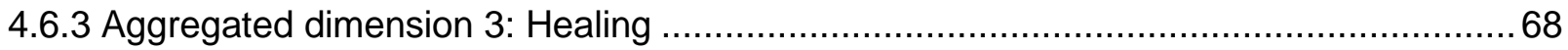

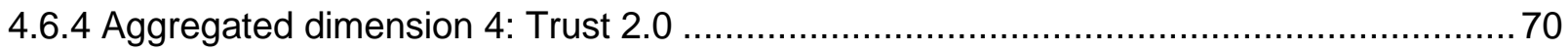

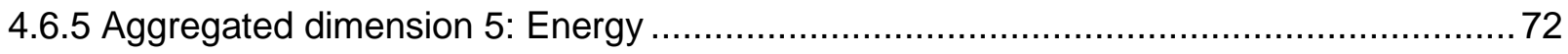




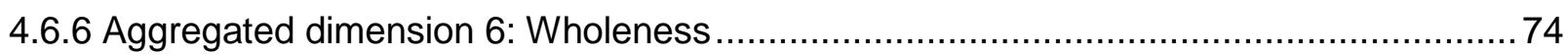

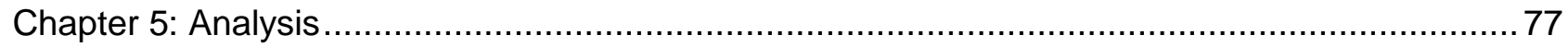

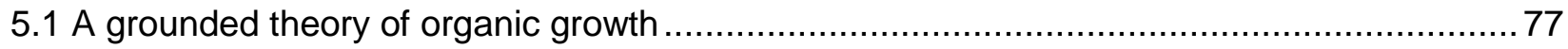

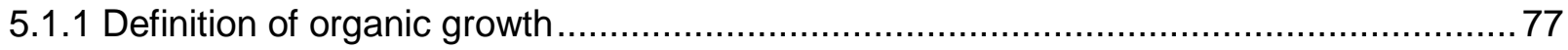

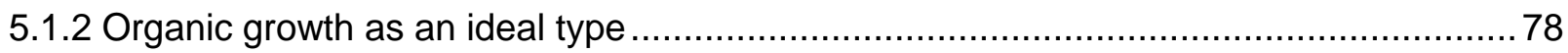

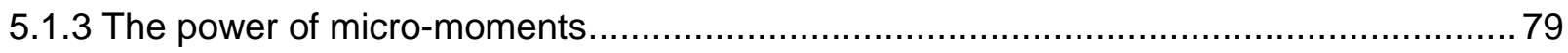

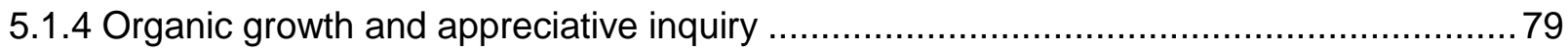

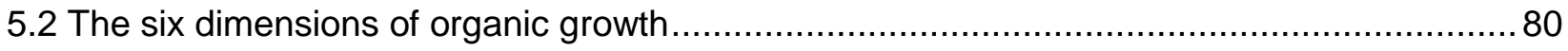

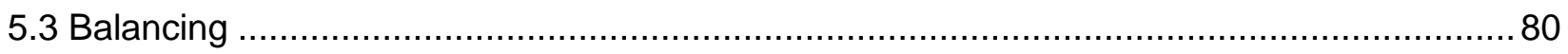

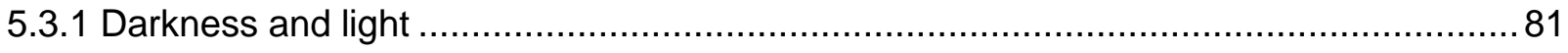

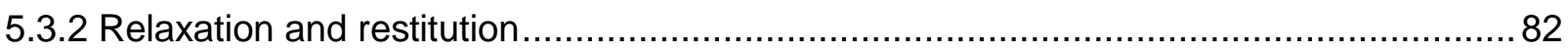

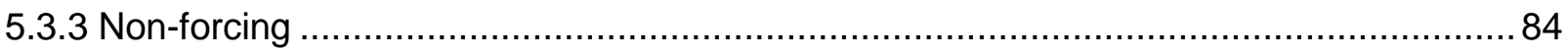

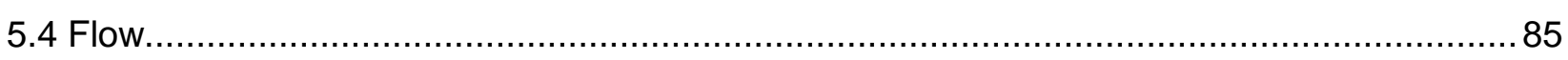

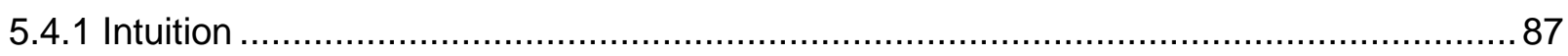

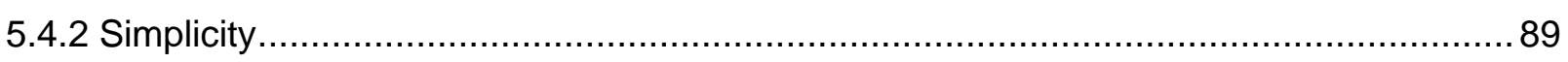

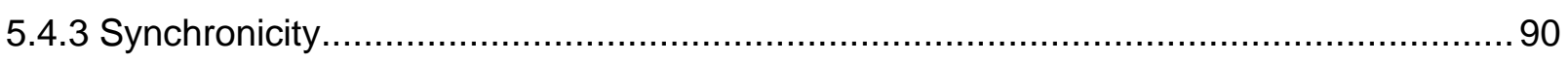

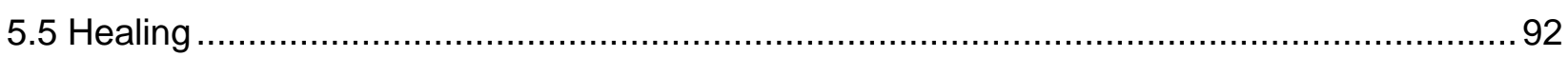

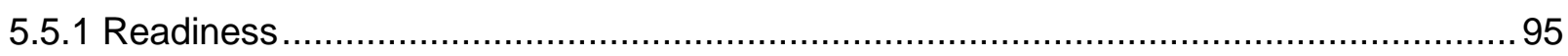

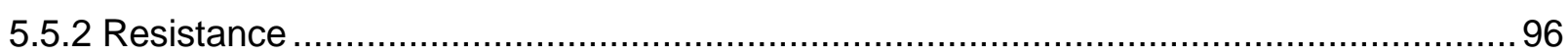

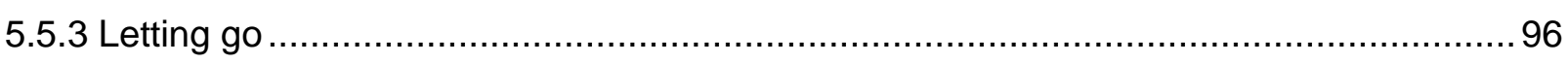

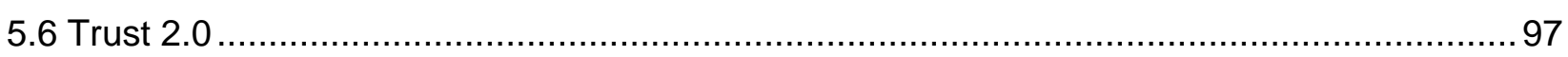

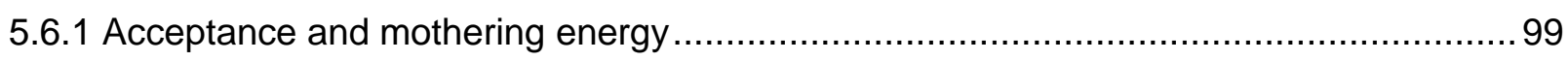

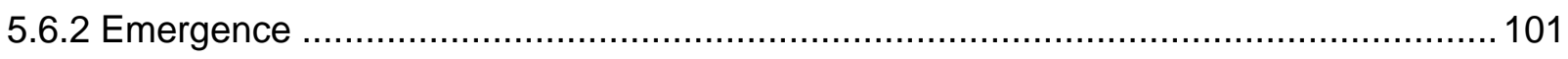

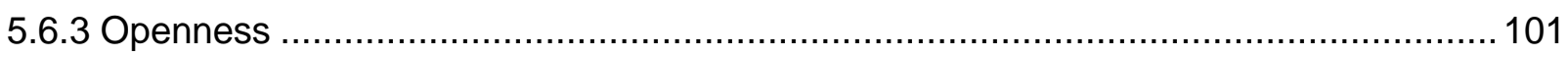

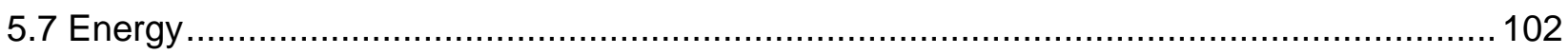

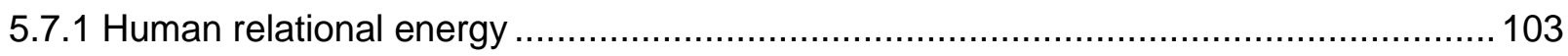

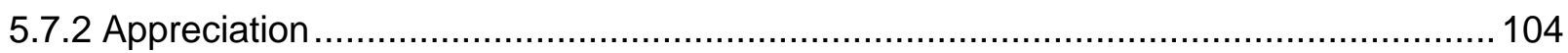

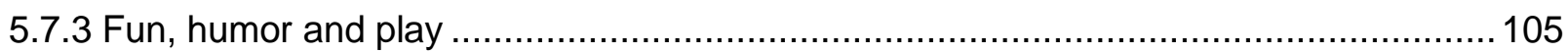

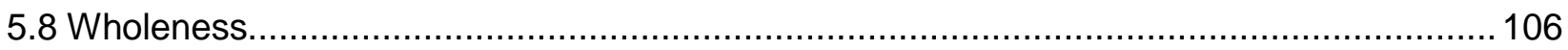

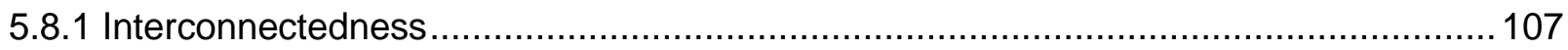

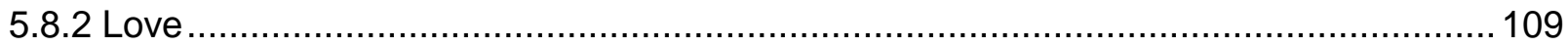

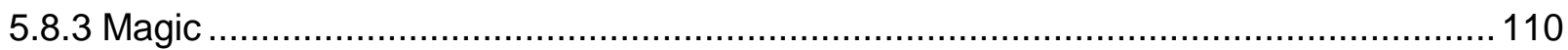

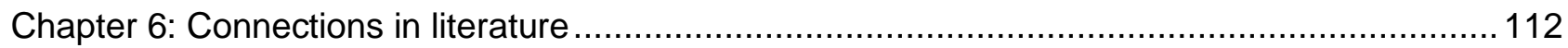

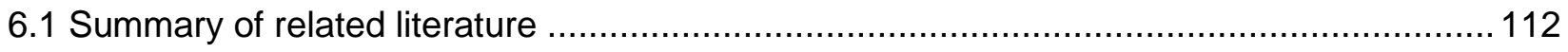


6.2 Connections to previous research on Al practitioners 113

Chapter 7: Findings and interpretations 117

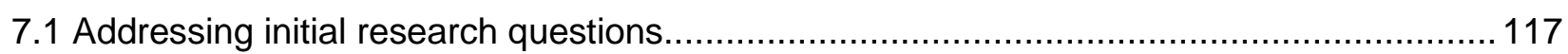

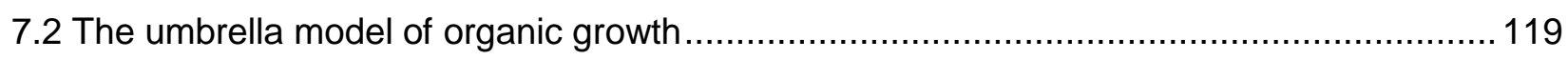

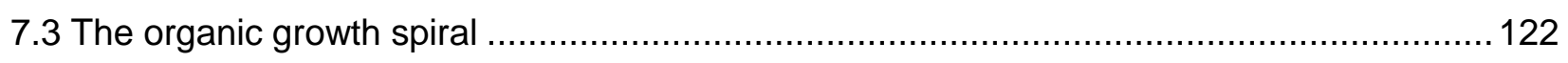

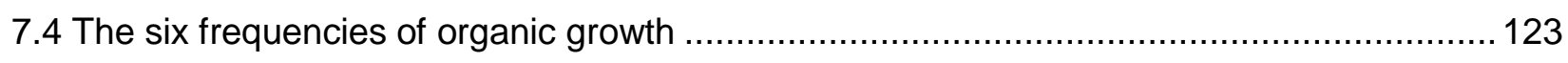

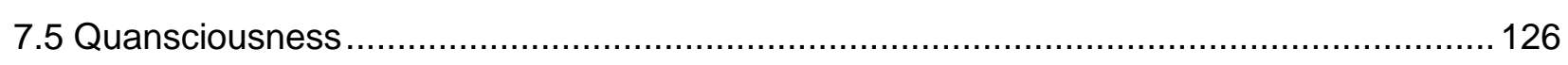

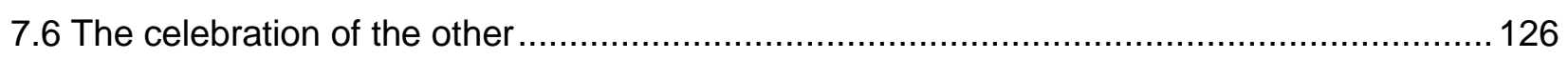

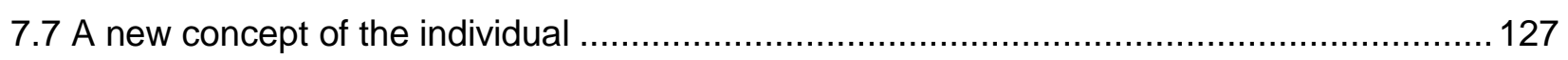

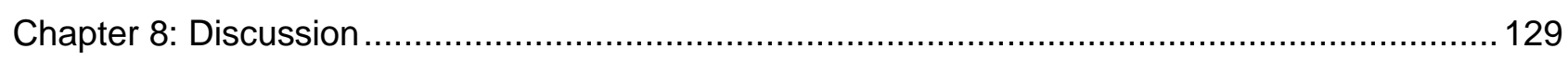

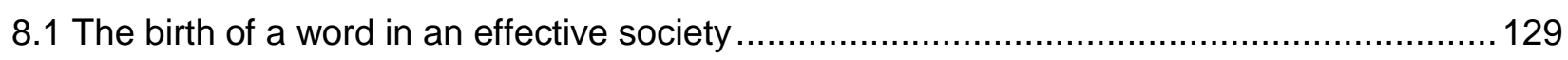

8.2 Negativity bias or wired for the positive? ............................................................. 130

8.3 Shifting roles: Social construction and appreciative inquiry ....................................... 130

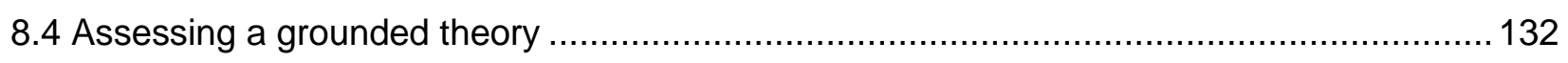

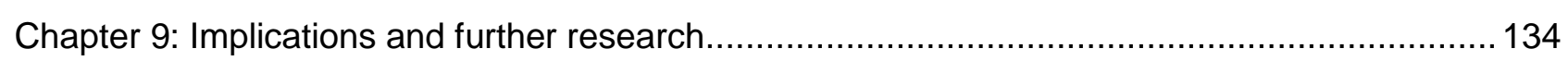

9.1 Implications for the scholarly field of learning theories .............................................. 134

9.2 Identity and emotional work for appreciative inquiry practitioners ............................... 135

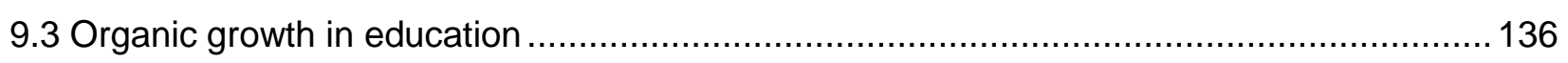

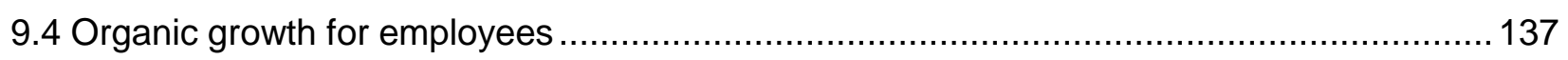

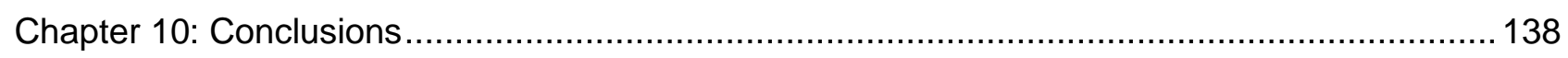

10.1 The organic growth of the positive change practitioner ............................................ 138

10.2 The relations between organic growth and its six dimensions ................................... 139

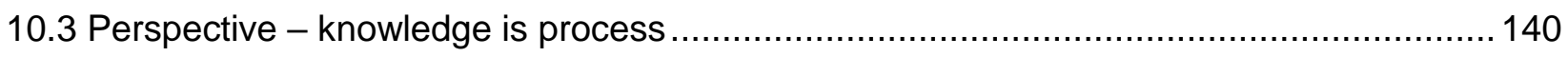

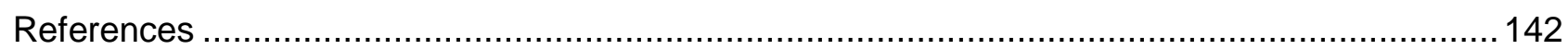

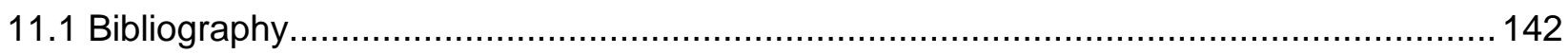

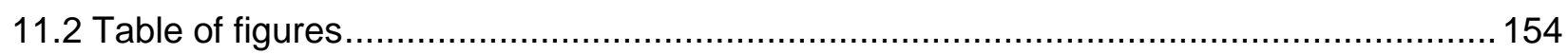

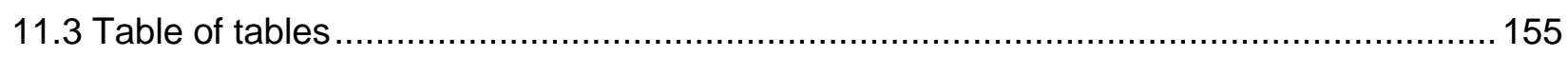

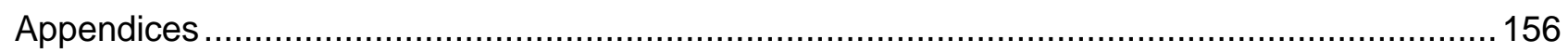

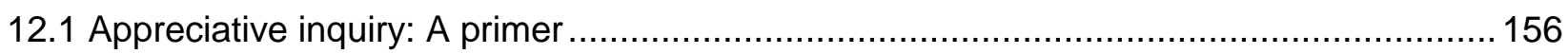

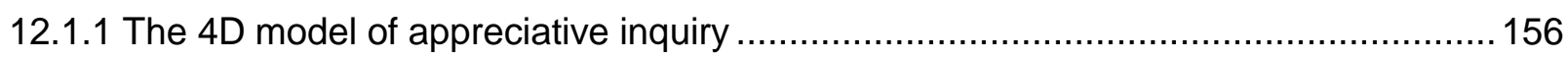

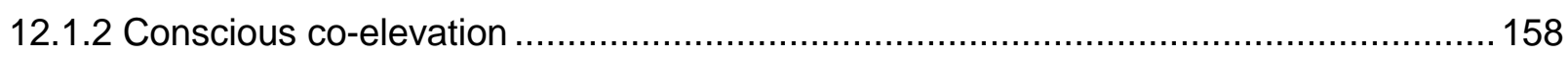

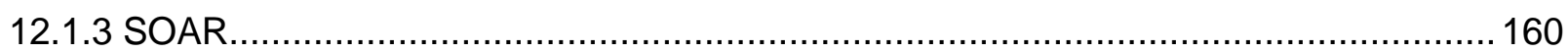

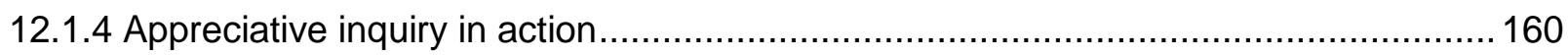

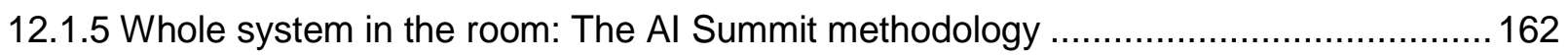


12.2 Slides for the "Co-creating Research" workshop. 164

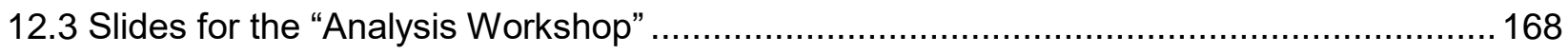

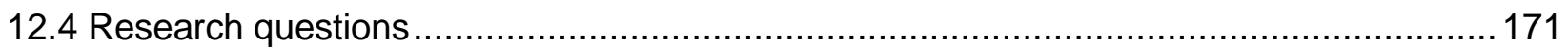

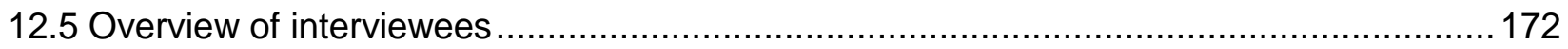

12.6 Quotes from interviews, observations and workshops ............................................ 173

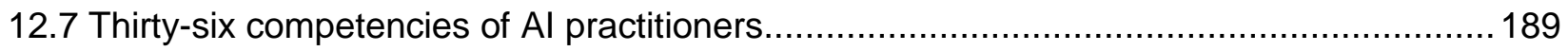

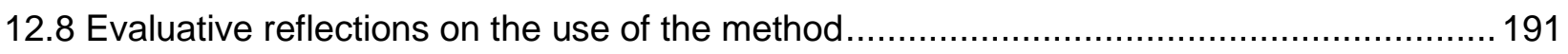

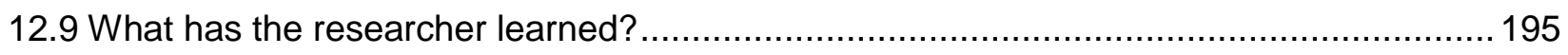

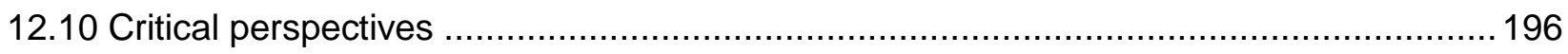

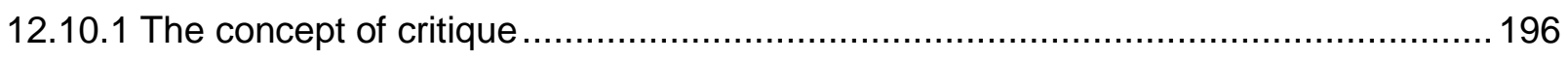

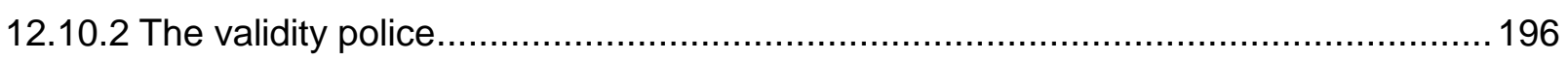

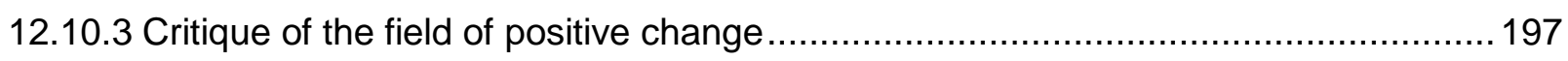

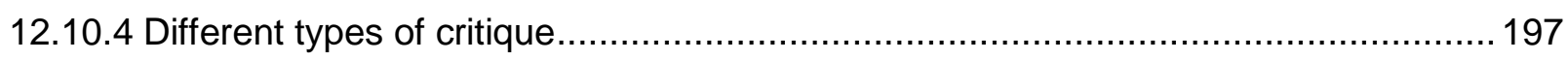

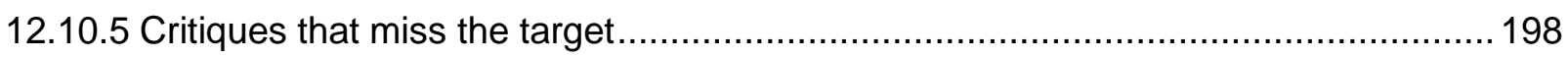

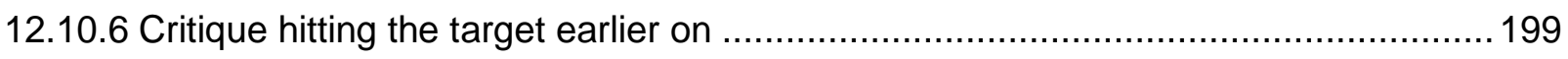

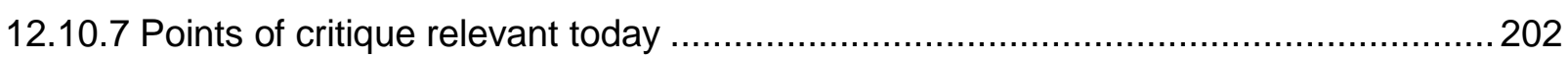




\section{Chapter 1: Introduction}

This introduction sets the context for this study, from the global level of change in our world to the group of people being studied. Calls for research are laid out in this chapter, as is the constructionist approach of future-forming research which inspired this study. The aim of the present PhD study and its basic assumptions are introduced and a summary of the research project is presented before moving into Chapter 2.

\subsection{A world of change}

Change happens fast in our world. In the early 1990's a model called VUCA was used in the American military as a way of describing the fast-changing and complex world we live in: Volatility, Uncertainty, Complexity and Ambiguity. VUCA characterizes the way the world is understood: uncertain and complex, often functioning in unpredictable ways. The model has been used in many settings, including management theory, strategic planning, nonprofit organizations and in education. A complex and fast changing world obviously affects human beings.

It can be argued that one way humans distinguish themselves from other living beings on this planet is by their ability to keep learning throughout their lives. Living in a world where many experience increased speed, rising amounts of information and high levels of demands, learning and adaptation have become crucial to survival in Western cultures. Change and development are no longer a pleasant bonus in life, but crucial, for example, in keeping a job.

In the field of health, it has been said that we live longer but we suffer more (Bhagat et al., 2016). Within the last three decades, the world has seen an increase in the number of people experiencing stress, anxiety and depression, and there are many examples of stress-intervention projects and research papers (Lamontagne, Keegel, Louie, Ostry \& Landsbergis, 2007). There are a number of reasons for the increase of work-related stress: "Rapid growth of the global economy coupled with the major technological changes in the workplace and the structure of the modern family are largely responsible for significant increases in work stress in the Western and nonWestern world" (Bhagat, Segovis \& Nelson, 2016).

In spite of the research funds that have been invested in this area, we have not yet turned the corner. An increasing number of people experience a high-paced and pressured work environment. The experience of the micro-system - the individual - and their family and network includes stories associated with loss, absence, disease, pressure, striving and lack of meaning in life (Antonovsky, 1979; Owens, Baker, Sumpter \& Cameron, 2016).

In the field of science, change has also been pronounced, and the shift between two important paradigms are significant. The Newtonian paradigm and the quantum approach are ways of characterizing the era in which we are living. Founder and CEO Emeritus of VISA, Dee Hock, puts it this way in 1996:

We are at the very point in time when a 400-year-old age is dying, and another is struggling to be born - a shifting of culture, science, society, and institutions enormously greater than 
the world has ever experienced. Ahead, the possibility of the regeneration of individuality, liberty, community, and ethics such as the world has never known, and a harmony with nature, with one another, and with the divine intelligence such as the world has never dreamed. (Waldrop, 1996, p. 1)

The Newtonian scientific paradigm takes its name from the English physicist, Sir Isaac Newton (1643-1727), who played a large role in formulating mathematical theories about the physical laws important to an understanding of the world we live in. These laws have been challenged by quantum physicists, and by the observation and greater understanding of the smallest elements scientists have been able to observe: the structure of atoms. When researchers began inquiring into atoms at the beginning of 20th century, they found that they did not behave according to Newtonian laws of physics. Since then, many writers have concentrated on what the findings from quantum physics mean, both to the world and to human ways of living (e.g. Bohm, 2005; László, 2008; Zohar \& Marshall; 1990; Lipton, 2008). The shift in paradigms is important to this study because the group of appreciative inquiry practitioners being studied here often embraces new ways of thinking and living in their work-life inspired by quantum physics. A new type of research in the social sciences belongs to this new paradigm and is called "future-forming research" (Gergen, 2015).

\subsection{Research as future forming}

The notion of future-forming research surfaced in the article From Mirroring to World-Making: Research as Future Forming (Gergen, 2015). In order to suggest a new approach to research, Gergen lays out the "no longer relevant" characteristics of research as we commonly know them. He calls this classic understanding of research "mirroring" and describes how all social science research starts with the assumption that we need to mirror the world we see: to illuminate, reflect, precisely reproduce and describe how the world IS. "As I have proposed, when research commences with an 'object of study' the result is an extension of existing traditions and suppression of alternative realities" (Gergen, 2015, p. 294). There are several arguments for choosing to direct research into forming the future. One of them is the changeable world we live in, a world of flux and VUCA. He asks an important question:

If we find ourselves in a world where increasingly unpredictable fluctuations mark everyday facets of life - from self-conceptions, family life, and community to global configurations of power, economy, and illness - what is the place of a research tradition that attempts to mirror a stable state of affairs? (Gergen, 2015, p. 297)

How does future-forming research represent an alternative? By "future forming", Gergen suggests research that not only mirrors what is in the world, but that which will co-create the future. The aim of the research is not to focus on what is and what has been, but is an invitation to co-create the future with the group being researched. Social change is therefore part of the purpose. It is "Research as a future forming practice - a practice in which social change is indeed the primary goal" (Gergen, 2015, p. 292). To create social change for the betterment of humans is noble. But social change has not been the primary goal of research through the centuries, even though much research has caused social change. Take, for instance, the inventions of the radio, the television, 
the internet and the smartphone - and the ways in which these devices have created social change (sometimes for the better, sometimes not), through years of scientific development. The difference is that social change is now directly desired and sought after through research, which implies a new way of conducting research as well as new questions to be asked.

As part of his explanation of future-forming research, Gergen gives the example of what to inquire into so that research helps form the future in valuable ways instead of shedding light on the "worst parts" of humanity. He suggests inquiring into the wellbeing of immigrants instead of their suffering; how discourses can foster mutuality instead of "otherness"; how late-life can flourish instead of all the challenges that surround becoming old; how creating new job programs instead of inquiring into poverty; and how to eradicate hunger instead of documenting it (Gergen, 2015, p. 295).

What if we replaced the persistent rush to establish "What is the case" and began to ask, "What kind of world could we build?" This would be to place the researcher's values in the forefront of his/her activities. Rather than their latent presence in the choice of terminology and methodology and in the vain hopes that an absent audience will somehow make use of one's work, what if purposeful and passionate visions supplied the source of inquiry? Given a valued vision of the possible, the challenge for research would not be to illuminate what is, but to create what is to become. (Gergen, 2015, p. 295)

In this study, the research project has been designed with inspiration from a future-forming understanding of research, and therefore seeks to place the researcher's values at the fore. To ensure that the researcher's values and passionate visions are front and center, the researcher's vision will be described in a following section.

\subsection{Call for research}

Gergen invites further studies in the area of future-forming research, where the research reflects the vision and values of the researcher, where the group being studied is invited to co-create their future, and where the research questions are focused on a desired future and how to create it (2015). This study is designed to meet the requirements for future-forming research.

In the area of consciousness development and quantum theories, writers have made contributions to the field that include keywords like "leap" and "revolution" (e.g. Graves, 1974; László 2008; Wilber, 2000; Beck \& Cowan, 2014). If humans have had this kind of knowledge and perspective for nearly fifty years, and everything is said to be moving at a faster pace, why aren't changes occurring in mainstream understanding and current global events? As in Laloux's research (2014), this study sets out to find the "bursts of lights", the "cracks in the asphalt" where weeds have found impossible ways through, and where life has already found a way.

In 2017, a PhD project called for further research on the subject of synchronicity (Merry, 2017) and though this was not the subject for this current study, the grounded theory developed in this project has certain similarities with Merry's understanding of synchronicity. Synchronicity is a sub-concept of the model of organic growth (see section 5.4.3). This study, therefore, also follows Merry's call (2017). The special group of practitioners being studied will be introduced in the following section. 


\subsection{The characteristics of the group being researched}

In the past, anthropologists traveled to distant countries, deep into the jungle or to remote islands to observe tribal cultures. It is hard for anthropologists to find isolated tribes to study these days, and much attention is directed toward the study of, for example, identity conflicts, subcultures and global flows (Gergen, 2015, p. 297). Today's ethnographic studies illuminate alternative constructions of the world by inquiring into small communities, for example bodybuilders, sex workers, or motorcycle gangs to name a few (Gergen \& Gergen, 2004). This current study explores one of today's tribes, to learn about their lives, their culture and how they make meaning in their lives.

The population is a group of people who are practitioners in the community of practice working with the organizational theory appreciative inquiry (AI) (Wenger, 1998; Cooperrider \& Srivastva, 1987). Professionals practicing appreciative inquiry are described in this research as "appreciative inquiry practitioners" (Al practitioners). What makes them a unique population is the fact that they carry out positive changes in their work life and are inspired by the theory of Al. They do not necessarily share backgrounds, sex, age, educational level or work environment, and have been chosen solely because they practice appreciative inquiry. The following model illustrates how this group of practitioners can be understood in relation to a wider population of change practitioners (see Figure 1.)

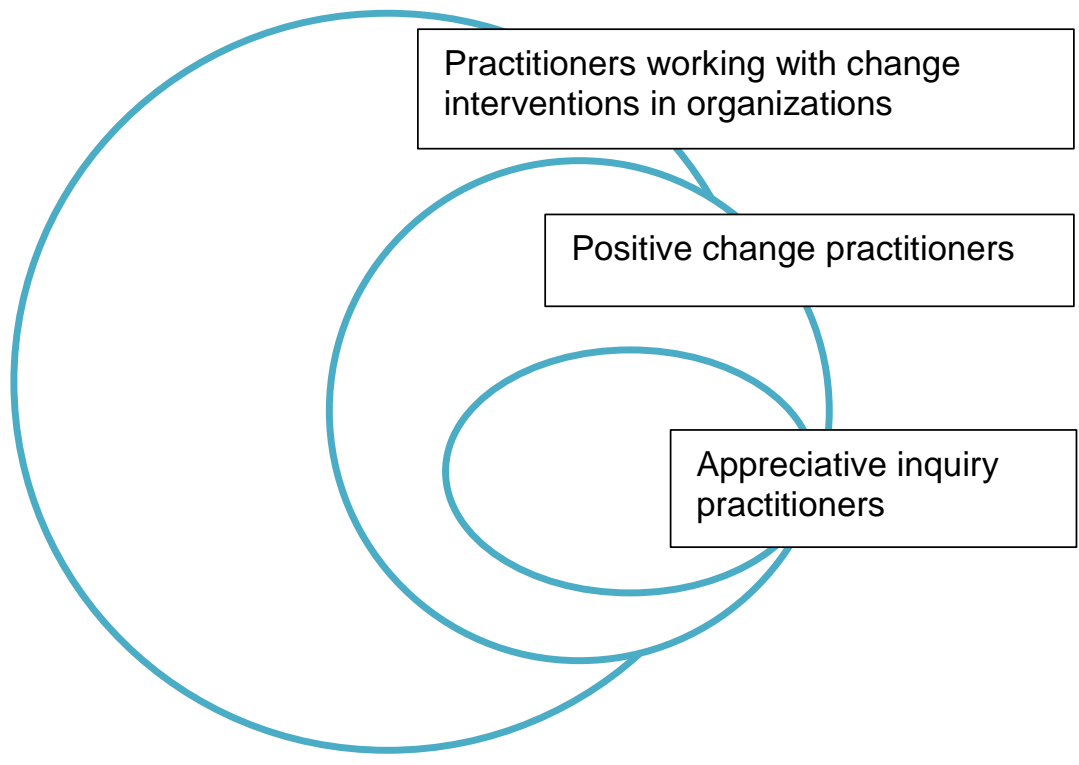

Figure 1. Appreciative inquiry practitioners.

The largest circle illustrates the population of practitioners working with change interventions in organizations; let us call them "change practitioners". A part of this population of change practitioners, shown in the middle circle, are working from flourishing perspectives, which means that they work to create and lead change initiatives that allow people and organizations to flourish and thrive. They are called positive change practitioners here, and they are often inspired by theories and methods that uplift, e.g. positive psychology and strength-based approaches. The reason why the circle also goes outside the largest circle is because these positive change 
practitioners mostly create positive change in organizations but can also work in other settings, like families, counselling or communities. A number of these positive change practitioners have a preference for using Al to create positive change, and we find them in the smallest circle. These practitioners most often work in organizations as well, but can also work with families, communities, etc.

Al practitioners approach positive change from a relational mindset inspired by social constructionism (Gergen 1982, 1996, 2008; Berger \& Luckmann, 1991) which means that they operate from an understanding of relational being and do not focus on the individual. Al practitioners seem to be passionately concerned with creating and co-creating the best, strongest and most connected frameworks for building and maintaining positive changes, and to consciously co-elevate systems in strength-based processes:

(...) we change the best when we are the strongest: as human beings, we change best and in the most elevated way when we experience the magnified and resonating power of every relevant resource available to us across the entire systemic strengths spectrum, outside and inside the system, including social and cultural assets, technical and economic ones, psychological and spiritual strengths, ecological strengths of nature, and the strengths of moral models, positive deviations and collaborative creativity. (Cooperrider \& Godwin, 2015, p. 10)

Al practitioners are interesting to study because their numbers include some of the agents leading the revolution of flourishing change in the world. First articulated as a method to generate theories, appreciative inquiry was introduced by David Cooperrider in his $\mathrm{PhD}$ research with a focus on what gives life to a living system when it is most alive (Cooperrider, 1986; Cooperrider \& Srivastva, 1987). The applied power of Al was soon obvious, and Al spread into domains such as change management, organizational development, design thinking, applied positive psychology, learning theory, coaching and counselling, and evaluation studies. Gergen uses the words "love affair" to describe his relationship with $\mathrm{Al}$ and emphasizes that the "growth and application of appreciative inquiry over the past two decades has been nothing short of phenomenal. It is arguably the most powerful process of positive organizational change ever devised" (Whitney, Trosten-Bloom, \& Rader, 2010, p. 1). There is no doubt about the power of this approach: Al has been included as one of three of the most significant academic catalysts of strength-based management, alongside Martin Seligman's and Peter Drucker's work (Buckingham, 2010). Robert Quinn, world-renowned University of Michigan professor, has said that Al is revolutionizing the field of organizational development and change.

But why has this approach been praised this way? The theory of $\mathrm{Al}$ is about creating lifegiving change and elevating strengths in businesses and organizations (Cooperrider, 2000, 2004, 2005; Cooperrider \& Srivastva, 1987; Bushe, 2001; Barrett \& Fry, 2008; Whitney \& Trosten-Bloom, 2010). Al marks a radical shift in human orientation to change, to organizations, to work, and to everyday life. If humans are free to construct alternative languages and therefore alternative realities (Gergen, 2005), then why not co-construct realities more beneficial for the people living in them? Al represents a shift in mindset away from a problem-oriented approach. It recognizes that there are valuable solutions which depend on a wide variety of conversations and collaborations between different viewpoints; and that what is good can always be re-negotiated. Al provides both 
a theory and tools for ways to elevate a system's strengths, and magnify systemic strengths in society with the identification and design of positive institutions.

We are profoundly shaped by what we study - human systems move in the direction of what they ask questions about most frequently, authentically, and rigorously. Instead of being woven at random like an afterthought in a larger fabric, inquiry shall become the centerpiece thread weaving things together for a theory of appreciative inquiry. For some this is a big claim, especially the idea of a snowballing effect or exponential inquiry effect from even a tiny question. Certainly, it is a big challenge for our conventional assumptions about the nature of knowledge. As it is typically understood, good science is objective and detached and the scientist is an impartial bystander whose methods should not influence the events he or she hopes to understand. But this view is unnecessarily limiting, and over many years has served to restrain us from fashioning a humanly significant science, unique in its own terms, and capable of helping life become all that it can be. (Cooperrider, 2017, p. 101)

Because of its social constructionist foundation, Al practitioners bring a clear focus to relations, collaborations, institutions and communities, and less to individualistic wins. The focus on connections makes Al practitioners relevant for this study, because they include relations and "wholeness" in the picture and provide an alternative understanding for the strong construction of the self.

In relation to stress discourses, the number of mental illness diagnoses have exploded within the last century (Gergen in Kaslow, ed., 1996). "Every time you build a world of ideas or join one, it is like a screening device that limits you from seeing other worlds" (Hoffmann in Kaslow, ed., 1996). Touching upon the field of occupational stress, there is a widespread language for negative emotions and for ways to seek professional help as an individual. Instead of reproducing this language, this study tries to open up to new ways of talking about wellbeing.

The Al practitioners included here have been studied as practitioners within a community of practice. "Communities of practice" are described by Wenger as places where learning happens socially in the interaction between people (Wenger, 1998). Communities of practice as a phrase has roots in works about social learning inspired by social theory and anthropology (Lave, 1988; Bourdieu, 1977; Giddens, 1984; Foucault, 1980; and Vygotsky, 1987). Communities of practice are social learning systems. The term derives from the social learning theory developed by Wenger (1998), where "situated learning" is understood to be the product of social structure (Lave \& Wenger, 1991).

It is a perspective that locates learning, not in the head or outside it, but in the relationship between the person and the world, which for human beings is a social person in a social world. In this relation of participation, the social and the individual constitute each other. (Wenger, 2009, p. 1)

Communities of practice can be a way to liberate innovation value for organizations (Pór \& Bekkum, 2004). A report made by the American Productivity and Quality Center (APQC) says, "Communities of practice are the next step in the evolution of the modern, knowledge-based 
organization" (Pór \& Bekkum, 2004, p. 8). This points to the possibility that communities of practice have the potential to help create or unleash potential within organizational contexts, and therefore may have the same potential in other contexts.

There are important arguments for choosing the population of Al practitioners. In addition to these arguments, the researcher has chosen this group because they have touched her heart. She has experienced how people involved in Al initiatives are uplifted and shine in their light together, how they passionately change themselves and their world by following these methods. As we will learn through this dissertation, this heart-based argument, or pull, is worth following when creating future-forming research. Before the end of this section I would like to emphasize that, even though $\mathrm{Al}$ is important for the group being studied and was the reason they were chosen as a group of practitioners, $\mathrm{Al}$ is neither the research method nor the core research object of this study.

The reflections listed provide a short introduction to the group of Al practitioners belonging to the community of appreciative inquiry. This leads to how this study contributes to the knowledge and practice of flourishing communities of practice.

\subsection{Contribution to knowledge and practice}

Because of the interdisciplinary nature of this research, the results of this study will, it is hoped, impact the following areas: social learning, flourishing theories and consciousness development. In the area of flourishing theories, samples are often created by general selection, for example of students or "average" adults (Fredrickson, 2001, 2004). It is hoped that this study will contribute to that body of work by inquiring into a certain group of people who represents clear tendencies to flourish, because they have been recruited specifically to meet that criterion.

In relation to social learning theories, there has been a wide focus on the relationship between the individual and social influence, and research has focused on how to describe the importance of both (e.g. Vygotsky, 1987; Bronfenbrenner, 1994; Bandura, 1977; Wenger, 1998). In this regard, this study adds a quantum perspective in reference to wholeness, because the practitioners work from a perspective of wholeness, which includes the individual and the social aspects, as well as all other aspects. Wholeness can be hard to grasp and will be addressed further both in the literature review and in the analysis. To operate from an understanding of wholeness yields therefore a new reference frame for social learning.

In relation to consciousness development, it is hoped that this study will contribute knowledge about a group of people who often work from "higher levels of existence" (Graves, 1974) - what Laloux describes as an "evolutionary-teal"1 area (Laloux, 2014) - with knowledge about what moves these practitioners, how they develop and how they navigate in their lives. This study invites further research within the communities of positive change practitioners in order to create more knowledge about this group and how they can serve as inspiration for others.

\footnotetext{
${ }^{1}$ Laloux uses the phrase evolutionary-teal to describe the newest form of human consciousness and collaboration; teal is about building on strengths, wisdom beyond rationality, wholeness with life and nature and inner rightness as compass among others (Laloux, 2014). Please find a further explanation in section 2.4.3.
} 
The primary group is the Al practitioners who co-construct and receive a frame resonating with their development processes. What characterizes the rather small population of Al practitioners is what Thatchenkery and Metzker call "appreciative intelligence" (Thatchenkery \& Metzker, 2006). It consists of an ability to appreciate the positive, to reframe situations, and to see the mighty oak in the acorn - that is to see the bright potential future in the current situation. They have persistence, tolerance for uncertainty, great resistance and a belief that their actions matter (Thatchenkery \& Metzker, 2006). They can imagine relevant, shared futures and make them real in co-creating with all the voices in a community or organization (Browne \& Jain, 2002). This study hopefully adds to this picture by providing a set of consistent ideas for how these practitioners develop and how they navigate in their everyday life in order to maintain and further develop this appreciative intelligence.

Apart from the contribution to the field of Al practitioners in particular, and positive change practitioners in general, it is hoped that this study will also find its way into professional practices of child care and teaching, because focus on flow and balance have the possibility of creating more lifegiving, fun and creative childhoods and school years. Employee wellness and thriving is the final area where this study can have an impact, because of the enriched language around trust, balance and wholeness, which are of immediate relevance for workplaces with stress issues. To be able to contribute, this study started out with curiosity and some research questions.

\subsection{Research questions}

In the initial phase of this research, the aim was to study what moves Al practitioners. The use of grounded theory allowed a theory related to personal and relational development to emerge, and it became clear that this new frame of reference enriched specific thought traditions. Part of the aim then became to fill a gap of what is missing in the understanding of social learning within the areas of flourishing and in the understanding of consciousness development. Another part of the aim was to co-create ways to manifest this frame of human development and making it real by involving practitioners in this future-forming piece of research in order to co-create the future.

The specific aim of this study was not obvious until about one-third of the interviews had been conducted. This was only possible because of the study's future-forming approach, as well as the grounded theory method. Grounded theory invited the researcher to enter the field asking openly "what is the main concern of the people in the group being studied" (Glaser \& Strauss 1967; Glaser, 1978; Glaser, 1998). The purpose of the research then became to present the new language of organic growth - which came to be the main concern - and its six dimensions: balance, flow, trust, healing, energy and wholeness, as well as to inquire into the following questions:

- How can organic growth be defined?

- What factors contribute to organic growth?

- How can organic growth be described as a process?

- How do Al practitioners benefit from growing organically?

- Which kind of theoretical landscapes does the frame of organic growth belong to?

- How does the frame of organic growth add to these landscapes?

Research and change are interwoven, and change starts the minute you ask the first question 
(Cooperrider \& Srivastva, 1987). This study is therefore designed accordingly, with the underlying yet explicit intention of helping to develop a richer language.

We cling to outmoded assumptions such as the one that states that inquiry and change are separate moments. In human systems things do and can change in an instant and that spells real opportunity, in our view, for a new kind of generative and anticipatory theory that affirms that there are no laws related to social systems - only the imaginative ideas, constructions, valued possibilities, and meaning systems that we give them. (Cooperrider, 2017, p. 102)

When research and change are interwoven, the aim of the research becomes to take care of both the construction of the research and the co-creation of social change. Beneath the set of primary research questions are four basic assumptions, all of which make it possible to ask the chosen questions.

\subsection{Basic assumptions of this study}

The basic assumptions behind this research are as follows:

1. People engaging in "communities of practice" are a new sort of group worth inquiring into as a place of learning and because communities of practice may prove to be powerful centers for future change initiatives (Pór \& Bekkum, 2004; Aurama, 2017).

2. The community of Al practitioners is worth studying because characteristics of the practitioners are similar to descriptions of people in what authors have called "newly developed states of consciousness" (Graves, 1974; László, 2008; Bohm, 2005; Laloux, 2014), which refers to layers of consciousness not developed in historical times but only in modern days.

3. There are streams of action inviting the historical split between what is labeled "science" and what is labeled "religion" into new dialogue (Laloux, 2014; Willerslev, 2004; Scharmer, 2000).

4. There is an openness and readiness in the world to not only have wisdom about abstract ideas such as wholeness, energy and intuition, but to have examples of how to practice these understandings in practical settings.

These basic assumptions have guided the understanding of the world that is the foundation of the current study. They clearly limit this research, in that it will not be relevant for those who do not resonate with them, and other studies may be more valuable to them. A summary of this research project is provided below before moving into the literature review.

\subsection{Summary of this research}

This study contains field research into the community of Al practitioners in order to learn what moves these practitioners and how they grow organically. This has included questions regarding organic growth, how it can be defined, what key factors describe organic growth, what the practitioners do on a practical level to grow organically, and how this relates to the surrounding 
society. The empirical data consists of three points of entry into the Al community:

1. Twenty-four qualitative interviews.

2. One research workshop and one analysis workshop with Al practitioners.

3. Participatory observations and field notes during an Al conference and a certificate course.

Relevant literature is presented in relation to organic growth; literature on social learning, flourishing theories and works on consciousness development, and their relation to the model of organic growth is included. The following key perspectives are incorporated: social development theory (Vygotsky, 1987); ecological systems (Bronfenbrenner, 1994); adult human development (Graves, 1974; Rooke \& Torbert, 2005); social cognitive theory (Bandura, 1977); learning in communities of practice (Lave \& Wenger, 1991; Wenger, 1998); positive psychology and flourishing theories (Fredrickson, 1998, 2009, 2013; Fredrickson, Mancuso, Branigan \& Tugade, 2000; Csikszentmihalyi \& Csikszentmihalyi, 1988; Csikszentmihalyi, 1990, 2014; Dweck, 1988, 2010); theory U (Scharmer, 2000; Scharmer \& Kaufer, 2013); intuition and synchronicity (Rosch, 1999; Jaworski, 2012); quantum theory (Bohm, 2005; László, 2008); and human consciousness development in organizations (Laloux, 2014).

As a result of this study, a grounded theory and a model of organic growth is proposed along with six dimensions and is discussed as a language for human development for positive change practitioners. Implications for practice and further research are identified at the end. 


\section{Chapter 2: Literature review}

In a study using grounded theory in a classical way (Glaser, 1978, 1998), the researcher would not conduct a literature review before going into the field, because the topic of the research would emerge in the field. When the core category has emerged, a literature review can be conducted if relevant for the topic, and a literature search in different scientific fields would often be necessary in order to learn more about the core category and its dimensions.

In this study, a literature review was not conducted before the interviews, coding and analysis phase, although some reading had been done within the field of appreciative inquiry before choosing the population of Al practitioners and the Al community of practice.

The review of literature was done after the core category emerged, when it became clear that a flourishing model about conscious social learning was the result of this study. The core category and the six dimensions of organic growth were all developed by working with the empirical data. This means that the following review is related to and was completed in order to position the model of organic growth within a scientific landscape. In this case, in three "lines of thought", where the model of organic growth pays tribute to and contributes to existing theories. The section is called lines of thought because they represent different ways of thinking, mostly scientific 'footpaths' but also studies with a practical approach toward knowledge creation.

\subsection{Three lines of thought}

The three lines of thought are: 1 . Social learning theories; 2 . Flourishing theories; and 3. Consciousness development. They are illustrated by this model:
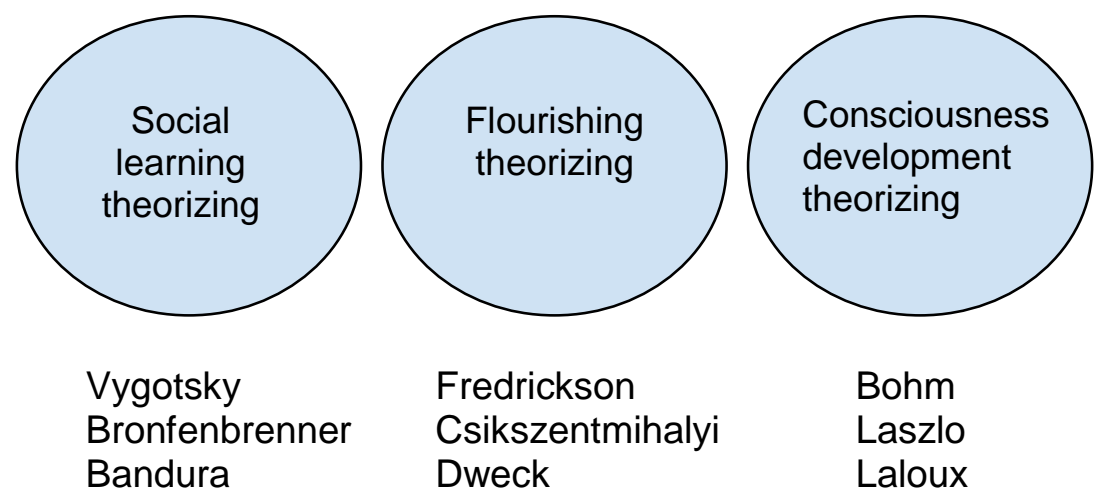

$$
\begin{aligned}
& \text { Bohm } \\
& \text { Laszlo } \\
& \text { Laloux }
\end{aligned}
$$

Figure 2: Three lines of thought

As mentioned above, these lines of theorizing are all related to the framework of organic growth and also resonate with appreciative inquiry as will be elaborated in Chapter 6 . 


\subsection{Social learning}

The first line of thought, social learning theories, turned out to be relevant for this study because the model of organic growth emerged as a result of working with the empirical data. As we shall see in the analysis, organic growth is described as a model about how these positive change practitioners develop in their lives and their careers. The following theories of social learning contain perspectives that resonate with specific parts of organic growth. These will be addressed at the relevant points (Bronfenbrenner, 1994; Vygotsky, 1987; Bandura, 1977) and connections to these theories will be made in Chapter 6 .

\subsubsection{Social development theory}

Social interaction has an important role to play in a person's development, and a human being's mental development processes depend on social and cultural interactions with others (Vygotsky, 1978). Vygotsky claimed that social learning is a precursor for development within the individual system, which means that the child needs to interact with the social world before it can develop higher mental processes. Vygotsky states that the child needs adults in order to develop cognitive abilities, but that children are born with basic functions including attention, sensation, perception and memory. These eventually develop into "higher mental functions" because the child interacts with the social world and close relations over time. The following notions are particularly relevant to mention, in that they resonate with the dimensions of organic growth. The "zone of proximal development" (ZPD) is a key idea in Vygotsky's theory and describes the zone where the child has the possibility of learning with a "more knowledgeable other", as opposed to discovery learning, where the child discovers for herself (Piaget, 1959). Worth mentioning is that Vygotsky distinguishes between inner speech, private speech and social speech, and that the concept of "inner speech" originated in Vygotsky's works:

Inner speech is not the interior aspect of external speech - it is a function in itself. It still remains speech, i.e., thought connected with words. But while in external speech thought is embodied in words, in inner speech words die as they bring forth thought. Inner speech is to a large extent thinking in pure meanings. (Vygotsky, 1962, p. 149)

Private speech is considered the transition point between inner and social speech, and inner speech is considered to be hidden, as opposed to private speech, which is open. Vygotsky points to the fact that children develop a "more knowledgeable" relationship with themselves or a more knowledgeable voice within themselves. This voice is based on a relationship to an adult in their childhood (or several adults) characterized as being more knowledgeable. When the child feels safe and guided by this more knowledgeable other, over time they create a voice similar to this adult guidance within their own system, where they collaborate with themselves through private speech in a way similar to that learned in childhood from an adult.

The "more knowledgeable other" as well as "private speech" are both relevant to the model of organic growth. The property called "mothering energy" resonates with the more knowledgeable other and "self-talk" resonates with the private speech - both are key in describing the behaviors of Al practitioners when they grow organically. The following section looks at the second approach to social learning theories relevant for organic growth: ecological systems. 


\subsubsection{Ecological systems}

One developmental theory that corresponds very well with organic growth is the "ecological model of human development" (Bronfenbrenner, 1994). Bronfenbrenner argues that, in order to understand how human beings grow, one must understand the entire ecological system where growth happens. Bronfenbrenner says that growth of humans happens throughout life in interactions with the environments that humans live in. "(...) human development takes place through processes of progressively more complex reciprocal interaction between an active, evolving biopsychological human organism and the persons, objects, and symbols in its immediate environment" (Bronfenbrenner, 1994, p. 38). This corresponds well with the model of organic growth because the human being is also seen as an active organism. Development is regarded as fundamentally relational and growth is understood as a progressive process - journeys unique to the human being. Organic growth also has a coherent connection to the larger systems and at the quantum level - to everyone and everything on the planet. Bronfenbrenner categorizes the environmental part into five "systems" to which the individual is related. 1. The microsystem is the close relationships, such as family, school and workgroups; 2 . the mesosystem is a system of microsystems, e.g. the relationship between home and school, or workplace and family; 3. exosystems are systems that have indirect influence, e.g. a neighborhood community or parent's workplace, for a child; 4. macrosystems consist of all of the systems mentioned above plus their basic assumptions, e.g. belief systems, material resources and lifestyles; and 5. chronosystems, which refers to time both chronological, as in the changes over a lifespan, but also the historical environment of the person (Bronfenbrenner, 1994, p. 39f).

Categorizing the systems in the world can be done in many ways - what is common to these Al practitioners is that they can understand and navigate the language of separation and fragmentation, but they do not place special emphasis on categories because they often work from understandings of wholeness and connectedness.

The understanding Bronfenbrenner represents is nonetheless highly useful because it provides a language for how systems are tied together from the single human system to the larger world, and points to the fact that these systems interact and affect each other. This perspective of systems can get us one step closer to the dimensions of wholeness and connectedness which is relevant for understanding organic growth. The next theoretical perspective in question is social cognitive theory.

\subsubsection{Social cognitive theory}

Bandura works with the notion of self-efficacy, a personal ability to act and think which includes the degree to which a person trusts her own ability to take required action when it is needed (Bandura, 1977). This is highly relevant for the understanding of organic growth, because the practitioner's ability to adjust is of key importance in organic growth. Self-efficacy is not a stable concept like self-worth; it depends on the context and the situation. A person can have a high self-efficacy in one area of life (for example cooking) where he has great trust in his own abilities, and in another can have a low self-efficacy, e.g. badminton, where he does not trust his abilities to take appropriate action because of earlier experiences with this type of activity. A basic assumption for Bandura is that the human being is able to change himself and the situations he is in because he is 
able to affect his own thoughts and behavior. The amount of belief in himself affects the action: if he has great self-efficacy, there is a greater chance that he will try something difficult. It also affects how long he keeps trying, how much resistance he can tolerate and how he understands the results of his actions (Bandura, 1977).

It is possible to strengthen self-efficacy. Bandura points to four "sources of efficacy expectation" which are understood as sources of information (Bandura, 1977, p. 195):

1. Performance accomplishments: This source of information is based on personal experience with success and failure and is therefore very influential. Experiences with failure tend to lower efficacy expectation and experiences with success raise mastery expectations.

2. Vicarious experience: To observe other people perform in challenging situations can affect the individual's belief in his own ability to try similar actions, but the effect on self-efficacy is not as influential because he has not tried it himself.

3. Verbal persuasion: Verbal persuasion is used by others when they try to support and encourage the person to believe that they can overcome an overwhelming challenge. This sort of information does not have the same degree of influence on efficacy because the person has not had their own experience of the challenge, which means that it is harder to believe.

4. Emotional arousal: Challenging situations that elicit emotional arousal may have information about personal competency and can therefore be used to enhance efficacy. Individuals tend to expect success with greater probability when they are not in a state of fear, and fear has the possibility of generating further states of fear or stressful emotions.

Self-efficacy resonates within the mindset of organic growth because the ability to be self-reflexive and to have a high degree of trust in oneself is key in organic growth. Bandura's understanding of positive and negative reinforcements is also related to organic growth. If a behavior has a positive reinforcement it is likely to be repeated and therefore strengthened; on the other hand, if a behavior is negatively reinforced it is likely to not be repeated. These ideas will be discussed in the analysis. Looking at the overview of social learning theories, it is clear that these theories all place emphasis on both the social interaction and the individual character. Through this section we have come to understand that the world is made up of many layers of systems surrounding the individual. The next section will describe the second line of thought that helps build the notion of organic growth: flourishing theories.

\subsection{Flourishing theories}

A second line of thought relevant for the framing of organic growth is "flourishing theories", theories chosen about human flourishing, positive emotions, flow, and open and closed mindsets. This line of thought is key for the model of organic growth because Al practitioners tend to work from an open mindset and towards positive emotions and flow, and their development processes are influenced by knowledge about wellbeing and thriving. Organic growth contributes to this line of thought by introducing the dimension of healing into adult development processes, and through this provides ideas for ways of achieving greater levels of flourishing. 


\subsubsection{Positive emotions}

The subjects "wellbeing" and "the good life" have been at the center of attention throughout history: they can be traced back to Aristotle's theory of the human flourishing eudaimonia (Gray, 2011). To have a sense of "feeling good" many times through the day is essential for practitioners in the model of organic growth. That is why theories about positive emotions are important.

Eudaimonia consists in a person taking charge of his own life so as to develop and maintain those ends (those virtues) for which he alone is responsible and which in most cases will allow him to flourish, he must direct himself (with others in mind). (Rasmussen \& Den Uyl, 1991, in Gray, 2011, p. 5)

The foundations of "positive psychology" can be traced back to humanistic psychology scientists and authors of therapeutic approaches such as Maslow (1971), Rogers (1961/1995) and Fromm (1956/2002) and were articulated by Martin Seligman in 1998. Fredrickson and colleagues (Fredrickson, 1998, 2001, 2009, 2013; Fredrickson, Mancuso, Branigan \& Tugade, 2000) among others have made significant contributions to research on positive emotions. It is also relevant to mention the "broaden-and-build" theory here. This theory describes how positive and negative emotions respectively function and affect the human system. Positive emotions are said to broaden the human's perspective of life quite literally and increase the tendency to have new thoughts and actions. Over time they enhance skills and build the resources available to the person. Negative emotions have the opposite effect on the system, narrowing the person's thought-action repertoire to a survival response from an immediate threat. On a short-term basis, people who are experiencing positive emotions show higher levels of creativity and are more likely to see and think in terms of "the big picture", and results of longitudinal studies show that long-term effects of positive emotions are greater sources of, for example, life satisfaction, thriving and psychological resilience. Fredrickson (2009) works with two other keywords relevant to organic growth: one is the "crown jewel of positive emotions", as she describes love, and the other is the power of "micro-moments". Love is described as the overriding positive emotion in her theory of positivity, which includes the ten most common positive emotions: joy, gratitude, serenity, interest, hope, pride, amusement, inspiration, awe and love (Fredrickson, 2009). Love is a union of these positive feelings. Instead of working with a traditional understanding of love, exclusively reserved for a romantic partner and the closest family, Fredrickson's understanding of love is characterized by a connection between any two or more persons who share a positive emotion in a micromoment and therefore have much more in common in everyday life.

First and foremost, love is an emotion, a momentary state that arises to infuse your mind and body alike. Love, like all emotions, surfaces like a distinct and fast-moving weather pattern, a subtle and ever-shifting force. As for all positive emotions, the inner feeling love brings you is inherently and exquisitely pleasant - it feels extraordinarily good, the way a long, cool drink of water feels when you're parched on a hot day. Yet far beyond feeling good, a micro-moment of love, like other positive emotions, literally changes your mind. It expands your awareness of your surroundings, even your sense of self. The boundaries between you and not-you - what lies beyond your skin - relax and become more permeable. While infused with love you see fewer distinctions between you and others. 
Indeed, your ability to see others - really see them, wholeheartedly - springs open. Love can even give you a palpable sense of oneness and connection, a transcendence that makes you feel part of something far larger than yourself. (Fredrickson, 2013, p. 23f)

In relation to organic growth, love is paramount because the practitioners share a characteristic openness to other people and work from a sense of oneness and connection, and many describe moments of "really seeing others wholeheartedly" in their work with appreciative inquiry and in their approach to life. Please find further elaboration on this topic in Chapter 5. Flow is the next of the flourishing model relevant to the present and key to organic growth.

\subsubsection{Flow}

The model of flow also became relevant because flow emerged as one of the dimensions of organic growth; this made it vital to inquire into pre-existing understandings of the concept. This section will present the understanding of flow provided by Csikszentmihalyi. His definition will lead to a discussion of its importance for the population included in this study and to how they operate from an expanded understanding of flow.

According to Csikszentmihalyi, people have the possibility to be in a state of flow when they are provided with a challenge appropriate to their level of skill (Csikszentmihalyi \& Csikszentmihalyi, 1988; Csikszentmihalyi, 2014). When the challenge level is too high compared to level of skill, it creates feelings of worry, anxiety and arousal. When the challenge level is too low compared to the skill level, it creates feelings such as boredom, control and relaxation in the person, as illustrated in Figure 3.

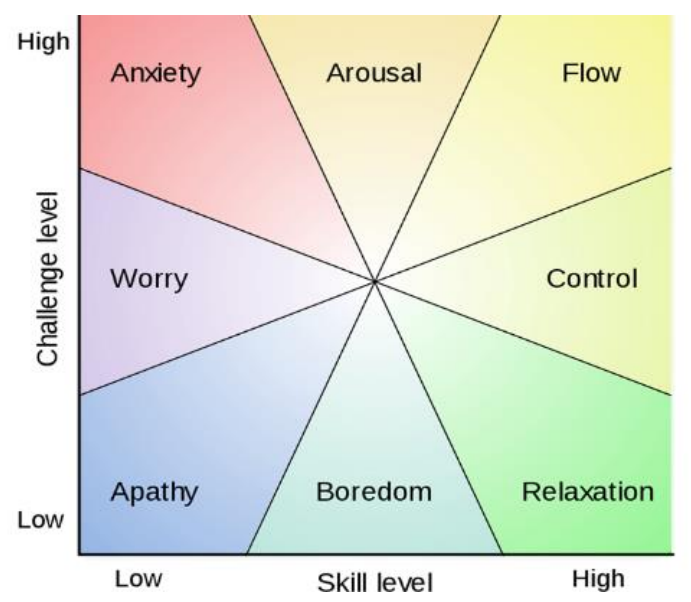

Figure 3. The flow model (Csikszentmihalyi, 1997).

What is this flow state, and why is it important to balance the challenges with the skill level in order to learn? Flow is characterized by a state of being where you lose sense of time and are fully engaged in the activity you are doing (Csikszentmihalyi, 2014). Csikszentmihalyi states that four main characteristics define a situation which has the possibility of producing an experience of flow: 1. Total concentration; 2 . Responding to greater challenges with increasing skills (appropriate challenge level matching the skill level); 3. Clear and unambiguous feedback; and 4. Enjoying the activity for its own sake (not an outside goal or reward). The author describes flow in this way: 
There is a common experiential state, which is present in various forms of play and also under the conditions in other activities which are not normally thought of as play. For lack of a better term, I will refer to this experience as "flow". Flow denotes the holistic sensation present when we act in total involvement. It is the kind of feeling after which one nostalgically says: "That was fun," or "that was enjoyable." It is the state in which action follows upon action according to an internal logic, which seems to need no conscious intervention on our part. We experience it as a unified flowing moment from one to the next, in which we feel control of our actions, and in which there is little distinction between self and environment; between stimulus and response; or between past, present, and future. (Csikszentmihalyi, 2014, p. 136)

As described, Csikszentmihalyi defines flow as a state of being with total involvement, as unified flowing moments with little distinction between self and environment, and with little sense of time. Csikszentmihalyi says that flow occurs in specific activities, often related to play. This is relevant in the analysis section, where the model of organic growth is discussed, including the dimension of flow, because the practitioners find themselves in states of flow in a variety of circumstances, not just in activities related to play.

A perspective on how to understand one's own possibilities of growing and how much one's own beliefs about development affects the results follows - the author works with a definition called a "growth mindset". This perspective has also proven to be relevant for organic growth, because many of the practitioners growing organically work from a growth mindset.

\subsubsection{Growth mindset}

Dweck and colleagues operate with two kinds of mindsets in studies of students: a growth mindset and a fixed mindset (Dweck, 2010; Dweck \& Leggett, 1988; Yeager \& Dweck, 2012). In short this means:

Individuals with a fixed mindset believe that their intelligence is simply an inborn trait - they have a certain amount, and that's that. In contrast, individuals with a growth mindset believe that they can develop their intelligence over time. (Dweck, 2010, p. 16)

This relates to organic growth in that all interviewees in this study seem to operate from a growth mindset, both for themselves and for the people they are working with - they believe that it is possible to change belief, to enrich one's understanding and become more intelligent. To believe that change is possible is, not surprisingly, a basic assumption for practitioners working with positive change. Another point in Dweck's theory is the key assumption that a person's mindset affects the results and life of the individual. This is a key factor in organic growth because many practitioners express how they work with developing their own mindset and beliefs, and how the changed beliefs create different results. This will also be addressed in the analysis, Chapter 5 . 


\subsection{Consciousness development}

This line of thought is included because notions such as "leap" and "revolution" in consciousness are relevant to this group working with change ${ }^{2}$. The following section unfolds three theories within the area of consciousness development, starting with László's ideas of a "quantum leap" in the development of humans (László, 2008). Next, Bohm's core ideas from working with quantum physics and their relation to humanity are presented (Bohm, 2005). Finally, Laloux's description of what humans in organizations will look like in the next stage of consciousness (2014) is added. The language of organic growth contributes to the field of consciousness development by providing a model of growth defined by balance, flow, healing, wholeness and a characteristic level of trust, and is thus an example of how a group works from and with quantum ideas as meaningful in their practical lives. The world is calling for humans to make a "quantum leap" in order to sustain and regain a natural environment on Earth. This is the topic for the following section.

\subsubsection{Quantum consciousness}

The Hungarian philosopher Dr. Erwin László has devoted much of his writing to the area of human development, especially "quantum consciousness" (László, 2008). In his "integral theory", he says that the planet is in such a bad shape that a major shift needs to occur for human beings as a species. As an example, humans use much more of the Earth's resources every year than can be recreated (László, 2008, p. 42). According to László, humans can either choose to create a "shift" in the "global brain", or they can carry on with business as usual to the point where it might be too late (László, 2008, p. 14). László talks with a clear sense of urgency when he describes how the macroshift can either turn out to be a breakthrough in the world or a breakdown. See Figure 4.

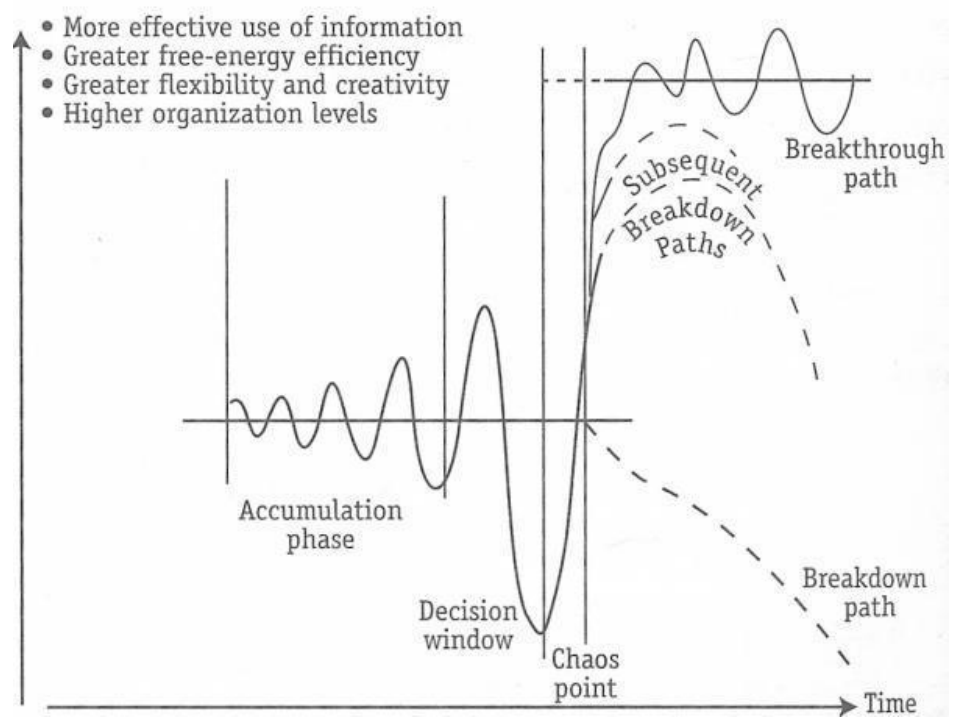

Figure 4. The four phases of the macroshift (László, 2008, p. 28).

\footnotetext{
2 The group of Al practitioners being studied help create change for their clients, change that make the clients ready for the future. Hence many of the change initiatives help create new insights and knowledge but also actions toward a better future both on the local organizational level but also on a planetary level given the current challenges both in climate but also in other areas such as poverty, education and peace.
} 
László assesses the development of humans on Earth by describing time as a factor and the desired future elements - such as information that is more effective, and having greater flexibility and creativity and higher organization levels - as another factor. There are different phases of this development, which eventually lead to a breakdown path for the Earth or to a breakthrough. A quantum shift in the global brain is happening:

The global brain is the quasi-neural energy and information processing network created by six-and-a-half billion humans on the planet, interacting in many ways, private as well as public, and on many levels, local as well as global. A quantum shift in the global brain is a sudden and fundamental transformation in the relations of a significant segment of the sixand-a-half billion humans to each other and to nature - a macro shift in society - and likewise sudden and fundamental transformation in cutting-edge perceptions regarding the nature of reality - a paradigm shift in science. The two shifts together make for a veritable "reality revolution" in society as well as in science. (László, 2008, preface)

László analyzes the root causes of unsustainability in the world and points to several areas: 1 . civil society, such as family structures, divorces, distant screen-based relations, fast-food and stress among others; 2 . the economic system where economic growth benefits a minority, and there is unequal distribution around the planet of wealth, pollution, health and unsustainable energy consumption; 3. the financial system's instability, with possible abrupt adjustments and the consequences for global trade, economic development and international security; and 4. the ecological system with unsustainability of physical and biological resources where "(...) the rising curve of demands is exceeding the descending curve of supply" (László, 2008, p. 42), including water supplies, pollution (as mentioned) and climate changes.

Perspectives from this view of the state of the planet proved to be relevant, because the practitioners in the study showed tendencies of living from a "breakthrough" instead of a "breakdown" path, with, for example, great flexibility and creativity and more effective use of information (see, Figure 4). They were also found to be working from an understanding of "a global brain", a sincere connectedness and an overriding focus on relationships. A further elaboration on this argument will be presented during the analysis, when the dimension of wholeness is examined. For now, this study will explore quantum theory as it has emerged in physics, to gain a deeper understanding of how and why its perspective on reality differs from that of classical physics, and why it is important for organic growth.

\subsubsection{Quantum theory}

Several of the Al practitioners attending interviews related to topics of quantum physics and, when the researcher worked through the analysis phases of this thesis, the categories of wholeness and energy emerged as important. This led to references to quantum theory. Many social researchers have combined different facets of insights from the area of quantum theory with the sciences related to the study of human beings ${ }^{3}$ (Zohar \& Marshall, 1990; Bohm, 2005; Lipton 2008; László, 2008). In this section six key concepts of quantum physics are introduced in order to give the

\footnotetext{
3 This section is only describing how concepts of quantum theory have been used as metaphors for understanding elements of the social world and it will not be discussing actual quantum theory, but provide a short selection of concepts from which the practitioners being studied make meaning within their area.
} 
reader a glimpse of why this scientific area has been hard to understand, and why it remains a challenge to understand what happens at the smallest known level of life. The six key principles are: 1 . the principle of complementarity; 2 . the Heisenberg principle; 3 . superpositions and the observer effect; 4 . entanglement; 5 . the explicate and implicate order of the world ${ }^{4}$; and 6. wholeness. It is worth emphasizing that even quantum physicists have had a difficult time understanding the results in their own scientific field, but because several of the Al practitioners relate quantum topics to their own work, it is relevant to acquire some insights in this area. Quantum physics gained its name from the Latin word for the small elements of life, the quanta. In the early 20th century, it was suddenly technologically possible to observe inside an atom, which until then had been the smallest observable unit.

The principle of complementarity says that "matter" can be "both-and", namely both a wave and a particle. This statement is in direct opposition to classical physics in the Newtonian paradigm, where particles were understood to constitute "matter", and where waves were thought to be vibrations (Zohar \& Marshall, 1990). In quantum physics, both particle and wave are equally important, and both are a way that matter can manifest itself. If we compare that to human beings, it is akin to suggest that human beings are defined as both a physical thing incorporating the body, and also a wave-like thing, the invisible character of the person, the energy field, the spirit, the consciousness.

The Heisenberg principle, named after one of the key quantum pioneers Werner Karl Heisenberg (1901-1976), is also called the uncertainty principle. It points to the fact that if scientists want to determine a precise position of a particle, the momentum of the same particle cannot be determined precisely. According to the Heisenberg principle, we can only focus on one aspect at a time. When we look closer and want to measure both the exact position of the particle and of the wave, we end up with a fuzzy picture of both - which is in opposition to classical physics, where exact measurement is part of the goal.

Superposition and the observer effect are other keywords in quantum physics. The most famous experiments were first conducted in 1801 by Thomas Young and called the "double-slit experiment". To understand the notion of superposition, an explanation of this type of experiment is shown (see Figure 5): A light source sends light from the left through a wall with two open holes. The light hits a photosensitive end screen on the right and makes marks that match the holes it went through. This means that the scientist can tell that the particles (in this case light) went through the expected holes, because the light goes through the slits and creates a pattern on the end screen that looks like the two slits. If the scientist, on the other hand, creates the experiment in such a way that there is no observer, something unexpected happens.

The light disperses in all possible ways, in and over and through the wall, and creates a pattern of all of the possible ways the particle can travel to the end screen. This is called the "superposition", meaning it takes all of the possible routes it can. Translated into everyday language it shows that, on the smallest level of the world (that humans can now measure), when there is no conscious observer, every possible path happens, but when an observer interacts with the world, only one of

\footnotetext{
${ }^{4}$ The terms "explicate" and "implicate" orders are phrases introduced by Bohm in his quantum theory of wholeness (Bohm, 2005).
} 
the possible expected situations occurs. It can mean that every path has the potential to occur and every outcome is possible in the moment. What manifests is a question regarding the presence of an observer and of consciousness. The interpretation of this is widely discussed and debated, but superpositions and the observer effect have been documented.

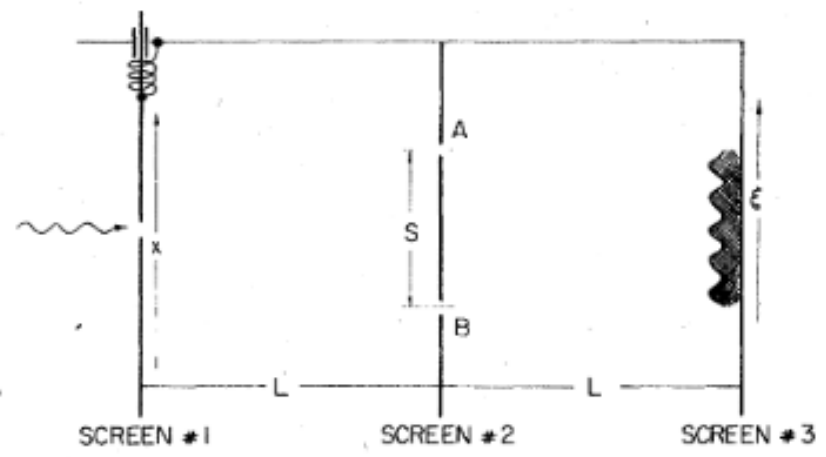

Figure 5. The double-slit experiment (Wooters \& Zurek, 1979, p. 474).

It appears that the energy knows when it is being observed and reacts to that consciousness. Taking this experiment into account and the resulting knowledge, the consequences can be many. First, human consciousness needs to be responsible to its surroundings when acting in the role of observer. Secondly, conscious minds may have the power to create concrete physical presence. Thirdly, if observations have direct impact and can change phenomena - how can science act when observing and describing phenomena? These initial questions can give rise to several others as well as answers that can affect the way humans live.

How is this relevant for the study of organic growth? From the data, it became clear that some of these practitioners operated from understandings derived from quantum concepts. One example is wholeness, which is relevant if the energy sent off in the double-slit experiment has a connection to the observer because of a knowledge on both sides that they are part of something bigger - a whole. This relates to the next quantum theme in question, entanglement.

Entanglement refers to the fact that it looks as though quantum particles are connected across time and space. This is another challenge for classical physics, because it becomes difficult to predict and control how information is transferred through these small units.

The elements of quantum physics introduced thus far are of interest for some of the practitioners in the group being studied because they help fill out explanations of elements the practitioners may not be able to explain in other ways. Most of the practitioners have curiosity as a character strength, and thus find new explanations of ideas worth exploring. Understanding the ideas indepth and their relationship to how the world is put together is a clear challenge for quantum scientists, not to mention nonprofessionals or scientists from different fields. Nevertheless, the fact that some elements remain inexplicable resonates with tendencies in data to take a leap and trust the wholeness of the world, even though the Al practitioners are rarely experts within quantum theorizing and research. Another perspective related to this is the language around life as a 
mystery and the idea that there are still areas to wonder about, which can be seen as a value in itself (Cooperrider, Cooperrider \& Srivastva, 2017).

Bohm wrote a book entitled Wholeness and the Implicate Order (Bohm, 2005) in which he describes another level of reality derived from his work with quantum science. Bohm operates with an explicate and an implicate order of things. The implicate order is a realm of pure information and is the "source" of the explicate order, the order of the physical world. From the implicate order, the physical, observable phenomena unfold (which are called the explicate order), which returns to the implicate order. This unfolding of the explicate order from the subtle realm of the implicate order, and the movement of all matter in terms of enfolding and unfolding, is what Bohm called the "holomovement".

Bohm understands wholeness as an attitude or an approach to the whole of life. Because of relativistic and quantum theory we can look scientifically at the world as a whole unfolding: a movement in which everything - any particular element of space - has a field which unfolds into the whole, and into which the whole unfolds. The implicate order is also referred to as the "enfolded" order, whereas the explicate order is understood as the "unfolded" order. In the implicate order, everything is related to everything and this goes even further because everything contains everything. The most common experience of the implicate order is ordinary consciousness, where consciousness enfolds everything humans know or receive. Humans act according to the content and are therefore internally related to the whole in the sense that they act according to their consciousness. Consciousness is the immediate experience of this implicate order.

Bohm operates with what he calls a "holoflux" theory. The main factors of that theory are:

1. Consciousness manifests as energy flux - information-encoded radiant energy.

2. Consciousness resonates between two domains: the space-time explicate and the nondual implicate.

3. The implicate order is everywhere at the "bottom" of space.

This leads to the final key notion introduced in this section, Wholeness. Artists, scientists, spiritual leaders and economists gathered in Amsterdam in 1990 at the conference called "Art Meets Science and Spirituality in a Changing Economy - From Fragmentation to Wholeness". At that conference, Bohm said:

Most of our understanding of things is fragmentation, like this country, this institution even our thoughts - we think that they claim not to be affecting anything but just telling you the way things are - that is why people cannot see that they are creating a problem and then apparently trying to solve it. (Bohm, 1990)

Bohm gives the example of pollution and claims that humans believe that every person is an individual and that each and every individual can go out and help solve the problem of pollution. He says that according to quantum physics this does not make sense, because it is all humans' collective thoughts being active simultaneously which causes the problem. A problem only stays in existence because humans think about it, and the shared thought energy of many people keeps 
the problem "alive". This is not a conventional way of thinking about problems, but if we follow this thought experiment, it could resonate with the mindset of organic growth because Al practitioners keep focusing on the positive, on strengths and on solutions. If a larger group of people kept thinking about solutions, they would help keep solutions alive, according to Bohm's thinking.

He describes the Earth as one household and says that humans are not treating it that way. He goes on to describe wholeness: "It is not that everybody depends on everybody, no everybody is everybody in the deepest sense. It is wrong to say that the environment is not us - we all come from the Earth and go back to the Earth," Bohm says.

The notion of wholeness makes sense for the ideal understanding of organic growth, because when growing organically the practitioners are working from a view of the world characterized by wholeness instead of fragmentation, connections and relations instead of divided categories. These six cases of quantum research can be difficult to comprehend and absorb, but the practitioners find meaning in them even though they may not understand the ideas in every detail. The ideas also express how they find value in awe and wonder, without being able to understand everything fully, but by surrendering to and trusting in the magic and mysteries of our world.

The next section is a newer contribution to the field of consciousness development, in which the author has inquired into organizations operating from higher levels of consciousness. The purpose of bringing this perspective into the study is to show that not only smaller communities of practice and their members can be working from newer levels of existence, but also whole organizations. Laloux (2014) describes the people working in these organizations, and they correspond very well with the description of the group of Al practitioners included in this study. This points to the possibility that people may be benefiting from the language around organic growth.

\subsubsection{Evolutionary-Teal}

Laloux suggests a model of how human consciousness has developed throughout history 5 . He uses colors to describe different approaches to human collaboration (Laloux, 2014) and builds further on the works of, for example, Graves $(1970,1974)$ and Wilber (2000). Laloux claims that humans have been able to collaborate in special ways throughout history and that new forms of collaboration have emerged. The newest consciousness category is emerging with keywords like integrated, integral, autonomous, inclusive, and systemic. Laloux describes this in relation to previous stages:

Where all the previous stages (Magic, Mythic, Rational and Pluralistic) had operated out of a sense of lack, scarcity and deficiency, this new level (...) acted out of a sense of radical abundance as if it were overflowing with goodness, truth and beauty. It was as if somebody put a billion dollars in its psychological account, and all it wanted to do was share it, so full it was. (Laloux, 2014, foreword xiii)

\footnotetext{
5 The work of Frederic Laloux has received some attention in the management field but have not been scientifically validated and is created on behalf of practical approaches to his field.
} 
According to Laloux, different kinds of collaboration exist, some more widespread in human history than others. Referring to the model below, the color teal characterizes the newest developed form of collaboration, corresponding to a specific understanding of consciousness of humans.

Exhibit 1: Evolutionary Breakthroughs in Human Collaboration

\begin{tabular}{|c|c|c|c|c|}
\hline Color & Description & Guiding Metaphor & Key Breakthroughs & Current Examples \\
\hline \multicolumn{5}{|l|}{ RED } \\
\hline & $\begin{array}{l}\text { Constant exercise of } \\
\text { power by chief to keep } \\
\text { foot soldiers in line. } \\
\text { Highly reactive, short- } \\
\text { term focus. Thrives in } \\
\text { chaotic environments. }\end{array}$ & Wolf pack & $\begin{array}{l}\text { - Division of labor } \\
\text { - Command authority }\end{array}$ & $\begin{array}{l}\text { - Organized crime } \\
\text { - Street gangs } \\
\text { - Tribal militias }\end{array}$ \\
\hline \multicolumn{5}{|c|}{ AMBER } \\
\hline & $\begin{array}{l}\text { Highly formal roles within } \\
\text { a hierarchical pyramid. } \\
\text { Top-down command } \\
\text { and control. Future is } \\
\text { repetition of the past. }\end{array}$ & Army & $\begin{array}{l}\text { - Formal roles (stable and } \\
\text { scalable hierarchies) } \\
\text { - Stable, replicable processes } \\
\text { [long-term perspectives }\end{array}$ & $\begin{array}{l}\text { - Catholic Church } \\
\text { - Military } \\
\text { - Most government } \\
\text { organizations (public } \\
\text { school systems, police } \\
\text { departments) }\end{array}$ \\
\hline \multicolumn{5}{|c|}{ ORANGE } \\
\hline & $\begin{array}{l}\text { Goal is to beat } \\
\text { competition; achieve } \\
\text { profit and growth. } \\
\text { Management by } \\
\text { objectives [command } \\
\text { and control over what, } \\
\text { freedom over how]. }\end{array}$ & Machine & $\begin{array}{l}\text { - Innovation } \\
\text { - Accountability } \\
\text { - Meritocracy }\end{array}$ & $\begin{array}{l}\text { - Multinational companies } \\
\text { - Investment banks } \\
\text { - Charter schools }\end{array}$ \\
\hline \multicolumn{5}{|c|}{ GREEN } \\
\hline & $\begin{array}{l}\text { Focus on culture and } \\
\text { empowerment to boost } \\
\text { employee motivation. } \\
\text { Stakeholders replace } \\
\text { shareholders as primary } \\
\text { purpose. }\end{array}$ & Family & $\begin{array}{l}\text { - Empowerment } \\
\text { - Egalitarian management } \\
\text { - Stakeholder model }\end{array}$ & $\begin{array}{l}\text { Businesses known for } \\
\text { idealistic practices (Ben \& } \\
\text { Jerry's, Southwest Airlines, } \\
\text { Starbucks, Zappos) }\end{array}$ \\
\hline \multicolumn{5}{|l|}{ TEAL } \\
\hline & $\begin{array}{l}\text { Self-management } \\
\text { replaces hierarchical } \\
\text { pyramid. Organizations } \\
\text { are seen as living entities, } \\
\text { oriented toward realizing } \\
\text { their potential. }\end{array}$ & Living organism & $\begin{array}{l}\text { - Self-management } \\
\text { - Wholeness } \\
\text { - Evolutionary purpose }\end{array}$ & $\begin{array}{l}\text { A few pioneering } \\
\text { organizations [see } \\
\text { "Examples of Teal } \\
\text { Management"] }\end{array}$ \\
\hline
\end{tabular}

Table 1. Evolutionary breakthroughs in human collaboration (Laloux, 2014).

The language of teal and the collaboration and consciousness patterns described in this perspective turned out to be relevant for this study because they resonate with some of the subcategories of the model of organic growth. The basic metaphor in this work understands organizations as living organisms, which also resonates with the model of organic growth.

The key points describing people who operate from "teal" are summed up in the following, which corresponds to the Al practitioners.

1. Taming the fears of the ego: One of the most important points is the fact that people who operate from teal seems to replace fear with a higher trust: "We come to believe that even if something unexpected happens or if we make mistakes, things will turn out alright, and when they don't, life will have given us an opportunity to learn and grow" (Laloux, 2014, p. 44). This point resonates with the dimension of trust described in the analysis chapter. 
2. Inner rightness as compass: This aligns with what is called intuition in organic growth and is characterized by a great ability to listen to subtle, internal voices and have the courage to act on that intuition. From the outside it may look like courage, yet from the inside it feels right and like an easy next step.

With fewer ego-fears, we are able to make decisions that might seem risky, where we haven't weighed all possible outcomes, but that resonate with deep inner convictions. We develop a sensitivity for situations that don't quite feel right, situations that demand that we speak up and take action, even in the face of opposition or with seemingly low odds of success, out of a sense of integrity and authenticity. (Laloux, 2014, p. 44)

To feel and to listen to those feelings and take these emotions seriously is allowed and even necessary in this realm.

3. Life as a journey of unfolding: It is not a question about success, rather a question about searching for who we are and what our purposes are in this life, and what we have to offer the world. "(...) life is seen as a journey of personal and collective unfolding toward our true nature" (Laloux, 2014, p. 45). It is about being authentic and expressing our "true" self and listening to the life that wants to be lived through us. This correlates with the basic assumption of organic growth as a journey.

4. Building on strengths: Human beings are not problems to be solved but potential waiting to be unfolded. "Life is not asking us to become anything that isn't already seeded in us" (Laloux, 2014, p. 46). Building on strengths is a core preference for this group and is relevant for ideal organic growth because the practitioners are aware of their own (and others') strengths and put them into play as often as possible to be able to stay in flow.

5. Dealing gracefully with adversity: Obstacles are learning opportunities; to see life as a journey makes it possible to accept and even enjoy detours and roadblocks. They also invite frequent adjustments because of learnings. It might even be possible to invite them in, the way we invite people with different voices into a conversation, because learning from contrasts can also be a way to clarity "(...) there is often an enjoyable tension in the journey of personal growth" (Laloux, 2014, p. 46).

6. Wisdom beyond rationality: This is about the ability to tap into different types of knowing, logical, rational and intuitive, and Laloux states that there is also wisdom to gain in one's emotions when asking: "Why am I experiencing these emotions right now? What does this say about me or the current situation that I am in?" (Laloux, 2014). He describes the term "beyond dualism", where two sides are not in opposition but are like two sides of a coin. He introduces the synergy of breathing in and breathing out, and goes on to paradoxes like freedom and responsibility, solitude and community, which he finds to be necessary for each other. This corresponds very well with the notion of wholeness in organic growth.

7. Striving for wholeness: The point here is to bring together supposed opposites, as for example mind, body and soul, and feminine and masculine. Laloux states that the more 
humans realize what their purpose in life is, the more they realize that they are part of a wholeness, and that separation is an illusion. He also talks about "repairing our broken relationships with life and nature" (Laloux, 2014, p. 48), which resonates with a discussion in this study around disconnection of mind and body (Ray, 2008). This is again related to the dimension of organic growth called healing.

8. Wholeness in relation to others: Non-judgment is important here: "(...) we can examine our belief and find it to be superior in truth and yet embrace the other as a human being of fundamentally equal value" (Laloux, 2014, p. 49). This is an example of non-dualism. When conversations are not about fixing or fighting each other, humans can create a shared space with deep listening, and through that help each other find a true voice - a place "where we listen each other into selfhood and wholeness" (Laloux, 2014, p. 49). This relational and non-judgmental approach towards other people resonates with the organic growth processes of the group being studied and is almost to be described as part of the Al practitioner's DNA. Løgstrup expresses this profound approach with the words: "Holding another person's life in one's hand endows this metaphor with a certain emotional power... that we have the power to determine the direction of something in another person's life... we're to a large extent inescapably dependent upon one another" (Løgstrup, 1997, p. 28).

9. Wholeness with life and nature: Laloux states that when humans learn to be their unique selves, they realize that they are fundamentally connected and then they realize how foolish and arrogant mankind has been, to think that humans were superior, which makes humans want to repair the relationship with nature.

Often, rekindling our relationship with life and nature causes us to pursue a simpler life, less cluttered by possessions we thought we needed until we understood that we are rich not through the things we own, but through the relationships that nourish our soul. (Laloux, 2014, p. 49)

This is evident in organic growth where notions of simplicity are key. This is elaborated in the analysis chapter. From this summary it is obvious how these points connect to several of the categories of organic growth. The next question is more practical: How do humans shift between stages of consciousness? Laloux says that the shift occurs when humans are able to reach a higher vantage point, from which they can see the world in a broader perspective. To make that shift humans need to "disidentify" with that which they were previously in (Laloux, 2014, p. 43-51). The "shift to teal" happens when people can disidentify from their own ego. This is not necessarily combined with comfort and ease. "Learning to live with that amount of freedom can take some time and there are often moments of doubts, frustration or confusion. It's a journey of personal unfolding, in which true professionals are born" (Laloux, 2014, p. 68). This relates to organic growth within the dimension of healing, where practitioners take responsibility for their own growth by letting go of old habits when challenging circumstances enter their lives.

Even though Laloux represents a line of thought that is not scientifically validated, his perspectives on possible characteristics for the people working in these organizations made his work worth mentioning as an addition to the theoretical treads on consciousness. 


\section{Chapter 3: Methodological approach}

This chapter will present the methodological choices made before, during and after this study. Future-forming research will be elaborated further, and the positions of the researcher will be touched upon, before describing and legitimizing the grounded theory approach. Finally, further reflections regarding the group chosen for the study will be introduced.

The way to choose the overall inspirations in a research project is often to start out with a metatheoretical perspective, a fundamental view of the individual, society, culture and the interactive processes between these (Søndergaard, 2000, p. 53). This initial perspective sets the direction and some limits for looking at the phenomenon. Often when that meta-perspective is set, the choice of method follows. But within the research process, over time, "the method, the phenomenon and the meta-perspectives interact and shape each other" (Søndergaard, 2000, p. 53f; author's translation). In this study, future-forming research was chosen fairly early on but, as Søndergaard states, the parts have been shaping each other. The population of Al practitioners was also chosen quite early in the process, which led to the question of which method to choose.

\subsubsection{Future-forming research}

As mentioned in the introductory chapter, future-forming research was chosen as a frame to support the aims of the study: to co-create a model about what moves Al practitioners and by that to provide new language that may help shape the future in valuable ways. This section will give a brief background about future-forming research and its origin in social constructionism.

Because of their book published in 1966, The Social Construction of Reality - A Treatise in the Sociology, Berger and Luckmann have come to be seen as a key departure point in social constructionism (Berger \& Luckmann, 1991). They point to influencers such as Mead, Marx and Durkheim in their understanding of how social knowledge is constructed. Social constructionism is based on the assumption that everything meaningful to people is socially constructed in relationships and in the language between human beings (Gergen, 1982, 2005, 2009; McNamee, 2010, 2014).

Kenneth Gergen is an important figure in the establishment and further development of social constructionism within social psychology (Gergen, 1982, 1996, 2009, 2015). He himself will say that this movement is not due to a single person, but to an ongoing dialogue and relational communal process, where ideas are being negotiated and experimented with around the globe in many different settings. People have used the lens of social constructionism in different areas of life, for example, in education, science, organizations, therapy, community building, businesses, minority groups, peace and conflict work, and much more. A handful of central premises includes (Gergen, 2009, p. 5-13):

1. The way in which we understand the world is not required by "what is". Human beings choose different words to name everything in the world. For example, we call the ocean "ocean", but the thing itself did not tell us that "ocean" is its name. We also have other names for the same thing, like "the sea", and in other languages, the word created is something else. That is a concrete example. It is the same for everything else, buildings, 
procedures, habits, places and even categories mentioned here were created at some point in time by human beings. That basically means that we can always question the way we speak about things in the world and we can always examine if the ways we speak about the world are good for "us". Which leads to the next premise:

2. The ways in which we describe and explain the world are the outcomes of relationships. Languages were probably developed because human beings needed to communicate about danger, food, sex or other basic needs. A person alone in nature does not really need language. Modern people learn about language in relationships, being brought up by other people. The little child is often curious about how adults use language to communicate and to make meaning of the world. In every dialogue people negotiate meaning and understandings of their world in relationships, and relationships are the place to create new meaning by communication.

3. Constructions gain their significance from their social utility.

People create words about their world because they need to. It is helpful to have words about illness, for example, because then we can tell others why we cannot meet them as promised. Wittgenstein, operating with "language games", says that language is a form of coordinated acting together (Wittgenstein, 1953). There are specific rules and patterns that we need to follow, because modern people are born into cultural settings, with a history of words and language creation. As time passes, new words are created in different cultures, giving meaning to new behavior: "internet" is a new word that now has a function for many people around the globe. Old words in a language sometimes disappear because the function is outdated, for example a typographer. When newspapers first developed that was the job of setting the letters in newspaper; today, the equipment only exists in museums.

4. As we describe and explain, so we fashion our future.

Here different implications are at stake. We create the world we live in by our shared language. What if we stop speaking the way we do - what will happen to the culture? Gergen uses the example of religion; in different societies people have stopped speaking about sin, the soul or the Holy Spirit, and then no one goes to church on a regular basis (or very few). In Denmark a century ago most people would meet on Sundays, for example, in church. But as institutions die out, so new forms come to life! If we create the world by the way we speak in relationships and in the culture, we have all the potential in the world to create something new and even better! This leads to the final premise:

5. Reflection on our "taken-for-granted worlds" is vital to our future wellbeing. Instead of just reproducing words and action, humans need to carefully reflect on the question, how do we like the world? In many areas of life, the world is taken for granted. Humans just reproduce what already exists, without being aware or asking, "Is this a good world?"

As Gergen states, we need to consider what part of our social traditions we will carry on and which pieces we will deconstruct in order to create something new. And that question is even bigger, because then we need to dialogue about what kind of world we want. We all have different values - a good world for me is not necessarily a good world for you. And specific communities and 
groups in the world have different views on what "good" is in this world. If we can create worlds where our "truth" can co-exist and be accepted side by side with their "truth", on a worldwide basis, then we have created humans living fully peacefully for the first time in history with multiple truths side by side.

For constructionists, such considerations lead to a celebration of critical reflexivity; that is, the attempt to place one's premises into question, to suspend the obvious, to listen to alternative framings of reality, and to grapple with the comparative outcomes of multiple standpoints. (...) If we are to build together toward a more viable future then we must be prepared to doubt everything we have accepted as real, true, right, necessary or essential (Gergen, 2009, p. 12f).

This serves as the argument both favoring giving voice to practitioners representing the $\mathrm{Al}$ community, as a small "tribe" in this world, and also as the argument for asking critical questions of Al practitioners who may have accepted something as real, true, right, necessary or essential.

Appreciative inquiry was created in the soil of action research (Cooperrider \& Srivastva, 1987). One of the important goals of action research is to have the possibility to create change in the researched reality (Kemmis \& Taggart, 1998). When the purpose of this study was to create futureforming research, action research might have been an obvious method choice. Why this is not the case will be argued in the following section.

\subsubsection{Why not action research?}

In some ways it seems relevant to choose an action research approach to this study, both because appreciative inquiry was born out of it and it fits into the notion of future-forming research, because practice is already impacted and engaged throughout the study and therefore changes are already happening. Why not use action research as a method here? Kemmis and McTaggart give this definition of action research:

A form of collective enquiry undertaken by participants in social situations in order to improve the rationality and justice of their own social or educational practice, as well as their understanding of these practices and the situations in which these practices are carried out. (Kemmis \& Taggart, 1998, p. 5)

First and foremost, the argument for not choosing to use an action research method is the positive argument for choosing grounded theory: that the intention was to co-create a theory on behalf of and in interaction with the population included in the study. Another argument is that action research may have felt "old fashioned" to the practitioners; they might have found it more meaningful to undertake an appreciative inquiry into their community of practice since they find this approach valuable. The assumption here is that the methods of this study had to make sense to the practitioners, which is in line with future-forming research.

A final argument is at a practical level. Most action research studies take place in a specific physical location, e.g. a team of teachers in a school, nurses in a hospital department or employees in an organization. These Al practitioners share online and meet at times during the 
year in real life at conferences, network meetings, courses and so on. Because Al practitioners do not share the same physical work environment, another approach turned out to be more relevant.

Action research projects have been done within a community of practitioners (e.g. Johnson, 2001; Ampartzaki, Kypriotaki, Voreadou, Dardioti \& Stathi, 2013). Whyte has described an approach called collaborative action research (CAR) as well as the connection between CAR and communities of practices (Whyte, 2015). It was not possible to find precedents for action research approaches into an online community of practice. Going back to the question about methodological approaches one can ask: If appreciative inquiry is a further development of action research, and the group being studied uses Al, why is appreciative inquiry not a perfect methodological approach?

\subsubsection{Why not Al?}

Appreciative inquiry was not chosen as research approach because of the benefit of other perspectives. It can very well be of value to use Al as a research approach, yet this study called for another set of eyes and for freshness to create innovation and new ideas. According to Maturana, (2002) learning and development happen through perturbations, and since one of the intentions was to expand the language and enrich the community of Al practitioners further, another research approach seemed to be a good idea.

A second argument for this choice was an urge to create a bridge to people outside the $\mathrm{Al}$ community. Grounded theory ended up being a good match with the research aims. The following is a short description of the researcher's position.

\subsection{The position of the researcher}

The reason for including a section on the researcher's position is clear. It is important to know where the researcher comes from when understanding her study because the work is co-created as a collaborational interplay between the researcher, the population chosen for the study and the environment she has been a part of, both inside and outside academia. Gioia, Corley and Hamilton (2013) find that researchers are knowledgeable contributors, and it is therefore valuable to have insights into the researcher's background. Looking back at his collected works in 2014, Csikszentmihalyi shares the same reasoning:

After all, science is supposed to be an impersonal endeavor. One's history and subjective experience are, in comparison, trivial epiphenomena of no consequence to the unfolding of objective truth. Yet, as a student of human nature, I cannot subscribe to this belief. The sciences - physics and chemistry, and the human sciences even more - are human constructions; even at their most rigorously abstract, their knowledge is a product of human minds, expressed in words and symbols most accessible to other human minds. (...) Hence, I must conclude, that whatever I have written over these past 40 years has been filtered through my own unique place in the cosmos, and therefore a brief acquaintance with the place where I am coming from may help the reader to put the ideas contained in these writings in a more meaningful context. (Csikszentmihalyi, 2014, p. xi) 
I agree with this perspective about the interwovenness of researcher and study, and of the sciences as social constructions, and will therefore enlighten the reader regarding the background of the researcher. But first a note on how to make future-forming research come alive in this text by placing the values of the researcher to the fore.

\subsubsection{All research is autobiographical: Introducing the researcher's voice}

Steier (1991) argues that all research is ultimately autobiographical and, if following that perspective, this research project, too, is a reflection of who the researcher is. With Gergen's quest for a "future-forming researcher" (Gergen, 2015) and the invitation to put the values of the researcher to the fore of the research, small sections are included throughout this dissertation called "researcher's voice". These include the voice of the researcher, sometimes personal and sometimes scientific, but in relation to a personal view. The intention of these sections is to make the researcher's voice transparent, so that the reader can see the position of the author and the way of interacting with the different phases and points of the project. A fully autobiographical methodological approach is not included as it was not a core interest because the researcher's experiences weren't the primary focus. Thus, the sections serve rather as a transparent way of seeing how the researcher works and thinks through the processes, not as the researcher being an example and using personal experiences to inquire from and with.

"Qualitative researchers... report their preconceived views, assumptions, concepts and hypotheses, and also note where the data has compelled them to think differently, communicate the changing nature of the context of the study and the instrument" (Collins \& Cooper, 2014). The researcher has followed this advice by including a section about the position of the researcher and by addressing the process of the researcher in the "researcher's voice" sections. In the next section the training of the researcher will be outlined along with the vision.

\subsubsection{Researcher's training}

The researcher has been attending conferences and courses within the field of social constructionism and appreciative inquiry since 2008 and has been trained in interviewing and listening during these events, often intensely because practitioners attending these events have this as a core competency.

During Bachelor's and Masters' studies, the researcher participated in groups doing projects on, for example, "stress and management of kindergartens", "the position of the body in appreciative inquiry processes" and "the long-term effects of appreciative inquiry projects in kindergartens", among others. The researcher attended Roskilde University and Copenhagen University. At Roskilde University, she completed most assignments in groups and has great experience in collaboration and communication in teamwork. She has been trained in different interview approaches (e.g. Kvale, 2008; Halkier, 2008) and has training in qualitative interviews when conducting interviews for different assignments as well as in different types of interviews, including research interviews, therapeutic interviews, coaching conversations and appreciative inquiry interviews. 
The researcher attended an in-depth three-year coaching and supervision research project while studying at Roskilde University, where students were trained to coach groups of students in the first and second years of Bachelor programs. The project contained the teaching of different coaching models and approaches, different conversation styles, questions and their power, group dynamics, communication and collaboration, the act of active listening, and philosophical discussions of key perspectives within coaching and developmental group work. The coaches worked in pairs and had one group each semester, with three or four meetings with coaching of the group and their goal for the semester. In between these meetings the coaches were given group supervision.

The researcher attended a seminar in grounded theory led by Barney Glaser, and through that received mentoring from experienced grounded theory practitioners. The researcher presently works as an adjunct professor at University College Absalon and is teaching courses at the level of a Bachelor's degree, along with those for professionals in the fields of child care and social education. She teaches Al and facilitates flourishing processes in her own consultancy as well. The next section will present the researcher's vision when following the quest for future-forming research (Gergen, 2015), which was to let the vision of the researcher lead the study and thus allow the study to be about how to co-create such a desired future.

\subsubsection{The vision of the researcher}

Following future-forming research, the researcher's vision will be shared as a narrative inviting the reader into the future to meet the people who live there.

\section{Speaking with Mr. Future}

Welcome to a world where people you meet on the street have a sparkle in their eyes. You can tell by their body language that they are relaxed while they are walking, and they say "hi" even if you have never seen them before. They seem grounded, open, uplifted and present. You get invited into a conversation with one of them and you are curious as to how they feel, what they do for a living and how they have become who they are. The person you engage with is eager to speak to you; it feels like he has all the time in the world. He is curious about you too and talks happily about his life. He speaks about his experience of balance in his life, where he has just about the right amount of work for his preferences in his stage of life, and he talks about his job freely. He learns a lot from it and has a deep feeling of contribution. You may feel like asking if he works with his "purpose" in life, and he almost laughs at you and tells you gently that everybody he knows works purposefully with a passion, and with something that they have unique capabilities of doing. You wonder in your quiet mind if you have landed on another planet, or many centuries into the future of planet Earth.

You ask about his life and he says that he feels that he can be 100\% himself, he does not have to hide certain sides of his personality or preferences. There is great tolerance and celebration of differences where he lives. He emphasizes how much support and love he gets from his relationships, that people always try to lift him up when he experiences challenges in his life, and that he knows that he has $100 \%$ responsibility for his own life, but endless love and support from others. 
You ask him if he knows how this society has come about and he says that a significant shift in consciousness happened in the world, where many people understood that everything was connected to everyone and, after some time, they succeeded in creating world peace as well as good living conditions for everyone. In order to join in this shift, many tribes needed to let go of earlier ways of understanding and acting, which happened over a period of time. Now he finds it almost unbelievable that very bad things happened in the past, even though he knows that this is part of history. He says that, because everyone knows that everything is connected, it does not make sense to harm others. Moreover, if people feel bad they usually know what to do: they ask for help, they have relations around them who love and accept them, and they are accepted as they are. Loneliness and stress are, along with war, symptoms of a time of imbalance long gone.

When playing with this vision - what is to come? This study represents an inquiry into a group of people who are already living some of the values seen in this vision. And so this study becomes an inquiry into what can be and what might happen - for these practitioners in the first place - in order to come one step nearer to living the vision. A challenge for the sole researcher presenting her vision, on the one hand, is that it can seem too naïve, too idealistic, too positive and too far from current societies and, on the other, that even though she is the product of all of her relationships and previous interactions in her cultural settings - she created the vision alone. If the vision were to be co-created within the community of Al practitioners, it could have had even more value.

The researcher always comes from relational settings and the envisioned future is therefore a voice for relational groups: "What pass for individual decisions are essentially social actions removed from their birthplace in the swarm" (Gergen, 2015, p. 306). Gergen emphasizes that research should not be founded on individual values and personal integrity, but on a relational responsibility and he points to the fact that dialogue is a key factor in multiple versions of what is considered "good". Having clarified the position of the researcher as well as methodological approaches relevant to but not chosen for this study, the next section will argue for the approach that was in fact chosen.

\subsection{Grounded theory}

To generate a theory or a model was a starting point; this led to the method of grounded theory. Some parts of grounded theory go hand in hand with the theoretical framework for future-forming research - social constructionism - even though there are differences (Charmaz, 2008). It was beneficial to choose a language like the one used in grounded theory, where the researcher "openly" goes into a specific field and lets the people in the group talk about what is important to them, co-creating a theory with them. This matched the assumptions of research as future forming.

In this chapter grounded theory will be introduced, different approaches to grounded theory will be discussed and an argument for choosing classic grounded theory will be provided. An overview of the important steps of a grounded theory research process will be presented, as well as key perspectives in the methodology. Finally, the approach will be discussed and a perspective on a small supplemental approach, energy-led research, will be introduced. 


\subsubsection{Why use grounded theory?}

Grounded theory is relevant because of the focus on generating new theoretical concepts and categories (Glaser \& Strauss, 1967, p. 6). This study aimed to go openly into the field of Al practitioners and generate ideas about how positive change practitioners in general - and appreciative inquiry practitioners specifically - continue their processes of learning, sharing and developing as professionals. Grounded theory places a strong emphasis on the people in the group being studied; the participants and their voices, stories and experiences. Grounded theory is the primary approach chosen because the design of the research is to open up to the practitioners to learn what they are passionate about. Grounded theory is both the name of the research method and the outcome of the analysis process. The approach was chosen so as to be able to co-create concepts relevant to the group in order to enrich the community and practices. The purpose of the following section is to give an overview of grounded theory, in order to have background information about how the research was designed, because the researcher chose to follow the method in a fairly strict and systematic way.

\subsubsection{The introduction of grounded theory in history}

Grounded theory, developed in co-creation between sociological researcher Barney G. Glaser (1930) from Columbia University and sociological researcher Anselm L. Strauss (1916-1996) from the University of Chicago, was originally articulated in the book The Discovery of Grounded Theory, published in 1967. The two were cooperating on research about dying patients in hospitals, and the awareness and social loss around the families and professionals surrounding the dying patients. The book was written as a general critique of the problematic gap between theory and research (Glaser \& Strauss, 1967) and they argued that too much effort had been put into creating better research methods for testing theories, while the improvement in research methods for theory development was inadequate. The authors provided suggestions for researchers on how to generate theory through their own data in the field or from other fields (Glaser \& Strauss, 1967, p. 53) and they presented a general method of comparative analysis and specific procedures for developing theory.

"Will the real grounded theory please stand up?" A section headline in a paper on the differences between Glaser and Strauss points to an important event in the history of grounded theory (Babchuk, 1995). In 1990 Anselm Strauss co-authored a book with Juliet Corbin, entitled Basics of Qualitative Research - Grounded Theory Procedures and Techniques, and that event made it clear that the original authors had gone separate ways, resulting in two different approaches to grounded theory: the Straussian and the Glaserian approaches (Stern, 1994, p. 212). In the book Doing Grounded Theory, published in 1998, two years after the death of Strauss, Glaser notes that they remained friends until the end (Glaser, 1998, p. 36). In the same publication is "the rhetorical wrestle", where Glaser recommends doing the research and keeping the rhetorical debate on the differences to a minimum level, only to be used when there is a useful purpose (Glaser, 1998, p. 36).

Since the split there has been debate in literature about these different approaches (e.g. Heath \& Cowley, 2004; Kelle, 2005; Walker \& Myrick, 2006). The two originators shared the naming of many of the key terms in their work, yet differences lie in the understanding and use of these 
words when carrying out concrete research processes. Walker and Myrick argue that the difference is mainly in the position and activity of the researcher, and to what extent the researcher engages in the data analysis process (Walker \& Myrick 2006, p. 549).

Glaser's approach and Strauss and Corbin's understanding (Glaser 1978, 1998; Strauss \& Corbin, 1990) resulted in differences in the theories they ended up producing, in coding, questions about induction, deduction and verification, and the issue of "emergence versus forcing" (Heath \& Cowley, 2004; Walker \& Myrick, 2006; Kelle, 2005). Strauss' model is very detailed, the process fully described; Glaser's model is parsimonious, has scope and is modifiable (Heath \& Cowley, 2004). Glaser describes grounded theory as primarily inductive "(...) a theory is induced or emerges after data collection starts. Deductive work in grounded theory is used to derive from induced codes conceptual guides as to where to go next for which comparative group or subgroup" (Glaser, 1978 original italic). The differences are subtle yet construct separate models. Heath and Cowley (2004) point to that fact that in overall terms induction is preferred in the Glaserian method, whereas deduction and verification is preferred in combination with induction in the Strauss model.

In the Glaserian model concepts, categories and finally theory naturally emerge, by being true to the systematically constant comparison and having trust in the process, whereas the Straussian is more focused on specific, detailed tools to compare and question the data (Walker \& Myrick, 2006). This approach has been criticized by calling it "forcing" of the data, whereas Glaser has kept the process of emergence by comparison, which also led to Glaser's critique that what Strauss and Corbin were doing was not grounded theory, but a new method, which Glaser named "full conceptual descriptions". Glaser's devotion to the original thoughts around grounded theory led to the name "classic grounded theory" (Glaser, 2014).

Glaser's approach to grounded theory fits this study; his suggested process suited the substantive area of Al practitioners well because of the shared emphasis on the group being studied and including their voice in the data. However, by not choosing Strauss' approach, the opportunity to be more detail-oriented may have been missed. Glaser's model was chosen because of the focus on emergence, and because the kind of theory created is modifiable, flexible and usable for the group, and has scope that makes it easy to use in other areas. According to Heath and Cowley (2004), qualitative analysis is a cognitive process and each person has different cognitive styles and preferences. Glaser's approach seemed to match cognitive preferences of the researcher. I agree with Booth's argument, assessing differences in the approaches, when she says that "the Straussian model is overly prescribed, rigid and formulaic; the Glaserian model (...) is, organic, intuitive and creative, while still adhering to a time-tested, rigorous set of procedures" (Booth, 2014).

In addition to Glaser's approach, a social constructionist approach to grounded theory is integrated by Charmaz $(2006,2008)$ who provides a discussion of how grounded theory can match a social constructionists' world view and invites the constructionist grounded researcher to adhere to the following principles; 1 . to look at the research process itself as a social construction; 2 . reflect deeply about decisions and actions in the study; 3 . keep innovating and improvising in relation to strategies around methods and analysis throughout the process, and 4. keep a curiosity towards how research participants construct their lives (Charmaz, 2008, p. 403). This advice has also inspired this research process. The following section will describe the essence of theoretical 
sensitivity, key for the grounded theory researcher.

\subsubsection{Theoretical sensitivity}

The researcher's competency within the process of generating concepts from data is defined as "theoretical sensitivity" (Glaser, 1998). To carry out grounded theory research, the researcher needs to be "sufficiently theoretically sensitive" to be able to develop the theoretical concepts as they emerge from interacting both with the group being studied and with the data (Glaser, 1978). Before starting the research project, it is important that the researcher aims towards being open to the field and the process; for the generated theory to be grounded, data needs to lead the way. This openness has to be carried on throughout the process in order to be able to absorb what is relevant, within data from other sources as well as the planned ones (Glaser, 1998). In this study the researcher has also tried to remain open to processes and people that did not resonate with the researcher, but which seem to have an important place in data.

Trust is another important characteristic for the researcher using grounded theory, because it is characterized by a delayed action and learning process (Glaser, 1978, p. 30). For the researcher this means that she needs to trust the process because ideas and concepts bubble up from the unconscious mind while interacting with the field and data. The researcher needs to trust the process and go through the steps; the theory will then gradually emerge, if the researcher works systematically with the steps. This was the case in this study, where the researcher had a hard time giving up control at a certain point and trusting that the core category would emerge. But the repeated practice of trust eventually led to the emergence of the core category of organic growth. A final approach worth mentioning here for the development of theoretical sensitivity in the researcher is tolerance for confusion, because the confusion is necessary for the process of generating a theory, and is important for learning: "Great scientists are people who could tolerate great regression and great confusion as their minds sort out the data. They do not need to prematurely formulate. Confusion is a powerful learning tool" (Glaser, 1998, p. 100).

The researcher needs to have and possibly increase the skills that allow for conceptualization to happen. At the seminar led by Dr. Glaser, he kept asking "so what concept does this point to?", when participants spoke about their data. No long explanations, but the continuous question "is there a concept for what you are talking about now and what is that?" To be able to conceptualize means to find relevant ideas and words that relate to a specific area in a precise way, to visualize and to synthesize and to be creative. The last parts required that the researcher had the ability to shift between different moods, for example between a narrow analytical mood and a more playful, open, conscious state where creativity can take place. The connection between play and creation is stressed as, "The harder one plays the better they create" (Glaser, 1978, p. 29f). This knowledge has resulted in the researcher's experimentation with different modes of being relative to the phases of inquiry, shifting when relevant between e.g., a playful approach and a strict analytical mood, as well as a broader sense of overview and systematic approach towards data. The following section will include a review of the basic steps of grounded theory.

\subsubsection{Steps of grounded theory}

Grounded theory is a general research method that can be used with both quantitative and qualitative data (Glaser \& Strauss, 1967, p. 18). The key parts of grounded theory are outlined 
here (Glaser \& Strauss, 1967; Glaser, 1978, 1998):

1. Theoretical sampling;

2. Theoretical coding;

3. Theoretical memoing;

4. Theoretical sorting;

5. Writing it up.

In the following sections these key points will form a framework for presenting grounded theory as used in this project. As mentioned above, the grounded theory researcher has an entrance to a field of inquiry, a question, a curiosity or just a field, that she wants to know more about (Glaser \& Strauss, 1967, p. 45). The way to co-produce data is "jointly collected" data, called theoretical sampling (1):

Theoretical sampling is the process of data collection for generating theory whereby the analyst jointly collects, codes and analyzes his data and decides what data to collect next and where to find them, in order to develop his theory as it emerges. (Glaser \& Strauss, 1967 , p. 45)

The process keeps going until the categories and properties are saturated. Saturation means that the same incidents come up again and again, and the understanding of a specific category is "completed" in a way where no new information comes from data to expand the category (Glaser, 1978 , p. 53). When a category is saturated, the researcher focuses on the subcategories - the dimensions and their properties - of the emergent theory which are not yet saturated and need more data in order to become integrated into the emergent theory. The saturation occurs almost "naturally". The researcher needs to trust that fact, and trust that when reaching a saturation for a category it is wise to move on. The core category of organic growth was the first category to become saturated in this study, along with the dimensions of flow and balance. The dimensions of healing and wholeness took longest to saturate, because not all interviewees described these. Another comment to make in this regard is that some concepts were not sufficiently saturated to enter the final theory of organic growth. At one time in the process there were seven dimensions rather than six, but the last category, called "consciousness", did not become saturated enough to be included in the theory and the model. Many concepts at a lower level of the theory shared the same destiny, such as: pace, repetition, authenticity, essentialism, improvisation, relations, transformative learning, purposing, chaos, vibration, unconditionality and contrasts. These were all born as codes in data. The process of theoretically coding will be described below.

Theoretical coding (2) is the part of the process where the researcher highlights specific codes in the data. Codes are words valuable for the participants and for the researcher in relation to the emergent theory. Glaser operates with different kinds of coding: open coding, line-by-line coding, theoretical coding and axial coding (Glaser, 2007). Open coding is used when the researcher starts out and codes line-by-line to find as many substantive codes as possible: "The analyst begins by coding the data in every way possible - running the data open" (Glaser, 2007, ๆ 48). Open coding is used to make sure that every possible code emerges and to make sure that the researcher stays open to the data and does not prefer to carry on with a preconceived "pet code" or category. 
There are two different types of categories when talking about codes; in vivo codes and sociological constructs. In vivo codes are those that the population of the field themselves talk about, when speaking about how they manage their main concern; sociological constructs are codes added by the researcher in order to understand certain patterns in the behavior and language of the population. They are also called first and second order codes, where first order codes are words mentioned by participants and second order codes are constructs seen in data and named by the researcher (Gioia et al., 2013). The challenge of articulating some of the researcher's own concepts is that the population might not recognize them. On the other hand, it can provide language to describe something that was not spoken about until then, or the notion can provide a sort of justification for an experience or perception. Axial coding happens at later stages of the analysis, when the researcher starts relating concepts to each other while continually comparing new incidents in order to ensure the relevance of the relations. When the researcher codes, she continually asks her field notes or recorded data the following questions "What is this data a study of?", "What category does this incident indicate?", "What is the main concern being faced by the participants?" and "What accounts for the continual resolving of this concern?" (Glaser, 2007, ๆ 48). According to grounded theory the whole point of the work is to discover the main concern of the population (Glaser \& Strauss, 1967; Glaser, 1978, 1998).

The notion of the "main concern" caught the attention of the researcher early on in this study. In a social constructionist perspective, language and words literally mean the world. The theory of appreciative inquiry tells us that what we focus on will grow (Cooperrider \& Srivastva, 1987; Cooperrider \& Whitney, 2011). If the focus is on a main concern, it might strengthen the concern of the population. According to future-forming research, it is key that the researcher is aware of her visions for the research. Because of that, the researcher quickly started reframing that term and came up with connotations like "main interest", "main mental occupation", and "main fill" - which refers to what the participants were mainly filled with. Another comment on the main concern is that there is a basic value in choosing the group to study before choosing the object of study. From a wider perspective, it shows that the people in the group are prioritized above the researcher's curiosity. Even though a researcher's curiosity is very important, this choice suggests that the people are more important.

To qualify the coding processes, part of the training for the grounded theory researcher is to learn as many theoretical codes as possible by reading research literature from a variety of different professions (Glaser, 1998, p. 165). For this research it meant that literature from a variety of interprofessional areas were involved, for example education, management, health, psychology, organizational development, sociology, pedagogy and quantum physics. The next step to consider is theoretical memoing.

To theoretically memo (3) along the way, from the very beginning to the very end, is a key point in the working process of the researcher. "Memos are the theorizing write up of ideas about substantive codes and their theoretically coded relationships as they emerge during coding, collecting and analyzing data and during memoing" (Glaser, 1998, p. 177). Memos are the external brain bank of the researcher, where she places all of her big and small ideas, initial thoughts, fragments, or even fully finished pieces of text. Memos are the free and personal notes to track ideas and thought processes in the moment, as they happen, and are therefore fully private and not sharable. It is advisable to memo as soon as the researcher feels the urge to do that, and it 
often happens in places where it is not expected, because the brain produces ideas when the focus is on something else.

In this research many memos were written when waking up at night, when interrupting a shower to write, when stopping the bicycle to write, when in the train, or stopping the car, and when coding and reading literature. The memo bank for this study was 155 pages long, containing the first memo bank of 130 pages, and a second memo bank of 25 pages, which was created during and after sorting the first 130 pages.

In Glaser's words, memoing leads naturally to abstraction or ideation (Glaser, 1978, p. 83). “(...) doing grounded theory requires an amazing flexibility and freedom in maneuvering ideas as they occur and as they change" (Glaser, 1998, p. 185). The purpose of memoing is to capture all relevant and potential ideas related to the project when they arise. It is well known that when researchers or authors sit to write, it can be hard to remember relevant incidents and codes, and one can experience writing blockages. With this approach, the relevant ideas, syntheses and connections in the data are captured the moment they emerge. Writing blockages have not been relevant in this study, since the researcher was blessed by their absence, maybe due to this approach.

Even though researchers are free to structure and capture within their personal cognitive and writing style, there is some advice for creating a high-quality memo bank: 1 . ideas, 2 . freedom, 3 . memo fund and 4. highly sortable. Ideas (1) means a word, sentence or even page written down following the energy of the researcher, and not stopped before the energy runs out and the idea is on paper. Freedom (2) underlines the freedom for the researcher to create the memo in her own style and in a way where misspellings, structure or lack of arguments will allow her to work faster and at the speed of her creativity and imagination. After the sorting process, the writing-up phase ensures that the right structure for the communication and references are in place. Memo fund (3) is, simply put, a "storage" or a "bank" - a safe place to put all the memos. When to stop memoing is a balance - and depends on which type of text the researcher memos and sorts for - for a book, it is wise to carry on and have a large bank; for an article, the researcher may want to stop earlier.

As memos mature the researcher starts to hear the same thing over and over again in interviews and sees it in memos. The pattern has been conceptualized. Relevance is assured. The core category and it is resolving the main concern of the participants is confirmed over and over. Saturation and delimiting occur. The theory works and fits at this stage and best soon be written. (Glaser, 1998, p. 184)

The fourth point is highly sortable (4) where it is advisable to give each memo a title and to underline any important concepts in the memo, so that it can be sorted by that concept as well and make the sorting process easier.

\section{Researcher's voice}

In Glaser's book Doing Grounded Theory (1998) he corrects himself for maybe being too formal about these written goals, because researchers have tended to take these on as burdens, therefore stopping their workflow and writing stream (Glaser, 1998, p. 179). That is highly 
interesting for this research, because it points to the fact that when an authority gives very specific directions, the followers risk having a hard time meeting these exact goals. It also sheds light upon the fact that, as I listen to and read both Barney Glaser and Ken Gergen, they keep refraining from talking about the truth. Knowing your own position as a scientific frontrunner and taking a stand, people will often ask for more details to clarify the understanding for them - and when giving them specific details or even tools, there is a great risk that they will use that piece of information to hold themselves back and not be able to follow their flow freely.

The next step is theoretically sorting (4). The process of theoretically sorting all of the memos from the memo bank starts when the categories are saturated and the researcher is ready to write up the memos. The goal of sorting is to be able to write up the integrated theory and present the theory with the core category, dimensions and properties to others. Sorting is a necessary step on the way to writing, because this is a final step in creativity, where the researcher discovers the best order in which to present the theory. There is no one theory in a population or in a set of data, and the data can often be sorted for different purposes (Glaser, 1998, p. 187ff). The researcher needs to trust that the outline will form while sorting and it is important to keep writing memos through the sorting process because new interrelations between concepts and categories may emerge. As well, the researcher's memory around a specific theme might be activated.

A goal for the sorting process and the generated theory is "the smaller amount of concepts that account for the greatest variation in substantive behavior resolving the main concern (..)" (Glaser, 1998, p. 190). In this study the memos were printed out on paper and cut into pieces, with one memo to each piece. The memos were sorted into piles by taking each memo and comparing it to the other memos. The sorting process is a conceptual sorting, because it sorts ideas, not data (Glaser, 1978, p. 116). After sorting the memos, the process of "writing it up" (5) starts.

To write it up simply means to take each pile of memos and write them up. The "writing it up" phase was straightforward in this study, in that I used the guidelines from Glaser $(1978,1998)$. On a practical level, one pile of memos was taken at a time, and written into a section in the analysis chapter. With the first piles, the researcher started from one end and then wrote the memos up. After four piles, every pile was sorted into sub-themes and then written up matching each of the headings. The next section discusses grounded theory with other perspectives in this study.

\subsubsection{Critique and discussion}

There are both differences and similarities between social constructionism as the philosophical frame for understanding, appreciative inquiry as the connecting factor of the participating group, and grounded theory as the way of generating new concepts in this field.

One common critique towards the approach of grounded theory is the idea of going openly into the field. When the researcher is guided not to engage in theoretical fields or write literature reviews before going into the field, to remain open to what happens, it can be seen as naïve: no researcher will be a "tabula rasa" - an empty canvas, clean white paper - because every researcher will always have had scientific training, previous knowledge, interests and preferences. There are some benefits to a researcher visiting a field with which she is unfamiliar. As described in the section, "The position of the researcher", the field of appreciative inquiry was familiar to the 
researcher, which on one hand was challenging, because it could hinder a full openness, freshness and curiosity. On the other hand, the questions might have been more clear and relevant because they came from a place of more knowledge. And because this study aims to serve as a piece of future-forming research, the vision for the project may have been clearer because of the earlier exposure to Al.

\section{Researcher's voice}

I want to challenge the common understanding that you cannot be "fully open and curious" when you have former experiences of something. I understand the difference in the approach as to whether you visit something for the first time or whether you have been there before. And I am not saying that you can manufacture that freshness. But with meditation and other types of awareness training, you may be able to prepare in such a way as to be fully present, as if every moment of your life is new - which it actually is, but many people do not experience that freshness in every moment because they live in habits.

In the following we will dive into the group of Al practitioners being studied to gain insight about this study's specific population.

\subsection{The group being studied}

The group being studied for this research were, as described, positive change practitioners within the community of "appreciative inquiry". In the following section the appreciative inquiry approach will be explored in order to gain understanding of key characteristics of these practitioners.

\subsubsection{Appreciative inquiry}

Appreciative inquiry is introduced in this chapter, both because it is an important and original voice within the field of flourishing theories, and mainly because it describes the approach of the practitioners. Al is a research method, philosophical mindset and change-process tool. Al marks a radical shift in human orientation to change, to organizations, to work and to everyday life. The following section, which describes appreciative inquiry, will guide the way to a deeper understanding of this field. The foundational mindset of the practitioners in this study is the lifegiving, positive lens, the appreciative eye, the openness and the curiosity of the inquirer.

Appreciative Inquiry in Organizational Life talks about the "miracle of life" and "mystery of social existence" as a root metaphor for an applied and creative human science that is more powerful than "the world as a problem-to-be-solved" if our knowledge-interest is to inspire our imaginative capacities. Reading the world gratefully so to speak, that is, embracing the sacredness or miracle of life on this planet for its intimations of something more and for what's next or possible, is a fundamental part of the call for an appreciative inquiry of valuing those things of value worth valuing. It's also a key to the spirit of inquiry that is moving from edges of the known to the unknown (mystery) in ways that opens minds, ignites genuine curiosity, and inspires fresh images of possibility. (Cooperrider, 2017 , p. 83)

Al represents a shift from a deficit mindset towards a lifegiving mindset. Watkins and Mohr talk about a current scientific paradigm and an emerging paradigm (Watkins \& Mohr, 2001, p. 8). With 
great inspiration from their table (p. 8), some of the major points are taken out and elaborated here:

\begin{tabular}{|l|l|}
\hline Current scientific paradigm & Emerging paradigm \\
\hline $\begin{array}{l}\text { Newtonian mechanics; reductionist (i.e. things } \\
\text { can be best understood when they are broken } \\
\text { into parts) and dichotomous thinking }\end{array}$ & $\begin{array}{l}\text { Quantum physics and new sciences: self- } \\
\text { organization systems; chaos theory; complexity } \\
\text { theory }\end{array}$ \\
\hline $\begin{array}{l}\text { We search for a model or method of objectively } \\
\text { perceiving the world }\end{array}$ & $\begin{array}{l}\text { We accept the complexity and subjectivity of } \\
\text { the world }\end{array}$ \\
\hline $\begin{array}{l}\text { We engage in complex planning for a world we } \\
\text { expect to be predictable }\end{array}$ & $\begin{array}{l}\text { Planning is understood to be a process of } \\
\text { constant re-evaluation }\end{array}$ \\
\hline $\begin{array}{l}\text { We understand language as the descriptor of } \\
\text { reality: "l'll believe it when I see it" }\end{array}$ & $\begin{array}{l}\text { We understand language as the creator of } \\
\text { reality: "I'll see it when I believe it" }\end{array}$ \\
\hline We see information as power & We see information as a primal creative force \\
\hline $\begin{array}{l}\text { We believe that there is only one truth for } \\
\text { which we must search }\end{array}$ & $\begin{array}{l}\text { We seek to understand the whole and } \\
\text { interconnectedness of all things }\end{array}$ \\
\hline $\begin{array}{l}\text { We believe in cause and effect } \\
\text { We live in a linear and hierarchical world } \\
\text { cooperation }\end{array}$ \\
\hline
\end{tabular}

Table 2. Current scientific paradigm versus emerging paradigm

It is key to understand that appreciative inquiry places itself within another paradigm of science, as described in the section on social construction. Cooperrider says:

Indeed, Al is not a thing or a static concept, but an ongoing co-construction of reality; it's the result of many voices, contexts and circumstances, planned and unplanned experiments, new discoveries and designs, narratives and cases, and unlimited imagination. The only thing I am certain of right now is this: as long as Al is constructed upon, practiced or inspired by the sense of the mystery and miracle of life on this planet, it will never become inert or lifeless. Why? Because life is alive, it's always bursting out all over and Al is about the search for "what gives life?" to living systems organizations, communities, industries, countries, families, networks, societies, relationships, and our global living systems when they are most alive and jointly flourishing in their inseparable 
and intimate interrelations. Al's generativity lies precisely in its "inquiry inspired by life" north star and in its starting search, not in current ideals (certainties), but in the lure of unexplored possibilities (those intimations of something more) where possibility and positive potential can be sensed in the texture of the actual (searching for our worlds' lifegiving best). (Cooperrider, 2017, p. 84)

To dig deeper let us look at the basic principles of appreciative inquiry (Cooperrider, Whitney \& Stavros, 2008).

1. The Constructionist principle

Everything important to human meaning-making is constructed and reconstructed within cultural communities, with relationships between people and within the use of language (Gergen, 2009). Having that principle as a guiding light opens up the possibility of creating and co-creating the future and the world we live in, in a positive way, building on resources and strengths. "The most important resource for generating constructive organizational change is cooperation between imagination and the reasoning function in the mind" (Cooperrider et al., 2008, p. 8).

2. The principle of Simultaneity

Inquiry and change are interconnected and happen simultaneously, because the first question asked affects the thoughts and behavior of the participants. This differs from other change management approaches where the process is often characterized by an inquiry process (to discover the problems) that is understood as "neutral" - a process of observation in order to create a final diagnosis of the organization - but that does not affect the organization until after the solution has been developed, during implementation. In this principle it is clear that "The questions set the stage for what is 'found' and what is 'discovered' (the data). These data become the stories out of which the future is conceived, discussed, and constructed" (Cooperrider et al., 2008, p. 9).

\section{The Poetic principle}

The metaphor for explaining this principle is to see the organization as an "open book". If we understand an organization in this way, its story can be co-authored and written anew all the time. And there is a choice to be made in order to decide what story is the red line and key focus of the book. "The choice of inquiry can focus on the nature of alienation or joy in any human organization or community. One can study moments of creativity or innovation or moments of debilitating bureaucratic stress. One has a choice" (Cooperrider et al., 2008, p. 9).

\section{The Anticipatory principle}

Anything shared exists because of collective imagination and discourse about what happens in the future. What we believe and expect about the future together will form our lives; "(...) human systems are forever projecting ahead of themselves a horizon of expectations that brings the future powerfully into the present as a mobilizing agent" (Cooperrider et al., 2008, p. 9). If we follow this principle, the vision we share becomes crucial, as does what we expect from ourselves, each other and this planet. It also bears an almost limitless possibility for what can be created, if there are enough visionary people coming together to create it. 


\section{The Positive principle}

Cooperrider et. al. (2008) state that this principle was born out of years of working with appreciative inquiry, and it relates to how momentum works if the questions and images in the change processes are positive. "(...) momentum for change requires large amounts of positive affect and social bonding, attitudes such as hope, inspiration, and the sheer joy of creating with one another" (Cooperrider et. al., 2008, p. 9f). They argue that the more positive the questions and the visions are, the more effective and long lasting the change will be.

Whitney and Trosten-Bloom add three extra main principles (Whitney \& Trosten-Bloom, 2010), which are:

\section{The Wholeness principle}

The principle of wholeness invites the wisdom of the whole, the collective mind, into the room. This is relevant because when "all" parts of the organization are represented in a dialogue, the diverse perspectives strengthen the process and the final design. It also ensures that very different people will act on the new change ideas, and therefore the fruition of the "whole" is translated into every corner of the organization.

\section{The Enactment principle}

This principle invites participants to act "as-if" the vision is already reality. This acting helps the vision come to life. Acting as-if makes the participant a living example of the desired future and becomes self-fulfilling when bringing the future into the present. This is not to be confused with "fake-it-till-you-make-it", because the participant is authentically acting as the person he is about to become.

\section{The Free Choice principle}

There needs to be free choice for participants in relation to how and when and with what they contribute. This encourages more motivation and drive, and creates a passion for the participants to contribute to the bigger picture.

What about problems? A key question people have when they hear about $\mathrm{Al}$ is what happens if you try to deny that problems exist. Whitney and Trosten-Bloom do not deny that problems exist but say that it is more effective to focus on strengths if you want to change a situation, a relationship, an organization or a community (Whitney \& Trosten-Bloom, 2010). The journey goes from the known to the unknown and Cooperrider often emphasizes how "inquiry" is the key word in appreciative inquiry:

Appreciation is about valuing the "life-giving" in ways that serve to inspire our coconstructed future. Inquiry is the experience of mystery, moving beyond the edge of the known to the unknown, which then changes our lives. Taken together, where appreciation and inquiry are wonderfully entangled, we experience knowledge that's not inert but alive, as well as an ever-expansive inauguration of our world to new possibilities. In many ways I've begun to question today whether there can even be inquiry where there is no appreciation, valuing, or amazement, what the Greeks called thaumazein: the borderline between wonderment and admiration (Cooperrider, 2017, p. 85). 
This section provided background information on the essence of the theory of appreciative inquiry, the mindset and method that characterizes the key inspiration of practitioners in the population. Again, Al has been chosen because the practitioners use this approach and Al is neither a key research interest in the study, nor the core methodology. In Chapter 4, the full research design will be treated before turning towards the analysis chapter. But first a word on energy-led research.

\subsection{Energy-led research}

As a supplement to the methodological approach in this research, a methodological perspective emerged during the process. Energy-led research sheds light on the micro-navigation that the researcher uses to handle the research process and it is inspired from grounded theory and from the model of organic growth. Many researchers will probably recognize this way of working through research processes, yet this gives languages to this specific methodological approach. If we are to transform from our current understanding of research as mirroring the world to the understanding of research into co-creating the future we need to develop new methodological approaches. Energy-led research is one suggestion for an approach concerned with the single researcher's micro-management of the time and tasks in a research project. It is a suggestion for how to handle this management in the most beneficial way, in order to create theory that helps shape the future, not in making sure everything remains exactly as it is. It is important to emphasize that this text is solely a first draft, describing a first try-out of this approach and that it will need further attempts in future processes to refine and adjust as well as articulate possible strengths and weaknesses with this approach. To develop supplemental methodological approaches in the area of future-forming research is quite demanding, because future-forming research is still new.

In grounded theory, every action is guided by the emerging theory. To be able to create a theory or model that co-creates the future with the group, the researcher needs to be sensitive to what is happening in that community, in the wider theoretical field, but also in the world today. Energy-led research refers to the micro-management of the researcher in a research process in order to take the right decisions about what to do when and in what order. To be led by energy means to follow the flow and the excitement of the process and to let the decisions be guided by intuition. To be led means to have the courage to be led, to let go of some control and to get into a state of mind that is softer, with freer boundaries. To lean into the flow. It requires a high degree of improvisation as a supplement to the rigorous system of the core method. "Rather than work with design and method, we prefer minimal structures and improvisation. Of course, some important decisions must be made before we embark on any inquiry. Yet (...) even these emerge within particular relational communities and then are more-or-less open to crediting or discrediting by those with whom we conduct our inquiry" (McNamee \& Hosking, 2012, p. 68).

Energy-led research emerged after ten interviews with the researcher's immediate resistance toward it. I found that I had enough new perspectives from developing a grounded theory and was not interested in developing a supplemental method as well. Reflecting further and being honest to the language of organic growth, I needed to accept that a supplemental approach had been born and to write it up, which was done in August 2017. Many writers and authors know about this phenomenon of writing: being inspired and having a feeling of just typing, being a medium for a kind of energy that runs through the body and into the fingers. If researchers can design 
circumstances with the possibility of creating such experiences frequently, the work will be effective and inspired instead of interrupted with writing blockages or procrastination.

Looking at other fields, management has a theory which resonates with energy-led research, called "leading from the emergent future" (Scharmer \& Kaufer, 2013). Scharmer (2000) defines the ability to sense and act into the emerging future as tacit or self-transcending knowledge:

The challenge is to develop the capacity for "precognition," the ability to sense and actualize emerging potentials. To do this, leaders must be able to see the emerging opportunities before they become manifest in the marketplace. This kind of knowledge can be thought of as tacit knowledge prior to its embodiment, or "self-transcending" knowledge. (Scharmer, 2000, p. 3)

This is also true for energy-led research, where the researcher needs to be able to sense and actualize the next themes and ideas coming from data. The researcher needs to be emotionally stable and able to handle the emotional states of a research process (Collins \& Cooper, 2014). From the researcher are also required: openness, wholeness, integrity, trust, intuition, letting go of control, wisdom of the researcher's own recharging processes and emotional intelligence $(\mathrm{EI})$ (Anderson, 2000; Glaser, 1998; Fredrickson, 2009, 2013; Cooperrider \& Srivastva, 1987; Goleman, 1996). Energy-led research invites in the emotions of the researcher 6 : not only invites them in, it gives them a front seat (Collins \& Cooper, 2014; Gergen, 2015).

McLaughlin argues that emotions in the research process are to be taken seriously (McLaughlin 2003; 68). According to McLaughlin, reason and emotions are falsely polarized because thinking and emotion are in fact completely linked in research processes. "El in the qualitative research process offers the possibility of a more nuanced role, greater flexibility, and more insightful findings, and therefore $\mathrm{El}$ is a useful instrument in the conducting of a study" (Collins \& Cooper, 2014, p. 99).

Our capacity to function intellectually is highly dependent on our emotional state. When we are preoccupied, our minds are literally occupied with something and we have no space to pay attention, to take in and listen to anything else. When we are frightened, we are more likely to make mistakes. When we feel inadequate, we tend to give up rather than struggle to carry on with the task. (McLaughlin, 2003, p. 73)

If the researcher places his or her values and visions at the forefront of their research, studies might mirror not the world, but the researcher. If the researcher is honest in sharing values, the mirror is clear, and it is then clear how that study can help create social change, if it resonates with the population. In other fields that would be called a bias. If we are to create future-forming research, we need to accept that social science is carried out in another way, where the researcher is not biased, but a resource to enrich and inspire the future being formed with the population. When the method of energy-led research emerged and was written down, it guided the

\footnotetext{
${ }^{6}$ Emotional energy as a concept has received increasing attention from different scientific fields and Baker (2019) invites further empirical research in this area. Such empirical studies will help to adjust both the theoretical understanding and use of the methodological approach used here but also the practical use.
} 
micro-management of both the last phases of data production, the interviews and the workshop, as well as the writing-up phase. The following chapter will outline the concrete research design. 


\section{Chapter 4: Research design}

In this section the research design will be presented with spotlights on the practical methods and steps used to co-create data. The section will end with a thorough review of the analysis strategy and the data structures used to analyze the set of data.

The following practical methods were used to produce empirical data:

1. Twenty-four qualitative interviews;

2. An interactive research workshop;

3. An interactive analysis workshop;

4. Participant observations, informal interviews with participants and field notes at one global Al conference and one certificate course.

The research started out with some research questions. Inspired by the grounded theory method, these research questions were dropped along the way in order to experience and grasp what was important for the Al practitioners. As discussed in the previous chapter, a grounded theory researcher enters the field with "grand tour" questions to learn about the group's "main concern". The four different approaches to the field were chosen in order to interact with the group in a variety of ways, both to meet different actors and also to experience a wide range of communications and behaviors. The two interactive workshops were chosen to invite participants into the core of the research processes in order to have the possibility of co-creating together. In grounded theory, the objects of study are articulated by the researcher on behalf of the group. In future-forming research, I find that the group being studied both helps define the research object and also participates in other parts of the research, such as the analysis. That was the intention for this study.

\subsection{Qualitative interviews}

Twenty-four qualitative interviews were conducted with Al practitioners from different settings in the global appreciative inquiry community. The selection of people being interviewed was guided by the emerging theory (Glaser, 1978). The participants fell into different categories and represented practitioners with the following experiences:

- Mutual mentorships between Al practitioners (1:1);

- Participation in learning communities around certificate programs in $\mathrm{Al}$;

- Al practitioners in a municipality;

- Participation in regional communities around Al;

- Participation in WAICs: World Appreciative Inquiry Conferences.

Most of the interviews were conducted online through video or telephone contact because of the global locations of the practitioners, and all interviews were followed by extensive notes that were afterwards coded, analyzed and memoed throughout the process. Notes were taking during the 
interviews as well. According to Kvale (1996), the qualitative research interview is useful when you are interested in learning about people's life-worlds and life experiences, and the subject of this study was the life-world and life experiences of Al practitioners. Anderson (1997) invites the interviewer to take a "not-knowing" state and to always approach each interview with curiosity and uncertainty, advice the researcher tried to practice.

\subsubsection{The experience of the interviews}

The interviews were all enriching experiences and varied according to the time taken for the process and the interviewee. Most went as expected, following the advice of entering the conversation with a freshness and deep listening, and following the interview partner with elaborating questions instead of following a prepared agenda. The text below is an extract from the researcher's diary, where an interview stood out as rich in learnings:

\section{Researcher's voice}

What I learned from the seminar was that I should go back to my field, my interviewees and do grand tour questions. Grand tour questions are questions that are as open as they can be, just wanting to start a conversation and wanting to know what is on the mind of the people from the population. Questions would be like "What's up?", "What is going on?", "What are you working on?" and so on.

At that time, I figured that I had been approaching the field in the wrong way (according to grounded theory) and wanted to try to re-enter my field, to see what would come up. To test the method in real life and for myself. To do my own experiences. And to be fully "true" to the method. Well, so I did. The next planned interview was a week later and happened to be an Al practitioner that I had met five years earlier at a conference. The interview was experienced as, well, a disaster! He was very kind, and gave feedback after the experience with the interview - he found it very awkward, distanced, and said that I took on a role of being outside the interview, hiding my own values, when he knew I was not like that, but usually was very kind, playful, loving, present and authentically listening - showing myself and who I am in relationships and conversations. This meant that I felt that I almost lost a good relationship with him; I felt that he found my approach to be weird and did not get why I would choose such an approach, when it did nothing but lower the level of a high-quality relationship.

That experience sent me back to my thinking box, spending some time digesting the emotions raised due to that experience and listening to what I had to learn. It became clear to me that, first of all, grand tour questions and a "pure" grounded theory, are not relevant choices when the researcher knows the interviewee already. Also, it taught me that grand tour questions are useful in the beginning of a (grounded theory) research, when you do not have a core category - you do not yet know what you are theorizing about. At the time of the grounded theory seminar, the core category of the model of "organic growth" had surfaced a few weeks before, and it was very new and fragile. 
It also became clear to me that the kind of researcher I am places values upfront. I knew that theoretically, with inspiration from, for example, Gergen's article, but I did not know what that meant in practice. I was developing my researcher identity.

Talking with him, I tried to explain grounded theory and that I did not want to "throw myself into the interview with all my preconceptions and high heels and everything" - meaning my values and my being. Giving me feedback, the interviewee specifically said, "I want you to be in the conversation with your high heels." That picture is representative for the whole experience.

After that, important lessons were learned: To trust the core category and to theoretically sample for the core category as well as the dimensions which were fast evolving. During these interviews specific questions would come up, such as:

- What do you understand by organic growth?

- Can you think of a time where you went through a specific growth period as an Al practitioner?

- How is balance important to you as an Al practitioner and how do you obtain it?

- What characterizes a growth-promoting context?

As well, questions were directed to saturate specific subcategories relevant at that time, such as energy, sensitivity, consciousness, simplicity, flow and trust.

\subsubsection{Strategy for finding interviewees}

The snowball sampling method inspired the strategy of finding interviewees (Biernacki \& Waldorf, 1981). As the data collection began, the emerging theory guided the choices of people to be interviewed. Halfway through data production the methodological approach of "energy-led research" emerged and was written down. That became the strongest way to invite new people to interviews. As well, four people were re-interviewed instead of asking new people to join. Reinterviewing was also good advice taken from the grounded theory seminar.

In the beginning, two pilot interviews were conducted and then two more practitioners were interviewed. A student then conducted two Danish interviews. The first impression was that the questions were relevant for overall curiosity, and that all interviewees had a great willingness to share. The student was not part of the international or national Al community, though very open and with a competency potential and curiosity in the area of strength-based approaches. This meant that she had a different approach to the interviews because of her position, which turned out to be valuable: she was able to ask questions with a strong and honest authenticity and listen with sincere ears, because she did not have preconceived ideas. That turned out to be an excellent supplement to the researcher's position, because the researcher was familiar with the field and with some of its practitioners. The downside of the interviews conducted by the student was her lack of interview training and her more superficial knowledge within the field of positive change.

The experiences with the interviews created a powerful learning possibility for the student, and she had a very profound experience with one of the interviewees. It also meant that her experiences lent perspectives to the research in order to see some of the truisms and things that the researcher 
took for granted, e.g. how important it is for positive practitioners to embody their strength-based methods and being in full resonance with what they teach and believe. That was something that stood out very clearly for the student.

\subsubsection{Interviewees}

In the following, each person being interviewed will be described along with the argument for choosing them for the study. As mentioned, the intention was to find a variety of Al practitioners. Some were chosen because they belonged to one of the categories. After energy-led research was introduced, it became the primary argument for including people in the interviews. A couple of the interviewees were re-interviewed because the emerging dimensions and propositions showed it to be a good idea to go back to those informants regarding specific topics (Glaser, 1998).

Kim

The first interviewee was chosen because he belonged to the category of "Al certification programs". I met him at a certificate program in Appreciative Inquiry at Case Western Reserve University. He has been working with Al for about fifteen years and had already used it for a long time before that without knowing the language and method, though focusing on the lifegiving parts in his life and work. He works as a change manager with a background in instructional design.

\section{Cathrine}

Cathrine was chosen as the second pilot interviewee because she belongs to the category of $\mathrm{Al}$ communities. I met her during a meeting within that community. She has been working with Al for about twenty-five years and was introduced to the method in the early days. Cathrine was reinterviewed as interview number fifteen because of her work with keywords like energy, spirit, interconnectedness, intuition and wholeness. These terms emerged as being important for organic growth and needed to become saturated in order to find a place in the theory, if relevant.

\section{Thomas}

The third interview was conducted during the World Appreciative Inquiry Conference in Johannesburg 2015 with the Al practitioner Thomas. Thomas works as an independent consultant and has worked with Al for fifteen years. Thomas agreed to be re-interviewed as interview number eighteen, because of his understanding of key ideas such as flow, balance, simplicity, healing and love.

Alfred

The fourth interview was conducted with Alfred, who had worked with Al for three to four years. Alfred works as a social educator and consultant in a municipality, working with preschool teachers. Alfred was chosen because he belongs to the category of Al practitioners working in a municipality.

\section{Sarah}


The fifth interviewee, Sarah, belongs to the category of practitioners joining a regional community. Sarah works as a storytelling consultant and her clients are stigmatized groups of people. Sarah creates workshops inviting the participants to powerfully share their stories in front of a live audience, and through that experience heal trauma in their lives. Sarah has worked with Al for approximately fifteen years.

Sasha

The sixth interviewee was chosen because she belongs to the category of regional Al communities and she also joined a world conference. She has been headmistress of schools for vulnerable children and youngsters, has worked as an independent consultant and is currently working as a head teacher in a school. She has used the principles of Al for decades and was introduced to the approach because a colleague suggested that she was already working from such a perspective.

Louis

Louis was the next interviewee, chosen because he belonged to the category of certificate programs. I met him during a research workshop in Amsterdam. Louis has a background in corporate consulting and is working as independent consultant while finishing his PhD studies. He has known Al for fifteen years and applies the approach both in his work and his personal life.

Mia

Mia has been working as a manager for about ten people in a kindergarten all her life and was chosen because she belongs to the category of Al practitioners working in a municipality who works strategically with Al. Al resonates deeply with her being and approach towards life. She was happy to discover the theory of Al and to know that her own managers found the approach valuable. She finds it beneficial both in her work with her employees but also with the children and their parents.

\section{Casper}

Casper was chosen because he belongs to the category of Al practitioners joining a world conference, but he has also attended certificate programs in Al. Casper is a researcher and an independent consultant who both teaches and works with positive change assignments for customers. Casper has worked with Al for ten to twelve years and has used the approach in his personal life as well with good results.

Martin

The tenth interview was conducted with Martin, who works as a manager in a kindergarten and belongs to the category of Al practitioners working in a municipality. Martin was introduced to the approach because his workplace used Al as an overall strategic approach in all kindergartens in the municipality, so he has known the theory for six to eight years. He finds the theory resonates with him and his approach, knowing that he also needs other tools to be a good manager. 
Anna

Anna is an experienced practitioner and has been working with Al most of her working life. She has obtained very good results working in third-world countries, especially with projects that empower women. She was chosen because she has attended several world conferences and uses the approach in her everyday life, too, with her husband and children. She is very grateful to be able to apply the approach, and she does not understand why more people are not aware of it.

Louise

The twelfth interview was conducted with Louise, who works with Al in a big consultancy firm. She has been working with $\mathrm{Al}$ for fifteen to sixteen years and continues to work with this approach because she gets good results with her customers. Louise was chosen because she has attended world conferences, and she also contributes to the current developments within the area of Al by, for example, participating in the field of creating positive education.

Marie

Marie works as a manager in a kindergarten and was invited into the study because she belongs to the municipality that works with AI at a strategic level. Marie has been working with Al since her workplace introduced it six to eight years ago, and she finds it valuable along with other approaches to management.

\section{Daniel}

Daniel, interviewee number seventeen, is a very experienced Al practitioner, who learned about Al not long after its emergence. Daniel works as an independent consultant and has trained a number of Al practitioners over the years. Daniel has attended world conferences as well as regional and national community gatherings and also participated in certificate programs.

Michael

Michael is also a very experienced Al practitioner and has been working with this method for nearly twenty years. Michael's background is as a teacher. He now works as an independent consultant. Michael was invited into this study because he belongs to the category of regional communities of Al practitioners, but he has also attended certificate programs and world conferences.

Christian

Christian was chosen because he fell into the category of 1:1 mentorships and, even though he is in the younger age range of interviewees, he has been working with the approach for nearly twelve years. Christian works as a researcher and scholar and has been attending certificate programs, regional and national community activities, as well as world conferences. Al resonates with his personal life, and he practices it in his own developmental processes, with his children and wife as well as students and colleagues. 
Carina

The interview with Carina was conducted as interview number twenty-one. Carina is also an experienced Al practitioner who has worked with Al for over ten years, and who finds that it resonates profoundly with her approach both in work and personal life. Carina has a spiritual profile and works as an independent consultant in CEO coaching and change initiatives and uses her spiritual awareness to let her intuition guide her towards a balanced and successful life. Carina was chosen because she has experiences with terms such as quantum theory, intuition, love, interconnectedness, synchronicity and timing.

Carl

Interview number twenty-two was a conversation with Carl, who has a background in the corporate world and is now working as an independent consultant and author. Carl has fifteen to eighteen years of experience within the field and was chosen because he has experience with notions such as emergence, balance, flow, openness, humor and fun.

\section{Oliver}

He was chosen because he has been practicing appreciative inquiry in a more subtle and indirect way because his wife has spent a lot of time practicing this approach. Even though he finds that he does not use the vocabulary to the fullest, he lives his life on these basic principles of looking for what gives life. Oliver has many years of experience and helped saturate categories such as appreciation, wholeness, love, openness, flow and resting.

\section{Brian}

The interview with Brian was conducted as interview number twenty-four. Brian was invited into the study because he has been working with notions such as flow, resistance, non-forcing, simplicity, healing, acceptance, energy, humor and fun. Brian is the only voice in the sample who does not belong to the category of Al practitioners, because he does not work consciously with the method. Following the principle of Glaser $(1978,1998)$ it can be relevant to invite voices outside the population in order to gain more knowledge of specific concepts emerging in the grounded theory, which is why he is the one exception. Brian works as an independent consultant and teaches courses and workshops to private individuals, and he has knowledge about positive emotions and positive psychology and works with these areas from a spiritual perspective.

\section{Carsten, Conrad and Camilla}

I chose to "double blind" three of the interviewees, which means that three of the interviewees appear under the pseudonyms of Carsten, Conrad and Camilla. The community of Al practitioners are globally very connected to each other, and many have years of experience and therefore have many relationships within the community. This means that these interviewees would easily be recognized, which would mean that it would not have been possible to keep the promise of

\footnotetext{
${ }^{7}$ To double blind in this case means that some of the interviewees first were given one pseudonym and thereafter were given a second chosen pseudonym for further security.
} 
anonymizing the interviewees. Only one interviewee made the request to be anonymized, and therefore the decision was taken to blind all of the interviewees.

Each of the interviewees, except Brian, lived up to the criteria that were set for interviewees entering the study. The criteria were:

1. Experience with practicing appreciative inquiry for at least three years;

2. Practicing appreciative inquiry in work-related settings;

3. Identification with the label "Al practitioner" - having the experience themselves of belonging to the category of Al practitioners;

4. Willingness to participate in the study, offering their time and their voice.

The last part of the sample was chosen theoretically, which means that the interviewees were chosen because of specific knowledge or experience with concepts emerging in the language of organic growth in order to assess possible saturation.

From participant observations within communities of Al practitioners, I knew that Al practitioners do not share the same demographic background, and therefore it was valuable to let in voices from different demographic background. The age of the interviewees ranged from those in their twenties through to those in their seventies, with people from every decade in between represented. Both men and women were invited, as well as those with different educational backgrounds and current work situations. Leaders and managers were included as well as scholars and researchers, a teacher, independent consultants and a school principal. Employees from both corporations and a municipality were represented. The national backgrounds of the interviewees were: the Netherlands (1), Belgium (1), Denmark (7), England (1), Singapore (1) and the USA (9). ${ }^{8}$ (You can find an overview of the interviews in Appendix 12.4). During the process of interviewing, a wish emerged to have a wider geographic range of interviews, and candidates from South Africa and India were on the list, but when the theoretical sampling started, four of the last six interviewees came from the USA because their voice was needed in order to reach one level of saturation. There was no articulated curiosity in the study to include cultural or national differences, and the study was therefore not designed to systematically meet such a request. The community of $\mathrm{Al}$ practitioners shows a wide variety of people but segments dividing the practitioners didn't come up as an important point from the research, and this is reflected in the choice of interviewees.

\subsubsection{Anonymization}

New names and identities were created for the interviewees in this study, because one practitioner wanted to keep the identity confidential. One can never know what happens with results in future circumstances if information is taken out of context or does not match how the interviewee changes his or her mind over time. Theories and studies cannot keep up with real time; they are set and saved somewhere. Therefore, the decision was taken to protect the interviewees. This was

\footnotetext{
8 The geographic background of the interview sample was not as diverse as the observations of the community of Al practitioners, which had participants from Nepal, South Africa, China, Belgium, France, Denmark, the Netherlands, Croatia, Japan, Spain, Germany, Australia, Colombia, Dubai, Malaysia and America among others.
} 
successful, except for one interviewee who decided to create a podcast episode out of parts of the interview with my accept. The in-depth reflections about this event are described in the evaluative reflections of the method in Appendix 12.6.

\subsubsection{Interview guides}

During the interview period, the protocol changed according to the phase of the research. Before the core category of organic growth emerged, the interview guide was designed to be semistructured and was concerned with an overall question "What moves Al practitioners"? The questions were organized into four categories: "history", "today", "online sharing" and "community", because of the research interests at that early stage. The following mind map is an example of an early interview guide as it looked during the first interviews in 2015.

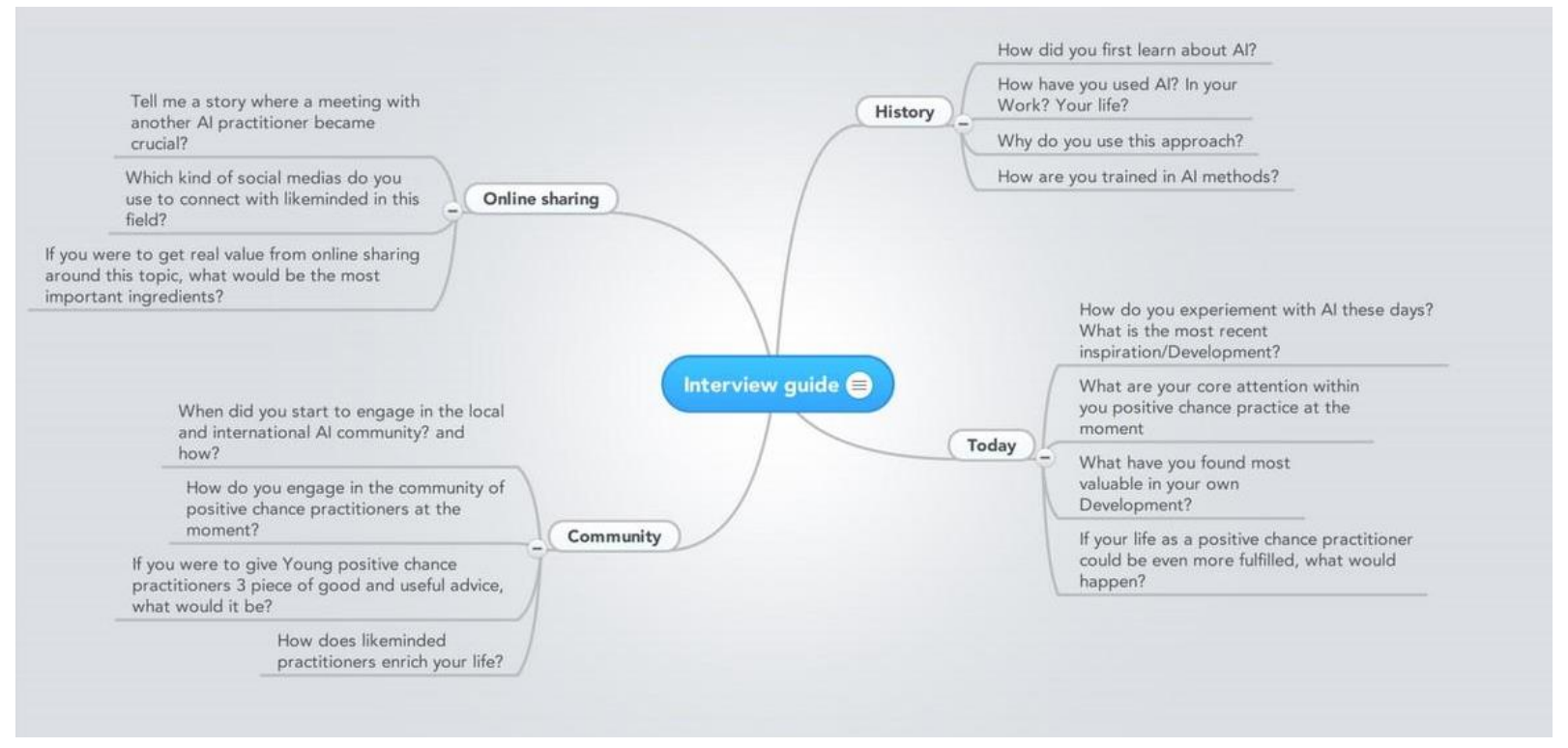

Figure 6. Early interview guide

The questions were regarded as guidelines because the interviews were semi-structured and served as inspiration throughout the interview. All of the interviews took place as a conversation and the interviewees were told to expect a conversation, not an interrogation.

After the core category emerged, a new interview protocol was created before every interview based on the categories which were to be saturated in the process. The questions were sent beforehand to those interviewees who requested them. Most did not, but expressed trust in the researcher and the situation, and were happy to contribute and looked forward to the conversation. With regard to the interview protocols, it was clear that they did not lead the conversation; the function was to be back-up questions in case the conversation went silent. This section has focused on the reflections regarding the choices taken in relation to the twenty-four qualitative interviews. The next section will unfold reflections on the interactive research workshop. 


\subsection{Interactive research workshop}

As part of the research design, two interactive workshops were conducted in order to align with the idea of co-creating research in collaboration with the population.

One way to think about this is to move away from the idea of research as an individual and private activity, in which it is seen as a demonstration of the unique brilliance of the single researcher or team, toward an idea of the research as being a collective activity, in which people share and develop ideas together to explore issues (...). (Reed, 2007, p. 95-96)

Besides approaching the interviews in this study as conversations between equals, the interaction with Al practitioners in the workshops made it possible to invite in processes of collective inquiry.

The first workshop was held as part of the World Appreciative Inquiry Conference (WAIC) in 2015 in Johannesburg, South Africa. The workshop was entitled "Co-creating research - how do you grow as a positive change practitioner"? The idea of growing was a key code within the first interviews and therefore the workshop had "growing" as a key area of curiosity. Throughout the workshop, the participants had the opportunity to add their voices to the research project as well as discuss their understanding of "growing" as a positive change practitioner.

Revisiting the title of the workshop when writing the analysis, I was amazed to see that "growth" was already a key interest at that early point in the research. Looking back at the early notes, it is clear that the understanding of growing was tied to a goal-oriented and "bigger-better-faster" understanding of growth, which does not resonate with the notion of organic growth. The emergence of organic growth happened because of the open and grounded approach toward the group being researched. And whereas grounded theory would be solely focused on generating a theory grounded in data, this research was also designed to interact with the people, to ask questions that might ignite new ideas and language, and possibly create frames for new connections and new learnings for the participants.

The workshop was designed to both enrich the participants and the research project and could be understood from this model:

The research was enriched by the participants during the workshop

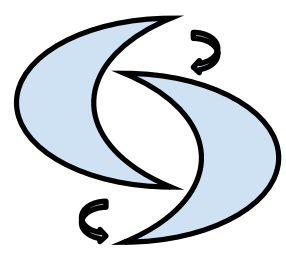

The participants were enriched by the research during the workshop

Figure 7. Workshop model for the interactive research workshop

\subsubsection{The co-creative improvisation}

The workshop was designed with visual slides to guide the process, a short presentation of the research, followed by questions and exercises for the participants, and a harvesting phase (please find the original slides in Appendix 12.1). Inspired by grounded theory, I had the idea of improvising the workshop to see what the participants "were up to" when I got on the plane to Johannesburg. 
The trust in the process (Glaser, 1978, 1998) and the decision to let the emerging theory guide my choices led me to conclude that the participants should choose on the spot. When I welcomed everyone, I gave them the option of going through my planned program with slides or improvising on the spot, together.

The participants chose to improvise, and we went through a shared process of grouping people with those they wanted to talk to, designing questions in groups, and pairing up for an appreciative walk and talk together, asking the newly designed questions. In many ways that was inspired by grounded theory, giving full empowerment to the group, who chose what was important for them to discuss.

It is clear that, even if the method of energy-led research had not yet been stated aloud, the method guided the approach in the facilitation of the workshop. New questions came with new learnings of how Al practitioners relate to each other, how they design questions and how they approach learning possibilities such as this one. They took the invitation to "play"; they took responsibility in co-creating and crafting the design and they carried it out. One interview was recorded on a smartphone, and this interview also became part of the data. Notes were written immediately after the workshop, and further notes were taken during the week after as new insights, experiences or memories popped up. What follows are reflections from the second interactive workshop in 2017, in which some practitioners were invited to co-analyze.

\subsection{Analysis workshop}

This section will describe the choices made around the analysis workshop as well as reflections on pros and cons of these decisions.

At the workshop carried out as part of the data analysis process, all Danish interviewees were invited to co-create and further develop the themes from the first coding process. The workshop was conducted in person in Denmark, which was the reason for inviting only Danish participants. From the beginning, the plan was to engage all of the interviewees in the analysis process, and one idea was to create an online analysis forum. As the time got nearer, the decision was taken to carry out a physical workshop, where people had the chance to meet face to face. I found it valuable to let practitioners meet in real life because of the special atmosphere that can be created in physical settings, and also because I expected it to be easier to explain the process of coanalyzing and carrying out the co-analysis without confusion when we were all in the same room. I also expected that it would be easier for participants to cancel or not show up for an online meeting. That decision had some benefits, but also some disadvantages. For example, I could not fly in all of the interviewees from different places in the world. One last reflection about that choice was that I did not have a lot of training in online facilitation, and no training in leading online coanalysis.

The purpose of the workshop was to engage participants in the process and to get a chance to talk to each other about the research. Since the philosophical stance of the research is relational - and is based on the assumption that new ideas are born within a social context - it was crucial for the theoretical concepts of the research to be co-created within relational conversations. 
When inviting participants into a collaborative analysis process, there are different approaches and things to be aware of. The researcher needs to consider how to engage in a collaborative analysis process, how to manage the process, what role the participants should play and how the process can be experienced as enriching and alive rather than chaotic, which can be the case when analyzing large amounts of data (Reed, 2007, p. 146). Collaborative analysis processes can contain both quantitative and qualitative methods. This workshop was designed with qualitative methods. The workshop was arranged at a time in the analysis approach after almost all of the interviews had been held, where the core category had emerged, and a number of the dimensions were visible in the data. Because of the theoretical coding and collection process, where analyzing and interviewing took place simultaneously, the first round of analysis had already been conducted when the participants were invited into the process. That had both disadvantages and benefits. In one sense, the participants were not equal to the researcher in the process because they were left with categories that had already "pre-emerged" from the set of data. Other categories might have emerged if the participants had been included during the theoretical coding and collecting process. A beneficial side effect was that the position of management of the process was very clear and therefore the tasks for the participants were well defined and clear. That potentially made it easier for the participants to take part in the process and not become too confused, as might have happened if they had joined earlier in more chaotic stages of the analysis. Some participants might have had an easy time joining in an open stage of the data collection and coding; others might have preferred more clarity for the path and their contribution to the project.

The purpose of the next section is to unfold the details of how the analysis workshop was carried out in practice and which theoretical foundation the inspiration came from.

\subsubsection{World Café}

The workshop in Denmark was designed with inspiration from the methodology of World Café. The name first appeared in 1995 when a group met at the home of the co-founders Brown and Isaacs in Mill Valley, California. Rain prevented them from having a planned large group session, so they broke up into groups around small tables and wrote their notes on the tablecloths (Brown \& Isaacs, 2005). The seven principles of the World Café are; 1 . set the context, 2. create a hospitable space, 3. explore questions that matter, 4. encourage everyone's contributions, 5. cross-pollinate and connect diverse perspectives, 6 . listen together for patterns, insights and deeper questions, and 7. harvest and share collective discoveries.

The goal of the interactive analysis workshop was to understand and further refine the core concept and the six dimensions as well as properties. ${ }^{9} \mathrm{~A}$ presentation was created as a visual guideline for the workshop and as a reminder of the questions and the next steps. (Please find the slides for the analysis workshop in Appendix 12.2.) The agenda for the analysis workshop was as shown in Table 3.

\footnotetext{
${ }^{9}$ See section 4.6 for details of the dimensions used in the research.
} 


\subsubsection{Program for analysis workshop}

\begin{tabular}{|c|c|c|}
\hline Time & Activity & Intention \\
\hline $14.00-14.15$ & $\begin{array}{l}\text { Welcome, presentation of the } \\
\text { researcher and project, and } \\
\text { introduction of the program }\end{array}$ & $\begin{array}{l}\text { Set the frame, create trust and a } \\
\text { clear management for the process }\end{array}$ \\
\hline $14.15-14.30$ & Startup game and mini Al interview & $\begin{array}{l}\text { For participants to connect with } \\
\text { one other practitioner on a deeper } \\
\text { level } \\
\text { Create a safe, open and warm } \\
\text { atmosphere }\end{array}$ \\
\hline $14.30-15.30$ & Interview on a topic, round 1 & $\begin{array}{l}\text { To understand and inquire into the } \\
\text { subcategories of the work } \\
\text { Make the theory and model richer, } \\
\text { more dense and relevant } \\
\text { Plant seeds for the participants to } \\
\text { pick up ideas or new insights that } \\
\text { might guide new actions }\end{array}$ \\
\hline $15.30-15.45$ & Break, breathe, do nothing & $\begin{array}{l}\text { Recharge, be in the moment, } \\
\text { refresh }\end{array}$ \\
\hline $15.45-16.30$ & Interview with a topic, round 2 & As round 1 \\
\hline $16.30-17.00$ & $\begin{array}{l}\text { Thank you for joining } \\
\text { Open space, stay and have a cup and } \\
\text { an informal chat if the energy is right }\end{array}$ & $\begin{array}{l}\text { Let the energy fade and the } \\
\text { conversations not end too abruptly, } \\
\text { unless that is what the participants } \\
\text { want }\end{array}$ \\
\hline
\end{tabular}

Table 3. Program for the analysis workshop

\subsubsection{Experiences from the workshop}

Seven people attended the workshop, including the researcher, four of the six Danish interviewees, one student who had joined for interviewing during the project (not the student who 
helped conduct interviews) and one colleague, who also belonged to the population of Al practitioners. The workshop was held one afternoon from 2.00 to $5.00 \mathrm{pm}$; it was raining outside and the atmosphere was cozy, warm, tense, close, opening and curious - in my experience. Some participants knew each other while others did not. Everyone shook hands as they entered and settled in. The room was quite big. In the middle were seven chairs in a circle, with no table. This was our base: the starting point and place to sit while sharing information.

Around the circle were sixteen small tables covered with white tablecloths, paper, crayons and colored marking pens to draw and write with, either on paper or on the tablecloths. On every table was a sign with the name of one of the subcategories of the hypotheses for the project, for example consciousness, balance, energy, contrasts and so on. On every table was also a brief interview guide with two to four questions about the specific topic of the table, so that the participants knew how to approach the topic in the conversation.

After the introduction, going through the agenda and talking about the research project, the attendees played two short games. The atmosphere quickly became more light and safe during the playing and laughing. In one of the games, you shook hands with the person you met, said your name, and then you used their name for the next person you met instead of your own. That caused confusion, in a funny way, very quickly and even the people who knew each other had fun remembering their own and others' names. The workshop was then divided into two rounds of mini-interviews of fifteen minutes each, following a structure for who to talk to when.

If the plan had been followed strictly, everyone would have interviewed every other person in the room. It was not important to do all of the interviews; it was more important that the participants had some good conversations and that there was no hurry, with time for breaks. This meant staying true to the emerging core category of organic growth, which includes breaks as an important feature. The structure also meant that they did not have to think about who to talk to that part was already taken care of. When they met with their interview partner, they had to choose a subject together - to choose a table, in other words. There were three conversations at a time and sixteen tables to choose from. Before joining the interview, the participants were given a few rules to follow:

- Find your partner and choose a topic;

- Ask and answer the questions on the table and feel free to ask further or other questions;

- Make sure to document;

- Activate your active listening style.

In the introductory speech the most appreciative, open, warm and curious parts of them were invited into the interviews following the principles of "words create worlds". During the introduction, a practitioner asked if they should tape the small conversations on their phone and send them afterwards. The project design followed a line of not taping because of the classical grounded theory approach, but it was confirmed that the practitioners could tape their conversations if they wanted to, in order to follow that energy. 
There are two points to make about the idea of not taping in grounded theory. The first point is that the classic grounded theory is quite old. As lively, cool and fresh as Barney Glaser is, I am not sure he understands how media is a natural part of many people's lives today, when many have a computer, a telephone, a television, a radio, a camera, a Dictaphone, a watch, their money, their photo album and so many other functions together in a smartphone in their pocket. The second point is that Al practitioners represent a certain population, a specific kind of people. From interacting with data, it is my experience that they have higher trust, a trust so high it might be hard for other people to understand. They often feel safe, connected with other people; they have a trust in the process, in the people they are co-creating with and in the world that might "break the glass ceiling" for how much you can trust. The downside of taping a conversation did not seem important for these practitioners. During the qualitative interviews no one had a problem with the conversation being taped, even though the researcher ensured that it would not happen because of the grounded theory methodological approach. The reason one participant suggested taping seemed to be that it would relieve them from documenting during and after the interview, and it seemed they wanted to listen fully and be present in their conversation. Therefore taping was easier and it allowed for that presence.

Another perspective on this question is that all of the workshop participants had met me before, during the interviews, and maybe therefore felt a greater degree of trust. That being said, not everyone taped their conversation: some did, some drew on the tablecloths, some wrote short sentences and words, and every piece was considered data. One of the slides from the workshop showed the purpose of the workshop, which was partly dedicated to the research project, partly to the practitioners. The purposes were to:

- Co-create further data for the research project;

- Saturate subcategories in the model about organic growth;

- Interact with like-minded individuals;

- Get new inspiration for the practitioners for their own practices;

- Gain insight into organic growth;

- Contribute to helping to shape the model of organic growth;

- Increase the likelihood of the model being used in practice.

During the interviews I kept track of the time, wrote notes, listened to bits of conversations and brought water. Every fifteen minutes, I hit a singing bowl and the participants would wrap up that conversation and find a new partner. During the break, we talked informally, had cake, fruit and coffee. I noticed during the break that people did not check their phones or leave the room; they continued the conversations and kept the special atmosphere of connectedness, curiosity, openness and warmth. Before ending the session, they were invited to join a short exercise named "The gifts I see in you are...", where you take turns to meet another participant and complete the sentence with what you noticed in them.

At the end of the workshop the participants shared their experiences, and the last interview round was given up in order to end ten minutes earlier than planned. Ten minutes can feel like a gift and it could change the whole day, when unexpected. It is a tiny thing, but it can mean a lot in the micro-system. It turned out to be a way of showing them respect and give a kind of a present as illustration for my thankfulness for their participation. 


\subsection{Observations and field notes}

The observations, participant observations (Kristiansen \& Krogstrup, 1999) and field notes were taken at two events where Al practitioners were gathered: the World Appreciative Inquiry Conference in Johannesburg, South Africa 2015, and a certificate course in Appreciative Inquiry at Case Western Reserve University in Cleveland 2014. The notes were taken during and after the events and were comprised of physical notes in a notebook and notes taken to be saved electronically on my computer, tablet and phone. They were notated using a simple system following three points: 1 . Time of events, 2. Description of events and 3. Immediate analytical or interpretive ideas and reflections on the events. Some notes were taken following this system in three columns; others were taken as mind maps of the events and related analytical reflections. The field notes were taken from all experiences, both formal and informal talks and dialogues, standing in lines, at the dinner party and on the grass in the sun outside.

\subsection{Analysis strategy}

The following section will show how the analysis was carried out according to the method, a stepby-step overview of the process. The data structures in several tables shows how the analysis process developed from raw interview quotes to first order codes, to second codes on to the six aggregated dimensions, one by one, to allow the reader to be in a position to read the analysis chapter (Gioia et al., 2013).

\subsubsection{Step-by-step method}

Having decided to study Al practitioners and to use grounded theory, I entered the field to cocreate data with the group via interviews, observations, two workshops and field notes. The first process of observations and field notes plus the first research workshop helped create knowledge about the group and shape the questions later asked in the interviews. The first two pilot interviews also took place in the initial phase, in December 2014; three interviews were conducted in 2015 and, due to a maternity leave in 2016, the rest of the interviews were carried out in 2017.

During the process of simultaneously producing and analyzing data, the core category of organic growth emerged as well as the six dimensions. Other concepts emerged as well, but only the concepts which were saturated through the process of theoretically coding and interviewing entered the final model of organic growth. During and after the process of producing and analyzing data, a large memo bank grew, in the end 155 pages, and then the process of sorting the memos started. The sorting process was old fashioned and manual: the 155 pages of memos were printed and sorted physically into piles under the relevant concepts, e.g. one pile for flow, another for wholeness and so on.

Each of these six piles were again sorted into themes, for example the pile of "flow-memos" were sorted into intuition, simplicity and synchronicity. When all the memos were sorted, the writing-up phase began. It is important to emphasize that the communications of the grounded theory of organic growth were created simply in order to be authentic both to the group being studied, but also to the model of organic growth. Simplicity is a property of flow in organic growth, and that is meaningful because when practitioners grow in this sustainable way, their work, their processes 
and their lives seem to become simpler. To pay tribute to this, the model and descriptions of organic growth are also simple, yet grounded and systematic.

When using grounded theory as a method for data collection, the analysis strategy is inherent, because of the joint collection - where the researcher co-produces data, codes and analyzes the data as a coherent research process. "One key dimension of grounded theory is the highly effective focusing that happens as a consequence of the requirement to simultaneously generate and analyze data" (Guthrie \& Lowe in Martin \& Gyllind, 2011, p. 55). It was decided to order the concepts into $1^{\text {st }}$ order and $2^{\text {nd }}$ order codes and afterwards into aggregated dimensions following the Gioia methodology as a supplement to strengthen the classical grounded theory approach and because this made it easier to keep a systematic structure towards the work (Gioia et al., 2013).

When understanding research as future forming (Gergen, 2015), a grounded theory approach fits because it lets the researcher continue the theory development in an ongoing process to continually make sense with - and for - the people in the community of practice. Another argument for choosing grounded theory as an analysis strategy is formulated in Glaser and Strauss' words: "The sociologist will find that theoretical sampling, as an active, purposeful, searching way of collecting data, is exciting, invigorating and vital" (Glaser \& Strauss, 1967, p. 77). That fits very well with the purpose of this research, which is to uplift the practitioners while developing new ideas about their relational development processes.

\subsection{Data structure}

Gioia emphasizes how a data structure in a grounded theory research project strengthens the sorting and the communication of the theory (Gioia et al., 2013). Glaser states that a data structure is relevant in some grounded theories, but not in others. The following presents the work with data from the raw statements, the development into first order codes, second order themes and on to aggregated dimensions.

\subsubsection{Aggregated dimension 1: Balancing}

The first aggregated dimension of organic growth is called "balancing", and the table below shows how that dimension emerged from data. 

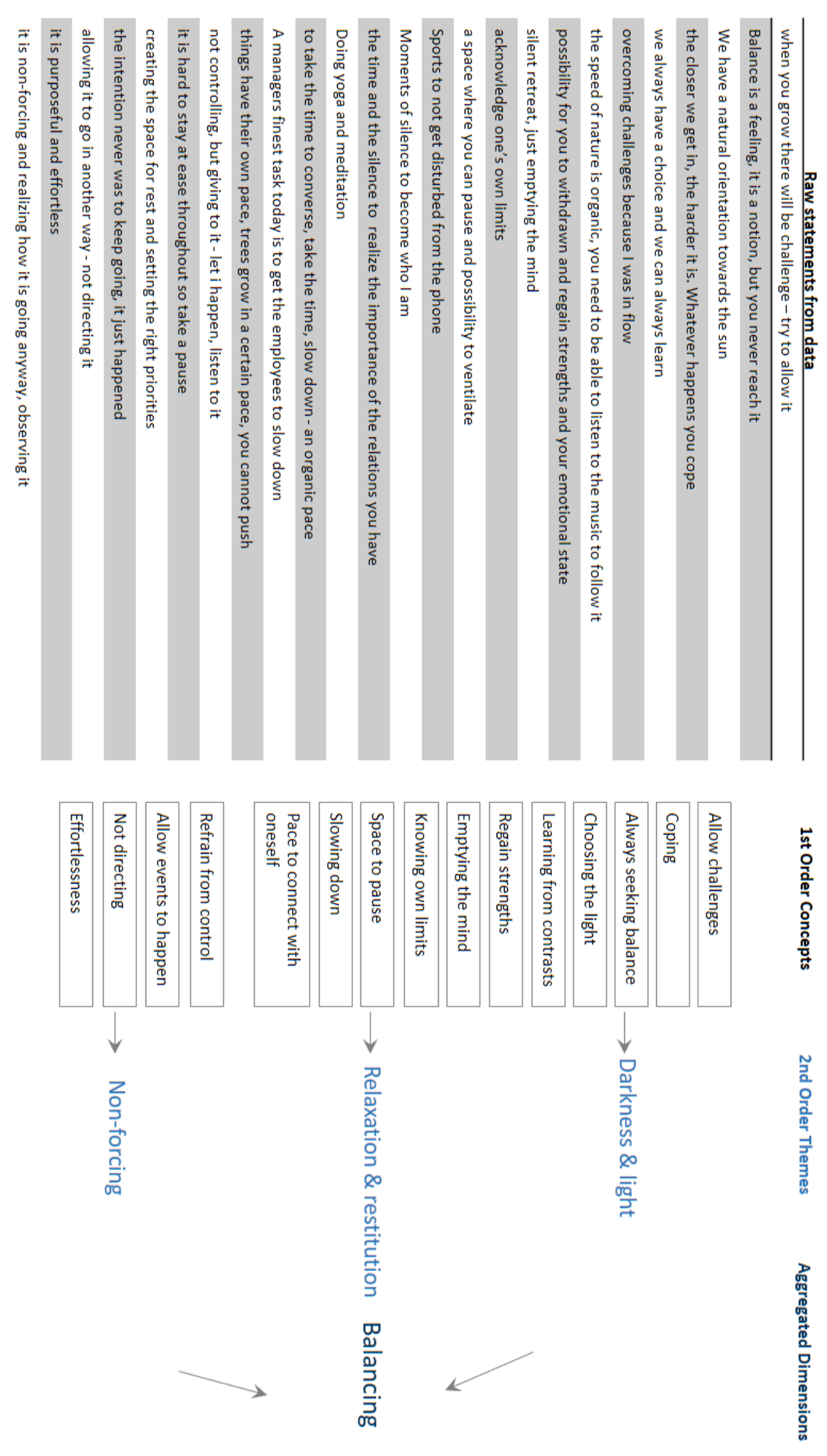

Table 4. Dimension 1: Balancing 


\subsubsection{Aggregated dimension 2: Flow}

The second aggregated dimension is "flow". Even though flow is a known theoretical construct, the understanding of this kind of flow is expanded compared to earlier perspectives. This will be unfolded in the analysis chapter. In the table below, it is possible to see the way flow emerged from the data. 


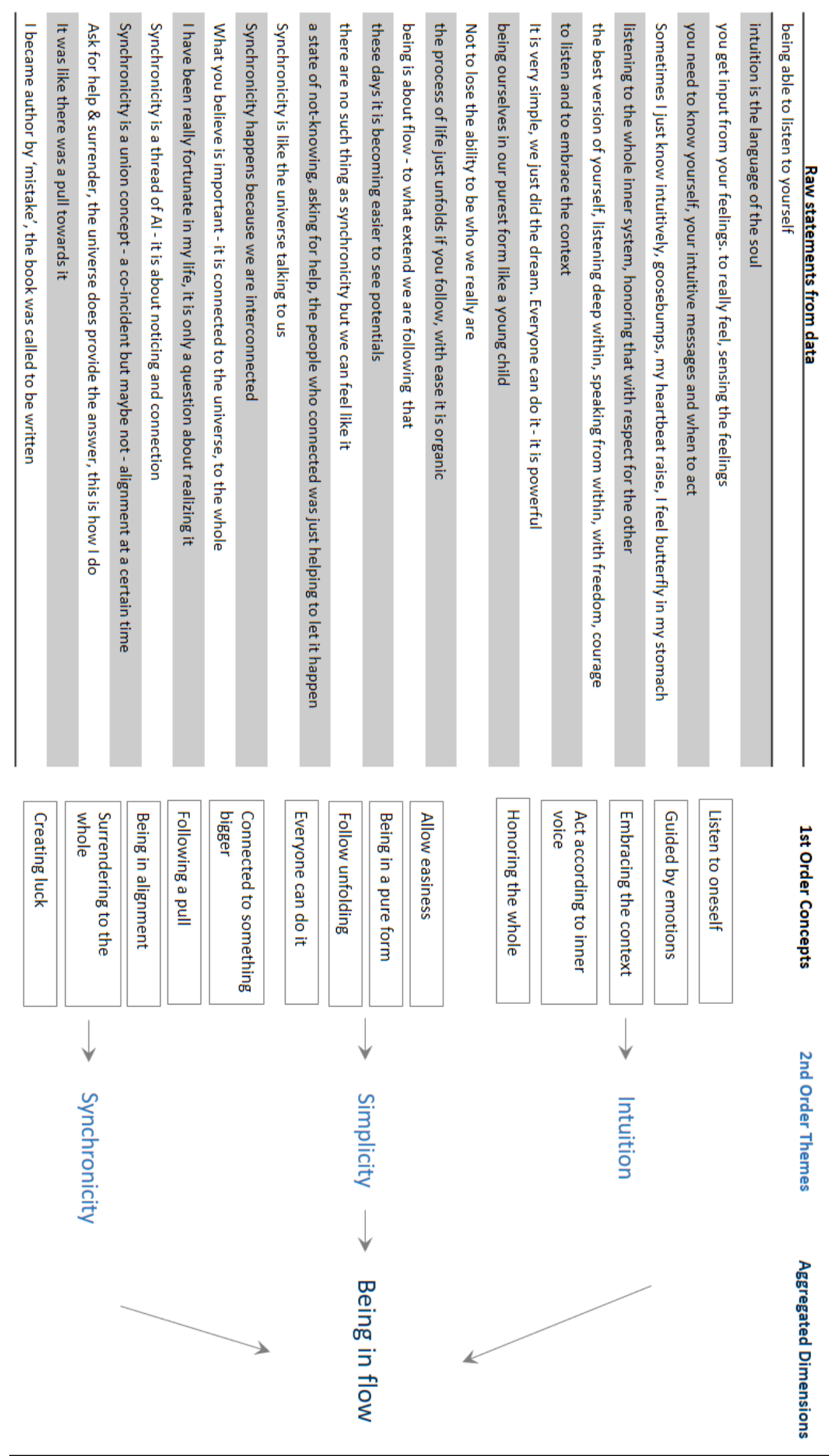

Table 5. Dimension 2: Flow 
4.6.3 Aggregated dimension 3: Healing

The third aggregated dimension of organic growth is called "healing" and the way in which this dimension was saturated into the theory grounded in data is visible in Table 6 . 

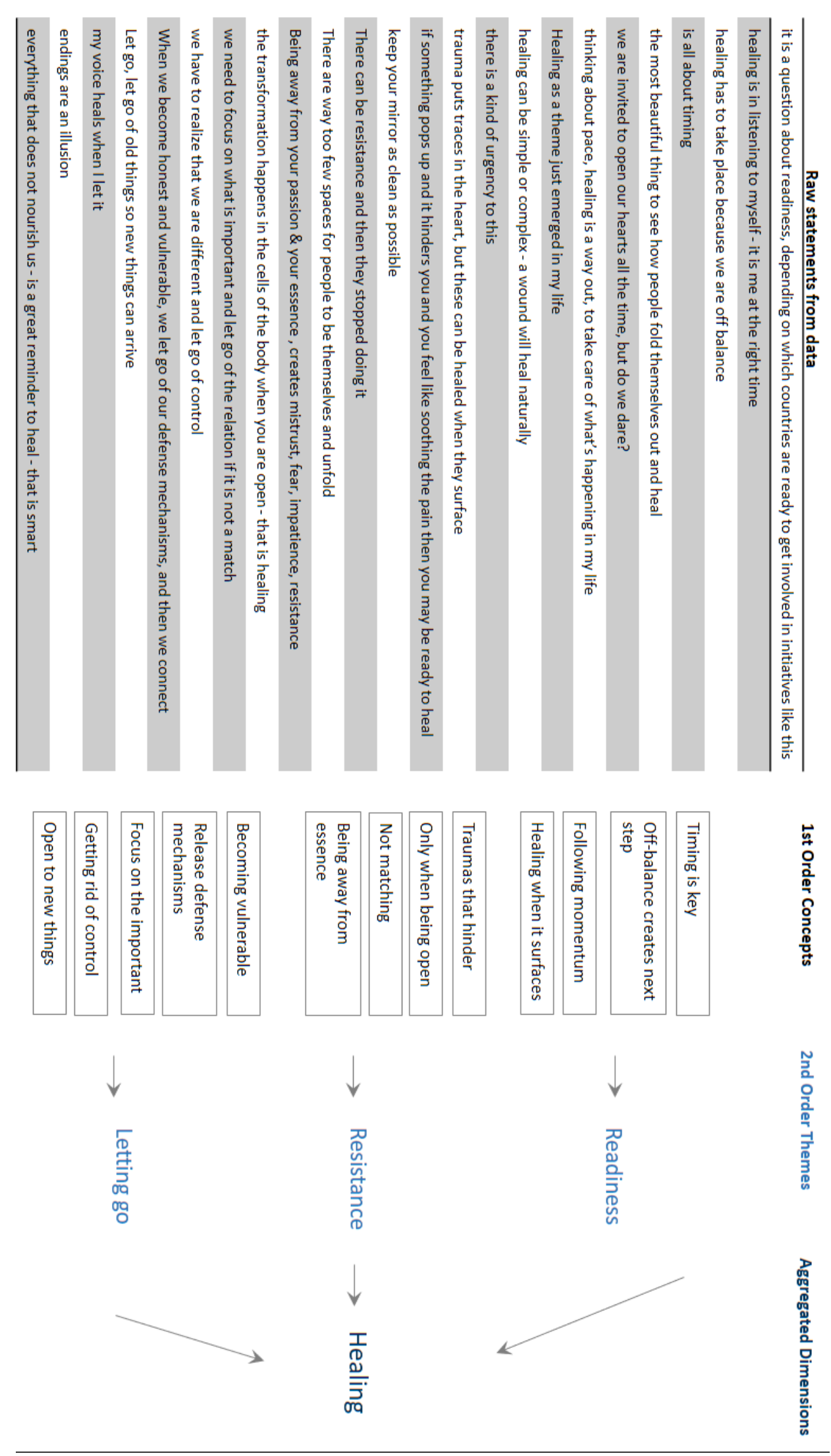

Table 6: Dimension 3: Healing 
4.6.4 Aggregated dimension 4: Trust 2.0

The fourth dimension of organic growth is called "trust 2.0" and in Table 7 it is possible to gain insight into what interview statements, concepts and themes, made up trust 2.0. 


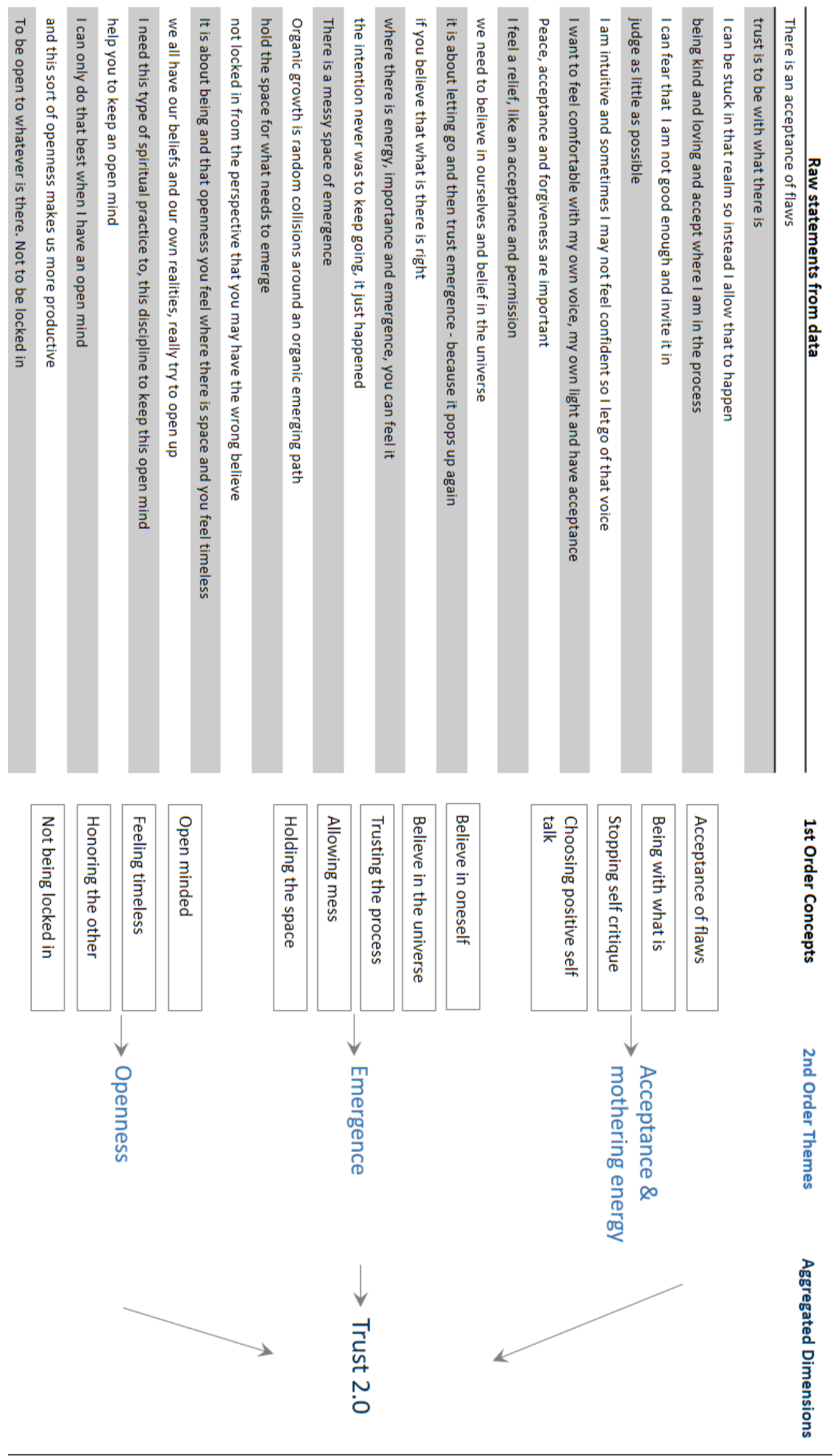

Table 7: Dimension 4: Trust 2.0 
4.6.5 Aggregated dimension 5: Energy

The fifth aggregated dimension of organic growth is entitled "energy," and the table below shows how the idea of energy was meaningful to organic growth and what concepts and themes contributed to this category. 


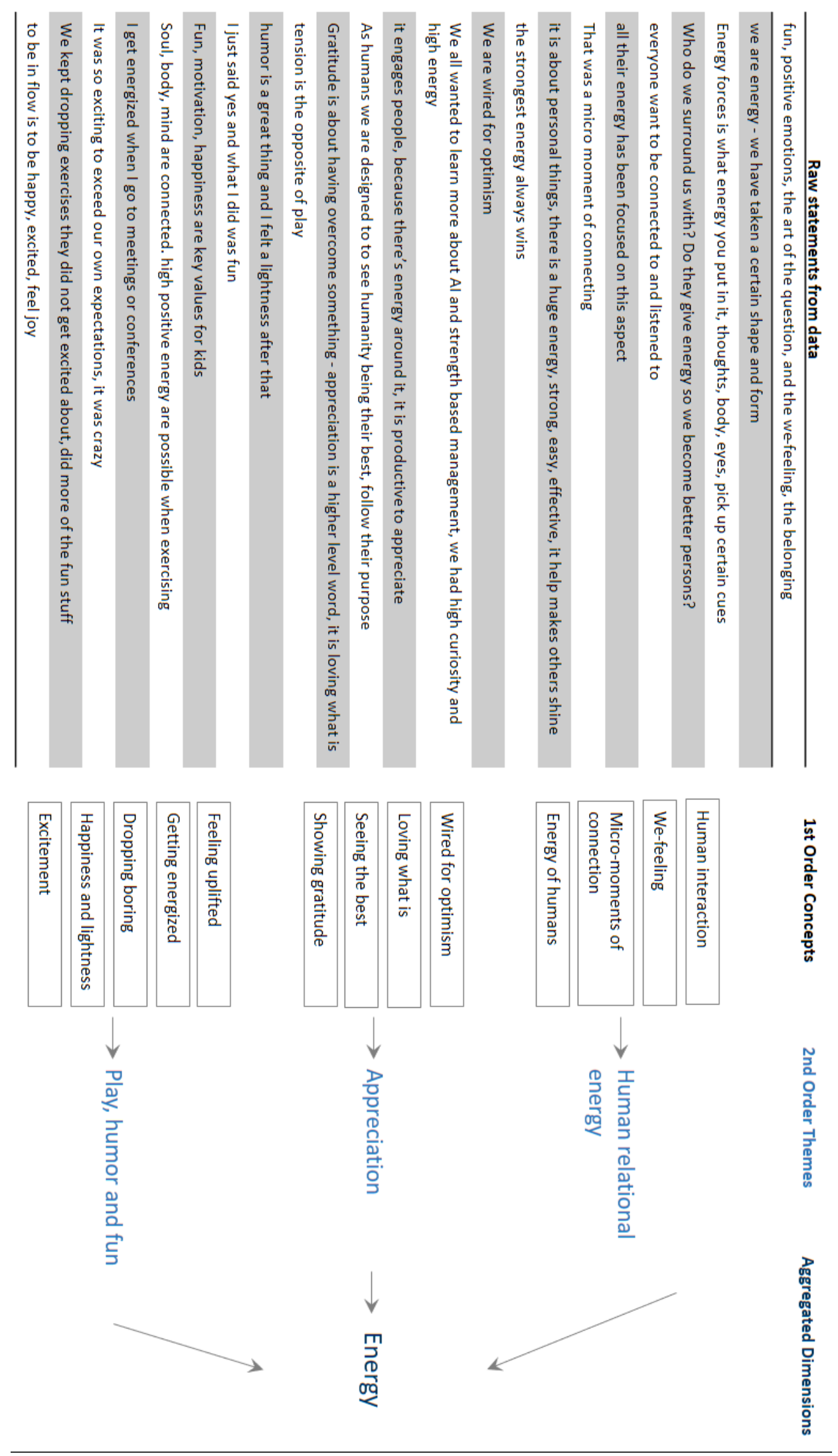

Table 8: Dimension 5: Energy 


\subsubsection{Aggregated dimension 6: Wholeness}

The final and sixth aggregated dimension of organic growth is "wholeness", and the following table shows the way in which wholeness emerged in the process from the data. 


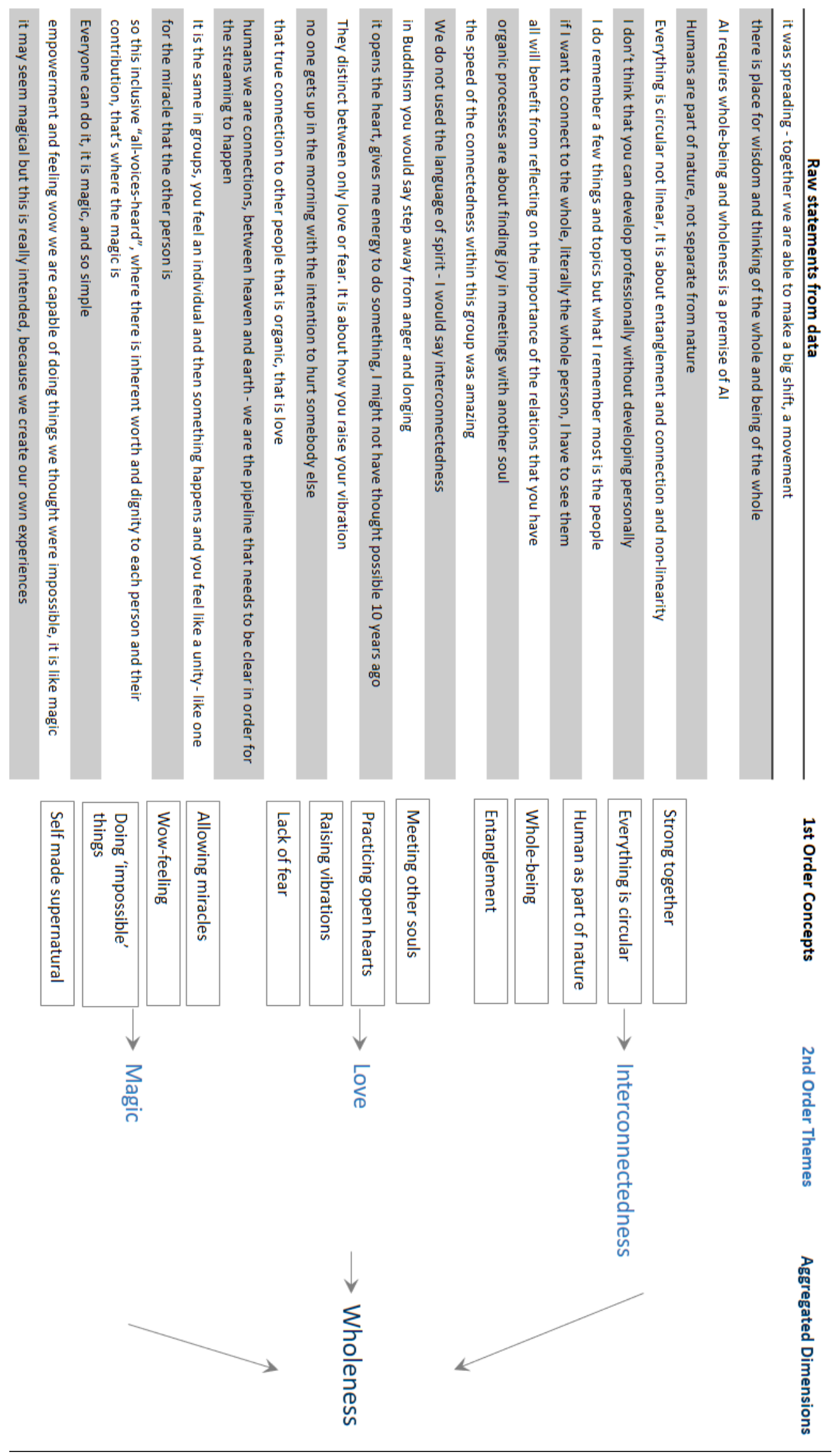

Table 9: Dimension 6: Wholeness 
This section showed the kind of analysis strategy used in the study and how the researcher progressed from raw data to codes and themes, and further on to the key dimensions of organic growth. All six dimensions are concepts that have formerly been described and used by other scientists in other fields. During the analysis it will be clear when new understandings of the dimensions are in play and these will be discussed with reference to former perspectives. In some cases the understanding of a concept rests upon a previous interpretation but is further expanded within this work. The in-depth understanding of each dimension and concept is presented in Chapter 5. 


\section{Chapter 5: Analysis}

This chapter presents the analysis of the data which led to the formation of the model of organic growth. After the core category of organic growth has been described, its six dimensions will be introduced. The model is also a visual reminder and an "ideal type". Different degrees of growing organically are discussed and two related notions are introduced. Before working our way toward different dimensions of organic growth, we look at the power of micro-moments, because this is key to understanding this way of developing, and a brief comment on the relationship between organic growth and appreciative inquiry is provided.

\subsection{A grounded theory of organic growth}

From a grounded theory perspective, we know that the key questions to ask in the research process are: "What is the main concern for this population and how do they resolve that main concern on a daily basis?" We also know that a population does not have just one grounded theory or only one main concern. For this research, the main concern was "How to develop without forcing or stress," and the population being studied resolved that by continuously living and growing sustainably with awareness, and by always trying to learn from their relationships and circumstances.

\subsubsection{Definition of organic growth}

With the emergence of organic growth, the researcher searched thoroughly to find out how other scholars or practitioners have used the concept. There are a few other uses of the idea besides the one characterizing human learning processes in this study. The first is biological, where the term is used in relation to "nature", where trees, plants and flowers grow organically, (without humans "spicing them up" with chemicals). The second use is from the corporate environment, where "organic growth" is a phrase describing a company's growth rate through growing internally by increasing output and enhancing sales, without expansion coming from takeovers or mergers. A kind of "internal growth" of a company.

These two uses of the term make sense when pointing to the growth of the individual practitioner, but not their contributions or place in the community or society. In this study, the focus is on the single practitioner and micro-moments. The relational perspective is the foundation on which the understanding of the single person rests. The researcher in this project defines human organic growth as:

To grow organically as a human being means to develop in a sustainable, flourishing way with a great amount of trust toward enriched consciousness, increased states of flow and more fulfilled wholeness in balancing, lifegiving processes.

Other words to describe it to give a more vivid understanding of organic growth are meaningful, supportive, loving, beneficial, caring, gentle and mild. The practitioner Carina talks about organic growth in this way: "organic means that it is something you find as your life unfolds - something that is growing naturally from your circumstances". The words organic growth set minds to thinking about nature for many people, and there are great pictures and metaphors to pick up on from 
nature to understand organic growth better. Even though humans mostly understand our species as being separate from nature, humans are still part of the natural order on Earth ${ }^{10}$. It is important to understand that organic growth is a state of non-forcing. Even though the sunflower follows the sun throughout the day, it does not board an airplane to follow the sun to the other side of the planet. It leans into the night and rests till the next day.

The construction of the idea of organic growth has been chosen because of its metaphoric value, in referring to the pace and order of development in nature. The Chinese historical figure Lao-tse is known to have said "Nature doesn't hurry, yet everything is accomplished" which also describes the underlying understanding of organic growth. The communication of the conceptual model of organic growth includes a definition, metaphors, an ideal-type description and its six dimensions, each explaining different parts. The understanding of organic growth as an ideal type is addressed now.

\subsubsection{Organic growth as an ideal type}

The point of an ideal type is to create a construct, a picture of a complete abstract model. Weber (2009) operated with ideal types, where these types may never exist in their perfect form, which is the point here as well. The ideal type of organic growth is unlikely to be seen in one single practitioner; the ideal type is a construction on behalf of all of the data and the voices in the data. Some speak to a few of the dimensions, some address one, and some interviewees illustrate several of them.

The work with the construction of an ideal type was chosen because of inspiration from Frankl. He tells a story in his book, Man's Search for Meaning (Frankl, 1985), about a flight instructor saying that mankind needs to aim high, aim at the ideal type of humankind, because then there is a chance that they will land somewhere "realistic". Whereas, the instructor continued, if you aim at the realistic, there is no chance that the full potential will unfold.

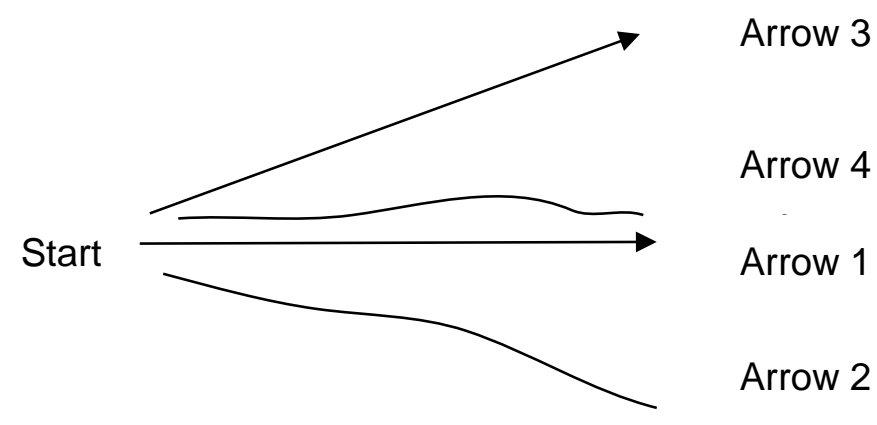

Figure 8. Man's search for the ideal of human beings' capability

\footnotetext{
10 The articulation of our planet as "the Earth" is visual at several places in the analysis, even though not a lot of practitioners said that word directly. This description is chosen to emphasize the more subtle impression this community of practice show from understanding and approaching their life with wholeness and by that 'taking care of' everything that is in our world. Hence, the concept is chosen to give voice to the rather undefinable approach.
} 
If mankind aims to arrive where Arrow 1 points, he will not arrive at Arrow 1 but at Arrow 2.

Whereas if man strives for the ideal, exemplified by Arrow 3, he will probably end up near Arrow 4 (see, Figure 8). According to Frankl, this is the reason that mankind should attempt to strive for an ideal version of humanity. Organic growth is an "ideal" state and, together, all of the interviewees' stories and data create a model similar to a shared painting (Laloux, 2014), resembling Arrow 3. The next section will look into micro-moments and explain why these are key in the understanding of organic growth.

\subsubsection{The power of micro-moments}

Micro-moments have emerged as being important to the mindset of organic growth because every interviewee talks about how and when they take action, and they point to "micro-moments" as being the most important place for being, reflection and action. From observations in conferences and courses, an intensified presence was played out by the "actors". In the micro-moments of the dialogues they showed careful presence and they listened deeply. They held the attention, they looked into the eyes of the other person and they practiced "being". They were present. And this is where organic growth happens.

Theoretically, the term "micro-moments" is often used to describe what is happening at the individual human level (Stokes \& Harris, 2012), as opposed to "macro-events" which characterize events in larger settings like communities, organizations or societies. The term micro-moments has also been used in a relational perspective to describe a new understanding of love (Fredrickson, 2013).

But why was it relevant to develop the expression of micro-moments in the first place? According to Ray (2008) most humans have lost the connection with their body and therefore often live in a state of "autopilot", where habits lead the way, and there is no time to stop and sense the body. Micro-moments may have been constructed as a justifiable way to invite a larger part of our selves to be able to listen to the body as a whole system and to return to a state of awareness of being as opposed to being on autopilot. This may also be the reason why the concept resonated with many of the interviewees, who find that micro-moments are valuable, and often the only place where they can create change. Awareness is key in that equation. The following section will shed light upon the relationship between organic growth and appreciative inquiry.

\subsubsection{Organic growth and appreciative inquiry}

Most practitioners say that appreciative inquiry has become a way of being for them; the way they show up in the world. Many talk about everyday practice in smaller and larger daily situations. Interviewee Christian talks about how being appreciative to himself is the hardest task and something he practices every day. Camilla tells how she consciously chooses to shift her mindset to trust emergence, and not to try to control chaos when it arises.

Even though they have to practice it, and it often becomes part of their everyday life, they believe and experience that appreciative inquiry is one of the most valuable "tools" in their "toolbox" and therefore they tend to choose it often. When asked directly about challenges, they prefer to shift 
the focus and talk about how they would look for resources, exceptions to the rules, hopes and small success stories in their own or others' lives.

Even though these practitioners have this as a main approach in their everyday lives, it does not mean that one size fits all. Every interviewee has their own style, their unique approach and their own way of interpreting appreciative inquiry and understanding their own path. This means that if people outside the communities of Al or positive change want to be inspired by organic growth, they need to find their own path in that journey. This point helps conclude the initial description of organic growth; next are its six dimensions: balancing, flow, healing, trust, energy and wholeness.

\subsection{The six dimensions of organic growth}

In this section the six dimensions will be explored in order to give further insight into the model of organic growth.

\subsection{Balancing}

Rest is not idleness, and to lie sometimes on the grass under trees on a summer's day, listening to the murmur of water, or watching the clouds float across the sky, is by no means a waste of time

John Lubbock

Balance was a key concept throughout the data set, and a core in the understanding of organic growth. Taking a metaphor from nature, trees need all the seasons of the year. They rest in the long wintertime to be able to produce beautiful shoots on the branches, all light green, when the spring comes. They stand, just as beautiful, in the autumn storms losing each leaf, to rest again.

For most of the interviewees, balance is key in their organic growth processes. The practitioner Carl describes balance as key to a process and gives an example from his own growth process. He has a great need for structure, logic and order, and has a well-developed right brain, and he actively reminds himself of the fact that he needs to trust the process, hold the space of what needs to come up and follow the energy. He emphasizes that he can only do that by being in balance himself. That means that his energy channel is free, and he can hear his own intuition and follow those instructions, Carl says.

Another point of view taken from the data states, "I don't really need vacation in that sense. Sure, I need to rest and relax but I feel best being active and relaxed in what I do, because I love to do it. I just need balance." Very few would like to have complete rest, to relax and do nothing. Another interviewee, Brian, says that many people dream about getting things "done" and then do nothing. But it is not complete calmness and doing nothing humans seek, because then they would be bored. Very few human beings in Western societies have such a great deal of rest that they arrive at the moment of boredom. Most people have a filled life, as another practitioner, Michael, mentions. So they might think that pure silence is the end goal. Brian believes that it is flow humans seek, the balance between quiet and busy, doing and being. 
Most of the interviewed practitioners talk about this living in seasons as something they need to be aware of and take actions toward. Few live it naturally, with all the breaks they truly need. Cathrine states that the "noise" of society, from media and social media for example, and a large number of emails to reply to - all this noise can very easily take her focus away from what is important to her.

Another definition of balance is given by the practitioner Sarah, who says: "Maybe balance is just something we chase the whole time. That we are always imbalanced but just always keep adjusting. That balance does not exist, and we always need to check in with our system and then adjust." From Sarah's definition comes a picture of a person standing on a tightrope trying to hold the balance. A tightrope can be seen as a line tied between two trees, a meter above the ground to train physical balance by walking on the rope. If the person on the line has trouble keeping their balance, but stays on the line, do we say that she is out of balance? Or is it only the moment she drops on the ground we say that she is out of balance? What about the person who walks on the line to perfection, who almost looks bored walking the line? She has balance, we would probably say - but she has been practicing. Some of these interviewees have been practicing this sense of balance in their previous working lives.

Another way of looking at balance is by using the words "growth" versus "protection", which Lipton uses to describe the cellular level of the body: "Evolution has provided us with lots of survival mechanisms. They can be roughly divided into two functional categories: growth and protection" (Lipton, 2008, p. 115). Lipton's research shows that many conclusions drawn about the single cell layer of life can be translated into multicellular organisms, like humans. His research shows that one cannot both grow and protect at the same time. What is very interesting in this study is the statement that "growth processes require an open exchange between an organism and its environment. For example, food is taken in and waste products are excreted. However, protection requires closing down of the system to wall the organization off from the perceived threat" (Lipton, 2008, p. 116). On the cellular level of the human body, there needs to be a balance between growth and not-growth, periods of closing down, of what Lipton calls protection. Al practitioners seem to be aware of this, trying to balance these two.

The following text will give insight to the three properties of balance; darkness and light, relaxation and restitution, and non-forcing.

\subsubsection{Darkness and light}

The first is the balance between darkness and light. One interviewee, Brian, talks about how candle lights do not have a shadow. He gives the picture of a completely dark room which, after lighting one tiny candle, is suddenly lit all over. Brennan talks about the fact that you can't really tell where the limit of light is, where it meets the rest of the room (Brennan, 1988). Another perspective in data says, "There are two buttons that you can choose, either press the red button or press the green button." This illustrates the category of darkness and light in relation to organic growth because the practitioners are aware of moments of "darkness" and moments of "light" in their life and they choose to find bursts of light and press the green button as often as they can.

The interviewees do not deny or neglect the presence of challenging events and times in life, none of them. They choose how to respond. They embrace their negative moments, take responsibility 
and shift to positive feelings when they can. They seem to look for uplifting moments and events in their life and that of others. The work they do using appreciative inquiry seems to be shaping how they approach their life and who they are.

Appreciative inquiry has been accused of having an exclusive focus on the positive. Throughout the interviews and interactions with these practitioners, there was space for things to be hard in people's lives. The key, again, was balance between "darkness and light". When asking a question about a dream, people often talked about why they did not succeed at the beginning, what sacrifices they made, who they lost on the way and other vulnerabilities. The positive aspects - the light - seemed to create an atmosphere where it was possible to remove the mask and be fully themselves - with every shadow side, blind angle and bad experience, because the atmosphere was safe. This is how the relationship between darkness and light is defined in organic growth. The next section describes another aspect of balance: relaxation and restitution.

\subsubsection{Relaxation and restitution}

The next property of the dimension of "balancing" is relaxation and restitution. As mentioned above, for the practitioners, there is a tendency shown in the data to be aware of breaks and rest in order to grow organically. Not a new idea, but many have forgotten to make use of it in current Western societies. Many of the practitioners talk about pace in different ways. They give examples of how a certain pace can be a parameter in the positive processes they lead and discuss how pace is an awareness in their own life. Some interviewees emphasize how important it is for them to actively create a slower pace or to take breaks that make it possible for them to slow down. One practitioner, Kim, tells about retreats he attends to "quiet down the noise in his life". Michael talks about how much influence social media has on the pace of humans today, on our minds and awareness. He says that we sometimes use social media as a break, but that this use of social media often fills the mind again and recharging fails.

A third practitioner, Marie, describes how she invites her employees to a monthly talk about their professional development and that the only thing she does not tolerate is the status quo. This statement has several layers. First, we can look at the intention of this practitioner, which was to be sure that the outcome for the customer, for whom the employee is working, was the best possible. There was also an intention of wanting to dialogue about professional development. This could be taken for granted at some places, but in some organizations there is a strict hierarchy, with no dialogue with the boss, just orders to complete. Another thing that strikes me was an "urgency" to develop: "it needs to move," she stresses.

It was completely acceptable to join the meeting and talk about attempts that failed and receive feedback and help to adjust. Doing nothing was not accepted. A wish for movement is understandable because everything moves and changes. The wish to help push her employees into the learning zone is also clear, as a way of guiding them into the zone of flow (Csikszentmihalyi, 2014). If they have a respectful cooperation and conversation practice, the employees might love this monthly chat and feel they develop in flow - that they grow organically. If the conversations are done with the emphasis on "I do not tolerate status quo", it may feel like a "push for development". To say something more about this would require interviews with the employees - this could be a suggestion for further research. 
During the research period, I had the pleasure and opportunity of having a conversation with a professor teaching students in Japan. She talked about a Japanese culture with both working conditions and education systems having inhuman stress levels, as she experienced it. They have a specific word invented in Japanese for "dying from stress". She went on to talk about the conditions in the country after World War Two, where everyone wanted the country to be strong again and therefore everyone was working hard to gain status. As she saw it, this tendency has accumulated, so that most people keep working very hard, and therefore have no free time to be able to enjoy the life they work so hard for. She gave the example of many young people's everyday schedule: students having extra schooling after school, sports after that, and then home to eat, shower, do homework and then go to bed. She wanted to research this phenomenon and try to change it. The need to invent a specific word for "dying from stress" points to the possible consequences in societies where people force development instead of growing organically. The practitioner Michael has another view on the notion of pace and says, "My days are so full, I do not have a lot of time, so I try to practice taking care of my needs. For example, I walk every day because it helps prevent back pain." This statement represents a fullness of life that resonates across the data. This is where organic growth has harder conditions or maybe this is exactly where it grows from.

This leads to an important perspective, a nuance in the theory, which is the counter-hypothesis that Al practitioners might be more at risk of having stress and work-related mental health issues, because they are very eager to help others. They often say "yes", and they see the possibilities. They talk about high levels of energy, a contributing purpose in life and a work life they mostly love. In Denmark this group is called ildsjæle which actually means "fire souls". Their souls are on fire. They burn. They inspire others. They take the lead. They keep reinforcing enthusiasm and a focus on what gives life and what gives energy. People who have high energy and a "burning" passion for their job can have a tendency to forget their own needs. This means that $\mathrm{Al}$ practitioners potentially could be suffering more from stress than other populations. A spinoff reflection from that oppositional hypothesis could be that it is especially because they burn that they have developed this way of growing organically. Maybe they have realized that they need to take care of themselves in order to serve others and the whole, and that the way to serve others is by taking care of themselves. Søren Kierkegaard says:

Of all ridiculous things the most ridiculous seems to me, to be busy - to be a man who is brisk about his food and his work. Therefore, whenever I see a fly settling, in the decisive moment, on the nose of such a person of affairs; or if he is spattered with mud from a carriage which drives past him in still greater haste; or the drawbridge opens up before him; or a tile falls down and knocks him dead, then I laugh heartily. (Kierkegaard, 2016, p. 17)

\section{Researcher's voice}

Reflecting further on this I visualize a situation where I look back one hundred years from now and I see that stress is a very non-logical thing in the world... a fault in human evolution. Like a program that went over the edge... did not know when to stop, before it went crazily too far. If we look at the larger perspective, could this be the Earth's way of trying to decrease the number of humans? People die from stress. 
Today, in Western societies, more people seem busy than seem balanced. There are several large and small examples in the data showing how the practitioners use breaks to balance their growth and their everyday life. To take a break sounds so easy but is not always carried out. According to this data, growth will often happen when you turn your attention to something else. If a group is struggling with a specific problem, it often helps to let go and do something else, and then solutions or ideas will start to bubble up. Most of these practitioners seem to know this and practice it to different degrees.

"Rest" often has negative association in Western societies, especially in workplaces. This may be because, in the capitalist worldview, everything needs to be bigger and better, always hunting for the next big thing. Production needs to be effective. In a hunt there is seldom time for breaks. If you have got the animal in your sights, you can't lose it, you need to follow the animal to know when it is time to shoot. Another history thread to find clarity regarding the notion of rest might be found in the Christian religion and its stories about work. According to the Christian religion, laziness is not a good lifestyle, and this historical thought line may continue to feed humans' habits and beliefs in the Western world about how to live a good life.

The question that is really interesting here is: What is the language we have access to around this topic? If status quo is not a possibility, will there be space for breaks? For saying "no" to courses or training? For taking time out? And what about the possible needs for resting or even relaxation?

In this piece we looked into the terms of relaxation and restitution, and the following will discuss forcing and non-forcing, and its relevance to organic growth.

\subsubsection{Non-forcing}

Forcing emerged as a contrast to organic growth, in the sense that the practitioners can either let themselves or others grow naturally, or they can force development. This led to the concept of non-forcing, which was the best description for many incidents about not pushing, about allowing, receiving, letting in, not directing and refraining from trying to control. To force development means to push, to try to manipulate, to decide what needs to be learned when, to set goals and standards for what kinds of competencies you need to possess at a certain age, or to let your growth be controlled by something outside yourself, as Brian describes:

In school we learn that growth is the main purpose and we keep striving for goals. When we reach a goal, we often do not even take the time to feel the victory or celebrate the result, because we are off in the hunt for the next. By the time we reach forty many of the stories we had that we would be happy when we finished education, got married, got a job, got kids... there are no stories left because for many, they are being transferred to the next job and next vacation, bigger house and so. Many find themselves in a sort of meaning crisis. (Interviewee Brian, in researcher's summary)

Growing takes time. It takes time to grow up and to grow organically in life. Many Western cultures have a sense of pushing and forcing and not accepting pauses. Maybe this has come about because the electric light was invented. People have the possibility of working into the night and in the winter, and then societies are designed to follow this. 
Conrad tells about how he needs time to adjust. He feels almost ashamed when realizing that he needs this time to adjust, e.g. from a specific learning experience or a period of growth. He can't be at his peak all the time. Another practitioner, Casper, tells about how he needed time to rest, away from academia, when finishing academic education. He felt he was supposed to be "upbeat", positive and contributing, but he needed time to rest and "get better". He ignored some basic needs while going through this education, and afterwards he needed to address them. He felt ashamed about that because he had a position within the field of positive change and felt that he should be a role model and full of flourishing. He articulates a need for rest and restitution after high performance.

The above described the first dimension of balancing and its three properties: of darkness and light, relaxation and restitution and non-forcing. The second dimension of organic growth is flow.

\subsection{Flow}

Flow was seen as a central dimension to organic growth, because it was being described by many of the practitioners as key for their personal and relational development processes. The dimension of flow will be described first and the three properties thereafter: 1 . intuition, 2 . simplicity and 3 . synchronicity. Some practitioners talked about flow, others pointed to an understanding of a state of being that is present, enjoyable, fun and where they forget about time and place, and are present in the micro-moment. One practitioner, Carina, says: "(...) you need to respond to feelings - to understand that we are not separate from nature, that we are wired for optimism." Carina also talks about "alignment": to check in with her intuition and to respond to what she feels, and she finds that the "natural" state of being is in flow.

Another interviewee, Thomas, says: "I use the metaphor of breadcrumbs on the way, following what excites you, just starting with the small and then doing more and more of what excites you." Thomas also describes "feeling good": "If I feel good, I do my best and I am sure that you will be seen like that by another person too." As described in the literature review, the understanding of flow is founded on Csikszentmihalyi's definition, and the further expanded version is already in play here. Carina's statement illustrates that flow is understood as a natural state of being different from Csikszentmihalyi's theory, where flow is experienced in certain special activities.

Csikszentmihalyi says that a flow experience depends on flow activities, and this is where I deviate, because the Al practitioners interviewed seem to be practicing being in flow, even though they are not in what Csikszentmihalyi calls flow activities. One explanation for this could be that most Al practitioners know Csikszentmihalyi's description of flow and probably have known it for years, and therefore have had the chance to "live it" and to experiment with how to be more in flow, and some of them have eventually succeeded. This may have provided the experience of expansion and of staying in flow in situations other than classical "flow activities", simply because they have known the concept and have striven to be in flow for longer periods of time. It can also be due to the fact that the practitioners have created a work life where several tasks are experienced as "play-like" - whereas in other groups work and play are separated. This leads to the next quote pointing to the notion of "relational flow". 
Interviewee Anna says: "Al processes and conversations put us in places where time is taken out of the equation: we are present, we listen, we are drawn into the other person's story, their world." The state of flow here is obtained in a dialogue and therefore opens up the idea of the flow state as not being for a single person exclusively, but as being shared states of flow or relational flow. Shared flow as a term is briefly mentioned by Csikszentmihalyi who encourages further research into this idea (Csikszentmihalyi, 2014, p. 259).

Another insight about this could be that these Al practitioners know a lot about positive emotions and what leads to positive emotions, and therefore they have the knowledge to get back into flow when they experience themselves to be out of flow. To be in flow here means to experience positive emotions.

A third point about this is that they work with positive change in their everyday work life, and therefore many teach and facilitate exercises of positive change and are re-exposed to these practices on a regular basis. This might prevent them from "forgetting" about these exercises as the rhythm of everyday life takes over. Csikszentmihalyi acknowledges this when he says that:

Some people, some of the time, appear to be able to enter flow simply by directing their awareness so as to limit the stimulus field in a way that allows the merging of action and awareness. But most people rely on external cues for getting into flow states.

(Csikszentmihalyi, 2014, p. 146)

He goes on to study how different activities are likely to invite experiences of flow. This may fit the description of what the population of this study is trained to practice. The way to tell the difference between these two understandings of flow is that, in contrast to the previously mentioned understanding by Csikszentmihalyi, the Al practitioners operate from flow several times and over longer periods of the day - which means that the understanding of Csikszentmihalyi's flow has been either expanded by the practitioners to include a wider spectrum of activities, including those that are work related, or that the practitioners have found a way to translate the more narrow "flow activities" into everyday tasks. This can be further illustrated by two examples.

The first illustration is a small child, who holds herself in flow almost constantly. She starts something fun, follows the flow of what emerges and when it is not fun anymore, she stops. The other is the quite simple technique that some of the practitioners use when they inquire into their micro-moment to see if they are in or out of flow. Brian describes a simple question to ask when in a specific situation: "Does it feel light and fun or does it feel heavy?" This creates an awareness to whether he is in or out of flow.

Entering the discussion about relational flow, the individual perspective is relevant:

Csikszentmihalyi describes how "loss of ego" is often tied to the experience of flow and explains that if a person is completely involved in an activity, it becomes irrelevant to think about "selfish" things (Csikszentmihalyi, 2014, p. 141). He suggests that this is solely possible when the activity is very simple, defined and manageable, such as a game, creating art or in a ritual, as in religion. This study finds that the population of Al practitioners are able to join and be in flow in many different activities, both within their professional lives and outside, and in activities that are not just 
simple and well defined. This understanding of Al professionals aligns with the theme of "loss of ego", because lack of ego is also key in organic growth.

In organic growth, flow is understood as a fluent, more-or-less positive state of mind. When the practitioners are describing their approach to life and to work tasks in their professional lives, they are either in flow or out of flow. In Csikszentmihalyi's understanding, flow is an exclusionary state of being that can only happen in very specific circumstances and therefore for most in the general population it can be quite rare. In many Al practitioners' understanding of flow, it is possible to obtain the state of fluent being often and it can happen under any circumstance, because it is the inner guidance, the emotions and the attention that the practitioner has that decides whether he is in or out of flow. In the more extreme metaphor of the fact that the environment is not a triggering factor, we find the example of Viktor Frankl, who maintained that even though a human is in the worst and most painful environment - being hurt and in prison and losing loved ones - he can still maintain a feeling of freedom and meaningfulness (Frankl, 1985).

For the practitioners in this study, it is as though they have obtained a longer-lasting experience of flow in their lives. They are still in and out of flow several times of the day, but they have a consciousness about it and they know what can bring them back into flow, and often have the resources and possibilities to do it. The practitioners are often in tune with their own inner voice or intuition, and listen and act according to that guidance when they are in flow. It is also key to mention that it is not a question of staying in flow. Flow is by definition not still. It is flowing and fluent. And then suddenly something else emerges out of the flow.

An additional perspective on the subject of flow is Bandura's idea of reinforcements, which contains the idea that behavior that receives positive reinforcement from the environment, will strengthen that specific behavior. On the other hand, behavior that receives negative reinforcement strengthens negative behavior. Compared to organic growth, Al practitioners are aware of the positive reinforcement and they know that what they focus on will grow. Therefore, they often use it strategically in their work. They are also aware of the positive reinforcement in their own organic growth and that is why they act to re-enter states of flow when they have the possibility. In the next pages we will be looking into the three properties of Al practitioners' idea of flow: intuition, simplicity and synchronicity.

\subsubsection{Intuition}

Intuition emerged as an important concept during the study, as many of the interviewees spoke directly about it.

One practitioner, Carsten, talks a lot about listening to his intuition by following its guidance and acting from there. He explains that he needs to be in balance and to meditate on a regular basis. He has another criterion in order to take action: "It needs to be something that is good for humanity, too," he says. He has an understanding of wholeness, meaning that what he does needs to be a good thing for all. This points to a place of not acting from an "ego" state of mind but acting for the benefit of all. Another practitioner, Carl, says that he needs to be able to "listen" and to follow that voice, and that he notices things that other people do not. This corresponds to what other practitioners describes as intuition. 
A definition suitable for this study is: "intuitions are affectively charged judgments which arise rapidly through non-conscious, holistic associations" (Dane \& Pratt, 2007, p. 40). This is described as a key factor by most of the interviewees and is closely tied to organic growth, because it relates to the micro-moments where the Al practitioner is aware of some kind of holistic association that goes from a non-conscious to a conscious state of awareness, from which the practitioner experiences whether they are in or out of flow and has "instructions" about how to act. Another way to describe this way of experiencing awareness is by the phrase "primary knowing". Rosch (1999) says that primary knowing is nowhere and everywhere, and that there is no separation between mind and world. This correlates with the understanding of wholeness and intuition these practitioners hold.

Michael believes that not only do words create worlds, but minds create worlds. In his experience, many AI practitioners are already very curious, positive, open and appreciating in their mindset and approach, and they seek ways to affirm who they are in the world. In doing that they happen to fall upon theories that resonate with them and support what they are doing. This points to an important awareness: The practitioners seek ways to affirm who they are in the world - that is a key factor for organic growth. To grow organically also means to become more aware about one's identity and to become aware of how approaches are mirrored around the practitioner such that the practitioner finds resonance. This means that as the practitioner learns more about his or her own preferences, mindset and character strengths, he or she seeks and attracts circumstances that mirror who they are.

Researcher's voice: The tool that hasn't been invented?

During the process of data co-creating, coding and analysis, I felt like the researcher who knows that he has a result, but that the right tool to experience the result has not been invented yet. That the language to describe it in more nuanced ways is yet to come. That these practitioners have emotional intelligence and are guided by intuition in a way leading to a faster and more direct way of knowing, and therefore they succeed. Those in this community seem to have the knowledge of and maybe embody the power of - a higher vibration and higher frequencies - it is built in their processes, their languages, their questions and their lives. I guess they succeed in combining intuition with reflection in a way valuable for them.

When trying to understand the dimension of intuition, the phrase "the power of pull" resonates. Hagel, Brown and Davison (2012) focus on a shift from forcing and controlling actions to a focus on leaning into flow and listening to what pulls, then acting according to that. This perspective corresponds with many of the dimensions and properties of growing organically. If the practitioner is able to shift from forcing to being "pulled" towards his or her life, then they need to be able to hear that pulling, and intuition may be key to that. It requires an openness to whatever opportunity arises, to be visionary and to be brave enough to act on what pulls. When the authors describe the shift toward living from an orientation of "pull" instead of forcing they emphasize that it requires engagement in emotional work to make that shift and that many realize that they are not prepared to do that (Hagel et al., 2012). From data in this study it seems as though the practitioners in this group on a general level are prepared to engage in such emotional work. The authors comment on the pace of change in general in modern Western societies "(...) what the exponential curve says is that the old dies faster than ever" (Hagel et al., 2012, p. 13). This sparks new questions, which are 
addressed in Chapter 9 on implications and further research. Moving on from intuition, the next property of flow is simplicity.

\subsubsection{Simplicity}

Simplicity caught the researcher's attention in the process of simultaneously interviewing and analyzing data for several reasons. First, many of the practitioners talked about simplicity and many of them talked from a place of simplicity. It is as though life seems simpler to them, like they have their priorities sorted out and they live with some sort of clarity which makes their life seem simpler. Not every interviewee made this impression. But simplicity was also present in other parts of the data, both at the conference and at the interactive workshops. Simplicity is key to some of the practitioners' approaches to appreciative inquiry. One practitioner, Anna, who has many years of working with appreciative inquiry in practice, works from three simple questions: What is working very well? (What's the good news?), What can we do more of and enhance? How do we get there?

Sasha, Cathrine and Kim expressed phrases like this: "The first meeting with appreciative inquiry, it blew my mind - so simple and yet with so very profound results". Simplicity also turned out to be a discussion point: A counter discourse in the data could be described by the following three statements "this is too easy, too simple", "if it was that simple, we would have done it by now" and "this sounds too simple to be true". Looking critically at this discourse: Could that be pointing to a tendency in our society to complicate things? And if "things" are not complicated and are too simple, then are they not "serious" enough? Anna specifies this by saying:

Everyone can do it. It is what is basically written within every big belief system, for example, the Bible - but the Bible does not tell you how. Like being nice to your neighbor, even though there is trash all over and the dog is barking at night. (Interviewee Anna)

The concept of simplicity is key for this data because some of the interviewees either have taken a conscious decision and made their life simpler or are approaching life with less complexity. One example of this is how they find joy in smaller things. Turning to research on simplicity, there can be a spiritual perspective to simplicity (Elgin, 1981), born from a critique of Western societies. The critique follows a voice about humans being disconnected and living in separate mental constructs as well as living separated from their bodies, and therefore being ignorant of the wisdom of the body (Ray, 2008). This perspective is also visible in this set of data, where some practitioners set aside time to connect with their body or meditate in order to be present in a simpler fashion. As will be discussed in later sections, some interviewees resonate with spiritual or religious inspiration, whereas others do not associate with that at all.

Looking at larger groups of people, Miller (1993) argues that organizational strategies, goals, cultures and processes over time will become simpler and he discuss the pros and cons of that. From this study, the analysis suggests that the more experienced in appreciative inquiry the interviewee is, the clearer is the relationship with simplicity. Simplicity is related to flow because when practitioners live more of their time in flow - things seem easier for them. To write many pages on simplicity would not pay tribute to the concept. The final property of flow, synchronicity, is presented in the following. 


\subsubsection{Synchronicity}

Synchronicity also became saturated as a property in relation to flow when several of the interviewees talked about it directly or shared stories, which later came to be labeled "synchronicity" in the set of data. First a couple of the stories will be presented.

Al practitioner Daniel says, "It was not like there haven't been ups and downs, it was just like there were very few obstacles and things seemed to fall into place". He describes this as leaning into the flow. Daniel is one of the interviewees who do not have a religious belief or spiritual orientation. He told a story in relation to the notion of synchronicity: He once attended a course and engaged in a brief personal writing exercise, where he was to write his hopes for the future. He wrote that he hoped for appreciative inquiry to somehow be broadcast to a wider audience. He forgot about that little exercise and carried on his work and everyday life. Three months after the course, one of the founders of appreciative inquiry called him and asked him to join a vision meeting with the purpose of creating a big educational program aiming for training future international Al practitioners. That eventually caused the spread of appreciative inquiry around the globe. As mentioned, this practitioner does not at all understand himself as having any higher belief in his life. He does see events falling into place, when he looks back at his career within appreciative inquiry. This example moves us one step closer to understanding the concept of synchronicity, which will be defined later in this section.

Carl sees a clear connection between synchronicity and organic growth. Carl defines organic growth in this way: "Organic growth is the random collisions around an organically emerging path". He explains that to be able to know and experience "random collisions" he needs to be in tune with his intuition all the time and he needs balance. He describes himself as very curious and as a "futurist", always preoccupied with learning what is good, what is better and what is next. The notion of "random" is interesting, in that there is wide variety in the data around understanding of random. Carina talks a lot about synchronicity, whereas Brian finds it old fashioned to talk about synchronicity and does not believe that anything is random in life. He believes himself to be fully responsible for everything that happens in his life, even (what we call) accidents but also health issues, being fired from a job, poverty, love, abundance and everything else a human can experience. Carl tries to be his best self, and to be open to when "wisdom happens". He follows simple three steps:

1. Plan well and hang loose (he refers to Jane Watkins, an experienced Al practitioner).

2. Hold the space for what needs to emerge.

3. Presence supports the process: "Don't just do something - stand there".

This also represents a belief in the process, in timing and a trust that good things will emerge when he follows this advice. Christian talks about being "fortunate" in his own journey. And to be able to be fortunate, he has tried to practice the following: 1. being open to flow and 2. to say "yes" when someone asks. From the outside listener or reader, this may seem too easy (see simplicity). For most of the interviewees, this is how they approach their own growth and their work life and, for the most part, also their family life. This is important in relation to flow, because he refers to "being open to" flow. This approach represents a calm energy of allowing, as opposed to manufacturing or forcing, and to not even striving for flow, just being open to it and setting intentions to join it. It also ties to the notion of non-forcing, discussed earlier. 
A keystone in the research field on synchronicity is Jaworski's book, Synchronicity - The Inner Path of Leadership (Jaworski, 2011). Jaworski refers to Jung's definition of synchronicity: "a meaningful coincidence of two or more events, where something other than the probability of chance is involved" (Jung, 2010).

In recent research, Merry has shown that synchronicity is a key subject for leaders (Merry, 2017). According to Merry the notion of synchronicity is unfolded through several scientific perspectives, for example the theory of morphic fields, neurological research on mirror neurons of the brain, and the complex attractor quantum, and synchronicity is related to the notion of "spirit" across several different cultures (Merry, 2017). Interestingly Merry finds that leaders are influenced by the linear Newtonian paradigm and are afraid to talk about decisions taken in non-logical ways, even though leaders from his sample take many decisions based on their intuition and from an understanding of synchronicity. But they do not want to share that with their staff, because they are afraid they will appear to be too spiritual.

In some ways these perspectives reflect discussions throughout this study of a dualistic approach to knowledge rooted in a construction of a split between mind and body, between the logical sense and the holistic existence. This data shows that the population of this study has moved beyond this discussion and operates from an understanding of wholeness and is open to incorporating both the logical competencies and the holistic.

To capture something mysterious, wondrous, unexplainable and something "bigger than life" within a language of control and predictability is only possible if both see the value in each other. Relating to the quote by Christian about "being open and saying 'yes' to opportunities", Mitchell, Levin and Krumboltz (1999) suggest the notion of "planned happenstance", which is to "plan" for lucky events to happen. The theory of planned happenstance includes two major ideas; 1 . exploration that creates possibilities for having a better quality of life and 2. certain skills which help people to seize their opportunities (Mitchell et al., 1999, p. 118). But even though the authors suggest increasing the chances of getting lucky, that does not mean proposing that people just lean back. They invite the readers to take action and take full responsibility and walk the necessary steps.

This leads us to look at the relationship between organic growth and synchronicity. With further research it would be relevant to study, with a narrow focus, the question: Do Al practitioners have more synchronistic life experiences? This has not been the subject here. From this study it is clear that some practitioners are aware of synchronicity in their lives, some have deep trust in these events and some state that they experience it when they let go of control and allow themselves to be in flow. In an ideal state of growing organically, as an Al practitioner, synchronistic events are likely to happen.

To sum up the chapter on flow, there is an important comment: This "returning" to flow that practitioners seek is not described as a "hunt", it is not even a striving, and there are no signs of urgency. They practice an awareness in the micro-moment where they quite precisely can sense whether they are experiencing positive emotions or not and, because of their knowledge of positive emotions, they consciously try to accept when they are out of flow. Through that acceptance, they try to contain their present emotions and let them rise and let go in a natural way, instead of holding on to them. Kelly (2018) operates with the notion of "divine intolerance", which refers to a 
state of being with little tolerance for things that are out of alignment. This corresponds to the Al practitioners because they are used to being in flow and therefore have little tolerance for not being in flow. This is why they seek to return to flow as soon as possible. This concludes the three flow properties of intuition, simplicity and synchronicity. The next dimension to be discussed is healing.

\subsection{Healing}

Al heals naturally because it invites in a curiosity and a presence and a deep listening in the relation that heals

Carl, Al practitioner

During the coding of the interview data, healing emerged as a dimension of organic growth. Healing can be understood from several perspectives. To heal means to make something more whole. This presupposes that something is not whole, is broken, is in disorder, fragmented or not well. In a physical perspective, the body is believed to have healing power because the body is able to heal wounds and diseases. Small wounds heal fast, can't even be remembered over time, and often heal with little or no resistance towards the healing process. Bigger wounds stay in the memory far longer and may heal with resistance. This will be elaborated in this section. From a psychological perspective, healing can be described as a process happening with or without medication - a place where a diagnosis, such as a neurosis or psychosis, has ended or improved to a stage where the patient can live a "normal" life with it. From a spiritual perspective, the notion of "spiritual healing" is often used to characterize a wide range of alternative methods and therapists working from different beliefs, usually outside academic settings. Some Al practitioners find inspiration from ancient healing traditions, religious paradigms or metaphysical belief systems.

The concept of healing, as understood and used in alternative medicine, has been widely discussed and criticized and, depending on which methods are used, some scientific evidence has demonstrated that there is no proven effect, while other studies prove that there is some effect (Jonas and Crawford, 2003). The purpose of this study is not to represent a voice in that field, only to accept that healing is a notion that makes sense for the group being studied and is relevant for the understanding of the ideal sustainable development. Some Al practitioners are working with an awareness of healing, and healing is found to be important for their organic growth.

Healing is understood broadly, in this study, which means that it contains physical, psychological, and mental aspects and - for some practitioners - a spiritual openness toward healing as well. This is also tied to the understanding of wholeness from which the practitioners tend to operate. It is a holistic approach to healing where the body, mind and spirit are inseparable. That means that, to different extents, they live lives where they carry an awareness of wholeness and of the connection between mind, body and spirit. And when there is a disturbance or a "malfunction", they try to heal it to become (more) whole.

Several practitioners talk about how they listen to the different parts of their system and try to fulfill the different needs. One practitioner talks about the body's need for movement, another emphasizes the body's need for rest, silence and meditation, and some talk about food and lifestyle, how healthy choices helps them thrive. Almost everyone talks about the need to feed the 
mind: the almost "natural" wish for learnings, knowledge and development, because this is characteristic for the vast majority of the group. Some talk about the spirit directly and how to nourish it, and many tell about the spirit with different terminology and in more subtle terms. As mentioned earlier, one practitioner described himself as not having any religion or belief in a higher power in life, but still practices a profound believe and trust in life. This shows that one does not have to have a spiritual awareness to be an Al practitioner, but that when growing organically the practitioner shows an openness towards something "bigger" and takes responsibility for healing both physical and mental wounds as part of their development processes and language.

So why healing? Why not learning? Why not change? Maybe this is the time to speak about transformation of the human being at a deeper level. This takes a different perspective on transformational processes. How does healing differ from learning? In some understandings, learning points to the need to "take in something new", "adopt a new fact", "integrate new knowledge", "put more wisdom on top of the already gathered data". This represents one voice in the learning discourse. In opposition, healing is about taking layers off. Letting go of older habits and former beliefs, to find that the system picked up parts through living that are not beneficial anymore or maybe even hindering wellbeing. Thomas says:

The most important thing for me is the undoing of my beliefs. That I keep working with the limiting beliefs I carry in my mind and undo them. Realize that they are not reality, they are a limiting belief. It is very important that the teacher keeps getting supervision. (Interviewee Thomas)

He works consciously with healing by actively changing mental patterns in order to adopt more lifegiving patterns. He elaborates: "You can use anything to change belief. You can change your path by the way you see it. You affect the past by how you see it." Thomas introduces this kind of work with a vocabulary that is "eatable" to the people he works with. His experience is that it is of little value to talk about healing or quantum physics with clients, yet these are often what people are most positively preoccupied with.

Camilla tells about how healing conversations happen and how she facilitates them when working with elderly people and caring for terminal patients. Asking specific questions leads to a certain kind of conversation where healing has the possibility of taking place. Brian mentions a wide range of helpers within the area of alternative medicine; he does not have any doubt about the power of these helpers in his life. Marie mentions how she "educates" her employees by giving them direct and constructive feedback, and she describes the process as "cleaning up". She is concerned with "cleaning up" patterns that are not beneficial, as for example in language, beliefs and habits. This resonates with the understanding of healing presented in this section, where healing is understood as a "natural", ongoing, daily, undramatic process, which represents something many people do in order to be and to become a better version of themselves.

Michael talks about our Earth as being "self-healing" and understands the human body to be selfhealing as well. Carl states that he understands healing as "dis-ease", that is, the conversations lifting away the experience of isolation and separation. As we can see from these practitioners' statements, they operate with a wide variety of understandings of healing which are specifically 
meaningful for them and for their actions, and which can all be related to healing as a process of becoming whole.

A proposed definition of healing from this study is: "micro-moments of returning to a state of wellbeing". Connected to the dimension of flow, where practitioners are aware of getting back into flow, healing is used to curiously inquire into states of being out of flow. Brian talks about an awareness of the fact that some things are ready to be healed. He finds that what sometimes happens on the journey of growth is that he has "hit" something out of flow, and he takes that as an insight about being ready to heal a specific part, which enters his consciousness from a subconscious level. As mentioned earlier, Thomas says that we can use everything to heal. This resonates with Brian's understanding: Every thought or insight that pops up can be used to adjust or to heal if necessary. Thomas' statement may expand the understanding presented by Brian. For Brian, situations out of flow primarily point to places ready to heal, whereas Thomas says that everything can be used to heal.

Most interviewees express an openness toward learning opportunities in their own lives and many embody the notion of "never being done". It is not how they grow or how they heal - it is more a question about the fact that they do it. They grow, they heal, they stay open to changing their beliefs and learning more as a practitioner. Cooperrider and Godwin (2015) discuss whether humans developed by chance, as Darwin suggests. The authors argue that development happens by choice - not by chance - because humans have consciousness and the ability to use that consciousness to develop in elevatory ways.

If humans have consciousness and have a choice, the only thing that is holding them back from elevation is meeting things that keeps them out of flow. According to organic growth, humans have the possibility to heal past experiences both on an individual, micro-level but also on a macro-level in the global perspective. Humans are at their strongest if they have access to all the resources in the system. If they do not have access, this study points to the fact that healing may be a key. Emotions function as a guiding line to point to how much of the human's own wholeness he can allow in. This is related to wholeness and will be further elaborated in that section.

Thomas, Cathrine, Carina and Christian share the opinion that the work they do with "themselves" in their "inner system" is crucial to their growth. Instead of creating and maintaining conflicts with others, they try to learn about themselves and take home the parts of themselves that they have banned or left or criticized or that are not allowed "space" in the system. "They don't even have to believe in healing". As interviewee Thomas says: "They do not have their 'usual' defense center up and running, like they might have had if they booked a healing session at a healer".

Silbert and Chadbourne authored a book called Healing Conversations Now describing how special conversations with elders can enhance relationships and create healing as well as a greater sense of love (Chadbourne \& Silbert, 2011). This perspective sheds lights upon what seems to be happening often in appreciative inquiry interviews, according to the data. The interviewees describe these situations as being extraordinary because the listening is so deep. They feel appreciation and express a feeling of being "seen" for "who they really are". According to Chadbourne and Silbert, this experience can be categorized as healing. 
In this set of data, most of the interviewees do not experience these conversations only when they facilitate or participate in appreciative inquiry processes and appreciative inquiry interviews. They try to practice the basic principles of appreciative inquiry and approach life in general from this understanding, and therefore experience this kind of "healing" or growing, sometimes frequently, in their lives. The following section is on readiness.

\subsubsection{Readiness}

The property of healing called "readiness" presents a point in organic growth centered around the importance of timing, momentum and preparation. In relation to healing, readiness represents the experience of timing where openness meets new insight which may cause the system to heal or to let go of a former hindrance of flow. These practitioners have an ability to sense when the timing is good and respect that the timing of events unfolding are often a question about the timing being right.

Marie says that she is sometimes too eager about implementing something new, like creating a full-blown appreciative culture in the workplace, and that this behavior keeps the results from being fulfilled. She is continuously aware of her own patience, acts in micro-moments toward the desired future and tries to take small steps when her employees are ready. Thomas states that when he sometimes facilitates a workshop as a consultant and the organization wants more, his work resonates with them and they are ready to take in what he brings. With other jobs he finds that it is as though nothing "lands" - as if what he brings does not resonate with them - and he has learned to accept that and understand it through the concept of readiness. Some are ready, some are not; some might become ready, others become ready for something else. About readiness in relation to organic growth, Thomas says that sometimes when he trains people, they are very excited, and they want to go out and do huge projects on the first day. He tells them to start by taking small steps and not to waste energy convincing other people.

Readiness is not a question about being ready or not. Every human is ready for something at a given moment in time and it is a question about finding out what they are ready for and then following that path. Many people and environments may never be a match to the language and activities of positive change, or organic growth, because they become enlightened through another language in a different approach to life in another kind of community, which is as enriching for them as the Al community is for the Al practitioners. Readiness is a question of experience whether he or she experiences himself or herself to be ready, and for what. Everyone is equally worthy and therefore it is a question of which journey to embark on at which moments of life. With their competencies to sense what is happening in micro-moments and to register whether they are in or out of flow, these practitioners have an attunement and an ability to sense when they are ready. And that is the reason why readiness is relevant in understanding their organic growth processes.

Bohm argues that awareness and holistic intelligence emerge simultaneously on the individual and the collective levels (Bohm in Brown \& Isaacs, 2005, p. 114f). Al practitioners are aware of this and take responsibility for the growth of the single human system while having awareness of relationships, inclusion and wholeness. But in relation to healing it is not always easy. The following section is used to describe the second property of healing, resistance. 


\subsubsection{Resistance}

Resistance is understood here as a state of being where the practitioner experiences oppression. This can either describe a state of being out of flow, where the resistance is towards being in flow and therefore the practitioner remains out of flow for a period. Or it can describe a state of being where the practitioner gains consciousness about a certain pattern he would like to let go of and heal, but which he finds hard to let go of, therefore experiencing resistance towards the process. According to interviewee Brian, one can simplify and categorize two types of emotions: 1. emotions in flow, and 2. emotions out of flow, or what he calls resistance (to flow). This is comparable to Fredrickson's understanding in her broaden-and-build theory in the way that when a human being does not feel threatened or stressed, he can have a very broad perspective on life and the situation he is in (Fredrickson, 2009). New competencies can be learned, and positive emotions can be built up as well as resources. On the other hand, if he feels attacked, threatened or stressed, his perspective on life becomes very narrow. This simple and dualistic way of understanding emotional states might seem stark; according to Fredrickson there are a wide range of emotional states.

Two other interviewees, Oliver and Daniel, express very little resistance to their own (organic) growth processes. Oliver gives an example of when he does experience resistance: when he has doubts about his own creative competencies. He consciously chooses to go with the flow, to trust the process and shift the focus, and just go ahead with the work and not listen to that voice of doubt. Daniel experiences most resistance when he is forcing his own growth, if the pace is too high or if he ceases taking breaks.

In the following reflection, a parallel is drawn between the micro-system of the single human being and the system of our planet. Extraordinary developments have happened in recent centuries; humans live longer, there are fewer diseases like polio and tuberculosis, education is more widespread, fewer people living in poverty, and nonprofit sectors are growing (Laloux, 2014, p. 3). When adopting this view and choosing to look at what gives life to the Earth throughout this period, we might say that the Earth in general terms has grown quite quickly. Comparing this with the microsystems of Al practitioners, the Earth might also "experience" signs of resistance if growth is happening too fast or is somehow forced. Maybe "growing too fast" creates some sort of resistance in humanity? Might resistance on an Earth-sized scale be, for example, world wars, hunger, stress and other mental diseases, terror or climate change problems? This perspective is born out of a thought experiment but, according to quantum theory, everything is tied together in an enveloping connectedness. Wholeness and its relation to flow and to organic growth will be followed up in the section on wholeness. The next section is about "letting go".

\subsubsection{Letting go}

Overall, most of these practitioners do not have much emotional luggage. They have healed it to one degree or another in their lives; they have integrated healing into an everyday routine or, if they have trauma, it does not hinder their general wellbeing and ability to return to flow, because emotional luggage did not come up as a key concept - rather the opposite. Healing on a practical level is often explained as "letting go" of something. A habit, a thought pattern, a way of 
communicating or even a physical blockage somewhere in the body which the practitioner is willing - and ready - to shed.

In summing up the chapter on healing, it is clear that healing is a key point in organic growth, because growth happens (for these practitioners in an organic way) when accepting that healing is an undramatic part of their life, journey and personal change. They do not feel bad about it or judge or hide it; they take full responsibility and embark with curiosity on a journey into which learnings they can take from a situation. They let the body and the system rest, because they find that rest is needed to heal, and they crawl back into flow when they can.

Healing is closely tied to energy, another dimension. The universe is expanding - this is the physicists' best belief currently - and humans can feel that through a faster pace. A fast pace may not be a problem if people are completely healed and whole. Many people do not experience themselves as completely whole, and this is where many practitioners in this study succeed because they use the language of healing and consciously let go of habits and patterns that no longer support them. Before ending this section on healing, there is a story to be added from one of the interviewees. While finishing up a huge performance and personal goal, one practitioner, Casper, talks about the fact that he became seriously ill. But instead of taking on the role of the victim (which he was invited to do by professional health caregivers), he decided to create his own appreciative inquiry "bootcamp" and to focus strongly on everything that worked in his life. This story is comparable to a lot of stories in the health sector around people "healing" themselves from a disease by focusing on the positive in their lives. By keeping himself in this flourishing bootcamp, he eventually healed the disease and is now healthy.

The purpose of this section was not to argue for or against healing but to give voice to how the practitioners work with ways of growing and leaving old patterns in a way that best found a description in the notion of healing. The properties of healing, that is readiness, resistance and letting go, were introduced and healing was discussed in this section. The fourth of the six dimensions of organic growth, trust 2.0, will be explored in the following section.

\subsection{Trust 2.0}

This section includes a basic introduction to the notion of trust in relation to the way the Al practitioners use it, as well as descriptions of the three properties of trust: acceptance and mothering energy, emergence and openness. But first an explanation as to why the concept of trust is called 2.0. Trust emerged as a theme early in the study, became saturated quickly and kept saturating during the final part of the interviews as well, even though the process focused on saturating other themes. In interacting with the group, trust was a significant theme and found throughout the data. Trust was both articulated as important, and also taken for granted, and all practitioners seemed to embody a high amount of trust and operated from that state of being. The "doing" and "being" of the notion were so overwhelming that the concept here is referred to as trust 2.0. The lending of the 2.0 notion is relevant because they practice trust in a more intense way. They trust other people, processes and life in such a significant way that it differs from an everyday use of the word. First, we will look at how the practitioners talk about trust before offering an academic understanding of the term. 
In several different places in the data, an interviewee offers sentences with the essential meaning: "It is key to trust the process". Another statement, repeated by several of the interviewees, was: "Trust that it is always the right people who are in the room. You need to trust that not 'everybody" has to be there". Sometimes appreciative inquiry processes work as a strategy meeting and therefore the people in the room take decisions. This can be in a large-scale summit, in a process for an organization or even a group meeting. The practitioners describe the kind of trust that they practice: even if someone is missing, the right people are still in the room. Of course, there can be circumstances where a person of importance is missing in the room, but generally, they practice trust in this way. Carina says, "Usually it is fear or another emotion not associated with positivity which guides the action that needs control". She goes on to describe how trust is more "effective" because it opens up possibilities in relationships.

Another example from the data is a fun story, where the researcher received practical advice during an interview from another practitioner: The procedure of the interviews was initially introduced, including the point of not recording the conversation (Glaser, 1998) but writing notes during and after the interview. During the conversation there were periods of silence, and the researcher apologized for writing notes. The interviewee replied, "Don't worry, it is all there, you can wait and just write your notes afterwards. If you trust that you can tap into that space of information and trust your brain, then all that is important is in there to take out". The researcher confirmed but kept taking notes. This interviewee clearly trusted in a great way and what she trusted was the "wholeness" of the world. She held the belief that the "connected world" was the memory bank, not the computer, and this showed a very practical use and sense of higher levels of trust. She also expressed the fact that if the researcher could practice that same level of trust, the key information and points from the interview would be ready for the researcher to write down after the interview. At that moment the researcher preferred to keep taking notes in order to follow the grounded theory method.

Trust has been researched in social sciences throughout the centuries. One example of a definition comes from research on relationships: a "mysterious quality that creates safety, security and openness" (Gottman, 2011). Trust is described as a condition which makes it possible to be vulnerable and is closely tied to love such that trust is foundational for love and trust needs to be practiced continuously in order to keep a loving relationship alive. According to Gottman, trust is understood as continuously being created and recreated in micro-moments. This understanding of trust fits with the understanding of trust created in micro-moments, because organic growth is happening through the practitioner's awareness and adjustments of everyday micro-moments. As described in the statements of the practitioners, trust has the same basis of relational value and necessity that Gottman describes, and for the practitioner that kind of trust is expanded to characterize the way they approach all relationships, as well as groups and processes and the wholeness of the world.

Merry notes: 'By this time in my life, I had a strong belief that 'life would provide', that somehow there was an energy permeating the world with which one could positively connect with beneficial results" (Merry, 2017, p. 78). This also resonates with a high degree of trust and an understanding of wholeness. The practitioners Christian and Kim talk about the fact that it is important to show up as who they are. They practice a high degree of trust which includes believing that if they show up as who they are, they will be authentic and therefore be met in a good way. They trust that they are 
able to show up as who they are. Many people show up with masks or show up with only parts of themselves. A part of this "being who you are" is also seen in their ability to accept their own mistakes. Several interviewees tell about challenging experiences - when asked! - and how they accepted what happened, tried to take responsibility, shifted the focus and adjusted their behavior. Some articulated the fact that they know that contrasts and variety are a part of their lives and they try to accept mistakes, yet still try to return to a state of positive emotions with their new knowledge and to learn from their experiences as often as possible. They try to practice a fundamental trust in what happens in their lives.

Anna told a story resonating with this. In her marriage she once had a fight with her husband that was draining them both and, in the end, he sniffed at her and said, "And you call yourself an Al practitioner, well how appreciative are you at this present moment?" She stopped the argument and went silent. In her mind she went back to when they first met. She was looking for a memory of just one good thing to say about her husband. It was not easy in the light of the fight. Finally, she arrived at a moment where she felt a small satisfaction with him, a tiny detail, something he had done, that pleased her. It took an effort, but she wanted to find something positive, and the one thing she found led to more deep feelings of gratitude and love towards her husband.

This sounds easy to carry out. It sounds simple: Be who you are. Accept your mistakes. Take full responsibility. Shift the focus to something positive, reflect and adjust your behavior. Simple enough. If it were that easy - organic growth would not have been their main concern.

This is what Al practitioners are trying to accomplish every day, much like top football players who have to stay fit in terms of their physical readiness to play well. And both groups succeed to different degrees at different times in their lives. But, as with elite athletes, it is as though Al practitioners have knowledge about it, like a recipe. And in the process of learning to master something, a recipe is a great gift - like baking buns for the first time. A recipe is a great tool, but few buns are perfect the first time. And no home-baked bun is ever the same, never ever. Even after years of practice. This can illustrate how they emphasize that personal growth is an ongoing journey. These practitioners might have some good ideas, beliefs and approaches to life that help them, and they know when to ask for help. This concludes the introduction of the dimension of trust 2.0. Now, I will address the properties of trust, which are: 1. acceptance and mothering energy, 2. emergence and 3. openness.

\subsubsection{Acceptance and mothering energy}

The two concepts of acceptance and mothering energy are tied together in one section because they both describe an "attitude" the practitioners have towards themselves and others. First acceptance will be the object of inquiry, followed by mothering energy.

Acceptance is a key word in the model of organic growth and is defined by the researcher as:

"Acceptance is understood as a specific state of mind, a frequency of open warmth and grounding from which the single micro-system resonates towards both the self, those the individual interacts with and events they are a part of." The concept is key, because acceptance is what the practitioners often first and foremost use when they find themselves out of flow in making mistakes, having feelings outside "positivity" or experiencing challenging events in their lives. After 
having identified that something is out of flow, they often try to accept the present experience, whatever it may be. They try to be with what is.

The interviewed practitioner Marie says that it is important for her employees to be accepted and "allowed". By allowing she explains: "to be allowed to be them and to be allowed to try things out". Another practitioner talks about acceptance by referring to it as a "mothering energy" which is a feeling of embrace, unconditional love, trust and comfort, and the voice most people (hopefully) recognize from their childhood of being safe in their mother's arms. She describes this voice as saying, for example:

Everything is going to be alright, it is natural to feel that way, you did the best you could and that is more than okay, I understand why this might be difficult right now, but you have your whole childhood to learn it. (Interviewee Camilla)

In the language of organic growth, it is not tied to the mother-child relationship; it represents a core, internalized approach to the practitioner herself when facing challenging circumstances, and an approach to other people that is mild and present in hard times. Brian also connects acceptance to allowance and talks about permission to feel good and be happy. It is interesting that he talks about a discourse where positive feelings need to be "allowed". Where are positive emotions allowed? Are there different allowances for children and adults? Are positive feelings allowed in school? At workplaces? For now, these questions open and inspire.

A concept that comes up in relation to the metaphor of "mothering energy" is the notion of the "good enough mother" (Winnicott, 1971) for two reasons: First because it refers to the importance of a mother's (or parent's) unconditional love, setting herself aside and completely reacting to the baby's need, so that slowly she can allow the baby to wait for her to come. And secondly, because that way the mother can accept herself as being good enough, even if she does not react promptly as the baby gets older.

Many practitioners in this set of data practice this to different degrees towards themselves. They are their own "caring mom" and they have a voice in the head that supports them, even though they know it might not be today that they will succeed. This is tied to what Thatchenkery and Metzker (2006) call "appreciative intelligence", which consists of perseverance and persistence among other qualities, and also ties into what positive psychologists identify as positive self-talk (Fredrickson, 1998). This also applies when interacting with family and friends, and some of the practitioners use it to teach to others in their work environment. It sounds very simple and commonsensical, but it seems to be of vital importance for organic growth. Some of the concepts and categories of the "theory" of organic growth might look simple at first sight, but these practitioners work with this as a main concern on a daily basis, and together these categories form what appears to be a strong kind of human developing. In relation to positive self-talk, Thomas says that he teaches his customers to be kinder to themselves and to have a closer connection from inner to outer.

The notion of mothering energy is also closely related to the idea of "the more knowledgeable other". Children can develop a voice of a "private speech" function as a replacement for the physical "more knowledgeable other" that the adult of childhood represents (Vygotsky, 1978). 
Practically, mothering energy is an internalized voice of a more knowledgeable other, not understood as a neutral guide or helper, but as a loving, caring and positive, uplifting and supporting voice. The next property of trust is emergence.

\subsubsection{Emergence}

Emergence is relevant when understanding how trust helps the practitioners to grow organically because what they often trust is emergence. First, a story from an interviewee. Camilla tells how she became author "by mistake" because she was in a position where she trusted the process and trusted emergence. Camilla experienced a personal event in the family that caused her to ask for help in the community of Al practitioners and was overwhelmed by many replies. She decided to publish some of the replies and then she was asked to write a book, and so she did. She felt that the categories and sections for the book emerged through the writing process and she just needed to trust the process. She emphasized following her intuition in doing that, and she found that she had to show her colleagues in the field that she was a beginner in writing books: to show vulnerability. She also emphasized that she felt not only compelled but also guided to write that book and that she almost felt that she was just a helper, even though she was the key figure.

This can serve as an illustration of trust and of organic growth: She becomes aware of something important, in this case she trusts what is emerging, she is brave and vulnerable enough to ask for help, and then the process spirals out for her because she has no resistance to it and she does not force it. Not that all organic growth processes are like this. But it is significant in its lightness, inspiration, guidance, fun and ease.

Cathrine says: 'You can only have an eye for what is emerging if you have presence, time, are relaxed, with no stress, but with patience, flow - if you are in the moment, if you look for it - if your mind is set on it". This stresses the connection from trust to emergence and flow in organic growth. Carl describes the "messy space of emergency" when he facilitates change processes. He holds his own trust through the chaos, he follows his intuition and he lets the group take ownership and take the responsibility for the process and the outcome. He emphasizes that it makes a difference that they take responsibility for their own "mess" and their future, and that to learn to take that $100 \%$ responsibility can be terrifying and messy but that it gives great power to create and cocreate.

Summing up the importance of emergence, the practitioners trust to a very high degree that what is valuable and relevant will emerge when the time is ready. Again, this can seem banal, but it is key to the process of developing in a sustainable way. Related to the concept of emergence is openness - the final property of trust 2.0.

\subsubsection{Openness}

Another category that came up in relation to emergence and trust was openness. Openness is a crucial shared characteristic; almost all interviewees had it in common. As with the expression of trust, the practitioners seem to be operating from a higher level of openness. They are open and curious, and they keep allowing themselves to be open. They are aware of their own openness and when they do not find themselves to be open, they adjust. When framing the concept of 
openness, this study uses Fredrickson's understanding, presented in her broaden-and-build theory (Fredrickson, 2004), where it is argued that positive emotions broaden people's mind and actions. Studies show that people literally have the ability to see and experience a wider range of objects in their environment and therefore are more open when their emotions are positive.

If the Al practitioner is not conscious about creating positive emotions on a regular basis, eventually their work reminds them of it, as Christian mentions: "I teach my students about gratitude rituals and then earlier this year, I figured I would take up that practice in my own life again and I have been feeling more gratitude since then". And because the interviewed practitioners keep experiencing positive emotions they keep opening up and that can place them on an upward spiral: "The more I listened, the more I was able to hear the others' perspective and therefore went into dialogue," says another practitioner about openness in a practical setting.

The idea of "openness" and also of "listening" are crucial within the theory and methods of appreciative inquiry and social constructionism, yet they can seem natural and inherent in conversation - and in the approach to life that these practitioners share. They are nevertheless subtle and were almost overlooked or taken-for-granted in this data.

Summing up, the dimension of trust has been presented with four themes. The concepts of acceptance, mothering energy, emergence and openness all help content fill, unfold and broaden the perspective of why trust is 2.0 for Al practitioners and why it is key for their organic growth processes. The next section will describe the fifth dimension of organic growth: energy.

\subsection{Energy}

Energy emerged as a key dimension and has three properties; 1. human relational energy, 2. appreciation and 3. fun, humor and play. These will be described following the text about energy. Energy as a concept was understood in various ways throughout the data, but the interviewees did not talk about volts or amperes. Energy is used in several scientific and everyday areas. It appeared in Western history as a Greek word, Energeia, in the works of Nicomachean Ethics in the fourth century BC. This study is related to social science, thus the physical and mechanical uses of the notion are not key to this description.

Energy both came up in data as describing personal energy in relation to growth and thriving, as relational energy in what happens in dialogues and interaction between people, and also as system energy (or wholeness energy), an important parameter in the whole-system change processes of Al summits. Everyone who talked about Al summits (not every interviewee talked about them) mentioned the special energy that characterizes such a summit. The following examples present the practitioners' understanding of energy, and resonating theoretical perspectives are woven into the presentation. Carl explains energy in this way:

It is something we can't grasp, like red light; we can both see it, but I can't hand it over to you. We can measure it in different ways, yet we don't really have the full understanding of what it is and then we call it energy. (Interviewee Carl). 
Energy is an indefinable size, although several scientific areas using the term of energy theorize about it and measure it. Examples of types of energy are electrical, magnetic, kinetic, mechanical, sound waves and radiant energy such as light. An interesting quote came up during an interview and relit curiosity into what energy is, how it shows itself, how humans are connected to energy, how we understand energy, and how we benefit from the constructed term of energy. The quote came from the interviewee Cathrine, playing with a definition of "soul" for her work, where she was writing a scientific text: "What if we understand soul as the first condensed form of energy?" She was in close contact with people doing research on how the big bang started and how energy moved around at that point in time. Besides highlighting an interest in what energy is, it proposed a direction of awareness that correlated in many ways with other concepts of organic growth, such as wholeness, intuition and synchronicity, where practitioners described guidance from "their inner voice", a "source" or "soul".

From a social constructionist view this is one way of creating language around energy, where metaphysical forms of energy are connected to the energy field of the single person. Cathrine also referred to ancient wisdom from the east, talking about a person's chakras, the seven energy fields every person embodies from the ground up to the sky above us. Lipton (2008) goes on to state that matter is an illusion, because at the quantum level of reality matter is empty: "(...) the universe is not made of matter suspended in empty space, but energy" (Lipton, 2008, p. 70). The word has been used in the history of religion, in art, fiction, poetry and spiritual communities, where energy often refers to a person's personal power or kind of energy field.

In a PhD dissertation within the area of $\mathrm{Al}$ and future-forming research from 2015, José Otte describes how energy is understood in the Japanese martial art Aikido as "ki" (Otte, 2015). Ki is explained in two ways in Aikido, one of which characterizes the energy making up the sun, the stars, our planet and everything belonging to the world we know, including human minds and bodies. The second use of the word is when describing the personal (and universal) energy that the Aikido practitioner connects with and uses within Aikido training. In this study energy is similarly understood as a personal, relational and wholeness energy. On a personal level, the word is tied to emotions, because emotions can reveal what kind of energetic frequency a person or a situation is vibrating with. A way to explain this is by trying to feel the frequency of appreciation, for example, and thereafter feel the emotion of fun, trying to sense the difference between them. Both may feel good, but there is a difference because they are vibrating on different frequencies. This is how energy is relevant in relation to organic growth and this will be explored in the following. The three properties of energy will now be unfolded; 1 . human relational energy, 2 . appreciation and 3. fun, humor and play.

\subsubsection{Human relational energy}

The relational side of energy (as opposed to personal and wholeness energy) became saturated because the practitioners have such a high awareness of the relational in their lives. This study has found that human relational energy is understood as the energy humans give to each other, "take out of" each other or create together in social relations. When one is out of flow, others around are easily infected. As mentioned, energy is expressed and felt through emotions, which is how energy and emotions are tied. Emotions are contagious and human energy can be transmitted through social interaction (Hatfield, Cacioppo \& Rapson, 1994; Owens et al., 2016). With positive 
emotions comes the feeling of higher energy. It is often possible to feel if a person has high energy or is low on personal energy. One can "run out of energy" when the body is tired, and some practitioners describe how they can always tap into some kind of energy, which they refer to as "source" or "soul." Collin (2004) refers to energetic activation as "emotional energy" and describes single human systems as being motivated to engage in social interaction because they have the ability to raise their own energy, but also says that they try to avoid interactions that reduce their energy. This assumption quite accurately describes the way the practitioners in this study understand energy. The practitioner Anna says:

The people were energized every time, the meetings were more fun, more productive and led to immediate action, saying: let us just do it now. They went out and cleaned the village, came back, made a bonfire and danced and drummed. (Interviewee Anna)

Cathrine says:

We are led into the noises and pressures of this world, because that is the strongest energy and the strongest energy always wins. So we need to consciously take a stand, reflect on balance in our life, be the stronger energy and take actions that supports that choice. (Interviewee Cathrine)

Carl describes himself as a facilitator and says that he tries to be authentic and to have a high level of energy, and that he positively reinforces what is working in the process which keeps lifting up the participants. He says: "This reinforcing gives the participants permission to have a positive energetic upheaval and practice a positive outlook". This leads back to the discussion about permission: Why is it that humans need permission? No one-year-old needs permission to be happy and playing and doing what is fun most of the time. Maybe appreciative inquiry processes touch upon some of these? To have permission to have fun, to have high energy, to dream and to make those dreams real. Even a two-day course on appreciative inquiry can be a life-changing experience, because if a participant experiences having permission to be happy and to act towards dreams, then he may take that experience of permission to other parts of his life. The second property of the dimension of energy is called appreciation.

\subsubsection{Appreciation}

Appreciation appeared as a concept important to organic growth because it characterized a special frequency, a certain energetic vibration that the practitioners often vibrate from. Not surprisingly, many practitioners prefer to vibrate from this frequency of appreciation. Interviewing Al practitioners, one might have expected that the two key words "appreciation" and "inquiry" were both concepts in the model of organic growth, because many practitioners live in a way that correlates highly with the foundational principles of $\mathrm{Al}$, as described earlier in this study. Inquiry did not emerge as a key category so it was not included, even though openness, emergence and trust are crucial and have similarities to inquiry. Appreciation did emerge as a central concept and the perspectives around this are unfolded in the following. The practitioner Marie says:

You should not be appreciative to a colleague if they do something that you do not recognize as being appreciative. Appreciation is a shared goal in the workplace and there 
is an open language around values of appreciation, and the employees know that they are expected to be focusing on strengths and giving each other feedback. (Interviewee Marie)

Sebastian, a manager, says that his employees do have space to practice having an appreciate approach and that he is mostly concerned with the employees who stopped practicing it. $\mathrm{He}$ emphasizes in a strong way the power of the ongoing dialogue between manager and employee in order to develop a "relational and appreciative competency". It is worth discussing if "appreciation" is a competency that is demanded from the workplace, but also if there are situations where space for failure is not created. Imagine what the world would look like if a key competency for getting a job was appreciation. But what would it look like in practical settings if there was no space created for trying and failing? Anna tells about the way she has worked with appreciative inquiry:

We broke out of the problem base because I noticed it wasn't working - then we just tried something else, and when that worked we just kept on doing more of the stuff they were excited about and less about the stuff they were not excited about. (Interviewee Anna)

This practitioner talks about trial and error - she tried it, it worked, did more, it worked better and every time the teams exceeded their own goal. When asked why this approach is not more common - if it is as powerful as she describes - she answers:

That problem-oriented, deficit-based approach to go about things is so common that we can rarely think outside that box. It is deeply rooted in our culture and inherited in generations, in schools, in families, in science; it takes time to change for some people. (Interviewee Anna)

She finds appreciative inquiry to be powerful in her many years of working with it in developing countries, yet she also finds the deficit culture to be a powerful habit. In the process of interacting with the data it seems as though the practitioners are already living in the future. They all prefer to appreciate in their everyday lives, and these actions of appreciation in many micro-moments sum up the essence of who they are and help them stay in flow. When they feel alone, it may be due to the fact that they are frontrunners, they might be living now as others will in the future. They have to some extent left behind their emotional baggage and live in flow and know their identity. They find that we are all energy and they trust in life and in the process, and do not have to go hunting something or force manifestations or burn out. When growing organically they keep trying to expand further and learn in balanced ways.

\subsubsection{Fun, humor and play}

A third frequency of energy is connected to fun, humor and play. Some address it by talking about "raising the energy level" and describing how they often experience a high energy in the room; others actively facilitate playful activities in processes and in their everyday life. There is an easiness towards these concepts when described by the practitioners, as though it is very easy and feels light to have fun, but they also strategically set out to encourage fun and play because this invites creativity and leaves spaces open for emergence and for losing control. 
Humor and creativity often occur in the processes where shared dreams are prototyped, and projects and visions are visualized. Many of the interview situations and interactions with the group can be characterized by the frequency of humor and fun, and most interviewees sent that vibration during the interviews, making jokes, laughing and inviting a less serious atmosphere. Participating in the world conference and at the certification cause were altogether fun experiences with laughter, jokes, great humor and a feeling of being light around the heart and in the body. Several of the practitioners do emphasize how important high frequency energy and feelings such as fun are in the processes and within their own growth and everyday life. As with simplicity, too many words will not pay tribute to the concepts of fun, humor and play, because when analyzing and reflecting, the logical competencies are alive. This stands in opposition to these frequencies which are more spontaneous, non-logical and generative, but also more lightly felt in the body.

This section has been devoted to a description of how energy serves as an important concept in relation to organic growth. When continuing the project of growing organically, the practitioners have an awareness of their own personal energy, how it is raised and what drains it, and that they prefer situations, people and approaches that raise their energy - that excite them. This is closely related to their awareness of micro-moments, and their reflection and adjustments regarding their own flow.

The practitioners show awareness regarding relational energy and they are sensitive to atmospheres and energy levels in groups of people. Together with responsibility, this awareness often leads them to take the position of a "lighthouse", where they help co-create higher levels of human energy through their facilitation, their questions or their "showing up" and just being. The sixth and final dimension of organic growth is wholeness, and the purpose of the final section is to complete the analysis of organic growth before carrying on to the literature connections, the findings and the discussion chapters.

\subsection{Wholeness}

Wholeness emerged as an important dimension during the study both directly in first-order codes where practitioners mentioned the concept of whole and wholeness in relation to their work, but also in more subtle terms, as a parameter some of the practitioners operated from in their approach to the world. Wholeness has three properties which are 1. interconnectedness, 2. love and 3. magic.

If the practitioner approaches life from a basic feeling of wholeness, actions will be different, because she knows that she is connected on a deep level to everything and everyone around her. To harm people around her does not make sense, because then she will hurt herself. In the interviews, wholeness was not only vivid in relation to the methods of "whole system in the room" and Al summits, but also in relation to growth. Bohm defines wholeness as an attitude or an approach and this resonates with the way the Al practitioners describe wholeness as a style and a mindset that allows them to show up in life, being aware of the wholeness of other people. Martin, a manager, is very aware of the "whole system" effect within the settings of his employers. He says: 
They cannot create their own little island of what works in one part of the kindergarten, they need to constantly develop and when they do, they need to do it in the whole setting, so that everyone knows what is going on and can learn from that. (Interviewee Martin)

Whole-system processes also appreciate the whole.

Having the whole system in the room also brings an ecological perspective: all the pieces of the puzzle come together in one place and everyone can gain an appreciation for the whole. The unique perspective of each person, when combined with the perspectives of others, creates new possibilities for action, possibilities that previously lay dormant or undiscovered. (Ludema, 2003, p. 42)

Wholeness is a key concept in quantum physics where elements can be in two places at the same time and there is a connectedness between parts that cannot be explained with physical laws. Some of the interviewees talk about quantum physics in this way, e.g. Thomas: "When I learned more about the details of it, it just made so much sense for me in my everyday life. It was like it gave voice and words to many things in my life." The practitioners talking about quantum physics all mentioned that it can be hard to understand. In the following we will explore interconnectedness, love and magic to gain further understanding of why they are relevant to organic growth.

\subsubsection{Interconnectedness}

Interconnectedness was mentioned several times throughout the set of data and described as something happening between people. One practitioner, Louise, was very passionate in the conversation about the idea of interconnectedness and emphasized that connections to other people in a positive, curious and open approach is key in her work as an Al practitioner. She also points to the fact that "intra-human" connectedness is important, but that connections to other people are central. All of the practitioners seem to be embodying - or coming from - an understanding of wholeness where the distinction between inter and intra are not relevant because they include both/and (Kelly, 2018).

It was not until writing up the category of wholeness, where the understanding of the deep relation to the single human system was complete, that it became clear that wholeness exists on every level and layer of reality. Wholeness is a state with inclusion, spaciousness, trust, collaboration and some kind of "perfect" order between smaller parts. The human body presents a good example. The way all of the cells are working, communicating and collaborating while at the same time each is a whole system in itself shows how wholeness can operate on a cellular level. If something does not function in an optimal way, the body shows signs of being out of balance, by for example illness. Most practitioners in this set of data express an understanding of the single micro-system being a "whole" including body, mind, mental states, beliefs, habits, actions, history and everything else that is related to that system. Thomas says, "The 'whole' that sums up the whole of a single human person is a very fine instrument in tuning into vibrations." This represents an understanding of the human system and wholeness relating to energy, as earlier described. 
Another interviewee, Anna, says, "Connections are what everybody is looking for, but they get distracted by focusing on the problem!" This leads to an interesting point: Problems and the cultural pattern of focusing on problems might be what is dividing and separating people who actually want to connect. To be listened to. To be seen as who they are. And to see others. Going with this notion makes the argument for choosing Al practitioners stronger, because if we create separation and fragmentation by focusing on problems, where we can create stronger connectedness, relationships and wholeness by focusing on strengths, we do have something to learn from these practitioners.

As described earlier, some of the practitioners do not speak directly about wholeness but show it. In one interview, the interviewer could not tell whether the interviewee, Mia, was just talking about appreciative inquiry or whether she actually approached work this way. By the end of the interview the researcher asked her informally about something other than her work, and she almost exploded in joy when she talked about a visit to another workplace. From this embodied telling and this story, the way she chose the words to describe that other workplace was very appreciative and constructive. There were clearly a lot of things that might have been different in the place she visited, but she talked about it in the most respectful way. She spoke from a place of wholeness. As a methodological comment, this interviewee appeared more relaxed as we changed the subject and, despite the work in creating a relaxed and safe atmosphere, she might still have felt pressure to "please the researcher". As soon as focus shifted away from that subject, she stepped into a powerful and free role as a storyteller that showed how she was in fact working from appreciation and wholeness.

Marie, who works in a kindergarten, talked about their mission for the employees: "We create whole and positive human beings". What an amazing mission! A critical voice would ask, what are the challenges of having wholeness as a strategy? What if people do not like to show all of themselves, but thrive in a workplace where only a small part of them is invited in? What if the kindergarten helps create "whole" children, but the family is deeply fragmented? What if we work to create "whole" children, but we are not willing to become whole ourselves? A curious question in relation to this could be; how do they work with this strategy? How do they approach the task of creating whole, positive human beings? The practitioners give examples of how they work with wholeness. A key factor is to contain the whole of the little child, especially when the child expresses strong feelings or unwanted behavior. Marie said that her biggest dream would be to work with the parents as well, in courses or education or whole family initiatives, as a way to work with the whole system of the family.

Rosch described the relation between wholeness and connectedness in the following quote, from an interview in 1999: "One of the manifestations of wholeness is connectedness. So much of people's crazy, neurotic behavior comes from their wanting to be connected. If that is not nurtured properly or is bashed, then they do all kinds of desperate things". In relation to this it seems like a brilliant idea to have a mission to create whole and positive human beings. Rosch goes on to say:

You could say that the path to that is that things become more and more integrated: intention, body, and mind come together, rather than being scattered all this way and that. And you start to be aware of perception happening as it actually does happen, from the whole field, not from within a separated perceiver. (Rosch, 1999, I VI) 
This suggests an explanation for how wholeness can be understood which resonates with the practitioners' "embodying" of the concept. One practitioner, Cathrine, lays out her understanding of wholeness and connection in this world to her clients or participants when she is teaching or facilitating: "Humans are the connection between heaven and Earth, but only if the energy can flow freely and the stream is streaming without blockages". Theoretically, the works of Bronfenbrenner resonate with interconnectedness in organic growth because Bronfenbrenner understands the social world as divided into ecological systems which are all part of our whole ecological system on this planet. The second property of wholeness is love, described below.

\subsubsection{Love}

Love appeared as a property of wholeness but also as a fundamental frequency in the interviews, at the conferences and throughout the set of data. Fredrickson (2013) defines love as what can happen in every warm micro-moment between two or more people, and states that love is therefore literally everywhere. When you smile at the woman in the grocery shop, when you bear with a colleague who arrives late and when your friend forgives you for forgetting his birthday, for example. Fredrickson emphasizes that, from this new understanding, love is not reserved for the closest family and friends, and it is not only that romantic, "once in a lifetime" love that resonates with the common understanding of love. It can be that as well, but love is an activity. It is what you do when you practice positive feelings together. Fredrickson even goes on to say that love is a superior feeling, it is the "superhero" feeling of all positive emotions (Fredrickson, 2013). All actions are carried out because of love. Love is the basic motivation for all human actions.

The practitioners Sarah and Thomas say that there are always two choices in every microsituation, "love or fear". Dualisms might not always bring us what we look for in relations, because there are always more than two voices or perspectives. On the other hand, what seems to be beneficial from this point of view is that it becomes easier for the single practitioner to sense their own state of being at a given micro-moment in time if there are only two choices: Do I feel a basic feeling of love at the moment, or a feeling grounded in fear? And then the practitioner can take full responsibility for that in the moment, accept what is there, approach themselves with a sense of mild caring, and work to shift their focus when they are ready - as we have seen previously with the example of flow (starting on page 84).

Love is heavily represented throughout this set of data, both directly and indirectly, from people's willingness to give interviews, give their time and their voice, from them always saying "get back to me if you have more questions", to descriptions of close relationships which have importance in their lives, and to caring colleagues in workplaces and in the community of practice of Al. I think one of the most significant signs of love is when the interviewee Christian describes appreciative inquiry as "the way I show up in this world". It is trying to practice listening, to look for what gives life, and to accept and contain different viewpoints.

These practitioners insist on being curious and asking questions and listening to other people, they insist on holding the space for things to emerge out of chaos, they insist on looking for light, for what gives life, for success stories and strengths. Self-acceptance and self-love are key for many of the practitioners. Thomas says, "The most important thing is to keep yourself happy and safe (...) to keep your own energy field clear so that you are the best possible tool for the world and 
your surroundings". Brian says, "The highest service is being in bliss," which means that if a person cares deeply about helping others and helping the world, to feel good is the place to start.

The notion of unconditional love is, at the fundamental level, the unconditional love that the single micro-system gives to itself. Svarre (2011) says that you cannot raise the level of self-worth of another person, e.g. your child, higher than the level of your own self-worth. That means that you have to work on raising the level of your own self-worth. The same goes for love: it is hard, maybe impossible to love other people more than a human being loves himself because the love toward himself is a place to "measure" the "love competency". In other words: if he is able to love himself unconditionally, to accept all of who he is, then he is more inclined to grow organically, especially when healing on an everyday basis as he reaches an awareness of not being whole. Peck says:

I define love thus: The will to extend one's self for the purpose of nurturing one's own or another's spiritual growth (...) Love is as love does. Love is an act of will - namely, both an intention and an action. Will also implies choice. We do not have to love. We choose to love. (Peck, 2003, 82ff)

This definition corresponds with Fredrickson's definition of love, in that love is an act and that to have a loving approach is a choice in every micro-moment. Peck begins his description of love by saying that love can never be pinned down in words, it is always mysterious and much more than we can understand in words and science.

\section{Researcher's voice}

I love this celebration of the limits of human knowledge and the point where our language ends and unlimitedness and wonder begin. It promotes a feeling of awe and not being able to control, but in being very small and humble about this life and planet and experience.

In relation to Fredrickson's understanding of love as shared positive emotions in connections - and not just exclusive and romantic - it is clear that this resonates highly with the group and most of the interviewees work from this understanding (Fredrickson, 2013). Yet the understanding of love in organic growth is expanded even further, to apply not only to human connections but to "everything". On a practical level, this means that a practitioner growing organically practices this shared positive emotion connected to everything, for example a horse they meet when running, a tree, a building, the sea or a stone. This is how "operating from a sense of wholeness" is described in everyday life: it does not mean that they love everything all the time. As mentioned earlier they experience moments and periods out of flow too. But they try to practice an understanding of love where everything is included, where everything deserves their loving attitude. Love, in this understanding, is the best way of describing their main approach to the world.

The third property of wholeness, magic, finishes the analysis chapter and is explored below.

\subsubsection{Magic}

Magic is a "natural" concept in quantum theory because things can split into two pieces, and the same thing can be in two places at one time. Things can act differently when we observe them than when we don't. These would normally be categorized as magical in the physical level of 
reality, but these practitioners, who seems to work from a sense of wholeness and quantum understanding of the world, may not talk about magic, because they find events like synchronicity and serendipity unfold naturally. Some of the practitioners do speak about magic, for example in descriptions of appreciative inquiry processes. Anna and Camilla express it thus, "It is powerful, very simple, everyone can do it and the power lies in the questions; it is almost magical".

\section{Researcher's voice}

During this research process a student of mine, who is a skilled magician, showed me a trick on campus one day that made me reflect on the position of the "magician": We all know they trick us, but we want to believe, we want to be tricked, we love it when something surprising happens. It is like we have an unspoken agreement with them about shared play before they start, and we are thrilled when they make something happen that transcends the physical laws.

When looking at the Al community from the outside, it may seem like they are magicians - and it often looks like magic when observing, participating and reading about their positive change processes. They are humans, though, and often experiment with these "technologies" in their own lives (Cooperrider, 2012). Carina says: "Everyone has the ability to some kinds of sources that are both without you and within you - and from that point, there is an ability to create miracles".

This quote concludes magic as the final property of wholeness. The purpose of this analysis chapter was to explore the research questions of organic growth: what it is, what factors it consists of, and how it emerged from the data. In the first section, organic growth was defined, described as an ideal type, and the importance of micro-moments were outlined. Following the elaboration of the core category of organic growth came a thorough examination of the six dimensions, 1. balance, 2 . flow, 3. healing, 4. trust 2.0, 5. energy and 6. wholeness, and their properties.

The following chapter sums up literature connections, and in Chapter 7 the findings from the analysis will be presented as well as models arising from the study. 


\section{Chapter 6: Connections in literature}

\subsection{Summary of related literature}

In the literature review, three lines of thoughts were presented in order to give context to the theoretical fields to which this theory contributes. Throughout the analysis chapter, further relevant theoretical perspectives have been included in order to connect current ideas with relevant thoughts from other researchers. In this chapter the theories from the literature review will be summed up and the connections to the theory and model of organic growth will be made clear ${ }^{11}$.

Three perspectives of social learning were introduced to position the study in this field because, despite the interdisciplinary character of this study, organic growth belongs to the category of social learning theories. The social development theory was presented in order to root the understanding of learning as socially dependent, and Vygotsky's description of private speech was relevant in relation to organic growth as well as his notion of "the more knowledgeable other", because when growing organically, one practices an inner, gentle voice of acceptance and mothering energy. Ecological systems were introduced, including a basic understanding of how human development occurs in different systems, from the single micro-system of the individual person to close relationships, school and work relationships, and on to the greater society and to the planets system, because the understanding of wholeness is so central to organic growth. Organic growth also lends an understanding of development occurring in interwoven systems, from smaller to larger, but adds wholeness to this perspective by borrowing from quantum physics, in that the smallest unit is a quantum, and everything is related. From social cognitive theory we know that reinforcement occurs, which is used consciously by the practitioners growing organically to reinforce positive behavior. More important is the concept of self-efficacy which relates closely to organic growth because Al practitioners generally have a great and realistic belief in their own abilities and, crucially, they rely on the development of their own acquired skills. They trust their timing in the way that resources and skills become available to them at the right time because they work from flow much of the time.

Three "flourishing" theories were presented in order to position the model of organic growth in that field, and to give insight about how these are related to organic growth. Positive emotions are an important contribution to the field of flourishing theories because positive emotions broaden a person's perspective and underlie a new understanding of love that can be defined as "any two people who share positive emotions, even briefly" (Fredrickson, 2009, 2013; Fredrickson \& Joiner, 2002). Positive emotions are key for organic growth because the ideal practitioner orients towards positive emotions in order to develop in a balanced yet upwardly spiraling path. The notion of flow proved to be key in understanding organic growth, and therefore it was relevant to introduce previous and current understandings of flow (Csikszentmihalyi, 2014). Flow, in this new understanding, is more common when practitioners grow organically and it is not exclusively for special activities. Flow is possible in every micro-moment and the awareness and consciousness of flow lets practitioners know whether they are in flow or not. The perspective of having a growth

\footnotetext{
11 The purpose of the study was not to inquire into certain theories to find out if these were applicable or 'true' within this community of practice and therefore that will not be addressed in this section.
} 
mindset was introduced in order to relate to organic growth because the practitioners work from a growth mindset as opposed to a fixed one (Dweck \& Leggett, 1998, Dweck, 2010). Organic growth contributes to the area of flourishing theories by providing a perspective on how to grow through flourishing, but in a balanced rather than a forced fashion, toward positive emotions. It contributes by adding an in-depth study, focusing on what moves a group of positive practitioners, who in fact have the ability to flourish because they work full time with positive change.

Three theories about consciousness development give perspectives on how humans develop in different stages ${ }^{12}$. László suggests the theory of a "quantum leap" because Earth is in such a bad state, a revolution is needed if humans are to survive and make it to a breakthrough instead of a breakdown (László, 2008). This researched group shows signs of acting in a way that can be described as having taken "a quantum leap". They act to take care of the planet and embrace wholeness, preferably by acting from a place of love. Quantum physics work with keywords such as entanglement, superpositions, uncertainty and complementarity, and Bohm defines how wholeness is a meaningful way to describe the world (Bohm, 2005). Many of the quantum terms are hard to understand in-depth but they resonate with organic growth because the practitioners work from a sense of wholeness on a practical level in their lives. Laloux (2014) also suggests specific levels of consciousness and collaborations and calls the newest stage "evolutionary-teal". He enquires into organizations who demonstrate this level. The characterization of the employees and managers of these teal organizations also looks similar to that of the Al practitioners, and was therefore relevant when the model of organic growth emerged. Organic growth has possibilities for contributing to the field of consciousness development by adding a description about one community of practice operating from these newer levels of existence.

The sample of this study differs because it enquires into a community of practitioners who fit the description of humans operating from the highest stages of existence or consciousness, as described by the different authors. This provides an opportunity to discover what theories and models these practitioners work from in their lives. This means that the language of organic growth has the potential to provide examples of how humans working from higher stages of consciousness operate, what moves them and what purposes in life they try to fulfill. To sum up, it is clear that the theory of flow has been extended with this study but that other theories mentioned have not been extended (or reproduced) but that certain concepts from different theories make meaning within organic growth and therefore helped validate certain perspectives in the model of organic growth.

\subsection{Connections to previous research on Al practitioners}

Besides the connections drawn with theories outside the field of $\mathrm{Al}$, it is relevant here to connect to two other studies on Al practitioners: an exploratory study of competencies in the discovery phase of appreciative inquiry (Newhard, 2010) and appreciative intelligence - seeing the mighty oak in

\footnotetext{
12 The choice of adding consciousness development as one line of thought was somehow contradictory to the group of AI practitioners, because it can seem quite arrogant and judgmental and it has the ability to create distinction between different groups, which is not a wish of the Al practitioners. It was chosen anyway because these practitioners are very humble and would rarely articulate own talents but may be worth celebrating and learning from.
} 
the acorn (Thatchenkery and Metzker, 2006). As mentioned earlier, the study on appreciative intelligence functioned as a part of the argument for studying Al practitioners in the first place, mainly because of key characteristics such as a great ability to see potential, tolerance for uncertainty, and showing persistence and great trust in their own capability to make a difference (Thatchenkery and Metzker, 2006). These features match key characteristics that will be needed in people working in the organizations of the future (Laloux, 2014).

During this study, it has become clear that many of the same characteristics of Al practitioners were found in the data set of organic growth. Yet, some of the characteristics did not show up as being significant to the same degree and therefore did not enter the full model of organic growth. For example, the "ability of being resistant" was a category that arose in the first round of coding, but it did not saturate in the study of organic growth. There was no doubt that most of the interviewees showed great abilities in being robust and resistant, it just did not turn out to be relevant "enough" when comparing incidences in my data set. This may only point to the fact that being resistant may be a key characteristic of Al practitioners, but maybe not a key for their balanced development. Their ability to see many potentials in humans was also recognized throughout the data but did not prove to be relevant. It would be necessary to do further research on these points in order to systematically evaluate the extent to which the key findings on appreciative intelligence resonates. The goal of this study was not to reconfirm or challenge certain features of Al practitioners, nor to compare appreciative intelligence with organic growth. These observations would require further study.

Newhard's dissertation on the competencies of Al practitioners is relevant to the present study because many of the key competencies also were found in my study of organic growth. As with much other literature, this text came to my awareness late in the process because of the grounded theory method, and therefore did not function as part of the content when starting out.

The single Al practitioner and his or her competencies were not relevant for this study to begin with because the focus was on the community of practice and on what the practitioners were "up to" as inspired by the method of grounded theory. Newhard combined competency list development with Al practitioners and came up with a list of thirty-six competencies in four categories: 1. personal competencies, 2. interpersonal competencies, 3. business acumen and 4. subject matter expertise (appreciative inquiry). As mentioned, many of the key points in the Newhard study are also found in this study (please find the full list of competencies in Appendix 12.7). Some are almost identical in wording, while others are more distantly connected. Others, again, can be recognized in data but did not emerge as relevant for the core category of organic growth. Let us first look at some of the competencies almost identical to codes in organic growth (found in the full list of Newhard (2010, p. 180-212), and not in the four distinctive categories). The codes from this study are placed in parentheses:

- Open mind - (openness);

- High ideals comprised of integrity, authenticity, sincerity, and honesty (authenticity);

- Appropriate sense of humor or playful, joyful and exuberant (fun, humor and play);

- Instills trust (trust 2.0);

- Collaborative, creates community, connections and inclusivity (human relational energy); 
- Innate or adopted resonance with Al (love);

- Being/living Al (how you show up);

- Strengths-focused/ "the positive core" (appreciation).

Listed below are the competencies given by Newhard (2010) where the content of the codes connected in a more distant fashion with the data (all are described in this thesis' analysis chapter):

- Critical thinking, lifelong learner, driven by curiosity;

- Comfortable with ambiguity;

- Hopeful and optimistic, seeks the light;

- Self-aware and self-confident;

- Dynamic leadership balanced with the reflective thoughtfulness, humility, and no ego;

- Innovative and creative;

- Quick and good at improvising;

- Appreciative listening;

- Treasures others;

- Need to be helpful;

- Gives away the show;

- Affirming, great mentor and confidence-inspiring coach;

- Appreciative listening and reframing;

- Asking meaningful questions.

The last eight competencies of Newhard's list are all related to business acumen:

- Facilitation skills;

- Appreciative framing and reframing;

- Effective synthesizer of large amounts of information;

- Firm grasp of traditional OD models, process and history;

- Results-driven to achieve client's goal and to demonstrate success of Al;

- Good at designing initiatives;

- Experienced consultant grounded in theory and practice;

- Identifies client's core values, industry and culture, and speaks their language.

From working with my data set, I recognize all of these competencies within interviews, interactions or observations, including Al practitioners working in the business sector. In the study of organic growth, it did not become relevant to sort the practitioner's development processes into personal, work-related or other categories, because the practitioners showed such a significant practice of wholeness and therefore the separation of segments was not meaningful for my analysis.

What differs in Newhard's study is the language and perspective, where Al is paired with the field of competency development, which is often based on a positivistic view of science, far from the quantum perspectives on organic growth that this study is founded on. 
Newhard (2010) created the study of competencies of Al practitioners because of a dearth of previous research in that field (Bushe \& Marshak, 2009; Watkins \& Mohr, 2001) and through that helped Al practitioners and others gain a language for which kinds of qualifications are crucial for those training or mentoring Al trainees. The motivation for the current PhD study was, on the other hand, a grounded curiosity in the practitioners as a unique group of people that might be relevant to learn from when navigating into the future. Another important difference to articulate is the difference between the degrees of complexity in the language of competency list development versus the attempt to honor the practitioners' observed urge to practice the concept of simplicity. This is also seen when Newhard argues that:

a language needs to evolve around the integration of competency studies and Al that honors the historical procedures for developing competency lists as well as satisfies the call for less constraint and acceptance of a more open approach to competency list development (Newhard, 2010, p. 249).

This study agrees with Newhard's in the sense that the paradigm and practice of Al people are described as fluent, cyclic and open-minded. Newhard goes on to argue that the field of competency development may stand in front of a shift, where the methodology might enter a constructionist mindset (Newhard, 2010). Another point is that Al evolves and Newhard emphasizes that the resultant list of Al competencies does not contain possible future competencies. These are obviously outside the field of my current PhD study, though the language on organic growth does tend to add to the research on Al practitioners in a way possibly pointing toward the future by describing how Al practitioners grow in a more balanced way as opposed to many similar practitioners with more stressed lives and development.

It is clear that most of the competencies listed in Newhard's list of thirty-six competencies of Al practitioners resonate within the language of organic growth. That in itself is not surprising, in as far as practitioners within the same discipline were studied. This result can serve as a validation mirror, not in the form of the same language or goal, but simply in the understanding of this group of practitioners. As Newhard's work entered the current study late in the research process, it was not part of the start point. Many of our codes resemble each other, and many themes were identified independently in both studies, which makes it more likely that they are an integral part of Al practitioners as a group. After demonstrating the connections, similarities and differences to these two important, related, yet independent studies on Al practitioners, it is clear that each study finds similar features significant for Al practitioners, whether we analyze their key characteristics of appreciative intelligence, their competencies or their development processes.

The purpose of this section was not to compare or analyze former relevant Al studies in depth, merely to connect and point out possible resemblances as well as differences, and mostly to point out possible future research directions that could shed further light upon the group of people called Al practitioners: what characterizes them, which kind of competencies they have, how they develop and what we can learn from them in order to navigate similar future contexts.

In the following chapter, the findings of this study will be presented and discussed. 


\section{Chapter 7: Findings and interpretations}

The findings and interpretations, based upon the analysis chapter and the work with data, will be summed up in this chapter. An umbrella model of organic growth is presented as well as a spiral model showing the different steps towards organic growth that Al practitioners commonly take. Key parts of the analysis will be discussed. Even though the interviews were conducted in five different areas, organic growth emerged as a main concern in all five. This made it less relevant to discuss organic growth between the five areas because it seemed that it did not matter whether the interviewee was in a 1:1 mutual mentorship within the field of appreciative inquiry or attended regional, national or international meetings, courses or conferences within the field of appreciative inquiry. First the findings will be summed up by providing answers for the research questions.

\subsection{Addressing initial research questions}

In the following section the initial research questions will be addressed.

1. How can organic growth be defined?

Organic growth is defined as: To grow organically as a human being means to develop in a sustainable, flourishing way with a great amount of trust toward enriched consciousness, increased states of flow and more fulfilled wholeness in balancing, lifegiving processes.

2. What factors contributes to organic growth?

Six categories helped shape the model: 1 . balancing, 2. flow, 3. healing, 4. trust, 5. energy and 6. wholeness. The essence of these factors is summed up in the description of the model of organic growth in the next section.

3. How can organic growth be described as a process?

Growth is directly described as a journey or a process. Even though the practitioners have dreams and goals and often seem to succeed in reaching them, they tend to focus on their life as a "journey". A suggested process of organic growth for Al practitioners goes through six "frequencies", from their first awareness of appreciative inquiry to integrating the mindset into their daily life as a preferred approach to the world. The six frequencies are placed on an upward spiral to illustrate the upward and expanding journey of the practitioners. The six steps are called frequencies because each comprises a certain energetic frequency in the practitioner - a state of mind that she is predominantly vibrating from. The spiral model is outlined in Figure 10 in section 7.3 .

The first frequency, called initial awareness, describes an energetic state of resonating where the practitioner, on the first meeting with the mindset, has an initial and less extensive understanding of the approach. The second frequency is the immediate response, which is characterized by the prompt reaction of recognition the practitioners describe. It is often felt as a genuine match and as though the approach gives words to a mindset the practitioners already use. The third frequency is called deep-dive experimentation and designates a state of being with many and deep experiments in different arenas in order to create the practitioners' own experiences and see the results for themselves. This is often associated with trials and more-or-less successful attempts, as 
well as hands-on experiences and many learnings. Deepen the competence is the fourth frequency and this is related to further efforts with the approach, refining the skills and then adjusting the next projects based on the improvements. The fifth frequency is called expanding and leaving the nest, and points to actions where the practitioners find themselves more selfpropelled and with great experience. Therefore, they take more ownership when designing their projects. They create their own questions and processes, adapt to the specific situation or group, take great responsibility, rely on their own competency and improvise on the spot when needed to support the group they are working with. Finally, frequency number six is how you show up, and this characterizes a state of being where a lifegiving mindset is quite fully integrated within the practitioner in a way where this is the preferred way of relating to people and engaging with projects, and they cannot or will not "take it off". These frequencies are "ideal" in the processes of growing organically for Al practitioners and each journey is unique to each practitioner. The interviewees who showed a highly integrated lifegiving mindset also spoke about how they kept practicing and held a daily awareness about what gives life and that an effort was required to keep choosing to show up to everything with a lifegiving mindset.

4. How can Al practitioners benefit from growing organically?

They seem to be experiencing more positive emotions, often finding themselves in flow and often reflecting on how they can learn. They have the possibility to heal and to adjust patterns instead of continuing to reproduce behaviors or thoughts in their lives that are no longer working, and they are of more help to others because they are balanced themselves. They are more helpful to the whole of planet Earth because they are aware of wholeness, and therefore take good care of the planet. They are less ego-driven, and therefore a resource and a role model for their families, workplaces, communities and societies. They are more likely to be proactive in suggesting breaks and adjusting energy, which may affect their surroundings positively. Being a resource for others helps reinforce positive emotions, which is also seen as a benefit for them.

The downsides of this may be that others do not understand their motivations, and their trust 2.0 can be regarded as blind trust or naiveté. It can be difficult to understand and accept that "wholeness" is a meaningful description of the world, and therefore it can be hard to follow the motivations for their behavior. Another downside is that the practitioners may be experienced as "closed" or "unwilling" if they politely turn down relationships or situations because they need a break or because they follow their intuition. If the event is not part of their flow and journey, they probably will not confirm their participation, which may be regarded as inappropriate because they are following their own alignment and have a strong personal energy field for which they take full responsibility. This could be viewed as selfish in early interpretations of consciousness stages, but in this arena, the practitioners operate from a belief that they cannot help others or contribute if they are not in alignment.

5. Which kinds of theoretical landscape does the model of organic growth belong to? The aim was to create a future-forming grounded theory and it resulted in contributions to the field of social psychology and social learning theories (Gergen, 2015; Vygotsky, 1987; Bronfenbrenner, 1994; Bandura, 1977). In learning more about what moves this group, it became clear that the theoretical landscape of consciousness development was relevant because the practitioners express and operate from values described in newer stages of evolutionary development of mankind (Bohm, 2005; László, 2008; Laloux, 2014). In this study, organic growth emerged, and 
this places the study in the field of flourishing and positive psychology. The language on organic growth contains key concepts from this field such as flow, love and positive emotions in general, and also contributes to the field, as organic growth can be described as a flourishing theory.

6. How does organic growth add to this landscape?

As mentioned in Chapter 6, the model of organic growth adds to the field of social learning theories by operating with a notion of wholeness as key for human development, not limited to a social or individual part. To grow in this sustainable way means to grow into more wholeness, with the wholeness connected in the world. It contributes to the landscape of flourishing theories by providing an expanded understanding of the concept of flow by focusing on a group practicing positive change, and by suggesting a balanced approach to achieving and creating positive emotions in their lives, not forcing or manufacturing them. The theory contributes to the field of consciousness development by studying a group of people who seem to be acting from newer levels of consciousness, who have taken a quantum leap of consciousness, and who can therefore be used as inspiration for others.

The following section will present the visual model for illustrating organic growth.

\subsection{The umbrella model of organic growth}

Having all six dimensions and their properties in mind, an umbrella model turned out to be a beneficial way of illustrating organic growth. The model is presented in Figure 9.

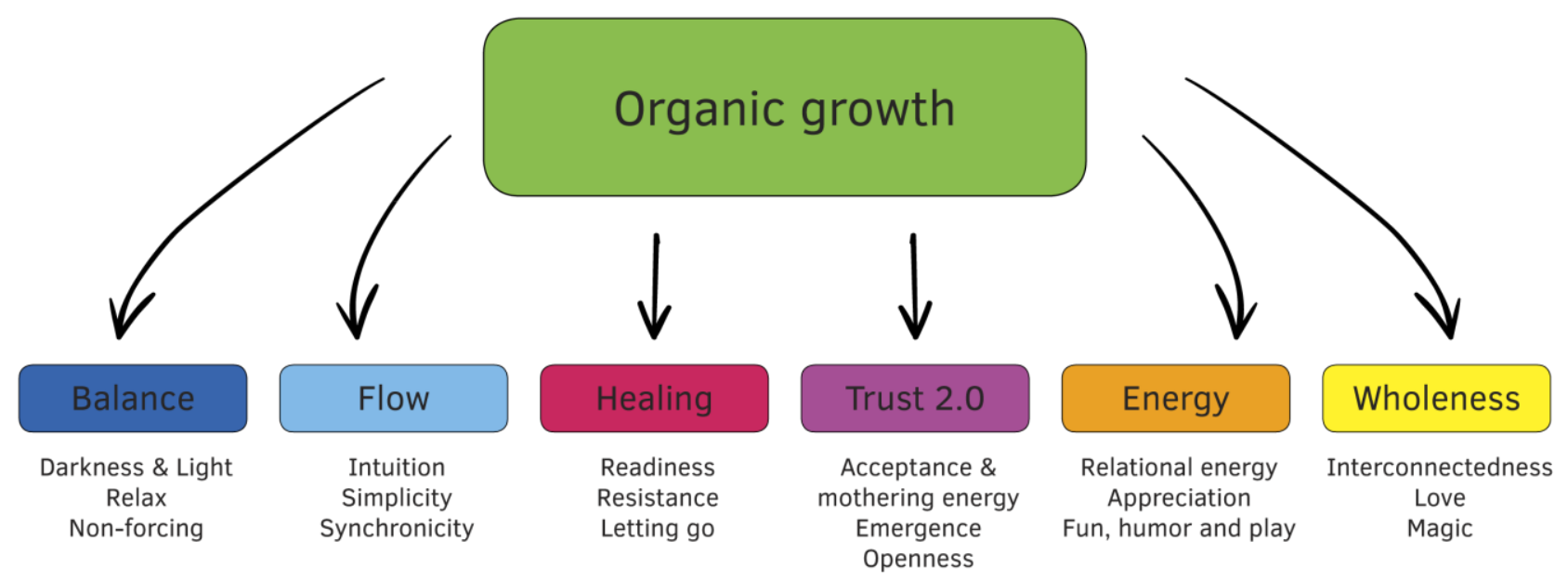

Figure 9. The umbrella model of organic growth

Based on the analysis, the model of organic growth contains six dimensions as illustrated in the bubbles of Figure 9. All six dimensions are key features when the practitioners grow organically.

1. Balancing: Balance is important because the practitioners work with an awareness about balance in their life between darkness and light - which means that they are aware of phases in their life that can be characterized as either challenging or easy. They constantly 
try to adjust and grow toward light, while they seek positive aspects in challenging times and ask lifegiving questions both of themselves and their relationships. To work towards a life of balance, they prioritize time for relaxation and restitution in order to spend time "being", and to take breaks from "acting". This allows them to "land new learnings" in the cells of their bodies and allows them to integrate new stages of growth in a balanced way without too much rush. Balance for these practitioners is also a question of not forcing the growth and not manipulating the development by pushing and controlling, but letting it in.

2. Flow: Flow is a key factor in organic growth, because flow is what the practitioners are constantly looking for and adjusting towards. They know that positive emotions create more positive feelings in an upgoing spiral and therefore they "check in" within their own system in micro-moments of a day, to evaluate whether they are in or out of flow, and try to adjust when they are out of flow in order to return to flow. Because they have knowledge about positive emotions and they know exercises that enhance positive emotions, they have access to that in their own lives. What they check into in their own system is their intuition; they slow down and focus on their body or breathing, or just moments of silence in order to hear the sometimes subtle voice of their intuition, and they follow the instructions arising from that. The act of listening and checking whether they are in or out of flow seems very simple. Simplicity is also a key term in relation to flow in the model of organic growth because certain aspects of the development processes seems simpler compared to a more and more complex world of high-paced and demanding requirements. That is because their key focus is whether they are in or out of flow, and making adjustments when they are not. To feel if they are in or out, they ask questions of themselves, for example "does this feel light or heavy to me?" When they follow questions as simple as this and return to flow when possible, they often experience events in their lives that can be described as "synchronistic" events. Synchronicity is described as "a meaningful coincidence of two or more events, where something other than the probability of chance is involved". To grow organically also means to lean into the flow and not to force it. Events often seem to appear "out of nowhere" to the practitioners, because the practitioners are aware of their own flow, and prioritize breaks and rest when balancing growth processes.

3. Healing: Healing is understood as: to make or become sound again, to transform something in order to become more whole. Healing is paramount in the understanding of organic growth, because healing is what happens when these practitioners do not succeed in returning into flow. Often, they will reflect upon a certain pattern or habit holding them from flow and will chose to heal that when possible. Healing is often associated with letting go, for example of a habit or a thought pattern that is not serving the practitioner anymore. Readiness is important in relation to healing because healing is not something the practitioner focuses all of their awareness toward all the times. They use the word when something happens in life that keeps them away from their flow, for example if a practitioner feels let down by somebody or feels wrong or ashamed, which would be described as emotions outside states of flow. They can realize that a behavior or thought pattern is ready to be shed, and then let go of that habit or acquire a helper in order to let go. The practitioners can also experience what is called "resistance" in the mindset of organic growth, which means that they resist being in flow, or they resist re-entering flow 
and therefore they become aware of the fact that something needs to be healed - to become whole again. With inspiration from one of the interviewees, resistance is used to label every state of being out of flow, because being out of flow means to be "resistant" to being in flow in the theory of organic growth. Flow is thus seen as a "natural" state of being, and healing is what they do to return to that natural state.

4. Trust 2.0: Trust is labeled 2.0 because it represents a whole other level of trust, where the practitioners who grow organically trust in a sort of "next" league - a higher level of trust. They trust themselves, they trust their relationships, they trust the processes they are participating in and they trust the world and the life of this planet. They know that everything is well, and that what happens will be something they can enjoy, or learn from, or heal. The first two properties of trust 2.0 are called acceptance and mothering energy. Together they answer the question of how the practitioners handle challenges and periods out of flow, filled with resistance. When they experience challenges they often handle them by accepting them. It sounds simple but is not always an easy task. To accept what is "in the moment" is the first step towards containing the emotions that are tied to the challenge. Acceptance and awareness are important in that part of organic growth. At this stage of a challenge, the practitioner practices what one called "mothering energy", which is the act and voice of a caring mother, directed towards themselves. It is mild, soft and comforting, and often includes loving self-talk, for example "you did the best you could and everything is going to be okay in the end". Trust 2.0 is also characterized by a deep trust in emergence. The practitioners trust that the right events, ideas and people will emerge in the right time, and therefore do not force growth but accept it when it comes. They have a special openness toward other people, and that openness is tied to their experience of flow. When they are aware of having and producing positive emotions, they are more open, because positive emotions create a more open mindset (Fredrickson, 2009, 2013).

5. Energy: The concept of energy is key because when the practitioners grow organically they are following the specific energetic frequencies of positive emotions. They are aware of human relational energy - a notion describing what happens between two or more people when they exchange "vibrations". Emotions are contagious, and the practitioner has a raised awareness of with whom and how they share their energy, and they use that knowledge when they practice appreciative inquiry because this approach often raises the energy and creates positive emotions among the participants. In order to grow organically they also prioritize breaks and consciously choose who to spend time with and work with in order to protect their own energy and flow feeling. Appreciation, humor and fun are some of the energetic frequencies resonating for the practitioners, and they often prefer to focus on events and people who enhance the vibration of fun and appreciation. In order to grow organically, the practitioners need to be well trained in these vibrations of happiness and thriving because it keeps them in flow; it makes it easier to enjoy the micro-moments and it makes life worth living for them, rather than a hunt for the next goal.

6. Wholeness: Wholeness is an encompassing concept because it denotes the journey for organic growth which is fundamentally a question of being whole. It is not a stressful hunt for wholeness, but the practitioners operate from a feeling and a belief in wholeness. They 
find themselves and everything else to already be whole. This means that they find everything to be connected on a quantum level of life: they feel connected to everyone and everything on this planet. When they feel interconnected instead of separated, it does not make sense to hurt others and their mind is set on helping people out and facilitating positive change processes in order to raise their energy. Interconnectedness is closely tied to love, which is the second property of wholeness. Love is the overall of positive emotions and love is the reason for all actions. The practitioners know this and act accordingly, and that is why love is also paramount for understanding organic growth. Love is understood as the positive emotions that one exchanges within every warm meeting with another human being and is therefore not exclusive to close relationships such as a spouse, parents or children. Magic is the final property of wholeness, and this term only makes sense because the language of organic growth needs to be communicated to readers outside the field of positive change. Magic is used when explaining how these practitioners grow organically, because it does indeed look like magic from the outside. It looks very easy and opportunities arises that they only need "to say yes to" - as one practitioner describes it. When looking at the inside, it is not magical, there is also work to do when trying to remain in - or return to - flow, and some of the practitioners find the work harder the closer it gets to themselves. With acquaintances it is easy to stay in flow, at work a little less easy, with the closest family members it is challenging, and with themselves it can also be challenging.

It is important to emphasize again that organic growth is an ideal way of developing, which means that not every practitioner in the data set expressed every concept, and the development journey is unique for everyone. It is also important to mention that organic growth is the result of how the researcher and the group being studied understand what moves them. In the next section we will look at the spiral of organic growth.

\subsection{The organic growth spiral}

As the theory of developing in more sustainable ways came to life, a language of certain steps of development became important - even though "steps" is not the appropriate word ${ }^{13}$. The picture illustrating organic development was an upward-going spiral, and the steps were specific energetic "places-of-being" called frequencies. The upward, ongoing spiral has been used by researchers in human development, such as Beck and Cowan (2014), building on the works of Graves (1974) and of Fredrickson and Joiner (2002), and is also relevant for the illustration of organic growth. The organic growth spiral symbolizes an ongoing, cyclic, upward spiral these practitioners find themselves in ${ }^{14}$. The organic growth spiral is described as a "learning journey" for an Al practitioner, which means that a "journey" is thus far the best way to describe the development through the spiral, because it is individual, it has adventures, detours and surprises, but also

\footnotetext{
13 This model is developed as an extension of the research results based on the researcher's interpretation of certain aspects of data that seemed to have generic relevance for the researcher.

14 Several voices in the data, also in the observational parts of the study, directly and indirectly refer to development as a cyclic upward movement and one interviewed person articulated this tendency directly, from which this model gained it's primary inspiration.
} 
waiting time (as in airports), queues, bad food or whatever less-than-pleasant events can occur on a trip. Let us look at the illustration in Figure 10.

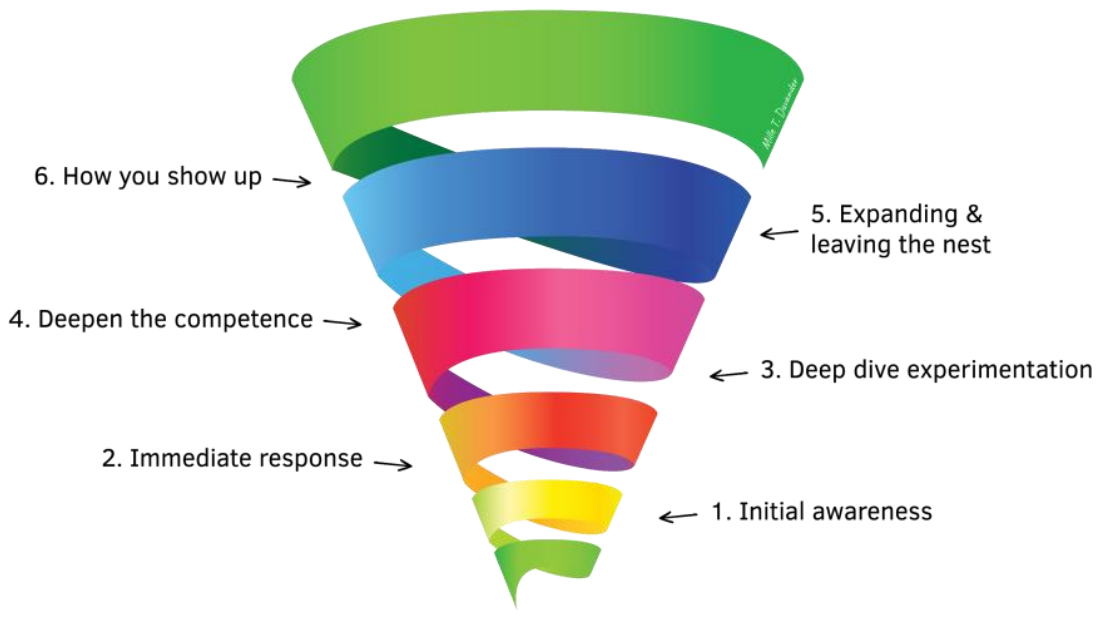

Figure 10. The organic growth spiral ${ }^{15}$

One of the Al practitioners who inspired this model talked about a scale of going from a mechanistic way of being an Al practitioner towards a more integrated, fluent and authentic way. Others have also described how Al can transform from a method to a way of living. This will be unfolded in the following section that can best be seen as an extension of the actual research results.

\subsection{The six frequencies of organic growth}

The spiral has, for now, identified six different "frequencies" which refers to different modes of being when operating. They are not static. They are called frequencies because they point to a certain "energy field" that the practitioners are entering, and they can change from one frequency to another in a second. Over time certain frequencies become preferred, and the practitioners can feel more and more aligned with one frequency, leaving others to fade.

To unfold this, it can be helpful to think about other learning models and about steps that a person goes through, for example six steps, to arrive at the end goal. But since the organic growth is a journey, it has no end goal; it keeps unfolding. It does not mean that the Al practitioners find themselves first in frequency number one and then go on to number two. But there is a tendency to "be" and operate more and more from higher levels of the spiral over time. As with other concepts relevant to organic growth, especially the ones borrowed from quantum physics, it can be challenging to fully understand the talk about a journey with "no end goal". We may have read the words and heard them many times, but to fully accept and understand them can be hard: we as humans have a basic storyline borrowed from the physical world which can be hard to transcend. We start as a baby by being born, we experience childhood, adolescence, adulthood and then we

15 This model is a first illustration of a model describing certain steps. In order for the model and the six frequencies to be validated, it needs to be presented within the community of Al practitioners to be refined and further developed in order to perhaps resonate within a wider audience in the community. 
die. Death is the end goal. This narrative is inherited in our culture and our consciousness. But, as we shall see, this organic growth is really a journey without a goal. In the following, the six frequencies will be elaborated further.

1. Initial awareness

The practitioner arrives at an awareness about the fact that appreciative inquiry exists, and $\mathrm{Al}$ is brought to the consciousness of the person. Maybe somebody talks about it, mentions it, gives the person a book or an article, sends a video or link, or maybe the practitioner comes across it in the social media world. Or maybe a manager or teacher expects the practitioner to know about it. When asked how they first knew about $\mathrm{Al}$, many of the practitioners say that appreciative inquiry found them, rather than the other way around.

\section{Immediate response}

This experience is described as an immediate response to the initial awareness. One practitioner, Carl, says, "When I first met Al in a group dynamics class there was an initial resonance with who I am as a person - I am curious, positive, optimistic and a futurist, asking questions and listening". Convincing has not been included as a theme because, for all of the practitioners interviewed, there was an immediate resonance with appreciative inquiry as soon as they met it. The interviewees described it with statements like: "I've always worked like that, I just did not know that there was a whole theory about it"; "I am very curious by nature and looking for the things that works"; "It was not like I needed someone to convince me that this was a beneficial approach".

\section{Deep-dive experimentation}

The immediate resonance often becomes an invitation to experiment with appreciative inquiry in the practitioner's life, both at work and at home, depending on their situation. The practitioner Thomas mentions that it is wise to take small steps and not go out and try to convince everybody, because they might not be ready. He says not to waste energy on trying to convince people.

In this phase many of the practitioners try out either a task for a course on appreciative inquiry they attended, or they try to ask appreciative questions, or bring them to their workplace, meetings, teaching, employees or colleges. Or they try to experiment with deeper listening, being more curious and asking follow-up questions instead of talking about themselves. Many of the interviewees have positive experiences in this phase: deep and fast positive results, stronger relations, a deep conversation with someone, life in people's eyes, heart-touching feedback from others, a feeling that people have been really seen and heard for who they are, among others. For these practitioners to create experiences seems like a natural choice. As the practitioner Daniel said, "You need to experience Al in order to know it - you cannot just read about it or hear about it to understand it fully". For this to be a deep-dive experience, the practitioners play with it in real life and change small or big things in their lives that way. This seems to be of vital importance for the interviewees and for their organic growth.

In this frequency, many practitioners mention the value of having a practitioner to talk with who is more experienced in appreciative inquiry. There can also be books, videos or like-minded practitioners to connect with via social media.

\section{Deepen the competence}


This frequency is often self-directed, as the practitioners often want to become better at what they are doing with Al. They express a wish to sharpen their competency and gain more knowledge. One practitioner, Carsten, says: "I needed to follow that call, that inner voice of mine, saying that I should take the training at Case Western Reserve University with the originators". Several express an urge to know more, to read books about it, to attend conferences, to talk to like-minded people, to hear cases and stories where appreciative inquiry has been used in fields other than their own around the world. One describes it as consciously thinking about how this works, why it works, where it works, supplemental approaches, methods to help scaling up, new areas to apply it, and other thoughts and questions that arise.

\section{Expanding and leaving the nest}

Some of the practitioners talk about "leaving the nest"; because they now own their own voice; they sweep into the identity of an Al practitioner. They stand on their own feet. Some have done that all along, especially those working as consultants or leaders, who do not share the experience of leaving the nest because they might be strong leaders or managing their own consultancy and maybe training other leaders. Some recognize this frequency as being more subtle and say they felt it very early on. They say that it is the feeling of succeeding in understanding the mindset and the principles, and being able to work from them, designing tasks, processes, courses, teachings and meetings from this mindset. They own the tools and the mindset and are able to carry them out independently. Whether you have learned from books, audio, video, courses, experienced AI practitioners - this frequency is about letting go of the "teacher" to find your own way of doing it. For some practitioners this frequency also represents a state of being proactive, seeking out their own network, expanding their own work, taking responsibility for their own learning and stepping into a sphere with even more self-agency.

\section{How you show up}

As the spiral expands in wider and wider circles, many of the practitioners mention a common frequency in later phases of their career called "how you show up". This frequency has been given different names by the practitioners: authenticity, integrity, embodying, a way of being - and it refers to a state of being where appreciative inquiry is a part of their being and they cannot or will not "take it off". Al is their preferred way of showing up in the world: to be curious, to listen, to ask questions and to change the perspective to focus on what gives life. The practitioner Christian says: "It is just how I do things".

The journey of the Al practitioner is individual, and this model suggests one articulated perspective on that journey. Not every interviewee follows these frequencies, but most probably recognize several of these steps. As the practitioner experiences and experiments more, they let go of the more mechanistic ways of doing appreciative inquiry and challenge the rules to find their own ways. A development has occurred, and the process has affected the practitioner.

One of the most important things is that they treat themselves kindly as they experiment with the different frequencies, and from the data it seems that the most important thing is to enjoy the journey. Most of the practitioners know that they want to develop but that there is never an end point where they will have completed their journey. They have realized that enjoying the journey might as well be the most important thing. The practitioner Christian responded like this when reflecting on the notion of "organic growth": 
I love the notion of organic growth, because it points to a more fluent flow, like an almost "natural" human and professional growth process of the authentic Al practitioner. The opposite is a mechanistic way of growing, where processes are controlled and forced.

Along with the umbrella model and the organic growth spiral came a new term describing the kind of consciousness characterizing these practitioners. In the following section the concept of quansciousness will be outlined.

\subsection{Quansciousness}

The notion of quansciousness emerged in the interplay of the research and the participants, and is a way of describing the awareness of the practitioners in the group when growing organically in an ideal fashion ${ }^{16}$. The concept describes the kind of consciousness these people have, inspired and operating from quantum wisdom. Quansciousness is quantum consciousness and, having this awareness, actions in line with quantum understandings follow. Quansciousness is lack of egofear, it is trust 2.0, it is to live from an understanding of wholeness that means never to harm anyone else and always cherishing what is good for the planet. It is knowing the unique contribution, purpose and talent for oneself, and having the courage to live it and to be vulnerable. It is being aware of emotional states and vibrating from the highest energetic frequencies by having fun, playing, being open and curious, and showing love for every small and large unit ${ }^{17}$. The purpose of suggesting a new notion is to give language to this particular awareness, and an approach to be able to invite others into this kind of being ${ }^{18}$.

\subsection{The celebration of the other}

Twenty years ago, humans could still be alone with themselves, traveling to distant places without connections to the family or the world. Today humans ARE relationships, because they are constantly communicating through what is many people's most prized belonging: the smartphone (Dickow, 2017). If humans are "only" our relationships, they might not be able to inquire deeply into the importance of the relationship to themselves. In this study, it was found to be more likely that they, besides their core relational being, found their body to be "real", and that the power and energy they felt within that system were important to use in their everyday lives. Most of them also had an understanding of wholeness which was both regarded as wholeness within their bodily system (billions of cells collaborating and communicating), but also that they felt like they were a part of a wholeness of all people and all other things on this planet, according to their understanding of wholeness. Because of this - for them - important understanding, it became useful to propose a meaningful notion for the single bodily system, the individual, the "self" in

\footnotetext{
${ }^{16}$ The concept seemed to be important for the practitioner's state of awareness and stood out as an important interpretation for the researcher and therefore not necessarily important for other researcher conducting the same study and approach.

${ }^{17}$ Again, the model of organic growth is an ideal model of development and therefore something to thrive for, not a model that mirrors the actual social world.

18 The purpose of including a short note on this concept is partly to pay tribute to the practitioner's creative unfolding and give an example of how they co-create (with fun and play) and also to pass on a possible new part of language which can give possible new actions - which again is part of the purpose of this study. To be further validated it needs to be tested out in the larger community of Al practitioners.
} 
complete connectedness. And there is one vital reflection on why such a construction may be important for the practitioners: This may only be a need because this group of practitioners acts in a world where most do not operate from a relational being. "This dialogic turn transforms the dominant project of the Western world, its self-celebratory, other-suppressing stance, into a necessary celebration of the other" (Sampson, 2008, p. 98). Sampson emphasizes the value of a relational approach to life and pays tribute to the conversation. The Al practitioners in this set of data are living in a relational- and wholeness-oriented way, while operating from a state of being founded in their physical body. How can this be captured? The next section includes the proposal of another new concept.

\subsection{A new concept of the individual}

This study has suggested, at least to me, that a new word for an individual human is needed ${ }^{19}$. It is clear why some would like to focus more on relationships, communities and institutions, because the concept of the individual has so many layers to it, many associated with an egoistic and narcissistic approach to life. Hence, it makes sense to create alternative ways of being.

But maybe it is time to renew the construction of the individual and the self, and to create a new meaning and understanding of the micro-level system ${ }^{20}$. Human beings are valuable and powerful. Maybe it would be of benefit to have another word better matched to those new and future times of quantum understandings, relationships and large-scale change processes.

The proposed construction for the new form of being a relational, whole system being is viveunia. The word is constructed from two ancient words roots, one the Latin vivat (vive, vivo, viva, vivi) which all means alive, live, lively, "live long". The other is the Greek word eunoia, which is a phrase in rhetoric which points to goodwill, a form of receptivity that the speaker creates between the audience and herself. Eüvold is the Greek root word and that means "beautiful thinking" or "wellmind". According to Romilly (1958), eunoia means approval, sympathy or readiness to help and describes a good feeling towards a person or a city. She also claims that eunoia is the opposite of fear. Aristotle made use of the word when he spoke about how a spouse has loving feelings that help form the basis of ethical foundations in life. It is also a rarely used medical term referring to a state of normal mental health, which makes good sense in relation to this actual intended use.

The meaning of this fresh concept of viveunia is that it characterizes what in earlier times was called the individual or the self. But in the understanding of it lies a deep understanding of wholeness that can mostly be experienced as and is associated with a consciousness level where high levels of trust and relatedness are deeply rooted. Viveunia is "life", lively lived and being alive as a single person-system with a glow of wellbeing, trust and celebration. It is a connection-based

\footnotetext{
19 The need for this concept development is also an interpretation of the researcher, chosen as important when working with the group being studied and when memoing in the memo bank of the data.

20 The main purpose of creating a new word addressing an individual is partly to acknowledge that there may be new ways of being and relating if a new word is introduced - ways that may be more collaborative and caring instead of cherishing egoistic wins: And partly to build new language to help support the rather new approach which future-forming research represents.
} 
entity that is playful, helpful and lovingly related to the surroundings. The viveunia bears value in itself, and at the same time plays a significant role of contribution to the whole.

"Relational processes construct both stability and change: they may close down or open up possible selves and worlds" (McNamee, 2010, p. 13). Selves and worlds are here written easily after each other and it is a reminder of how both constructs can open up and close down - and be experienced and constructed in multiple ways - and how the self can be seen as just another world. Looking at the bacterial level of the body's system, humans are not in charge of their body the bacteria are! If there are an imbalance, humans have no control. Bacteria decide whether humans need to visit the toilet sixteen times a day in a week - and the human cannot do anything else. It is a whole world.

Social constructionism would say that our words create worlds. So why not create a world where the construct of the egoistic individual slowly dies as we begin to develop a new understanding of human beings? Viveunia could be a term allowing human beings to be more kind, more generous, more loving, more whole. In the field of quantum physics, physicists work with a definition of a relational - and spatial - whole system when describing the individual:

(...) the quantum world view stresses dynamic relationship as the basis of all that is. It tells us that our world comes about through a mutually creative dialogue between mind and body (inner and outer, subject and object), between the individual and his personal and material context, and between human culture and the natural world. It gives us a view of the human self which is free and responsible, responsive to others and to its environment, essentially related and naturally committed, and at every moment creative. (Zohar \& Marshall, 1990, p. 220)

In this optic, relationships are seen as the basis of all that is. It points to the fact that everything is related and works with the individual as a separate unit. Not in spite of, but because of. Gergen developed the idea of the relational being in opposition to that of the "intervention" of the individual mind developed during the Enlightenment period, because the latter notion caused humans to think and act in terms of separation, which eventually caused human lives to include "Alienation, loneliness, conflict, self-doubt, selfishness and manipulative relations..." (Gergen, 2009, p. 397). But instead of being angry at former ways of being, speaking and thinking, he gives credit to the process and emphasizes that this account prepared the way for the relational alternative ${ }^{21}$. The concept of viveunia may contribute by providing language to making it easier to practice relational being while having a corporeal body.

Having shown the chosen important findings and interpretations of the study, the next chapter will discuss points raised by the new "theory" of organic growth.

${ }^{21}$ Gergen claims that the smallest entity is a relation (Gergen, 2005). This can be hard to understand when we see the physical boundaries of bodies moving around. If we combine the constructive assertion and the physical perspective, then we may help guide new actions with this concept. 


\section{Chapter 8: Discussion}

In this chapter the full idea of organic growth will be discussed, new questions will be raised, and the following headlines will be touched upon: the effective society, the new understanding of the self, academia and the shifting roles between social constructionism and appreciative inquiry. First, a discussion on effective societies.

\subsection{The birth of a word in an effective society}

The capitalistic framework has been used to characterize the kind of society many Western cultures belong to in the present period of history, and effectiveness is one corner stone. There is no doubt about the fact that this framework has contributed to most of the health and wealth experienced in many Western countries. We owe a lot to this approach and we need to celebrate the richness of what we get from this and ensure we carry the best of this into the future. Adjustments to this approach may also bring value. A problem with an effective society is that as soon as a concept is created or redefined, there is a tendency to associate it with a wider discourse in society saying: "how can this concept help us get smarter, get richer, get more collaborated, get the results faster and help us focus on optimizing and being as effective as possible". This both mirrors an eternal longing for growth and expansion and shows how new concepts can be used to add pressure.

Organic growth is not about being effective, although that is possible. It is not about doing something to be more resilient or robust or feel better in order to return and work harder and be more effective. It might be a side-effect, but it is not a goal. Going through some of the dimensions of the model of organic growth, e.g. flow, trust, balance and wholeness, it is easy to think that once humans work to master these, they can be more effective. It is almost like humans can't think about concepts such as intuition, synchronicity, heart-based decisions, meditation etc. without thinking of a goal. To set goals can be very helpful. Working towards goals led by an outside society without working from a heart-based intuition is not compatible with this understanding of organic growth.

A thought experiment could be fun here: How will the world look beyond our current society? Can we imagine that? Is there peace and collaboration? Respect for diversity? A green planet in a blue universe? Shared language and different voices? Healing happening naturally without drama in everyday life? And what are the helpful forces of our current societies when creating the next? These are all interesting questions and the next would be: Where is this already happening? And where are old economic forces now working towards sustainability, wind power, solar cells, clean oceans and saturated people?

A voice in the data stated that change will not be a revolution - it will happen slowly and organically, and that the "old dinosaurs" of business will hold on as long as they can until the pain becomes too obvious. The next discussion point will focus on the question of humans and how they are wired. 


\subsection{Negativity bias or wired for the positive?}

Throughout the analysis, there has been a question whether human beings have a negativity bias or whether humans are wired for the positive. Two different Al practitioners participating in this study point to two different perspectives toward human preference in attending to awareness, to what is called negativity and positivity. Thomas talks about the negativity bias and refers to the work of Fredrickson $(2009,2013)$ and states that the brain works like velcro for negativity and like teflon for positivity. He says, "this is what research says that we are up against". Fredrickson $(2004,2009)$ describes humans as having a negativity bias, tracing it back to our historical roots. Humans living among dangerous animals had to develop a mind that would always "prefer" to be aware of danger first. The essence of this understanding is that if a human is confronted by a tiger, there is no need to think about being hungry, needing to pee, who to have sex with or where to sleep next. The brain shuts down some feelings and narrows the sight, as Fredrickson described with her broaden-and-build theory (2004). To survive, it is very smart to focus on what is dangerous when there is a threat. In modern society humans rarely confront a tiger. The function of the brain in narrowing down focus onto the danger is sometimes a malfunction today, because the negative emotions are not the preferred state in most situations. The result of this current study shows that the Al practitioners often succeed in broadening their sight.

Another practitioner, Carina, stated: "Human beings are wired for the positive. That is our natural state of being. That is the preference when you are a child, before you are introduced to 'dangerous' things in the world". This is her strong belief, and she lives from that understanding. From a social constructionist standpoint, the question is, how do either of these help humans as a species? How does the story of "the brain works like velcro for negativity and like teflon for positivity" help? If it can help humans be easier on themselves, if they accept when they do not succeed in being positive or being in the flow - it might be helpful. If humans by knowing this can give themselves a break, saying "Well, my brain is designed that way - it is not me that there is something wrong with", then they might find it easier to go back into flow, because they are using positive self-talk, and therefore manage to feel acceptance and even love for themselves and therefore return to flow. But that notion could also have another perspective: if there is an evidence-based researcher's words for the fact that humans focus more on the negative, might that become a collective belief which humans then start to live by? Maybe that would create more brains wired for the negative? On the other hand, how will humans act if they live by the notion that humans are wired for the positive? These questions will be left open for further discussion. The next point of discussion is social constructionism and appreciative inquiry.

\subsection{Shifting roles: Social construction and appreciative inquiry}

In the social scientific world of Western countries, there has been a tradition where a specific metatheoretical direction or philosophical arena has guided the way for theories closer to practice with works of, for example, Immanuel Kant and John Locke. The greatest recognition so far might have been for larger meta-theories that tried to grasp what the world is and how humans can interact with it. Why? Human beings like meaning and order. During the period of conducting this research, it came to seem that social constructionism would take the place of the meta-theory, while appreciative inquiry would occupy the position as the theory closer to practice. 
This study shows that social sciences are headed in a direction where practice has a higher status and plays a more important role. These Al practitioners act according to practice in their everyday lives. They know that it can affect their lives, how they speak about certain things, but they also know new questions keep coming to life. They practice appreciative inquiry because it works for them. And it is the practice, not the ideas, that count. Following a social constructionist perspective, they could keep on asking if what they were living was right. And they more or less do, but on a practical level. They live their life every day. They act, they interact, they communicate, they adjust, they fail, they try. But they do not question the basic principles of appreciative inquiry every day. If we build a practice where we need to question life in philosophical terms every day, then what about being present in the life we live?

They are not writing about life, they are living it.

The roles are shifting. Great social theories that address "everything" in life are not close enough to the diverse practice. For any one of the Al practitioners in this sample, life is a mystery to embrace and they keep working with that mystery every day. The roles are shifting, and the practical theories are now moving into the front seat. New philosophical thought traditions have given us many good things, but also work that has been less beneficial, e.g. the atomic bomb. They have also provided the thought frames which may now be causing many people pain and suffering, though they have also helped even more people into wealth and health. This is not said with guilt, shame, blame or critique. Humans could not have been without any of these thought frames, which allow them to stand where they do today. It does not make sense to reduce recognition of historical contributions just because humans are expanding the use of other terms these days. They are to be celebrated.

Studying these Al practitioners, it was clear that they are practitioners: learning, doing, sharing, living, in practice. Appreciative inquiry has, in that sense, transcended the scientific realm and become an important guiding star for practice. Not something that needs to be measured or reconstructed or generalized or validated. It just is what it is. It signals a shift from outside measurement to following the pull of life and trust in a stronger way. That is a new way of thinking and of approaching life. Some may not resonate with that and it is not for all. But the values that these practitioners share may be shared by many human beings. The simple things: love. Curiosity. Trust. Connections.

Is appreciative inquiry the story of a movement that has outgrown its shoes? It was born as a change management theory and method, but it contained a shift in the perspectives of worlds, which transcended what is normally expected from a change management theory. It transcends boundaries. What will the future questions be? How does it give language to other change movements? How can it facilitate the collaboration of many world-changing movements? What is the role for $\mathrm{Al}$ and $\mathrm{Al}$ practitioners in the future? What are the lifegiving aspects for people not resonating with $\mathrm{Al}$ ?

These questions will be left for further discussion. The following section will be used to expand key reflections about the implications of this study, as well as pointing toward further research possibilities related to organic growth. 


\subsection{Assessing a grounded theory}

In this section, the grounded theory of organic growth will be assessed based on the four original criteria of grounded theory (Glaser \& Strauss, 1967; Glaser 1978). The quality of grounded theories varies due to methodological thoroughness, how incisive the analyst is and how good the research questions are (Holton, 2008). Charmaz (1994) argues that to be able to assess these areas, the principles need to arise from within the logic of the approach itself and not from other research paradigms.

The four original criteria for assessing a grounded theory are 1. fit, 2. work, 3. relevance and 4. modifiability (Glaser \& Strauss, 1967; Glaser 1978). 1. Fit is used to assess the extent to which the concepts and categories emerge from the data or are reused from extant theories. 2 . Work refers to how well the theory explains behavior in the group of people being studied. 3 . Relevance is the question of how relevant the new theory is to the core concern of the population being studied and is judged by observing how grounded the theory is in data and in the substantive field. 4 .

Modifiability is the theory's ability to adjust and modify itself to new data as time goes by so that the theory continues to be relevant for the practitioners.

1. Fit: All of the concepts and categories in organic growth emerged from data, yet many of the concepts are words known from pre-existing theories, such as flow, consciousness and balance. Flow is in this study understood in a way that differs slightly from Csikszentmihalyi's original understanding (2014), where e.g. balance is understood by Csikszentmihalyi in a way that aligns more with common, everyday use of the term. Key concepts such as energy, consciousness and wholeness already have meanings attached to them, many from quantum theories, yet the understanding of, for example, energy in the theory of organic growth varies from common understandings of the concept. One can discuss whether the number of new words and concepts coming from the data is great enough and also to what extent a study makes sense if the whole new theory is compiled of unrecognizable words. In the practical settings of this study, I have tried to stay true to the concepts which became saturated first and most, even though many words already existed. This did not correlate with my preconceived understanding of what a good theory would be, as mentioned earlier, but the value of following the method in a systematic way was more heavily weighted. The word healing also became saturated, but again was understood in another, "lighter" and "more common" way, associated with the simple act of letting go of something. The same goes for trust, which was originally understood in a "classic" way from pre-existing theory, but which through the data process turned out to be practiced in a significantly extended version by the practitioners and therefore was named trust 2.0. In general, I found the concepts of the theory of organic growth fit each other in a way that makes the whole theory dense and nuanced.

2. Work: Does the theory of organic growth succeed in explaining and predicting future behavior? The Al practitioners may be the right people to answer that question, but it does give a "full" view of the ingredients of organic growth. It would probably be wrong to claim that this theory is able to predict the future. Because these practitioners are innovative and 
create changes within a single human system of life, another theory with other concepts that are relevant to describe developmental processes may arise in the future.

3. Relevance: Looking through this set of data, the theory of organic growth is assessed to be relevant, because the Al practitioner's main concern is how to develop in balanced and sustainable ways. They are highly concerned with how they grow and develop themselves in order to stay authentic to their field, customers, students and collaborative partners. They are also concerned with how to become more whole as a micro-system by letting go of old habits, because wholeness is key for them. As with every grounded theory, another researcher could enter the same field and the outcome could be a different grounded theory of that same field. The notion of balance did seem relevant, too, for these practitioners and for other similar practitioners, an important result in the light of the dysfunctional stress-related diseases in the Western world.

4. Modifiability: The possibility of adding or changing the concepts of this theory has already been shown: see the model of "the Earth Bow", demonstrated on page 141. In this model, the key concepts have changed their places but the meaning of organic growth and its dimensions remains consistent. The theory of organic growth is fluid and evolves as this thesis is sent to the interviewees participating in this study and, after, to every Al practitioner interested in reading or skimming through it. The theory will probably continue to be adjusted and rearranged in order to continually stay relevant.

The responses I have had to the concept of organic growth and its dimensions have been positive, and several participants have mentioned that the concept resonates with their understanding of their development processes. In March 2019, I gave a presentation of the theory for people representing the group studied at the World Appreciative Inquiry Conference in Nice, France and received an immediate response when the participants giving feedback said that it resonated with their understanding of their own development processes and fundamental mindset. I have yet to receive further feedback on the concepts so that the current formulation may deepen and be extended or nuanced in future. 


\section{Chapter 9: Implications and further research}

Implications of organic growth are tied closely to suggestions for further research, because when discussing the implications of this study, it is clear where further research is needed. Implications are first and foremost relevant for the group of Al practitioners and, more generally, the group of positive change practitioners. It is a hope for this study that the language of organic growth will resonate within the population in a way such that the practitioners will be even more aware of their own growth processes and the possibility for enhancing their development processes to become even more organic and balanced. If this is part of a practical result of this study, then it may help the practitioners to shine even more and, by that, keep reigniting them to inspire others around them - clients, colleagues, customers, students, children, family and friends. A further possible implication is that of the Al practitioners directly using the language and models of organic growth when guiding positive change initiatives.

The grounded theory of organic growth has been designed for and with AI practitioners, and it was not the purpose of this study to inquire into the possibility of organic growth being relevant for other groups. Further research is required if that question is to be addressed. Three areas outside the field of positive change have been selected as being relevant when discussing implications and further research. These are: 1 . questions related to identity research and emotional development, 2. implications of organic growth in education, and 3. possible benefits for employees in organizations. But first is a summary of the contribution organic growth makes to the scholarly field of learning theories showing where the theory belongs.

\subsection{Implications for the scholarly field of learning theories}

In Chapter 6, the connections between related literature and organic growth were made clear. This section will elaborate on these considerations and outline how organic growth adds to the three learning theories in question: social development theory (Vygotsky, 1978); the theory of ecological systems (Bronfenbrenner, 1994); and the social cognitive theory (Bandura, 1977). The section will conclude with a comment on the general contributions made to the field of social learning.

Vygotsky's theory about social development is similar to the model of organic growth because of the core assumption that relationships are vital for learning and development processes. Organic growth accords with that belief. What organic growth adds to this theory is the quantum inspiration: the idea of tapping into a stream of energy to follow the energy - via intuition - to flow and to act from this inspired place. The quantum understanding of energy adds to the understanding of human development by providing the dimension of the micro-moment and emphasizes the importance of sensing and following the energy in these micro-moments for continuous flourishing and learning.

Organic growth resonates strongly with the work of Bronfenbrenner because of the understanding of ecological systems; organic growth adds to this by placing emphasis on the experience of wholeness. This can be compared to the picture of the astronaut seeing the whole of our planet from space for the first time. This powerful experience of connectedness and wholeness can perhaps only be obtained when seeing the whole picture with one's own eyes, yet this 
understanding of wholeness on a cellular level is what the Al practitioners live from and is fundamental for organic growth.

Bandura's social cognitive theory posits that the individual human system has influence over its own development processes and can choose the belief systems and behavior that are a good match, while at the same time being influenced by surroundings. This fits perfectly with the understanding of organic growth, where the practitioner can also have the possibility of choice and can adjust behavior and thoughts in micro-moments. Organic growth adds to this theory mainly through the concept of trust related to that of wholeness. In organic growth the single human system trusts in a profound way, and in a way that goes beyond what is normally understood by the word "trust". This is a trust that life will find a good way to unfold for the person as a part of the whole, a trust in the whole, a trust that everything is connected and everything happens for a reason. This makes the practitioners growing organically take $100 \%$ responsibility for their own lives and adds to Bandura's understanding of a person's influence over their own life. When taking full responsibility for one's life, complete freedom emerges, allowing the individual to create freely what he or she wants, while still adjusting to contrasts and challenging life circumstances and healing important patterns when they surface.

The key contribution to the field of social learning theories in the big picture is the quantum perspectives of energy and wholeness. Organic growth provides quantum understanding of human development, where everything is energy, and everything is connected to everything else. When following organic growth, the group being studied showed a high level of flourishing and many, many micro-moments of being in a state of flow and fluid happiness and satisfaction.

\subsection{Identity and emotional work for appreciative inquiry practitioners}

One perspective within organic growth is the point about the practitioner's journey of learning more about who they are and what their preferences are, and how this is reflected in the environment. This is most clearly seen in the frequencies of the organic growth spiral and is articulated in the phrase "this is how I show up in the world". This theme about identity calls for a range of new questions inviting further research:

How is organic growth related to identity? Do Al practitioners only mirror who they are when they are in wider frequencies of organic growth? How do they become more aware of who they are? Does everyone reflect who they are in their surroundings? How do minds create worlds? If minds do create worlds, what is co-creation?

This leads to a related topic, touched upon in the analysis chapter on flow, about the power of pull. Clearly resonating with organic growth, Hagel et al. (2012) describe how to live life from an orientation of pull in opposition to the actions of forcing and pressure. In ideal states of growing, it is beneficial to be led by this kind of pull, by being aware of emotions in the micro-moments, adjusting towards states of flow and following the intuitions and that "pull". To be able to follow the pull requires emotional work. The authors describe how it requires a shift to be able to respond to a pull and how such a shift demands emotional work in a way which many realize they are not ready for. In organic growth this is where the notion of healing comes in, because this exactly describes how one needs to be able to let go of habits or thought patterns in order to act according to pull. 
But even though healing is part of the answer in this case, the emotional work pointed out still inspires new questions, inviting further research: What kind of emotional work is required? Why would Al practitioners be more ready than others? What kinds of ways are possible to let something go? What happens when old habits die quickly?

There may be many implications for organic growth because of its essence as a theory of human development. The implications presented in the following are within educational and organizational settings, because these two areas could have obvious benefits: in education because children early on could keep following their own flow, listening to their intuitive voices, acting towards pull and living and learning with the possibility of a more balanced life. This could lead to fewer diagnoses of stress, anxiety and depression in adolescence. In organizational settings, organic growth could be another way to flourishing for employees in order to cease stress or other overload-related health issues.

\subsection{Organic growth in education}

Something happens on the way from the free, playful childhood many people have to adult life. Most enter an educational system where children do what the teacher says and do not follow their own flow. Children often have enormous inquiry capacity and curiosity. They explore everything, and they have fun. When children have been attending school, in Denmark at any rate, for six or seven, eight or nine years, many become what is called "school-tired". To address that phenomenon, we have developed theories and terms like "motivation", "flow" and "zone of proximal development", to create environments which get children back into what is fun in order to learn (Vygotsky,1987; Csikszentmihalyi, 2014). Somehow, the Al practitioners in this set of data have managed to keep or retrieve a connection to what is fun.

Organic growth adds to these models of understanding human learning by integrating ideas of healing, intuition and wholeness. Following this theory, the educational system would need to develop new ways of teaching. These would take into account, for example, breaks in order to ensure balance, a variety of different learning styles to ensure ongoing flow-invitations, play in order to legitimize healing, love and support, as well as the training of positive self-talk in order to develop a higher level of trust, acceptance and openness. It would also require teachers to introduce knowledge about the energy existing between people. How to take care of this energy, how to raise vibrations together and alone, by appreciating and having fun, for example. Finally, it would take the wisdom of quantum physics to create an understanding of interconnectedness and love. Many of the points would be the same for preschool teachers and children, and therefore this model and mindset could have positive implications in the area of preschools and kindergartens too.

The above description is based upon the teacher's work arena, which may benefit from the language of organic growth, depending on the individual teacher's readiness or match. There are several other levels where implications of this "approach" would be strong and create vivid change: if, for example, networks of school principals decided to create buildings and structures to support this kind of growing, and policy makers in a particular country chose to set goals and curricula for teachers' and students' organic growth processes. As such, organic growth would contribute to the 
emergent field of positive education. An exciting subject for further research would be to inquire into schools and teachers already operating this way, with questions such as: Who are they? What do they do? What are the benefits? What practical solutions have they developed? In the next section we will seek out possible implications for people in organizational settings.

\subsection{Organic growth for employees}

In an organizational context, organic growth may belong to the area of Human Resources and the primary implications may be to prevent employees from becoming stressed, because balance and breaks are built into the working context. When flow is a word in the shared language of managers and employees, it is also possible to try to meet the strengths of the employee and design, or hand over, tasks inviting the employees into flow, at least at some points in time. This can create better thriving and therefore happier employees who may make more significant contributions. When healing is a legitimate and common term to discuss in the workplace, people may be able to share openly their resistance to change or towards challenges, while having the possibility of feeling safer and attaining specific help with letting go of beliefs or energy blocks within the body. A workplace providing the amount of trust that is described in this model would also most likely benefit from the atmosphere in the workplace. Many workplaces already work specifically with trust. An implication could also be that the workplace chose to integrate the voice of the "mothering energy" and create an even more nourishing and supportive culture, where people were invited to make mistakes and encouraged to try out ideas that were not perfect in order to be creative and innovate. Many organizations already have such elements integrated. A language around human relational energy in the workplace may also cause a higher awareness around the individual's and others' energetic levels, as well as a focus upon how, for example, appreciation, humor and play can help raise the energy level in the room. To organize the workplace on a foundation of wholeness could ensure a feeling of interconnection and equality.

As was previously stated, further research is required into these alternative contexts to test, for example, how a school or an organization is changed if organic growth is in place as the basic assumption for human development. This allows us to reach the final chapter, where the conclusions of the study are presented. 


\section{Chapter 10: Conclusions}

You may say l'm a dreamer. But l'm not the only one.

John Lennon

The initial curiosity in this study was to learn about positive change practitioners. The specific population, who are inspired by the positive change approach appreciative inquiry, were chosen because of their focus on relational aspects and the inspiration from social constructionism. A core motivation was to study how they learn and share with each other in online and non-online communities of practices. It was centered on their relational learning and sharing in the global appreciative inquiry community - a community of practitioners which has numerous conversations online and courses, conferences and gatherings in physical settings.

Grounded theory was chosen as methodological approach because of the wish to create a theory about these practitioners which resonated with them. The main concern of the population was a theme called organic growth - a concept pointing toward their personal and professional development. The group works from a fundamental orientation of relationality and wholeness, which means that they do not understand their own personal growth as being individualistic, egoistic or selfish. Instead they operate from an understanding of being one "system" which is part of many "systems" in different sizes from micro-bacteria to cells, human bodies to organizations, countries, planets and solar systems. This resulted in a theory of the "single micro-system" called a human and the journey taken throughout life.

\subsection{The organic growth of the positive change practitioner}

The "theory" developed in this study is called "the organic growth of the positive practitioner" and organic growth is the core category. Six dimensions support and unfold the core content: 1 . balancing, 2. flow, 3. healing, 4. trust, 5. energy and 6. wholeness. Together these form the complete theory at present, and these dimensions will be summed up following the definition of organic growth:

To grow organically as a human being means to develop in a sustainable, flourishing way toward enriched consciousness, increased states of flow and more fulfilled wholeness in balancing, lifegiving processes.

What is most important to know about the theory of organic growth is that every developmental journey is unique and therefore it does not make sense to compare one growth spiral with another. Organic growth points to learning processes in individual human beings who work with positive change and who grow in sustainable ways. When growing organically they generally:

- Work from their purpose;

- Are aware of many micro-moments in the day to ensure they are in flow;

- Adjust when they are out of flow;

- Listen to their intuition;

- Take breaks; 
- Act according to their intuition;

- Accept the many firsts they go through that they have never tried before;

- Have a "mothering" energy towards themselves;

- Accept the journey and the fact that it is their own;

- Invite in opportunities to learn and take responsibility for integrating the new learning;

- Are aware of self-talk, both positive and negative.

The communication of organic growth can be represented by an umbrella model showing the six dimensions of organic growth and the themes important for each (see section 7.2). It also contains a spiral model with six frequencies to show the journey the positive practitioner often follows (see section 7.3). In the following, the six dimension and their relationship to the core concept of organic growth will be summed up.

\subsection{The relations between organic growth and its six dimensions}

Organic growth is tied to the six dimensions and their properties, which are described in detail throughout the analysis. Organic growth is regarded as an ideal, which means that no single practitioner showed all of the characteristics and the theory is an idealized one. Together, their voices formed a theory with resonance within the community of practice of Al practitioners.

Balance is the first dimension, and organic growth is related to that notion because balance is crucial for organic growth such that the practitioners need - sometimes momentarily - to be in balance, to seek balance and experience balance. If the practitioner's life is characterized mainly by unbalance, it would be for a specific period of time, and the individual most likely would seek to return to or obtain balance when possible. In the ideal understanding of organic growth, "balance" would describe both the state of being in balance or seeking balance by adjusting frequently in micro-moments. Both are acceptable and possible.

Flow is the second dimension, and organic growth is related to flow in a similarly crucial way, because when growing organically the practitioners are aware of their own state of being in micromoments and know that flow is important to them. They check in often to see if they are in flow and, if not, they try to adjust in order to return. Flow is described as a feeling of being in the moment and losing track of time while feeling good. But it is not exclusive to specific individuals, moments or activities, and it is not reserved for high positive emotions; it can also occur in states of satisfaction or relaxation.

Healing is the third dimension and is related to organic growth in that, when the practitioners find themselves out of flow from time to time (or sometimes for longer periods of time), they become curious about that situation and they open up to healing patterns, thoughts or behaviors. They hold the belief that if they are out of flow, they must be hindering themselves, and what is hindering them may be thoughts or behaviors which no longer serve. They become aware that they might be ready to let go of something that has been valuable but no longer helps. As with the concept of flow, healing - in relation to organic growth - is not exclusive to specific persons or environments; as one interviewee put it, everything can be used to heal. 
To grow organically requires a deep sense of trust, making trust the fourth dimension, a trust so extensive it has been called trust 2.0. The practitioners show exceptional trust in themselves, in life, in their development processes, in their relationships - and in the world, basically - in a way where fear is almost left out of the equation.

Energy is the fifth dimension, related to organic growth because of a certain awareness and sensitivity toward personal and relational energy, as well as the energy of the environment they are a part of. The practitioners let that energy guide them and their actions when adjusting into flow. Growing organically requires an openness toward wholeness, which is the sixth and final dimension of organic growth. The practitioners demonstrate how they find everything to be connected to everything, and they operate from a state of connection, collaboration and love.

Organic growth was born out of a curiosity toward practitioners working with the positive change approach appreciative inquiry. It turned out to have the possibility of being a valuable language in the discourse around stress and work-related mental diseases, because it provides an understanding of how to live a balanced life, moving toward higher states of flow with greater consciousness.

To create future-forming research with this study has been an adventure, and to interact and cocreate with the group of practitioners has been fun, rich in learnings and valuable for the researcher. Following organic growth, we will deeply trust the process from here and hope for many magical rings of influence in practical settings, in research, and in everyday micro-moments of endless and breathless joyous journeys.

\subsection{Perspective - knowledge is process}

During the final weeks of writing this dissertation, a new way of presenting the dimensions of organic growth emerged. This was a clear sign that knowledge is always in process and that just because this research project had been written down and communicated in a specially chosen format, it does not mean that it will not keep expanding both in insights and in ways of communicating. This new concept is called the Earth Bow and is another way of ordering the dimensions and properties of organic growth. These dimensions and properties are almost the same, but they have been placed in a different order (see Figure 11). The understanding this concept brings is a valuable piece in organic growth because it emphasizes humility and respect towards the Earth in relation to wholeness and points to the importance of relations, connections, and also of a conscious mind. Together, they take care of the planet. In this perspective the microsystem of the human is still important and powerful but has a profound respect for the whole of our planet and our universe.

As noted earlier, the concept of "the Earth" is chosen by me to capture the approach the practitioners show towards their life and work where wholeness is essential and where they sincerely respect our planet as a system we all are a part of. 

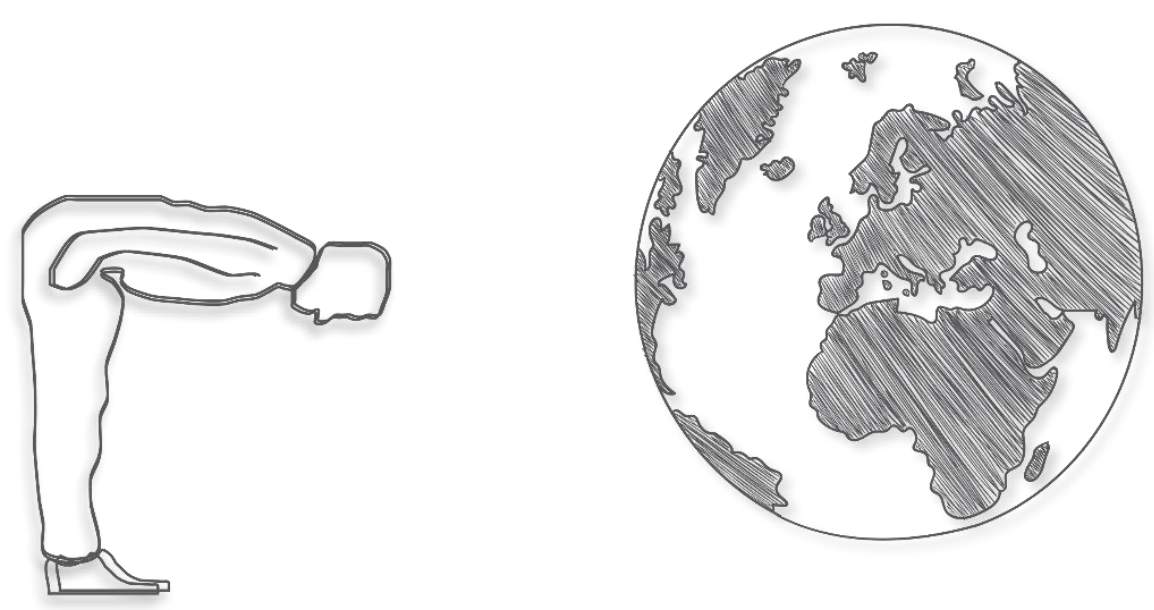

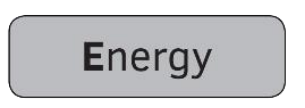

Flow

Play, humor \& fun

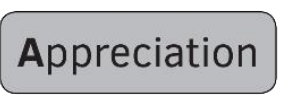

Acceptance Love

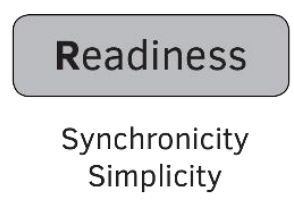

\section{Openness \\ Non-forcing} Beina

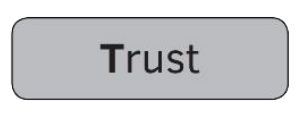

Emergence

Mothering energy

\section{Healing}

Intuition Letting go

\section{Balance \\ Darkness \& light} Relaxation

\section{Figure 11. Earth Bow}

So why didn't the researcher reorder the analysis chapter to include this new model? The most precise answer is that if she had done that, another new model would probably have surfaced through that work. Most of the concepts are the same, and to be understood in the same way. To unfold the meaning, as well as that of the concepts highlighted here, but not in the umbrella model, the reader will have to wait in anticipation for the book and the article about organic growth yet to be published.

The purpose of including this model relating to organic growth is to emphasize how a grounded theory can develop over time. In this specific example it is also shown that organic growth may be easy to communicate to the practitioners with this illustration, because it includes a visual reminder of the concept of wholeness which can be difficult to capture in language. Finally it also points to the fact that future-forming research is not static but keeps evolving over time, within dialogues with representatives from the field being studied. 


\section{References}

\subsection{Bibliography}

Ampartzaki, M., Kypriotaki, M., Voreadou, C., Dardioti, A. \& Stathi, I. (2013). Communities of practice and participatory action research: The formation of a synergy for the development of museum programs for early childhood. Educational Action Research, 21(1), 4-27.

Anderson, H. (1997). Conversation, language and possibilities: A postmodern approach to therapy. New York: BasicBooks.

Anderson, R. (2000). Intuitive inquiry: Interpreting objective and subjective data. Journal of Consciousness and Transformation, 22(4), 31-39.

Antonovsky, A. (1979). Health, stress, and coping. San Francisco: Jossey-Bass.

Aarts, M. (2000). Marte Meo: Basic manual. Eindhoven: Aarts Productions.

Aurama, A. (2017, December 9). Why communities of practice? Part 1 - Cop's are turbochargers toward a teal world. [Accessed March 22, 2018]. http://www.enliveningedge.org/views/communities-of-practice-turbochargers-teal-world/

Babchuk, W. A. (1995). Glaser or Strauss: Grounded theory and adult education. Proceedings of the fifteenth annual Midwest research-to-practice conference in adult, continuing \& community education. Nebraska, USA.

Baker, A. \& Wright, M. (2006). Using appreciative inquiry to initiate a managed clinical network for children's liver disease in the UK. International Journal of Health Care, 19(7), 561-574.

Baker, W. E. (2019). Emotional energy, relational energy, and organizational energy: toward a multilevel model. Annual Review of Organizational Psychology and Organizational Behavior, 6, 373-395.

Bhagat, R. S., Segovis, J. \& Nelson, T. (2016). Work stress and coping in the era of globalization. London: Routledge.

Bandura, A. (1977). Self-efficacy: Toward a unifying theory of behavioral change. Psychological Review, 84(2), 191-215.

Barnett, C. (2005). The consolations of 'neoliberalism'. Geoforum, 36(1), 7-12.

Barrett, F. J., Cooperrider, D. L. \& Fry, R. E. (2005). Bringing every mind into the game to realize the positive revolution in strategy: The appreciative inquiry summit. In W.J. Rothwell and $R$. 
Sullivan (Eds.) Practicing Organizational Development: A Guide for Consultants (pp. 510538). Hoboken, NJ: Pfeiffer.

Barrett, F. J. \& Fry, R. E. (2008). Appreciative inquiry: A positive approach to building cooperative capacity. Chagrin Falls: Taos Institute Publications.

Barros, I. O., \& Cooperrider, D. L. (2000). A story of Nutrimental in Brazil: How wholeness, appreciation, and inquiry bring out the best in human organization. Organization Development Journal, 18(2), 22-28.

Beck, D. E. \& Cowan, C. (2014). Spiral dynamics: Mastering values, leadership and change. New York: John Wiley \& Sons.

Berger, P. L. \& Luckmann, T. (1991). The social construction of reality: A treatise in the sociology of knowledge. London: Penguin Books.

Biernacki, P. \& Waldorf, D. (1981). Snowball sampling: Problems and techniques of chain referral sampling. Sociological Methods \& Research 10(2), 141-163.

Bohm, D. (1990). Art meets science and spirituality in a changing economy. (Conference). [Accessed April 26th, 2018]. https://www.youtube.com/watch?v=mDKB7GcHNac\&feature=youtu.be

Bohm, D. (2005). Wholeness and the implicate order. London: Routledge (Taylor \& Francis eLibrary).

Booth, B. K. (2014). Toward sexual well-being: A grounded theory study of the lived experience of sexuality (Doctoral dissertation). Widener University, Center for Human Sexuality Studies, ProQuest Dissertations Publishing.

Bourdieu, P. (1977). Outline of a theory of practice. Cambridge: Cambridge University Press.

Brennan, B. A. (1988). Hands of light: A guide to healing through the human energy field. New York: Bantam Books.

Bronfenbrenner, U. (1994). Ecological models of human development. International Encyclopedia of Education, 3(2), 1643-1647.

Brown, B. (2015). Daring greatly: How the courage to be vulnerable transforms the way we live, love, parent, and lead. New York: Penguin.

Brown, J. \& Isaacs, D. (2005). The world café: Shaping our future through conversations that 
matter. San Francisco: Berrett-Koehler.

Browne, B. W. \& Jain, S. (2002). Imagine Chicago: Ten years of imagination in action. Chicago: Imagine Chicago.

Buckingham, M. (2010). Go put your strengths to work: Six powerful steps to achieve outstanding performance. New York: Simon and Schuster.

Bushe, G. R. (2001). Five theories of change embedded in Appreciative Inquiry. In D. L. Cooperrider, P. Sorenson, D. Whitney \& T. F. Yeager (Eds.), Appreciative Inquiry: An emerging direction for organization development (pp. 117-127). Champaign: Stipes.

Bushe, G. R., \& Marshak, R. J. (2009). Revisioning organization development: Diagnostic and dialogic premises and patterns of practice. The Journal of Applied Behavioral Science, 45(3), 348-368.

Bushe, G.R. (2013). The Appreciative Inquiry Model. In E.H. Kessler (Ed.), Encyclopedia of Management Theory (pp. 41-44). Thousand Oaks (CA): Sage Publications.

Chadbourne, J. W. \& Silbert, T. (2011). Healing conversations now: Enhance relationships with elders and dying loved ones. Chagrin Falls: Taos Institute Publications.

Charmaz, K. (2006). Constructing grounded theory: A practical guide through qualitative analysis. London: Sage.

Charmaz, K. (2008). Constructionism and the grounded theory method. In J. A. Holstein \& J.F. Gubrium (Eds.), Handbook of constructionist research (pp. 397-412). New York: The Guilford Press.

Collins, C. S. \& Cooper, J. E. (2014). Emotional intelligence and the qualitative researcher. International Journal of Qualitative Methods, 13(1), 88-103.

Cooperrider, D. L. (1985). Appreciative inquiry: A methodology for advancing social innovation (Doctoral dissertation). Case Western Reserve University, Cleveland, $\mathrm{OH}$.

Cooperrider, D. L. (1990). Positive image, positive action: The affirmative basis of organizing. In S. Srivastva \& D. L. Cooperrider (Eds.), Appreciative management and leadership (pp. 91125). San Francisco: Jossey-Bass.

Cooperrider, D. L. (2012). The concentration effect of strengths: How the whole system "Al" summit brings out the best in human enterprise. Organizational Dynamics, 41(2), 106-117. 
Cooperrider, D. L. (2017). The gift of new eyes: Personal reflections after 30 years of Appreciative Inquiry in organizational life. Research in Organizational Change and Development, 25, $81-$ 142.

Cooperrider, D. L. (2018). A time for action: Appreciative inquiry, positive peace and the making of a Nobel nomination. Al Practitioner, 20(1), 7-18.

Cooperrider, D. L. \& Godwin, L. N. (2015). Elevation and change: An eight-step platform for leading P.O.S.I.T.I.V.E change. Al Practitioner, 17(3), 7-17.

Cooperrider, D. L. \& McQuaid, M. (2012). The positive arc of systemic strengths. How appreciative inquiry and sustainable designing can bring out the best in human systems. The Journal of Corporate Citizenship, 46, 71-102.

Cooperrider, D. L. \& Srivastva, S. (1987). Appreciative inquiry in organizational life. Research in Organizational Change and Development (1), 129-169.

Cooperrider, D. L., \& Whitney, D. (2001). A positive revolution in change: Appreciative inquiry. Public Administration and Public Policy, 87, 611-630.

Cooperrider, D. L. \& Whitney, D. (2011). Appreciative inquiry: A positive revolution in change. San Francisco: Berrett-Koehler.

Cooperrider, D. L., Whitney, D. \& Stavros, J. M. (2008). Appreciative Inquiry handbook: For leaders of change. (2nd ed.). Brunswick: Crown Custom Publishing and San Francisco: Berrett-Koehler Publishers.

Corbin, J. \& Strauss, A. (1990). Grounded theory research: Procedures, canons, and evaluative criteria. Qualitative Sociology, 13(1), 3-21.

Csikszentmihalyi, M. (1990). Flow: The psychology of optimal experience. New York: Harper and Row.

Csikszentmihalyi, M. (1997). Finding flow: The psychology of engagement with everyday life. New York: Basic Books.

Csikszentmihalyi, M. (2014). Flow and the foundations of positive psychology: The collected works of Mihaly Csikszentmihalyi. Dordrecht: Springer.

Csikszentmihalyi, M. \& Csikszentmihalyi, I. S. (1988). Optimal experience: Psychological studies of flow in consciousness. Cambridge: Cambridge University Press. 
Dane, E. \& Pratt, M. G. (2007). Exploring intuition and its role in managerial decision-making. Academy of Management Review, 32(1), 33-54.

Dickow, T. (2017). Tæl til Tina, Aarhus: Finest Gramophone.

Dweck, C. S. (2010). Even geniuses work hard. Educational Leadership, 68(1), 16-20.

Dweck, C. S. \& Leggett, E. L. (1988). A social-cognitive approach to motivation and personality. Psychological Review, 95(2), 256-273.

Elgin, D. (1981). Voluntary simplicity: Toward a way of life that is outwardly simple, inwardly rich. New York: Morrow.

Foucault, M. (1980). Power/knowledge: Selected interviews and writings. C. Gordon (Ed.). New York: Pantheon.

Frankl, V. E. (1972). Why believe in others? [Accessed September 9, 2018]. https://www.ted.com/talks/viktor frankl youth in search of meaning

Frankl, V. E. (1985). Man's search for meaning. New York: Simon and Schuster.

Fredrickson, B. L. (1998). What good are positive emotions? Review of General Psychology, 2(3), 300-319.

Fredrickson, B. L. (2001). The role of positive emotions in positive psychology: The broaden-andbuild theory of positive emotions. American Psychologist, 56(3), 218-226.

Fredrickson, B. L. (2004). The broaden-and-build theory of positive emotions. Philosophical Transactions of the Royal Society B: Biological Sciences, 359(1449), 1367-1378.

Fredrickson, B. L. (2009). Positivity: Groundbreaking research reveals how to embrace the hidden strength of positive emotions, overcome negativity, and thrive. New York: Crown Publishing Group.

Fredrickson, B. L. (2013). Love 2.0: How our supreme emotion affects everything we feel, think, do, and become. New York: Hudson Street Press.

Fredrickson, B. L. \& Joiner, T. (2002). Positive emotions trigger upward spirals toward emotional well-being. Psychological Science, 13(2), 172-175.

Fredrickson, B. L., Mancuso, R. A., Branigan, C. \& Tugade, M. M. (2000). The undoing effect of positive emotions. Motivation and Emotion, 24(4), 237-258. 
Gergen, K. J. (1982). Toward transformation in social knowledge. New York: Springer-Verlag.

Gergen, K. J. (1996). Social psychology as social construction: The emerging vision. In C. MacGarty \& A. Haslam (Eds.), The message of social psychology: Perspectives on mind in Society (pp. 113-128). Oxford: Blackwell.

Gergen, K. J. (2005). Virkeligheder og relationer: Tanker om social konstruktioner, (2nd ed.). København: Dansk Psykologisk Forlag.

Gergen, K. J. (2008). An invitation to social construction. London: SAGE Publications.

Gergen, K. J. (2009). Relational being: Beyond self and community. New York: Oxford University Press.

Gergen, K. J. (2015). From mirroring to world-making: Research as future forming. Journal for the Theory of Social Behaviour, 45(3), 287-310.

Gergen, K. J. \& Gergen, M. (2004). Social construction: Entering the dialogue. Chagrin Falls: Taos Institute Publications.

Giddens, A. (1984). The constitution of society: Outline of the theory of structuration. Los Angeles: University of California Press.

Gioia, D. A., Corley, K. G. \& Hamilton, A. L. (2013). Seeking qualitative rigor in inductive research: Notes on the Gioia methodology. Organizational Research Methods, 16(1), 15-31.

Glaser, B. G. \& Strauss, A. L. (1967). The discovery of grounded theory: Strategies for qualitative research. Chicago/New York: Aldine/Atherton.

Glaser, B. G. (1978). Theoretical sensitivity: Advances in methodology of grounded theory. San Francisco: University of California.

Glaser, B. G. (1998). Doing grounded theory: Issues \& discussions. Mill Valley: Sociology Press.

Goleman, D. (1996). Emotional intelligence: Why it can matter more than IQ. London: Bloomsbury.

Gottman, J. M. (2011). The Science of trust: Emotional attunement for couples. New York: WW Norton \& Company.

Graves, C. W. (1970). Levels of existence: An open system theory of values. Journal of Humanistic Psychology, 10(2), 131-155.

Graves, C. W. (1974). Human nature prepares for a momentous leap. The Futurist, 8(2), 72-85. 
Gray, M. (2011). Back to basics: A critique of the strengths perspective in social work. Families in Society: The Journal of Contemporary Social Services, 92(1), 5-11.

Hagel III, J., Brown, J. S. \& Davison, L. (2012). The power of pull: How small moves, smartly made, can set big things in motion. New York: Basic Books.

Halkier, B. (2008). Fokusgrupper. Roskilde: Samfundslitteratur.

Hatfield, E., Cacioppo, J. T. \& Rapson, R. L. (1994). Emotional contagion: Cambridge studies in emotion and social interaction. Cambridge: Cambridge University Press.

Heath, H. \& Cowley, S. (2004). Developing a grounded theory approach: A comparison of Glaser and Strauss. International Journal of Nursing Studies, 41(2), 141-150.

Hill, T., \& Westbrook, R. (1997). SWOT analysis: It's time for a product recall. Long Range Planning, 30(1), 46-52.

Hirsch, P. M. \& Levin, D. Z. (1999). Umbrella advocates versus validity police: A life-cycle model. Organization Science, 10(2), 199-212.

Holton, J. A. (2008). Grounded theory as a general research methodology. The Grounded Theory Review, 7(2), 67-93.

Horkheimer, M. (1982). Critical theory. New York, NY: Continuum.

Johnson, C. M. (2001). A survey of current research on online communities of practice. The Internet of Higher Education, 4(1), 45-60.

Jonas, W. B. \& Crawford, C. C. (2003). Science and spiritual healing: A critical review of spiritual healing, "energy" medicine and intentionality. Alternative Therapies in Health and Medicine, 9(2), 56-61.

Jung, C. G. (2010). Synchronicity: An acausal connecting principle. (In Vol. 8 of The Collected Works of C. G. Jung). Princeton: Princeton University Press.

Kaslow, N. J., Deering, C. G. \& Ash, P. (1996). Relational diagnosis of child and adolescent depression. In F. W. Kaslow (Ed.), Wiley series in couples and family dynamics and treatment. Handbook of relational diagnosis and dysfunctional family patterns (pp. 171185). Oxford: John Wiley \& Sons.

Kelly, P. (2018). Earth is hiring: The new way to live, lead, earn, give. For millennials and anyone who gives a sh*t. Cardiff: Waterside Press. 
Kemmis, S. \& McTaggart, R. (1998). The action research planner. Geelong, Australia: Deakin University Press.

Kierkegaard, S. (2016). Writings of Kierkegaard. Woodstock, Canada: Devoted Publishing.

Kristiansen, S. \& Krogstrup, H. K. (1999). Deltagende observation: introduktion til en samfundsvidenskabelig metode. København: Hans Reitzel.

Kristjánsson, K. (2007). Aristotle, Emotions, and Education. Farnham: Ashgate Publishing, Ltd.

Kvale, S. \& Brinkmann, S. (2008). InterViews: Learning the craft of qualitative research interviewing. Los Angeles, CA: SAGE.

Lamontagne, A. D., Keegel, T., Louie, A. M., Ostry, A. \& Landsbergis, P. A. (2007). A systematic review of the job-stress intervention evaluation literature, 1990-2005. International Journal of Occupational and Environmental Health, 13(3), 268-280.

Lave, J. (1988). Cognition in practice: Mind, mathematics, and culture in everyday life. Cambridge: Cambridge University Press.

Lave, J. \& Wenger, E. (1991). Situated learning: Legitimate peripheral participation. Cambridge: Cambridge University Press.

Laloux, F. (2014). Reinventing organizations: A guide to creating organizations inspired by the next stage of human consciousness. Brussels: Nelson Parker.

László, E. (2008). Quantum shift in the global brain: How the new scientific reality can change us and our world. Rochester, NY: Inner Traditions.

Lipton, B. H. (2008). The biology of belief. Carlsbad: Hay House.

Ludema, J. D. \& Barrett, F. (2008). Appreciative Inquiry Summit. In Holman, P., T. Devane \& S. Cady (Eds.), The change handbook. The definitive resource on today's best methods for engaging whole systems. Oakland: Berrett-Koehler.

Ludema, J. D., Whitney, D., Mohr, B. J. \& Griffin, T. J. (2003). The Appreciative Inquiry summit: A practitioner's guide for leading large group change. San Francisco: Berrett-Koehler.

Løgstrup, K.E. (1997). The ethical demand. Notre Dame: University of Notre Dame Press.

Maslow, A. H. (1971). The farther reaches of human nature. London: Penguin Books.

McLaughlin, C. (2003). The feeling of finding out: The role of emotions in research. Educational 
Action Research, 11(1), 65-78.

McNamee, S. (2010). Research as social construction: Transformative inquiry. Saúde \& Transformação Social, Florianópolis, 1(1), 9-19.

McNamee, S. (2014). Research as relational practice: Exploring modes of inquiry. In Simon, G. \& A. Chard (Eds.), Systemic inquiry. Innovations in reflexive practice research (pp. 74-94). London: Everything is Connected Press.

McNamee, S. \& Hosking, D. M. (2012). Research and social change: A relational constructionist approach. New York: Routledge.

Newhard, M. L. (2010). An exploratory study of competencies of appreciative inquiry practitioners: Discovery. (Doctoral dissertation). Pennsylvania State University, Pennsylvania.

Maturana, H. (2002). Autopoiesis, structural coupling and cognition: A history of these and other notions in the biology of cognition. Cybernetics \& Human Knowing, 9, 5-34.

Merry, P. (2017). Synchronicity and leadership. (Doctoral dissertation). Tilburg University, Tilburg.

Miller, D. (1993). The architecture of simplicity. Academy of Management Review, 18(1), 116-138.

Mitchell, K. E., Levin, A. S. \& Krumboltz, J. D. (1999). Planned happenstance: Constructing unexpected career opportunities. Journal of Counselling \& Development, 77(2), 115-124.

Nørgaard, B. (2005). Axel Honneth og en teori om anerkendelse. Tidsskrift for socialpædagogik, $16,63-70$.

Otte, J. (2015). Appreciative inquiry makes research future forming. (Doctoral dissertation). Tilburg University, Tilburg.

Owens, B. P., Baker, W. E., Sumpter, D. M. \& Cameron, K. S. (2016). Relational energy at work: Implications for job engagement and job performance. Journal of Applied Psychology, 101(1), 35-49.

Peck, M. S. (2003). The road less travelled. New York: Touchstone.

Pedersen, C.H., Kousgaard, N. \& Hansen, H.J. (2011). Anerkendelse i kristent perspektiv. Hillerød: Kristent Pædagogisk Institut.

Piaget, J. (1959). The language and thought of the child 5. London: Routledge \& Kegan Poul.

Pór, G. \& van Bekkum, E. (2004). Liberating the innovation value of communities of practice. 
Amsterdam: CommunityIntelligence Ltd.

Powley, E. H., Cooperrider, D. L. \& Fry, R. E. (2002). Appreciative inquiry: A revolutionary approach to strategic change. In P. Goett, (Ed.), Handbook of Business Strategy, (pp. 165172). New York: EC Media Group.

Ray, R. A. (2008). Touching enlightenment: Finding realization in the body. Boulder, CO: Sounds True.

Reed, J. (2007). Appreciative Inquiry: Research for change. London: Sage.

Rosch, E. (1999). Primary knowing: When perception happens from the whole field. Interview with Professor Eleanor Rosch. [Accessed September 19 ${ }^{\text {th }}, 2018$ ]. https://www.presencing.org/\#/aboutus/theory-u/leadership-interview/eleanor rosch

Rogers, C. R. (1961/1995). On becoming a person: A therapist's view of psychotherapy. New York: Houghton Mifflin Harcourt.

Rogers, P. J. \& Fraser, D. (2003). Appreciating Appreciative Inquiry. New Directions for Evaluation, 100, 75-83.

Romilly, J. D. (1958). Eunoia in Isocrates, or the political importance of creating good will. The Journal of Hellenic Studies, 78, 92-101.

Sampson, E. E. (1993/ 2008). Celebrating the other: A dialogic account of human nature. Hertfordshire: Harvester Wheatsheaf / Chagrin Falls, $\mathrm{OH}$ : Taos Institute Publications.

Scharmer, C. O. (2000). Self-transcending knowledge: Sensing and organizing around emerging opportunities. [Accessed May $26^{\text {th }}, 2018$ ]. http://www.ottoscharmer.com/sites/default/files/2000 STK.pdf

Scharmer, C. O. \& Kaufer, K. (2013). Leading from the emerging future: From ego-system to ecosystem economies. San Francisco, CA: Berrett-Koehler.

Seligman, M. E. \& Csikszentmihalyi, M. (2000). Special issue on happiness, excellence, and optimal human functioning. American Psychologist, 55(1), 5-183.

Shaw, J. (2008). Appreciative inquiry. Lecture by Professor Jody Shaw, Roskilde University.

Sommer, D., Pramling Samuelsson, I. \& Hundeide, K. (2013). Early childhood care and education: A child perspective paradigm. European Early Childhood Education Research Journal, 21(4), 459-475. 
Stavros, J. \& Hinrichs, G. (2009). The Thin Book of SOAR: Building strengths-based strategy. Bend, OR: Thin Book Publishing Company.

Stern, P. N. (1994). Eroding grounded theory. In J. Morse (Ed.), Critical Issues in Qualitative Research Methods (pp. 212-223). Thousand Oaks, CA: Sage.

Stokes, P. \& Harris, P. (2012). Micro-moments, choice and responsibility in sustainable organizational change and transformation: The Janus dialectic. Journal of Organizational Change Management, 25(4), 595-611.

Svarre, D. (2011). Glade børn med højt selvværd. København: Politikens Forlag.

Søndergaard, D. M. (1996). Tegnet på kroppen: Køn, koder og konstruktioner blandt unge voksne $i$ Akademia. København: Museum Tusculanums Forlag.

Thatchenkery, T. J. \& Metzker, C. (2006). Appreciative Intelligence: Seeing the mighty oak in the acorn. San Francisco, CA: Berrett-Koehler.

Vygotsky, L. S. (1962). Thought and language. Cambridge, MA: MIT Press.

Vygotsky, L. S. (1978). Mind in society: The development of higher psychological processes. Cambridge, MA: Harvard University Press.

Vygotsky, L. S. (1987). Thinking and speech. In R. W. Rieber \& A.S. Carton (Eds.), The collected works of L. S. Vygotsky, Vol.1, (pp. 39-285). New York, NY: Plenum Press.

Waldrop, M. M. (1996). The trillion-dollar vision of Dee Hock. Fast Company, 5(10-11), 75-86.

Watkins, J. M. \& Mohr, B. J. (2001). Appreciative Inquiry: Change at the speed of imagination. San Francisco, CA: Jossey-Bass/ Pfeiffer.

Weber, M. (2009). The theory of social and economic organization. New York, NY: Simon and Schuster.

Wenger, E. (1998). Communities of practices: Learning, meaning and identity. Cambridge, UK: Cambridge University Press.

Wenger, E. (2009, October 27). Communities of practice and social learning systems. [Accessed April 20 $\left.{ }^{\text {th }}, 2018\right]$. https://wenger-trayner.com/wp-content/uploads/2012/01/09-10-27-CoPs-and-systemsv2.01.pdf

Whitney, D. K. \& Trosten-Bloom, A. (2010). The power of Appreciative Inquiry: A practical guide to positive change. (2nd ed.). San Francisco, CA: Berrett-Koehler. 
Whitney, D. K., Trosten-Bloom, A. \& Rader, K. (2010). Appreciative leadership: Focus on what works to drive winning performance and build a thriving organization. New York, NY: McGraw-Hill.

Whyte, S. (2015). Implementing and researching technological innovation in language teaching: The case of interactive whiteboards for EFL in French schools. London: Palgrave Macmillan.

Wilber, K. (2000). Integral psychology: Consciousness, spirit, psychology, therapy. Boston, MA: Shambhala Publications.

Willerslev, R. (2004). Spirits as "ready to hand": A phenomenological analysis of Yukaghir spiritual knowledge and dreaming. Anthropological Theory, 4(4), 395-418.

Willig, R. (2016). Afvæbnet kritik. København: Hans Reitzels Forlag.

Winnicott, D. W. (1971). Playing and reality. London: Tavistock Publications Ltd.

Wittgenstein, L. (1953). Philosophical investigations. Oxford, UK: Blackwell.

Yeager, D. S. \& Dweck, C. S. (2012). Mindsets that promote resilience: When students believe that personal characteristics can be developed. Educational Psychologist, 47(4), 302-314.

Zohar, D. \& Marshall, I. N. (1990). The quantum self: Human nature and consciousness defined by the new physics. London: Bloomsbury. 


\subsection{Table of figures}

\begin{tabular}{|l|l|l|}
\hline Fig. no. & Title of figure & Page number \\
\hline $\mathbf{1}$ & The appreciative inquiry practitioners & 4 \\
\hline $\mathbf{2}$ & Three lines of thought & 11 \\
\hline $\mathbf{3}$ & The flow model / Csikszentmihalyi (1997) & 16 \\
\hline $\mathbf{4}$ & The four phases of the macroshift / László (2008) & 18 \\
\hline $\mathbf{5}$ & The double-slit experiment / Wooters and Zurek (1979) & 21 \\
\hline $\mathbf{6}$ & Early interview guide & 56 \\
\hline $\mathbf{7}$ & Workshop model for the interactive research workshop & 57 \\
\hline $\mathbf{8}$ & Man's search for the ideal of humans capability / Frankl (1985) & 78 \\
\hline $\mathbf{9}$ & The umbrella model of organic growth & 119 \\
\hline $\mathbf{1 0}$ & The organic growth spiral & 123 \\
\hline $\mathbf{1 1}$ & The Earth Bow & 141 \\
\hline $\mathbf{1 2}$ & Appreciative inquiry 4D cycle & 156 \\
\hline $\mathbf{1 3}$ & $\begin{array}{l}\text { The Cooperrider-Godwin 8 step P.O.S.I.T.I.V.E change } \\
\text { platform }\end{array}$ & 158 \\
\hline
\end{tabular}




\subsection{Table of tables}

\begin{tabular}{|l|l|l|}
\hline Table no. & Title of table & Page \\
\hline $\mathbf{1}$ & $\begin{array}{l}\text { Evolutionary breakthroughs in Human Collaboration / Laloux } \\
(2014)\end{array}$ & 24 \\
\hline $\mathbf{2}$ & Current scientific paradigm versus emerging paradigm & 42 \\
\hline $\mathbf{3}$ & Program for the analysis workshop & 60 \\
\hline $\mathbf{4}$ & Dimension 1: Balancing & 65 \\
\hline $\mathbf{5}$ & Dimension 2: Flow & 67 \\
\hline $\mathbf{6}$ & Dimension 3: Healing & 69 \\
\hline $\mathbf{7}$ & Dimension 4: Trust & 71 \\
\hline $\mathbf{8}$ & Dimension 5: Energy & 73 \\
\hline $\mathbf{9}$ & Dimension 6: Wholeness & 75 \\
\hline
\end{tabular}




\section{Appendices}

\subsection{Appreciative inquiry: A primer}

This Appendix provides an introduction to Al for readers who may not be familiar with the discipline. As the historical roots and main principles have been described in the main text, this section is an introduction to three different models used within or in relation to Al processes, followed by a brief selection of applications - brief stories of Al in action. Finally, another key application is described, called the AI Summit methodology. The section titles are:

1. The 4D model of appreciative inquiry;

2. The Cooperrider-Godwin 8-step P.O.S.I.T.I.V.E. model;

3. SOAR - an updated SWOT model;

4. Examples of $\mathrm{Al}$ in action;

5. The whole system in the room: The AI Summit methodology.

\subsubsection{The 4D model of appreciative inquiry}

The 4D model has been used in many settings as a framework for Al processes. When the Al approach emerged in the 1980's, it did not come with a "how-to" book, and the originators refrained from creating one because they found the principles to be the most important element and they wanted people to invent their own ways of doing Al, to be inspired to find many approaches and not make it too rigid (Bushe, 2013). Eventually Cooperrider, Whitney and Stavros (2003) published the first five principles mentioned above. Later, the three extra principles described in section 3.3.1 were suggested (Whitney \& Trosten-Bloom, 2010). The 4D model was launched to suggest a process to carry out these principles in real life (Cooperrider, Whitney \& Stavros, 2003/2008; 5).

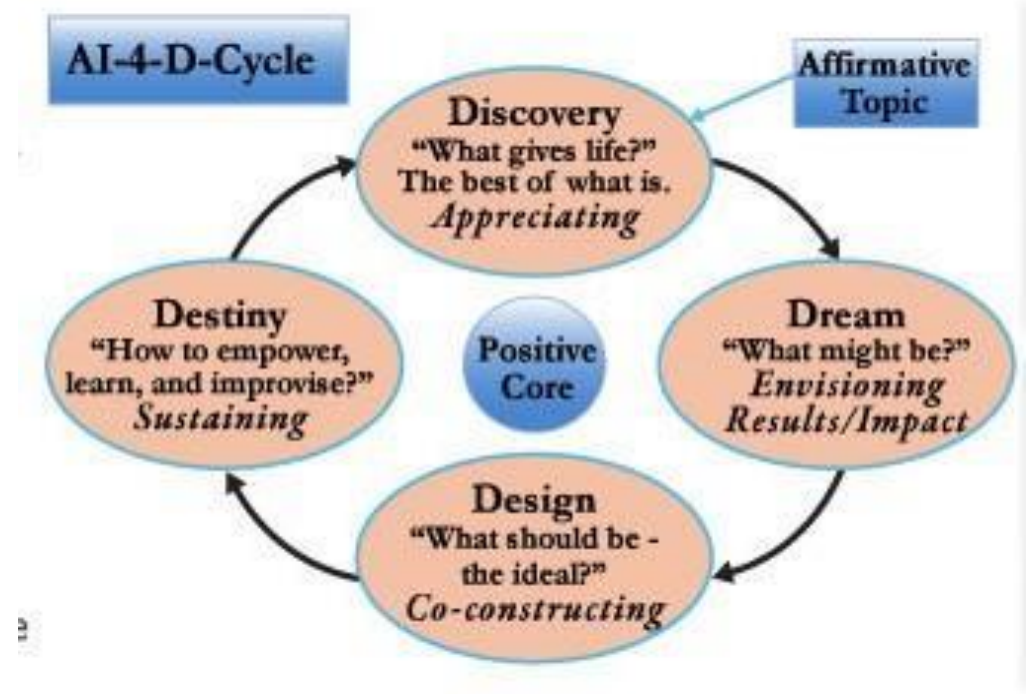

Figure 12: Appreciative inquiry 4D cycle 
Before heading into a cycle of a 4D process, the first step is to choose an affirmative topic; the socalled positive core (the blue middle circle). It is crucial that this topic is focused on "what we want" and "what we want more of", and that it is something inspirational, hopefully to the whole group, something "we" cannot help but work toward.

\section{The discovery phase}

When the work is done with the affirmative topic and a shared vision has been created, the discovery begins, dedicated to an inquiry into what gives life to the organization (or other group of people) when it is working at its best. Often this is arranged as assignments in pairs, with interviews and questions that are designed to discover one's core values, high point experiences and stories of what happens when these people are at their best, feel most alive and/or succeed in their jobs. After discovering what is already working very well, the participants go on to share their dreams.

\section{The dream phase}

In this phase, the participants are curious about each other's dreams and visions for the future related to the affirmative topic, "valuing the best of what is leads to envisioning what might be" (Cooperrider et. al, 2008, p. 6). There are no limits for the dreams in this phase, and the participants are invited to dream big, because maybe out of one of these (crazy) dreams a relevant point will arrive that is key to developing a practical and realistic goal for the future.

\section{The design phase}

This phase is characterized by a shift because this "free" phase of talking about what works and imagining what could be in a "perfect" world, is changed into rolling up the sleeves and beginning to design the desired (agreed-upon) future, often in small teams that differ in makeup from those taking part in the initial dialogue. This is where the physical and practical work occurs, prototypes are drawn and designed as miniature models, mistakes are made and so on. Adjustment occurs when the different groups in the intervention try to build their dream together. A designed prototype is more than a vision, it is a "strategic intent" (Cooperrider et al., 2008, p. 7).

\section{The destiny phase}

"Once guided by a shared image of what might be, members of the organization find innovative ways to help move the organization closer to the ideal" (Cooperrider et al., 2008, p. 7). The destiny phase was first called "delivery" but was changed because it led to traditional implementation approaches (Bushe, 2013). I have found that both are used, depending on the context. The destiny phase is designed to be the bridge from the creative room of prototypes and visions into the real and practical world, where ideas that translate into actions and projects ensure the important ideas to come to life.

The 4D model has been used in many different settings, from the organizational development, where it was born, to education, social work, government, whole industries, churches, communities and cross-religious initiatives and in different societies including third world countries, to create dialogical space. 
It is understandable that the originators hesitated to create a model and give how-to advice, because, as was foreseen, the understanding of Al has in many places been limited to this model, which might have meant a loss of whatever else it could have been. There is also much good to say about a model because it can help people do Al projects from reading the literature only and it is not reserved for academics, leaders or people who can transform abstract principles into practical initiatives. The dark side of that is that if you can easily learn an approach and just go out and do it, without certification, then it might also be more easily misunderstood. This and other, more critical aspects can be found in this thesis' critique section (12.10). From the description of the "classic" Al model we move to a new model inspired by appreciative inquiry and positive organizational development.

\subsubsection{Conscious co-elevation}

Cooperrider and Godwin worked with a model called "The Cooperrider \& Godwin 8-step P.O.S.I.T.I.V.E change platform" (Cooperrider \& Godwin, 2015) which supports the direction of conscious co-elevation. Conscious co-elevation is suggested as an "early articulation of an affective theory of social construction that is to meaning-making human systems, what genetic change is to biological systems" (Cooperrider \& Godwin, 2015, p. 8-9). The concept is created as a contrast to the concept of conscious evolution and, while evolutionary selection happens slowly and genetically, co-creation and co-elevation can happen fast.

Conscious co-elevation is one of the newest directions of thoughts within the area of appreciative inquiry and therefore relevant to describe here in order to gain insights about what Al practitioners have been occupied with over the past few years.

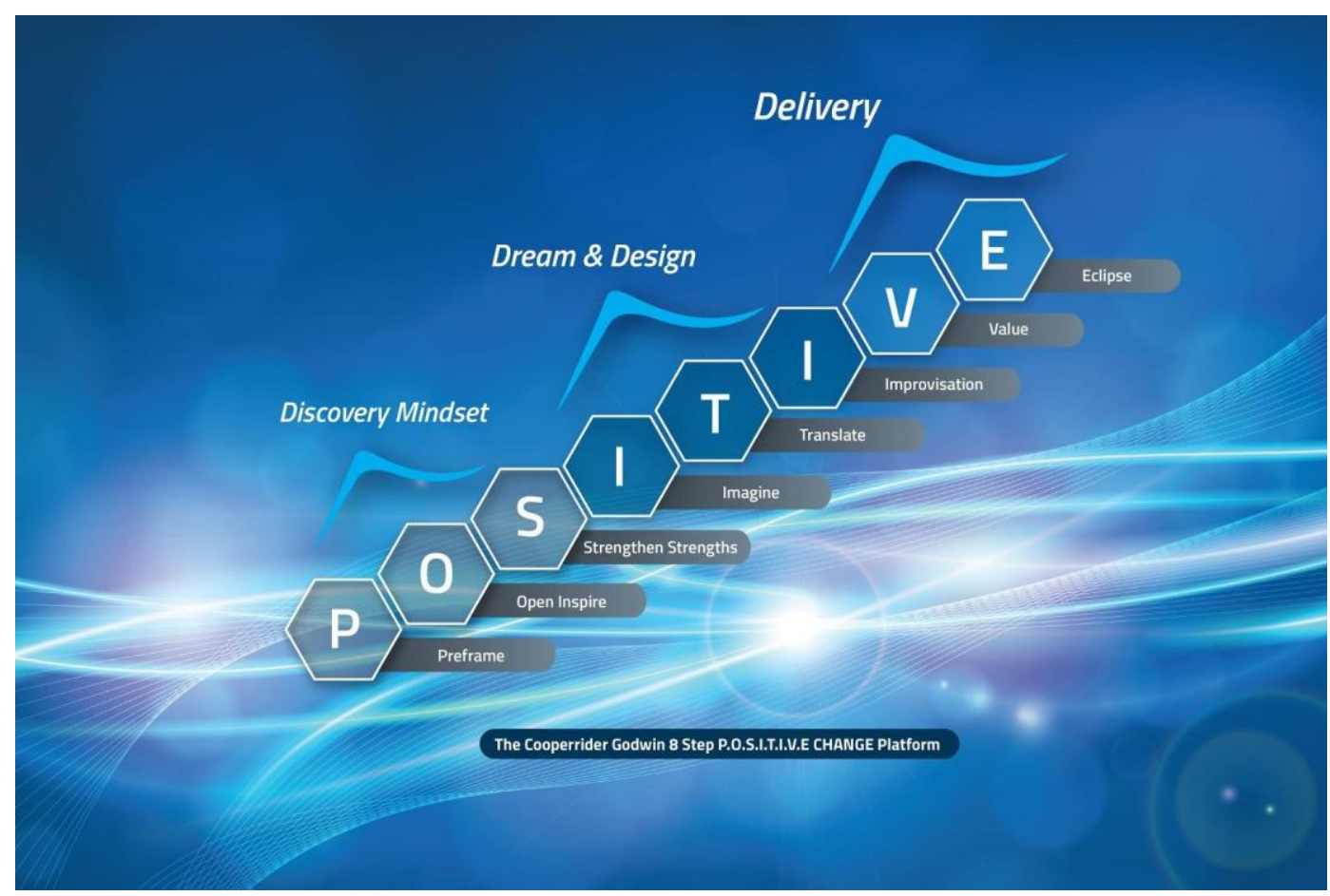

Figure 13: The Cooperrider \& Godwin 8-step P.O.S.I.T.I.V.E change platform. 
The eight steps of the model are:

P stands for preframe, which means to positively reframe what we sense could be better in the organization and to dare to formulate epic opportunities in what the authors calls "urgent optimism" (Cooperrider \& Godwin, 2015, p. 13).

$\mathbf{O}$ is open-innovate or open-inspire and invites the creation of a platform of change by bringing in the voices of various stakeholders. Such an open platform inspires them to unite and elevate strengths coming from a wider audience as well as attracting success.

$\mathbf{S}$ is to strengthen the strengths, following the idea that "(...) you change the best when you are at your strongest - or have access to everything you need" (Cooperrider \& Godwin, 2015, p.13). This is all about inviting all strengths into the process to create an atmosphere where is it possible to tap into a supra-strengths spectrum. On a practical level that can mean, for example, bringing in people with specific knowledge in IT, design, finance, arts, language, sports, environmental experts or whatever would be enriching the specific process.

I is for imagine, the idea of thinking big and using the imagination to create a "positive emotional attractor" as a vision or "magnetic images of the future" for co-creating. "Imagination sees a vivid victory that provides the whypower to sustain" (Cooperrider \& Godwin, 2015, p.13). With help from the imagination, it is possible to see clearly the desired future and that helps in remembering why we wanted that kind of future.

$\mathbf{T}$ is about translating, the process that happens after ideas and dreams starts to "get real" when the participants design prototypes, go beyond words and start to live tastings of the new and through that realize that the vision is possible in real life, that it is a just matter of time before it will be fully realized.

I is for improvisation. In this phase, everyone is invited in to help prototype the desired future instead of just talking about it, or worse: having it communicated. A picture says more than a thousand words, so if people help build and rebuild prototypes, and build in their own suggestions, everyone can feel invited in, included and valued for their contributions.

V refers to value, because at this time in change processes, moments of progress are needed as well as rigorous valuation. The authors use the metaphor of time-lapse photography and describe how we need to see moments in full motion towards flourishing, because then we can see the value in it for the longer term and we can trust the process and the end-product enough to invest in it, scale it up and make it visible to others.

$\mathbf{E}$ is for eclipse and refers to eclipsing the old and letting the new emerge and establish.

There are significant connections between the 4D model in this 8-step model, as the steps are characterized by, respectively, discover-mindset, dream and design-mindset, and a deliverymindset in the end. The introduction to these two models had the goal of providing more insight 
into how such processes can take place in practical contexts. To show a third way of using inspiration from Al, the following section will dive into the adjusted model of SWOT, renamed SOAR.

\subsubsection{SOAR}

The strategic approach of SOAR is introduced to give an idea of the impact Al has had in other areas. SOAR is an approach towards strategic development (Stavros \& Hinrich, 2009) building from the widely used organizational analysis model SWOT (Hill \& Westbrook, 1997). SWOT is the acronym for strengths, weaknesses, opportunities and threats. SOAR is based in a strength-only perspective, and is an acronym for strengths, opportunities, aspirations and results (Stavros \& Hinrich, 2009).

1. Strengths: What are we most proud of, what strengths do we have?

2. Opportunities: How do we make sense of opportunities outside?

3. Aspirations: What are we passionate about and what are our compelling aspirations?

4. Results: How do we know we are succeeding?

This model changes both the perspective and the language to look at what works, at the hopes, strengths and results we are creating together. SOAR is another example of combining organizational scholarship and practice where a shift towards lifegiving aspects and supportive language helps create more fertile, practical results. To inquire a bit more into how Al has been used in practical settings, let us now look briefly at examples of $\mathrm{Al}$ in action.

\subsubsection{Appreciative inquiry in action}

There are many stories of the impact that has occurred where Al has been tried out in practical settings. The following two stories are classical ones and have been told several times both within the community of practice and outside. Many other examples can be found in the journal $A l$ Practitioner (https://aipractitioner.com ).

The beginning of the Global Compact

In 2004 two of the originators of Al, David Cooperrider and Ron Fry, received a phone call from UN Secretary General Kofi Annan. The UN wanted to use the AI methodology to help launch the Global Compact initiative to engage top CEOs from the world's largest companies as well as leaders from non-profit and government to join forces in order to help the world with some of its biggest challenges. Today over 12,000 companies and nonprofits have joined the Global Compact, an agreement to live up to a certain set of criteria in order to address some of the world's challenges and take great responsibility.

Religious Leaders United

In 1996 Al helped provide the engine for a new organization, United Religions Initiative, whose primary purpose is dialogue across different religions. It is massively important when two men representing two religions - that have been fighting each other for hundreds of years - suddenly start talking, which is one of the practical stories that is a result of that process. The United Religions Initiative has been nominated for a Nobel Prize in 2018 (Cooperrider, 2018). 
There are many stories from all over the world giving insights into how Al has been used for different purposes and impacts: both success stories and stories about what did not work. Every practitioner will say that there are Al-successes and Al-challenges. The practitioners that I have interviewed talk about how they keep going on and keep on trying to shift perspective in many situations. The two examples mentioned here have had an impact on a large scale; many other stories of $\mathrm{Al}$ in action are on a smaller scale.

To dig one layer deeper, I want to add some reflections about the journey of Al in Denmark, which is my home country and where I have witnessed the development of Al almost since the beginning, when the first books were written in Danish in 2002. The argument for doing this is that I want to provide nuance to the Al approach in order for the reader to understand more of what can happen when mindsets shift due to new perspectives.

Al in Denmark

I want to include a short section on how Al entered the Danish culture to provide some insight to how it was and is now understood, how the term was translated and where and how it became useful, mainly because almost a third of the interviewees in the data set of this study are from Denmark. Al was introduced to Danish readers in 2002 with the two books "Værdsat" (Appreciated) and "Forandring" (Change) by Charlotte Dalsgaard, Kaj Voetmann and Tine Gaihede (Dalsgaard, Gaihede \& Voetmann, 2002).

In English the word "appreciation" means both to bless something and give praise to it, but it also refers, for example, to real estate: when a property increases in value, it "appreciates". In Denmark, we do not have that meaning integrated into the word "anerkendelse".

In the first two books, appreciative inquiry was translated as "værdsættende samtale", which directly translated means "appreciative conversation" and the core meaning given to conversation here was lifted up as a very central part of the approach, with association to the social construction of life and language in relations. Later on, the two words of "værdsættelse" and "anerkendelse" were discussed, and the latest Danish translation of the classic "Handbook of appreciative inquiry" (Cooperrider, Whitney \& Stavros, 2008) uses the term of "anerkendelse", where the word of "conversation has been shifted to "undersøgelse", which more directly means "inquiry" or "study".

The discussion behind the shift from "værdsættelse" to "anerkendelse" was partly the confusion about "praise" that happened in practice after the original books were published. Some practitioners that may have had a short introduction to Al or read the book, found it to be compelling to "only" focus on the positive and therefore gave a lot of "praise" when the approach spread. Discussions between "praise" and "appreciation" was taken and points were made that praise offered a positive feedback on a person's performance and therefore helped build selfconfidence, as opposed to "appreciation" which was understood as offering positive feedback on the person herself, for her actual being, for who she was, which was understood to build self-worth (e.g. Pedersen et al., 2011).

Appreciation as a theoretical concept was in Danish contexts traced back to German philosopher Axel Honneth's understanding of "recognition" (Honneth, 2003) which in Danish is translated to 
"anerkendelse" and is therefore often a supplemental understanding when discussing AI. Honneth - working with the backdrop of works by Hegel and Habermas among others - understands recognition as vital for every human being in three spheres (Nørgaard, 2005):

1. The sphere of love: The recognition we (hopefully) get in the family is emotional and, when received, leads to self-agency in a way that constitutes a level of self-confidence.

2. The rights every human has in the modern society, where we ideally are met as a human being, with rights as equals along with the obligations (e.g. to vote and pay taxes in a democracy like Denmark), as well as the right to join and receive social rights (such as free education, hospital etc.) If humans are met with this approach, they develop self-esteem and the recognition in this area is cognitive.

3. The social recognition is largely characterized by the appreciation humans get when they are met as a person with unique skills and potential and therefore invited to contribute on behalf of that uniqueness. This kind of recognition is both emotional and cognitive and when given leads to humans developing self-appreciation / self-worth.

In Denmark, this discussion points to the fact that every person has the right to receive recognition - or in Danish - appreciation on a very basic level, both in the family and in society. Working with strengths and resources has a long history in Denmark, and governments, organizations, schools, kindergartens and municipalities, among others, have been working with approaches building on the human right to receive appreciation.

The next section will shed light upon a scene where Al is used in very large settings to create whole-system change, often in global settings.

\subsubsection{Whole system in the room: The AI Summit methodology}

The following text provides a brief introduction to the AI Summit methodology, please see the following references for further reading. There have been different developments in the methods that have grown out of Al. One is the development of the Al Summit methodology that takes the process of $\mathrm{Al}$ and scales it up to include many participants, bringing in the wholeness of the system (Barros \& Cooperrider, 2000; Powley, Cooperrider \& Fry, 2002; Ludema \& Mohr, 2003; Barrett, Cooperrider \& Fry, 2005; Ludema \& Barrett, 2008).

Instead of having a small group of people deciding on a strategy for an organization, the Al Summit method is about inviting a large number of people from the organization and other stakeholders into a big room and guide them through an uplifting and creative process, where everyone is invited into creating input for the strategy. In one example, an organization gathered about 1000 employees in a large hall with white plastic chairs in order to co-create following this methodology (Barros \& Cooperrider, 2000).

Barrett et al. (2005) point to the idea that strategy is an ongoing transformation, which rests on the assumption that "organizations are most innovative and adaptive when everyone is thinking and acting strategically" (Barrett et al., 2005, p. 514). To help include all voices in the "inner circle" and ensure that enterprises grow, they point to the following five shifts: 1. From a deficit orientation to 
appreciative inquiry, 2. From small groups to whole systems, 3. From strategic goal setting to strategic visioning, 4. From strategic planning to strategic learning, and 5. From strategic thinking to strategic relating.

The Al Summit methodology has been used with great success because it brings a voice of wholeness and lets a greater number of people experience the process, the energy and the cocreated results at first hand, meaning that more people are likely to take action afterwards. Especially within the area of sustainability, AI Summits have proven to be very successful at matching the wishes of many organizations of moving toward greener and more cooperative social responsibility (Cooperrider \& McQuaid, 2012).

So far, I have not become aware of a training certificate into facilitating AI Summit processes, though smaller online courses and general courses on Al touch upon this subject. If the method is to gain further success, a training certificate may be a key way forward for Al to be carried out adequately in the great many settings that would qualify and be eager to engage in Al. 


\subsection{Slides for the "Co-creating Research" workshop}

Below are the original slides for the workshop. They were not used because of the shared decision to co-improvise, but participants had access to them afterwards.

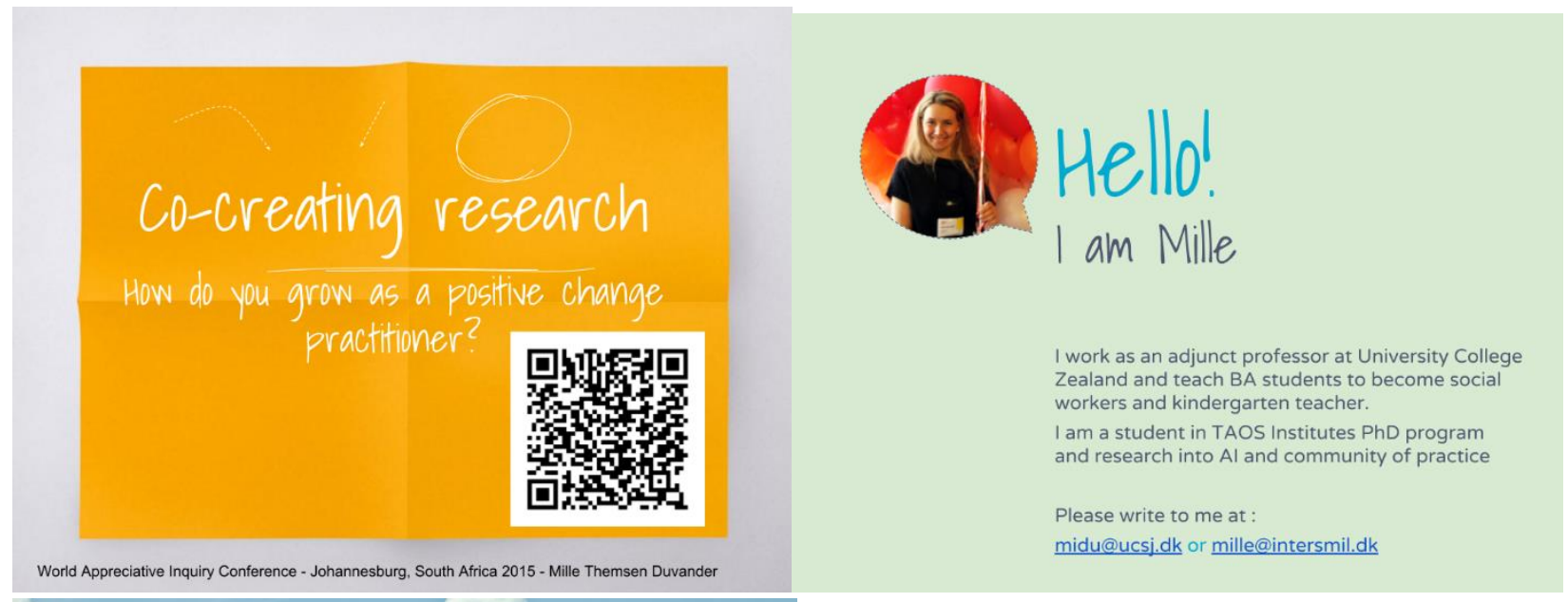

The purpose of our time together

Motivation for doing this research

How do you grow as a practitioner?

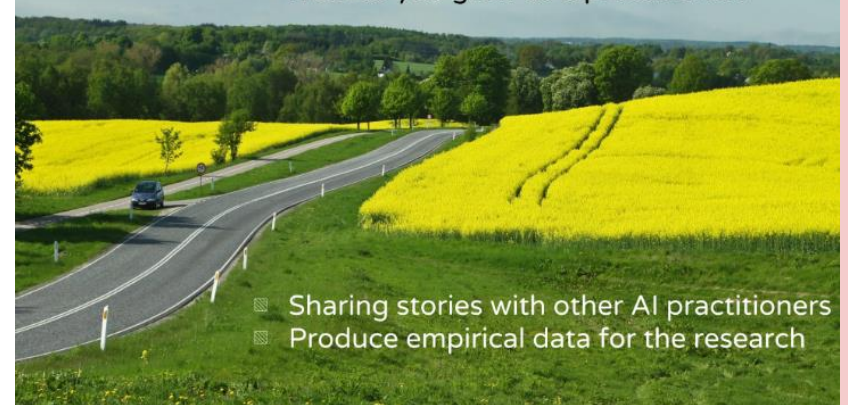

Where are you from?
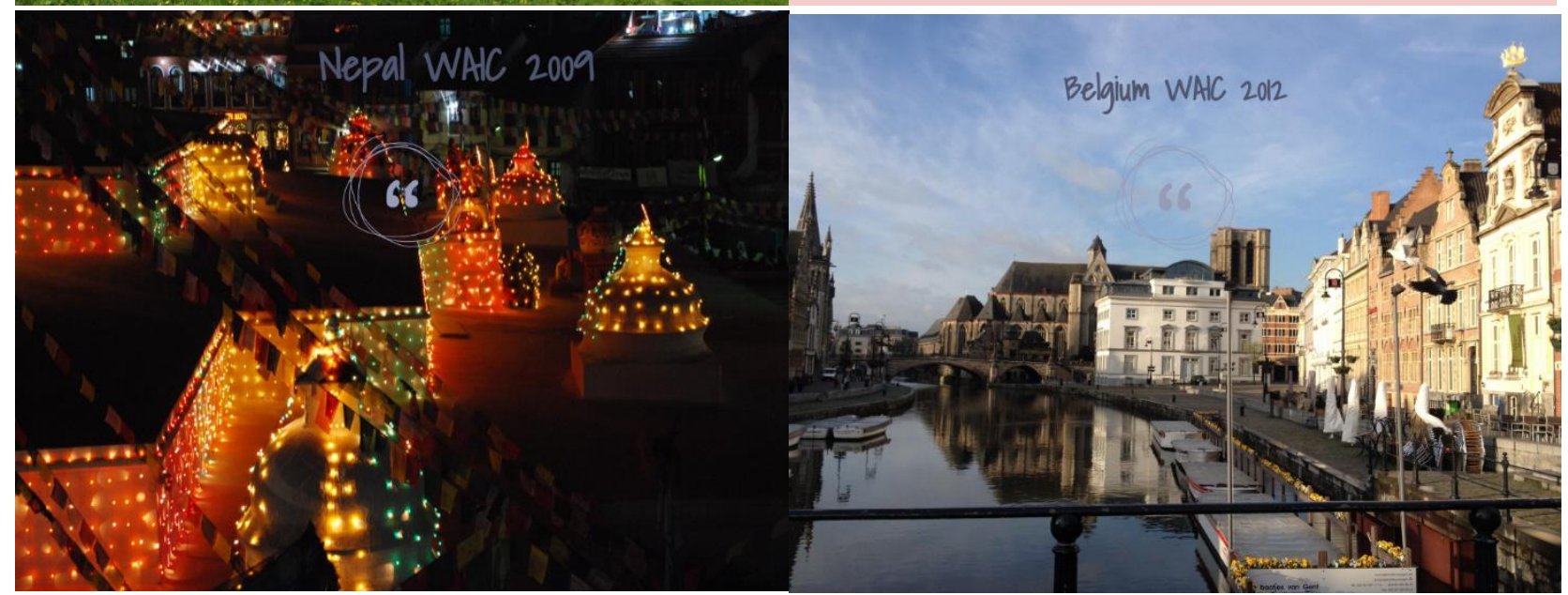


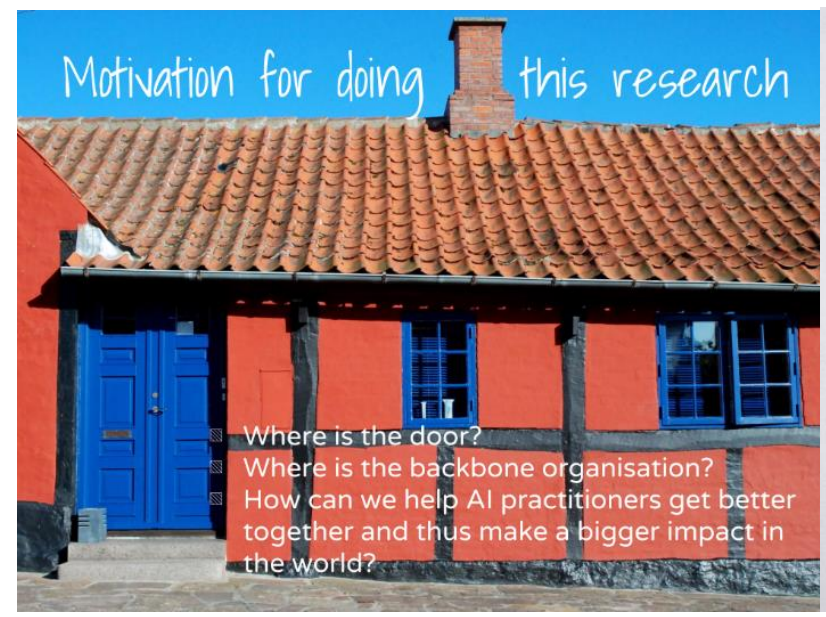

The hypotheses for the research

1. If you are a part of a supporting community you thrive better as a practitioner

2. If you have an important relation you feel safe and share honestly ups and downs

3. When practitioners thrive they do their job better and make a greater difference

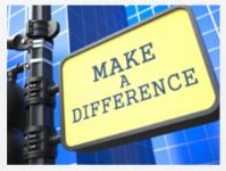

Interviews: Stories as data with a soul

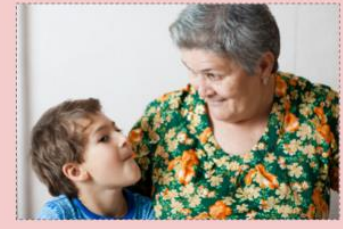

Walk + talk
1. In this exercise you will join a group of 3 people Person A will record the conversation on your smartphone

Person B will ask questions to person C

(It is alright to be 2 persons in a group)

Breene Brown

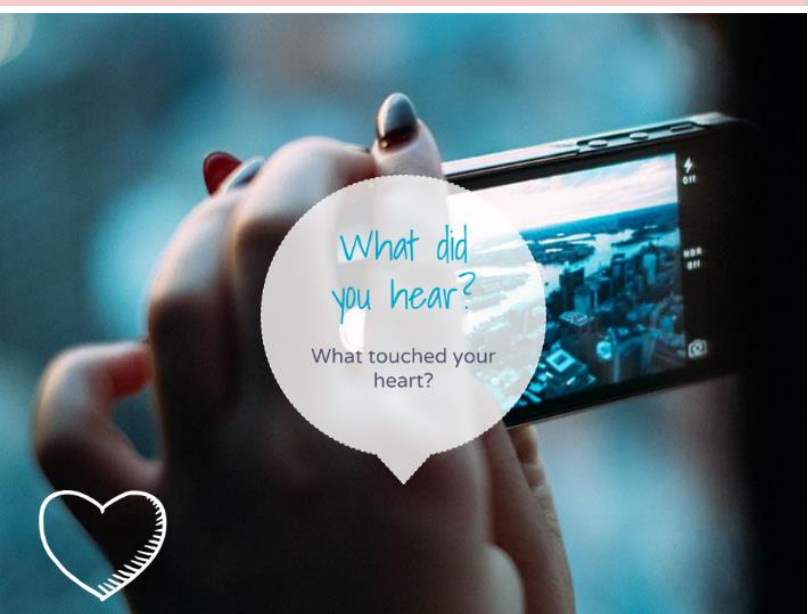

Questions to ask

1. Tell me a story where you became a better practitioner because of another positive change practitioner?

change practitioner?
How did this special event change you to the betterwhat did you learn or develop?

If this Al community should support you and/or the world even more - what would be essential?
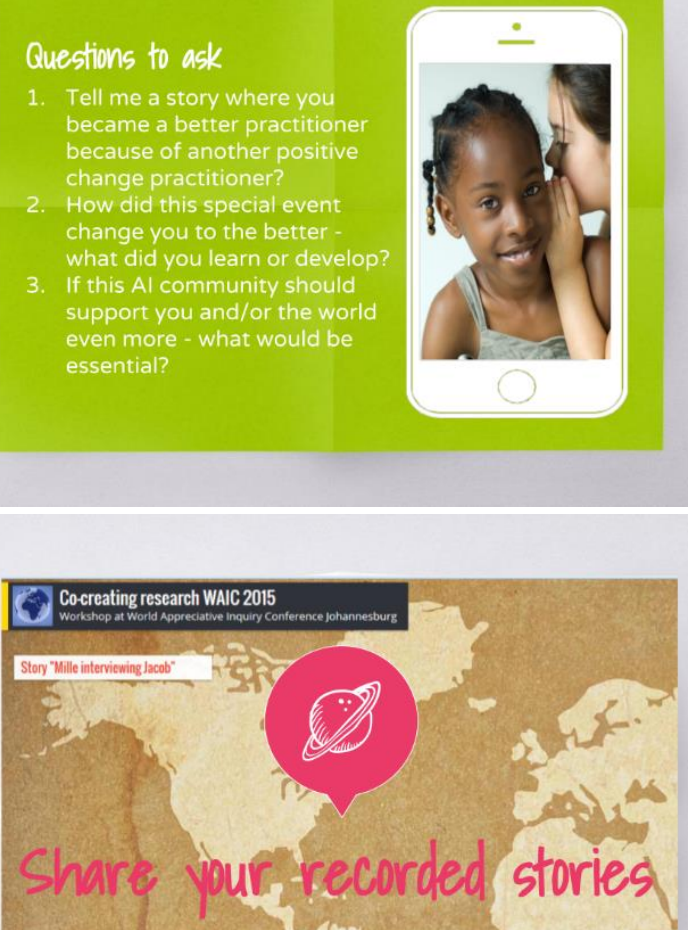

Find this padlet and upload your video/recording bitly.com/co-creatingresearch 


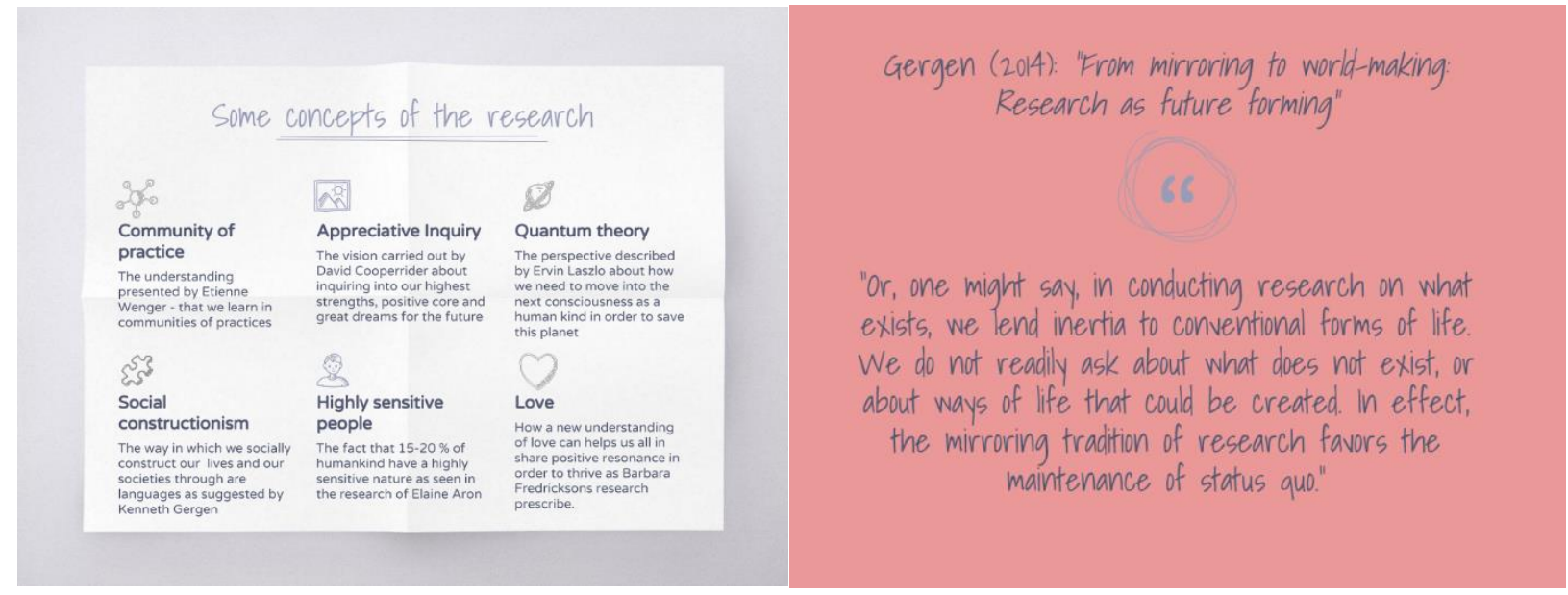

Gergen (2014): "From mirroring to world-making: Research as future forming"

"What if we closed our eyes and began to imagine the worlds of our hopes? What if we replaced the persistent rush to establish "what is the case" and began to ask,. "what kind of world could we build"? (..) what if purposeful and passionate visions supplied the source of inquiry? The aim of research would not be to illuminate what is, but to create what is to become".

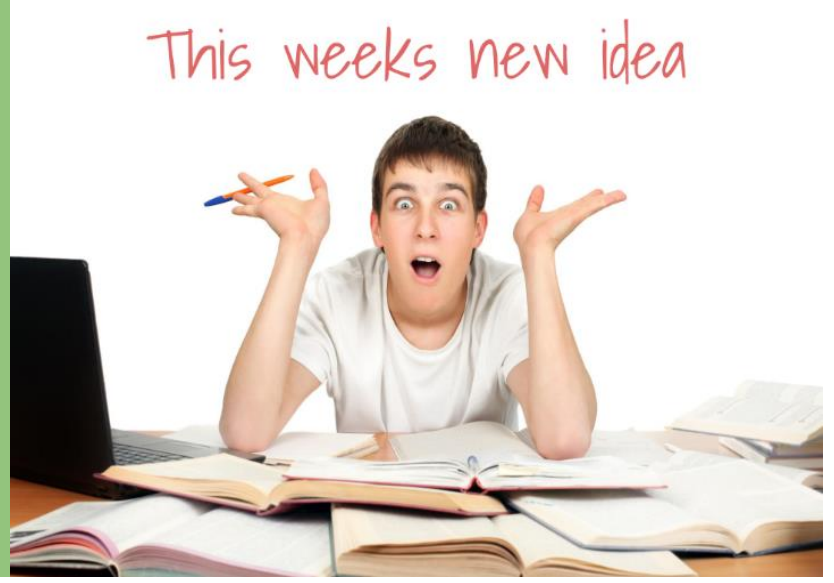


Communities that makes an enriching difference in the World:

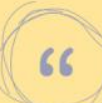

NGOs, Positive change communities, 12 steps communities, Green communities, Social responsibility groups, knowledge sharing communities (like TED, wiki, )

Social media groups (FB, tw, Linkedin), Peace groups, Countries, Religious communities, Political parties, Sport communities, Business / sectors, Rotary and ...
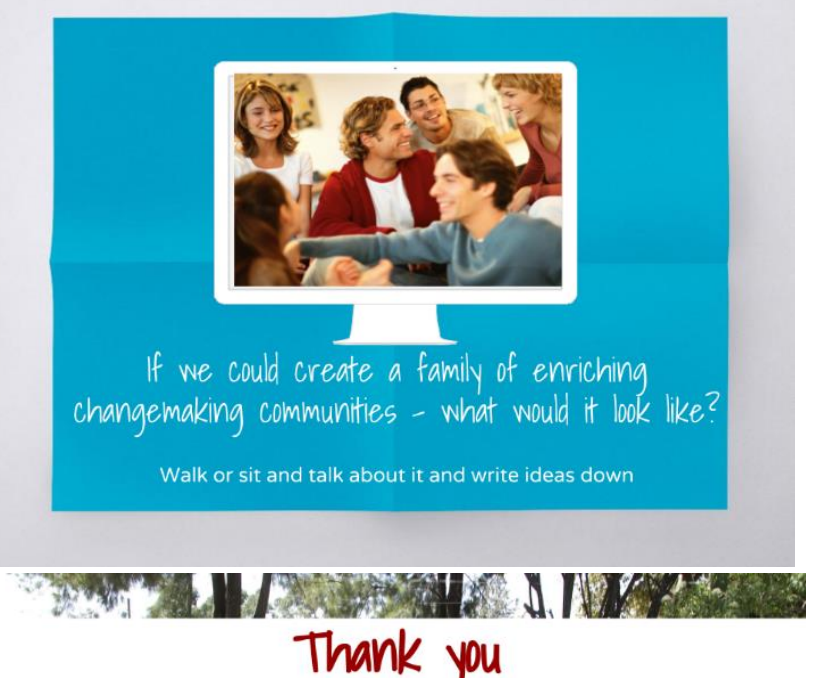

Thank you very much for co-creating research

\section{Enjoy}

The rest of the conference

and keep an eye on those

essential meetings with

other special practitioners -

you will change the world

together

\section{Let us}

Get out and experience

this beautiful country

together

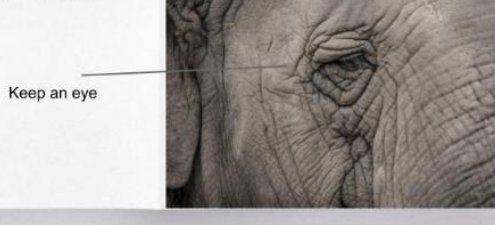

Thank you

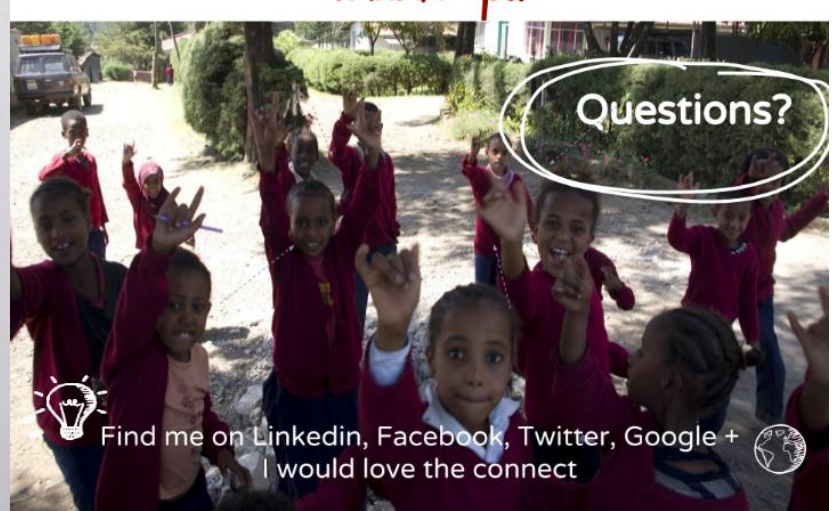




\subsection{Slides for the "Analysis Workshop"}

The slides from the analysis workshop held in Denmark, in Danish.

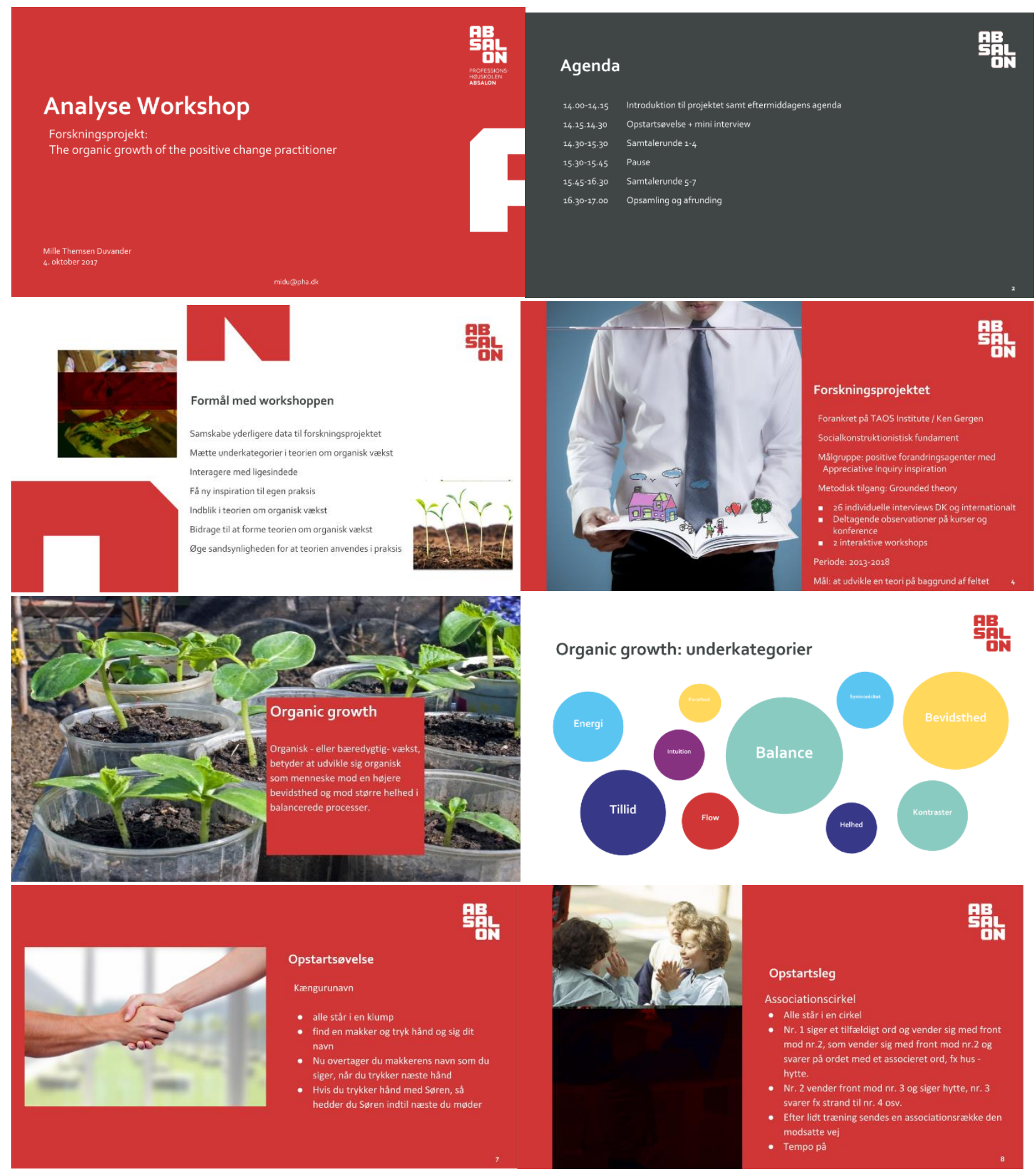



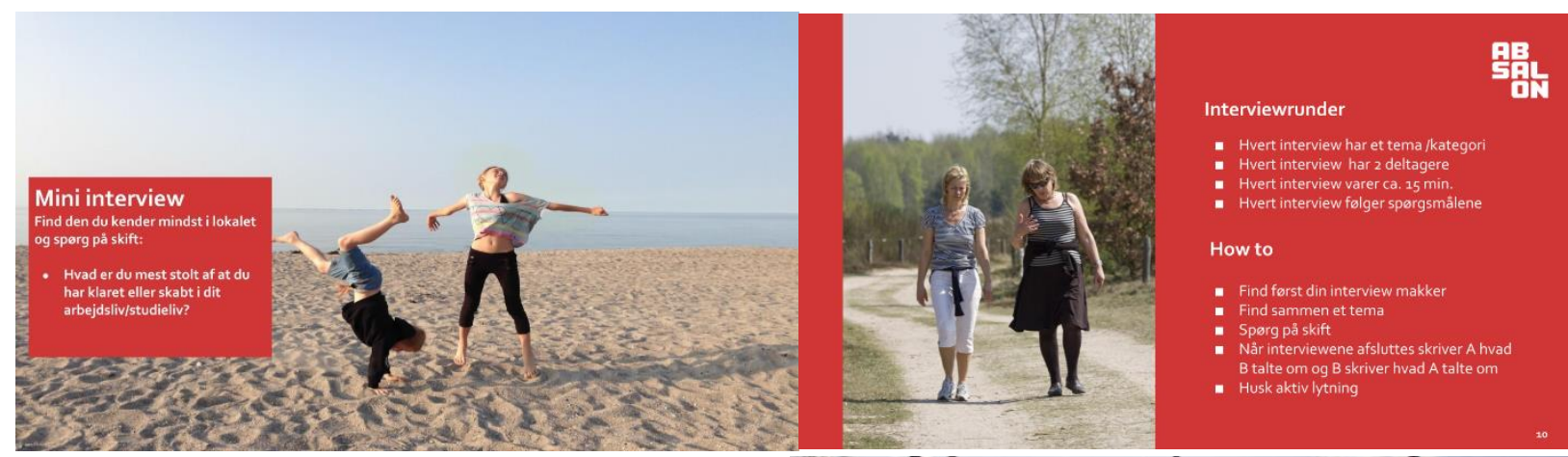

Hvem interviewer hvem hvornår?
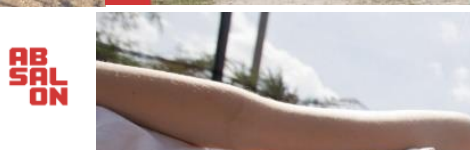

\begin{tabular}{|l|l|l|l|l|l|l|l|}
\hline & & 1 taler med & 2 taler med & 3 taler med & 4 taler med & 5 taler med & 6 taler med \\
\hline $14.30-14.45$ & 1. runde & $1+2$ & $2+1$ & $3+5$ & $4+6$ & $5+3$ & $6+4$ \\
\hline $14.45-15.00$ & 2 .runde & $1+3$ & $2+4$ & $3+1$ & $4+2$ & $5+6$ & $6+5$ \\
\hline $15.00-15.15$ & 3. runde & $1+4$ & $2+5$ & $3+6$ & $4+1$ & $5+2$ & $6+3$ \\
\hline $15.15-15.30$ & Pause & & & & & & \\
\hline
\end{tabular}

盟影

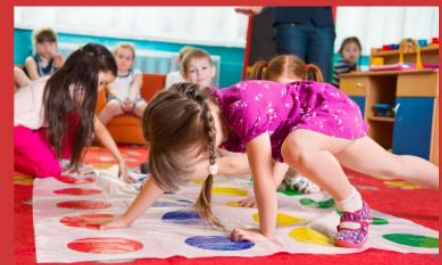

Kom i gang igen leg

Kaos i rundkreds

- rundkreds - alle tænker på en

anden person $i$ kredsen

- pả NU skal alle hoppe over den de

tænkte på på samme tid

- En enkelt gang til..?

Hvem interviewer hvem hvornår?

骂朐

\begin{tabular}{|l|l|l|l|l|l|l|l|}
\hline & & 1 taler med & 2 alaer med & 3 taler med & 4 taler med & 5 taler med & 6 taler med \\
\hline $15.15-15.30$ & Pause & & & & & & \\
\hline $15.30-15-45$ & 4. .rnde & $1+5$ & $2+6$ & $3+4$ & $4+3$ & $5+1$ & $6+2$ \\
\hline $15.45-16.00$ & 5. r.nnde & $1+6$ & $2+3$ & $3+2$ & $4+5$ & $5+4$ & $6+1$ \\
\hline
\end{tabular}

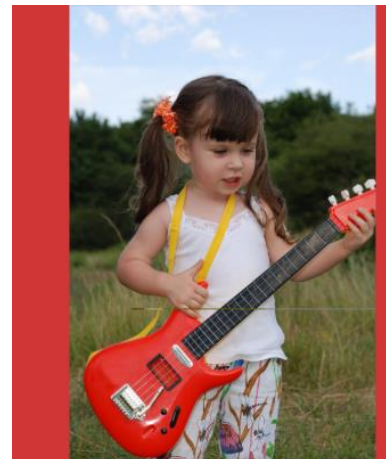

\section{Opsamling}

照

- Hvilke andre begreber er re

Hvordan hænger begreberne sammen med organisk

vækst?

- Hvordan er balance vigtio for at volse og

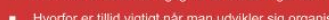

Er heling en del af jeres ucvikling?

Hvis ja hvordan?

- Hvilken del har givet jer mest energi i workshoppen?

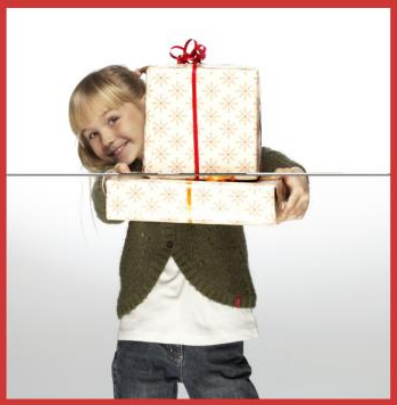

骂部

Gaverne jeg ser i dig, er..

- Alle går rundt mellem hinanden

- Năr man møder en makker skiftes man til

at sige: Gaverne jeg ser i dig, er...

- Alt, der kommer til dig, er tilladt at sige

- Stort og smắt, indvendigt og udvendigt

- Du skal nå forbi alle de andre 


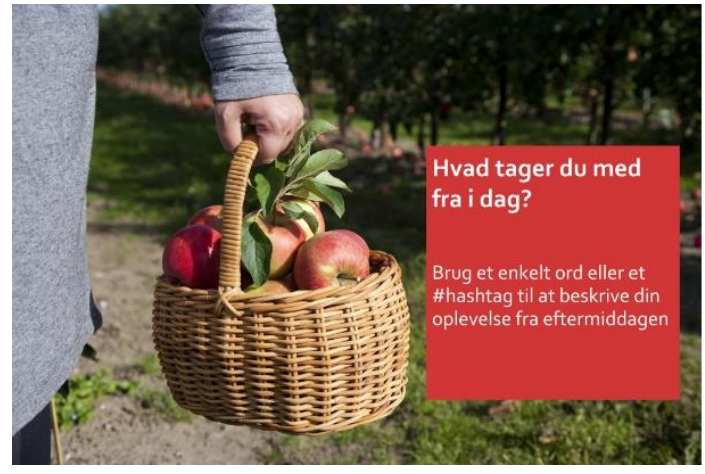

Ekstra: Fuldt overblik over interviews

\begin{tabular}{|l|l|l|l|l|l|l|l|}
\hline & & 1 taler med & 2 taler med & 3 taler med & 4 taler med & 5 taler med & 6 taler med \\
\hline $14.30-14.45$ & 1. runde & $1+2$ & $2+1$ & $3+5$ & $4+6$ & $5+3$ & $6+4$ \\
\hline $14.45-15.00$ & 2. runde & $1+3$ & $2+4$ & $3+1$ & $4+2$ & $5+6$ & $6+5$ \\
\hline $15.00-15.15$ & 3. runde & $1+4$ & $2+5$ & $3+6$ & $4+1$ & $5+2$ & $6+3$ \\
\hline $15.15-15.30$ & Pause & & & & & & \\
\hline $15.30-15-45$ & 4. runde & $1+5$ & $2+6$ & $3+4$ & $4+3$ & $5+1$ & $6+2$ \\
\hline $15.45-16.00$ & 5. runde & $1+6$ & $2+3$ & $3+2$ & $4+5$ & $5+4$ & $6+1$ \\
\hline
\end{tabular}

PA는 Af hjertet tak for jeres nærvær og bidrag

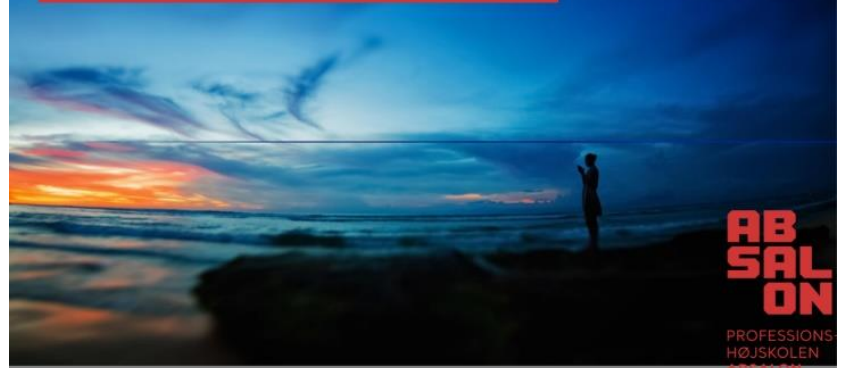

骂

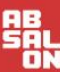

Øvelser/leg

Helligtrekonger

- Alle sidder ned

- 3 rejser sig op. Når de sætter sig ned, rejser

andre sig.

- Der skal hele tiden være 3 der står op

- Sæt tempo pá

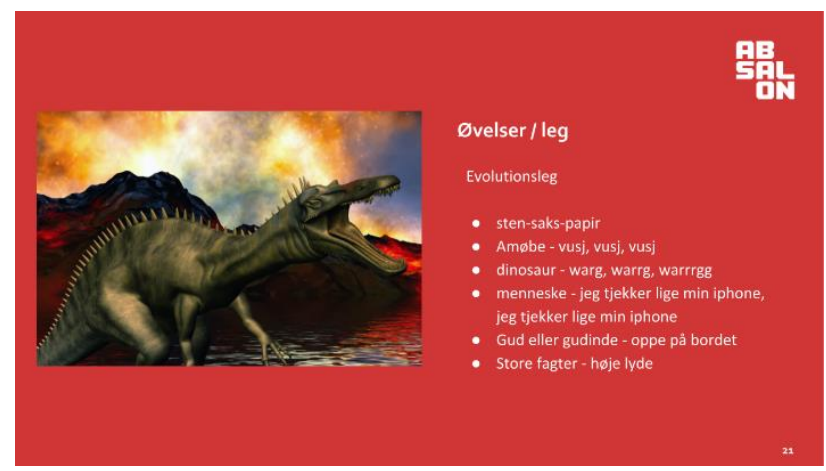




\subsection{Research questions}

During the earlier stages of the study, different research questions emerged in the process. In the following bullets are some examples of these questions:

- Where do you learn Al?

- Where do you train skills and competencies?

- What is the problem about learning Al for yourself?

- What was the idea from the originator about how people should learn AI?

- What is the wish today?

- How come the Al community feels fragmented and like a cliquey environment to some practitioners/newcomers?

- How come the energy is so high around world Al conferences and the energy is almost dead in between conferences?

- What can we do to enrich the community and create the best sharing around practitioners?

- How can we help newcomers to feel welcome and safe in the community?

- How can the community use its resources in the best possible way to support web users to get a good experience and meeting their needs in this field of area?

- How can a strong community fulfill its goals?

- Are there spoken goals in the community?

- Does the community fulfill the goals?

- What is the best degree between structure and chaos?

- How can a focus on structure and goals make a barrier for the community to thrive and develop?

- How can the community connect to other communities in order to better use capacities and be role models for others?

- How can alliances of positive communities be a real alternative to the organizing in countries? And why is that important at this time?

- Why is it important for Al practitioners to share?

- What is the good thing about meeting other practitioners? Why is it important?

- Why do the practitioners need to share online?

- Why do the practitioners need to meet up in the real world?

- Do world Al conferences create enough value? And what is enough value?

- Why do we need the Al practitioners to be as good as possible? 


\subsection{Overview of interviewees}

\begin{tabular}{|c|c|c|c|}
\hline No. & Date & Pseudonym & Country \\
\hline 1 & December 2014 & Kim & USA \\
\hline 2 & December 2014 & Cathrine & The Netherlands \\
\hline 3 & July 2015 & Thomas & England \\
\hline 4 & October 2015 & Alfred & Denmark \\
\hline 5 & October 2015 & Sarah & Denmark \\
\hline 6 & June 2016 & Sasha & Denmark \\
\hline 7 & June 2016 & Louis & International / USA \\
\hline 8 & May 2017 & Mia & Denmark \\
\hline 9 & May 2017 & Casper & UK \\
\hline 10 & May 2017 & Martin & Denmark \\
\hline 11 & June 2017 & Anna & USA \\
\hline 12 & June 2017 & Louise & Belgium \\
\hline 13 & July 2017 & Sebastian & Denmark \\
\hline 14 & July 2017 & Anna & USA \\
\hline 15 & August 2017 & Cathrine & The Netherlands \\
\hline 16 & August 2017 & Marie & Denmark \\
\hline 17 & August 2017 & Daniel & USA \\
\hline 18 & August 2017 & Thomas & England \\
\hline 19 & August 2017 & Michael & USA \\
\hline 20 & September 2017 & Christian & USA \\
\hline 21 & September 2017 & Carina & Singapore \\
\hline 22 & September 2017 & Carl & USA \\
\hline 23 & September 2017 & Oliver & USA \\
\hline 24 & October 2017 & Brian & Denmark \\
\hline
\end{tabular}




\title{
12.6 Quotes from interviews, observations and workshops
}

\author{
In the following is inserted a list of raw quotes from data, including statements from interviews, \\ observations and workshops
}

1. You have to live everything you teach

2. Al requires whole being

3. Wholeness is a premise of $\mathrm{Al}$

4. We are skilled in the quality we want to learn - maybe we have just not tried it yet

5. You have to unlearn the mindset about academia

6. It is a process of life if you let yourself do it

7. Whatever happens, you cope

8. Let go, let go of old things so new things can arrive

9. When I am stuck I ask, when have a tried this before? What resources do I have?

10. It is responding to feelings and reclaiming our position

11. Wholeness means that we humans are not separate from nature

12. We are wired for optimism

13. We are part of nature, not separate from nature

14. We have a natural orientation towards the sun

15. Everything is circular, not linear as we're taught from the Newtonian paradigm. It is about entanglement and connection and non-linearity

16. Al is a topic that you teach and a topic that you live - if you don't live it, it is not that powerful

17. I have been learning about positive psychology and humans do become happier when we are more positive

18. As human beings we are wired to see humanity being their best, follow their purpose

19. Synchronicity is like the universe talking to us

20. Reflexivity are important and to ask - what are my values

21. I read the book Entangled Minds

22. I wanted to join the conversation myself and organically, there had to be an answer, so I started the journey of a PhD

23. If the plant isn't in good soil, then uproot the plant and put it in different soil

24. Ask for help and surrender, the universe does provide the answer, this is how I do it

25. I have been learning about biology in the morphic field, quantum physics, neurological mirror neurons of the brain and complex attractor

26. I learned that I wanted to study with the creators

27. I was working with what works even before I met Al - with what we could make better

28. I have used Al in leadership across cultural borders

29. I have felt a pull towards what's working, I am an optimistic person

30. The focus is important, the focus on what can be better

31. Al is a natural fit with who I am

32. Organic growth is something that you find as your life unfolds, it emerges, it is naturally growing from your own circumstances

33. How am I showing up, because I am the designer. How do I present myself and how I interact with myself and others genuinely?

34. How am I embodying AI myself? I try to be generative, honest, inquiring and focus on what I want more of

35. People need to be able to journey - not that there's a "should", it is more of an ideal to strive for

36. Al became my operating system, there was a turning point when I embedded myself in the community

37. I use it with my students, clients, colleges, family and myself, but the closer we get in, the harder it is

38. If there is a mental disconnect there is a problem with integrity and there is a difference between doing $\mathrm{Al}$ and showing up as "Al" - the internal alignment is key

39. In every situation, we always have a choice and we can always learn

40. It is harder to be appreciative with my closest family than to people at the distance, and the hardest work is with myself with my inner monologue

41. I love the notion of organic growth, I understand it as embodying Al instead of in a more mechanistic way, this is more mature, intrinsic and a way of being

42. Al is a framework for whole communities and it is just how I do things now

43. My own learning journey started with an initial awareness - that Al existed - it came into my consciousness and I felt an immediate resonance, there was no convincing. I tried it in deep-dive experimentations in real time. After that I deepened my competency, trying to own my own voice and consciously thinking about practice and then I felt like leaving the nest and proactively expanding my own network 
44. The inner voice has been a challenge, to get back on track, but it helps that I am married to a very appreciative man - it is very relational

45. Crystallizing and embodying Al

46. Who do we surround ourselves with? Our inner circle? Do they give energy so that we become better persons?

47. I now keep a gratitude journal and it is a notable shift on the micro-level - and I show gratitude towards others

48. What do we want to see more of in the world? How do I be the change I want to see? It is about showing up

49. It is in the micro-processes, the tangible, the possibility and doability, like "today I will", it is in the habits. When we are embodying, we actually do them and they evolve into habits

50. The Al community is in a circular realm, ever ongoing cyclical season, collectively having organic growth, old wisdom and new wisdom, continuing between the learner and the teacher, and spiraling

51. There are greater impacts when people embody Al. If not, there is a cognitive dissonance

52. I think I have been overcoming challenges because I was in flow, I feel I have been fortunate. I just said yes and what I did was fun. I was open to the flow. At times it could feel overwhelming

53. It is a mental paradigm shift and there are some critical steps on the way, like self-awareness, how am I showing up, what are my intentional practice?

54. Al is a tool for the family also, a philosophy, a set of principles for daily life

55. My obstacles are my own, the feelings of inadequacy and being unworthy - I want to feel comfortable with my own voice, my own light and have acceptance

56. Sometimes I feel that I am not worthy, like the impostor syndrome, that people will find out, but I guess that is pretty normal and an existential condition for many people - especially women in professional spheres

57. Al helps us have language besides the normal

58. Organic growth is not a line, it is not the shortest way, it is a journey, a path, if they want to be proactive they can

59. There is a mutuality - going from a student to be a teacher, but it happens simultaneously and the teacher is the student over again

60. Organic growth is an invitation that never ends - it goes from an expert, frozen mentally, to never being done

61. The best learnings in my life have been personal experiences

62. Walk your talk is important - in grounded experiential stages of knowing

63. There are various stages of one's own path

64. Healing as a theme just emerged in my life, it was like there was a pull towards it

65. Al and the positive resonated naturally, there was an initial resonance with who I am

66. I was working with strengths assets and strengths on a smaller scale, but I began to move quicker

67. I became an author by mistake, the book was calling to be written, categories emerged and that build trust. It was so fascinating to work with this topic. I had to be vulnerable because this was new to me

68. I am naturally curious and ask questions and always have been, looking for connecting to people

69. When you are in a state of not-knowing, you are asking for help and the people who connected were just helping to let it happen

70. In the strength-finder I am a futurist / optimist

71. Connections are fabulous, I try to surround myself with appreciative people, family and great friends

72. I feel blessed that I do not work in a big company, when I feel a spark I can follow that - I have an easy job

73. When I attend a conference I always feel recharged

74. If there is an unresolved issue I try to find balance instead of fighting - I have a healthy mindset and try to stay healthy

75. Healing is all about relational practices, Al heals naturally and invites connections

76. I see healing as a dis-ease of isolation, of separation - it is balance and flexibility

77. Intuition is listening, noticing things other people do not and following the voice - one needs to trust even more

78. There is a messy space of emergence and the intuition helps - to let the group take ownership of the mess and their future

79. What I do is called positively reinforcing the energy, I give them permission to stay energetic and presence supports the process

80. Organic growth is random collisions around an organic emerging path

81. I follow three pieces of advice: plan well and hang loose, hold the space for what needs to emerge, don't just do something stand there

82. Stay in tune with intuition is what I try - my best self - then wisdom happens in the moment

83. There is a shared agenda in Al processes, where there is energy, importance and emergence, you can feel it

84. Peace, acceptance and forgiveness are important, and purpose can shift when changes happens

85. Every kid can learn something at home if we believe in the parents

86. I am worried about the employees who may have stopped practicing

87. Fun, motivation, happiness, learning curiosity, verbal language, stimulation, ask for help and know one's own limits are key value for the kids

88. One employee came back from a leave and just move on in the old patterns, so we needed to have a talk and adjust

89. I am trying to re-define appreciation and am interested in wholeness

90. The employees are responsible for the positive relation, the lifegiving 
91. Maybe the kid has just not seen it yet or tried it yet

92. We work systematically with what we have seen

93. In one case, the kid had a story about having a very complicated behavior and so we tried to shift the perspective to see the strengths and see his geniuses

94. Self-worth and clear communication are very important and we see every kid as a focus kid

95. The rich get richer and the poor stays poor

96. There is a difference between appreciation and praise and that is important in the work with kids

97. There was a time where focus was more on effect than on the activity and there is never a fact, it is just for fun and the kids helps loosen it up

98. You should not be appreciative towards your colleague, but approach them with wonder: can we talk about this, like I am having a hard time seeing how this is appreciative - give clear feedback - and it is important that they dare do that

99. There is too much visuality in the world, seeing things through multimedia, we need to grow thicker skins

100. I am mostly concerned with asking: Where is our humanity showing up in the world today?

101. I find that sensibility is to be aware of the wholeness of other people and of life, a compassion - emotions --a heightened and increased awareness on the relations in the field - sometimes the unspoken and the unobvious

102. I help people hope. I see people at their best, I lift people up

103. I don't manage, I love my work

104. It is about balance, also online and to product content, it is healthy to have variety

105. I value balance, I exercise, I bake bread, I meditate, I sleep and have social connections - I have time to total chill and to let my mind rest - but it can be hard to put these values to practice

106. Relational energy is very interesting, I work with jobs in Al that I love and feel high energy around big Al processes, that feel of the energy in the room, created by what is shared in the room with Al lens

107. Everything is about change, habits and beliefs, awareness constantly changing and there are new choices

108. The enactment principle in very important

109. Sometimes I just know intuitively, I get goosebumps, my heartbeat is raised, I feel butterfly in my stomach, and I feel a relief, like an acceptance and permission, like it is legitimate and affirmed by an authority - a personal liberation

110. It can be really challenging at the same time when you are going against the mainstream, but I try to take responsibility and choose the frame and language is very powerful for empowerment

111. I always shift the focus to talk about resources from the past story, awareness and imagination and to give voice to people, to see the possibilities for flourishing - if they can't find them in their own life, it is okay to imagine or look at others for inspiration

112. There can be resistance, e.g. in some places like the US Navy - there was a story where it was too challenging and then they stopped doing it

113. You need to integrate it into your life - it is woven into the life

114. I see most Al practitioners as being seekers and most people are already doing it and just seek ways that affirms who they already are in the world and support what they are doing - to find theories

115. It fits my personality make up - I am Al by nature, it is seen in my preferences, personality tests and VIA

116. It is about who they are in the world

117. Synchronicity is a union concept - a coincident, but maybe not - alignment at a certain time

118. Contrasts are a human condition - it is knowing the difference, the yin and yang - a certain experience and the being able to know the difference - the abstract and the experience

119. Energy forces is what energy you are putting into it - it can be thoughts, body, eyes, picking up certain cues

120. Synchronicity happens because we are interconnected, you know quantum theory?

121. Soul, body, mind are connected and high positive energy is possible when exercising

122. I believe that the Earth is self-healing and that humans are self-healing

123. We are invited to open our hearts all the time, but do we dare?

124. I work with Al as learning from excellence and when serious incidents happen in the workplace, we cover it up instead of learning from it, it is a question about safety and we invite in a constant learning environment instead

125. My very first exposure to Al was in a local, international society for performance improvement meeting

126. It was a presentation of where she was engaging the whole group in an appreciative inquiry into what we wanted - where we wanted to go with this professional organization for its future

127. I have always in my professional life and in my work gravitate towards identifying what is working well and then activating the things that are working well

128. The structure of appreciative inquiry was new to me at that time, the underlying principles were just part of how I thought about group dynamics and what worked well

129. So, very early on in my career, I learned that I needed to focus my questioning around those things that are working or reframe things that weren't working and so help the process of reframing

130. So, I use appreciative inquiry because it works, and because it engages people, because there's energy around it, and $\mathrm{mmm}$, because I believe that it's a productive way to get things done

131. For me it was a natural fit 
132. It fit that way I approach my life, how I have been as a parent, very early on, when I would talk with my kids, about their day, rather than just saying how was your day, l'd say, tell me a story about the best part of your day

133. This was long before I had put a name, heard of David Cooperrider, or put a name to that process, and what I'm finding now is that I used appreciative inquiry in my faith community

134. I am also on social media and over the years since I started appreciative inquiry, I am noticing more and more people focus on what's working, post about gratitude, and make space for people to share their stories, and so there is an organic rippling, that is completely outside of a structured intent, you know, you couldn't predict that it would happen this way

135. I love that about the process, I just love this unsupervised positive action towards our goals

136. She's been listening to me, seeing what's happening in the congregation and... Effort, that are now kind of moving forward without any particular push

137. That energy there, that's organically just evolved - what it means to me is that, it takes on a life of its own

138. It's not something that is planned and, you know - put a timeline necessary to it, and you don't have people in charge, its spontaneous

139. I think that every time you get people involved and you empower them, and they are bringing their strengths - there may be strengths there, that you just didn't know, because you never asked

140. And once you have given people permission to step outside of their defined role in an organization or in a community, or in a family, and you give them kind of a space to bring their gifts and to activate their gifts, then you can't predict, things can ripple exponentially in directions that you wouldn't have predicted

141. Because with appreciative inquiry, you're asking questions, there is a certain level of predictability and that, with the project (ed.) our topics were transformative moments and times when people felt drawn to belong and creating a far-reaching and positive community presence

142. I'm seeing more of those things happening and so from that perspective, that is predictable, because those are the areas that we questioned into, those are the areas that we focused on, we called attention to, so from that perspective, it is predictable

143. If you ask me at the very beginning, so how is this all going to turn out? Wow I don't know. And people can be uncomfortable with that

144. Let's just say we took it to a cooperation and they are right in the middle of a major lay off, they're cutting $1 / 3$ of management, and so they are going to have a lot of pieces to pick up after that is done and their culture and their moral is very, very low, so that's a perfect time to come in with an appreciative inquiry because my experience with appreciative inquiry is that it brings energy, where energy needs to be, where energy works

145. You can spend a lot of energy unproductively in complaining or saying that'll never work, or protecting your space and your department, protecting your position or protecting your authority and when you broaden the lens, using an appreciative approach, then you broaden it out to a point where everyone can agree and until you get to that point, your topic is not big enough

146. That's when you know that you have got something that will work, that people can get energy around, with this particular cooperation, it's that space that happens between desperation and hope, and right in the middle there is an incredible amount of energy and that energy can go towards desperation or it can go towards hope and appreciative inquiry, it's a process to bend the arc towards possibility

147. It's really been tremendously supportive to have someone to bounce ideas off of, someone who is actively engaged in thinking about the inside process of becoming an appreciative inquiry practitioner as well as the outside process, because both are there

148. The really interesting thing is, you know, that what we have found is that our conversations help to inform our personal and professional lives. It enriches

149. So I was actually to call her, and then I went over to her and it was after the first workshop that we did together in Florida and before the second one, I went to her home and we sat and we just, you know I haven't talked with somebody, because I have been doing all this reading by myself and I felt so isolated and it seemed so silly, reading about a generative process being together all by myself - I needed someone to talk to

150. I was just like, oh my gosh, I've got so many feelings I want to talk about, so it is critical to be able to talk things over with colleagues and just... It's part of professional development but it is also part of personal development.

151. If all you do is sit and read and you're still in your own thoughts, it's a narrow lens to view and to talk to others, you see other people, you hear other people's stories and it's just, it broadens the lens, it gives you a wider view and it's putting the focus further away from you, than if it were just your own thoughts

152. I can keep a journal and, I keep kind of a learning journal about appreciative inquiry and when I read books, I write down what I think about, but I love to be able to talk it over with others

153. Who I am as a professional is an extension of who I am personally

154. The more authentic I can be, that is, that my professional live, my personal life is the foundation of my professional life and so I don't think that you can develop professionally without developing personally, it's all intertwined, it's not separate

155. The best I have learned about appreciative inquiry is to do it, it is important to read about it

156. I would say that keeping a journal of how you do it and what worked and what didn't work or where you were challenged so that when you have the opportunity to be with others, you can, your questions can be fresh, so you can ask other people "this is where it got sticky for me, how did you, have you ever experienced this and how did you handle it?" 
157. I had a project plan and then I kept a diary of the project, so I can go back, and I can look at what I thought was going to happen and what did happen and it's very helpful in planning next steps, planning the next project

158. I think it is really important to read a variety of perspectives on how appreciative inquiry is used, because it's such a flexible process and so different people use it different ways

159. So, I'm very interested in the evolving practice

160. What does it do to stay connected with the evolvement process? Well, because we're always learning and we're making meaning together, it's a generative process and so even if at the meta-level, so not just one project but many, many projects, there are things we can learn as we look at them as a whole

161. My belief is that we can't get better as a field if we don't keep looking at what we're doing and talking about it with each other. It's an evolving field, it's not done yet

162. It's very flexible. If you're asking questions in a corporate environment, the values that come out of those conversations are probably going to be, you know, around business values and work ethics and that's valuable and useful for that setting. If you're going to a faith community and you start asking about high point experiences, then you are going to get values perhaps around maybe transformative moments and times when people felt drawn to belong. So that is entirely different emphasis. The process is the same

163. The outcomes can be tremendously different depending on who is at the table and what's important to them and where they find energy and I think it work

164. It works well with different ages, with people widely varying, with large communities where what they have in common is a geographic area. Other than that, they are very, very diverse. And certainly, the work in Chicago and of course Cleveland and Atlanta and many, many cities have used Imagine, like modeled after the Imagine Chicago project

165. It can work well with individuals, it can work well with families, it can work well in communities, it can work well in non-profits, it works well in large international loosely associated settings

166. It's worked very well with the global - that interfaith project, was hugely... I mean to get so many people together of different faiths was pretty remarkable

167. I really think that as I have developed as a positive change practitioner, that it has helped me to see a path through difficult situations that seemed stuck, when they really weren't stuck

168. I think that sometimes we can't help it but we have this like little troll on our shoulders and the troll is saying things like "that'Il never work" and "how could you dare to think about such a big idea, you're just one person" and you have this troll on your shoulder and I think that the more you develop as a practitioner, the easier it is to go "off the shoulder"

169. It's been tremendously helpful to me, it's helped me in my relationships with my son, it really gave me a path through, so he is truly loved by me, he trusts me, and you know, I mean, we have had a difficult time for a long time, and once I started focusing on what was important, what I wanted in that relationship, and the positive, it made my path so much clearer

170. I didn't feel compelled to talk with him necessarily about what was wrong or what wasn't working and I begin to connect with his highest hopes and find out what they were and then it gave me much more to talk about with him, it gave me things to have in common and so I truly believe that this is, strength-based process, it opens the mind, it opens the heart and it gives me a will and energy to do something, that I might not have thought possible 10 years ago

171. You know some of the attributes of someone who has an appreciative intelligence, and (Tojo ed.) he talked about someone with appreciative intelligence, they have resilience, they have the ability to reframe, they believe that their contribution matters and they're persistent. And these are all very important attributes, because - you know - contrary to what somebody might think, if they're looking in from the outside of appreciative inquiry, they might think that we're all just like wearing rosy glasses you know, and that's not the case

172. It is not that I don't see, that things that are working better, it's that I'm able to, I have a desire to see a path through and a path through needs to be built on strengths. If you build a path through without a clear foundation of people's values and their core strengths, then it's not going to last and it's not going to be embraced, so this inclusive "all-voices-heard", where there is inherent worth and dignity to each person and their contribution, that's where the magic is

173. These shootings can't continue. We can't as a society continue like this, we can't go from one to the other, you know, without being profiled, and potentially killed, so the reason I bring that up is, to me that's all of the things that are happening are the contexts, which is the real context, it's having eyes for exactly what's happening moment by moment and being present to that and then starting there

174. I think probably new practitioners get kind of stuck in the high point moments and they lose the transition to actual action, what happens, how do we take this energy and move it forward, which I think, that's what's important about appreciative inquiry, is that you have built the foundation on strengths, then what do you do with that, and that's the struggle that I think any practitioner meets to face and continue to work with

175. Not everybody is going to work at that level, but they do have a level they CAN make a difference at. And it is individual and individual minds and individual feelings, individual spots, that when you get them together, create momentum for change. So, we're not this, we can't never lose track of the fact that we're all individuals and we all want, you know, all of us want a voice

176. I've been reading appreciative inquiry practitioner's blog and websites, I would like to see more people bringing their own practice into the conversation as opposed to just kind of "Here are the 4 or 5 steps" or "Here are the typical questions" and because that doesn't take us forward

177. Because you hear about this and then you hear about this and you're wondering, what happened here 
178. Since you've said that, you encourage me to bring, you know - because I have all the documentation for the "communicate with intention" project, I documented it particularly so I know just what said, I have all the documents, there could be a rich conversation around what I thought was going to happen and what actually happened

179. There are always perfect learning opportunities

180. Peer to peer are very important as part of our learning processes

181. Alignment, intention and inner voice are key in the work

182. There is an inner authenticity and always expanding possibility

183. And for me it is a question about alignment, connections and trusting the wholeness and a lot of that is a consequence of energy and a lot of it, a person's energy and whether you are resonating with it or not and the energy fields of the people

184. Readiness is when there are sometimes great resonance and other timers where nothing lands $-I$ have been reading about "anticipating" from Zen Buddhism and very much believe in timing

185. I guide people to practice in a small way and you will feel if someone is ready to take the next step or hear from you what to do

186. I find that feelings don't get much space - and it is really woven in the tapestry - El into Al

187. The most important thing is to take care of yourself - to know what you are willing to and also must!

188. That is this pull and push factor and we need to be ready to be ready

189. In punitive systems there are no allowance for mistakes - do you know the 7sevenspiritual years?

190. I have tried spiritual retreats and felt uplifted, it is about the uplifting, the higher levels, your intentions. Is it possible to have fun in the academic world?

191. Have you read the book of Frederic Laloux? Reminds me of Dalai Lama and he talks about being authentic and have intentions and also about credibility

192. I'm leaning into the homecoming event, it is smaller, with $40-50$ people and doing an Al process

193. You need to take small steps, I call it the small steps way, it is in the micro-moments of possibility where you can feel the mutual excitement. These steps count as much as the big ones. There are some psychology professors working with this

194. Do you know a course in miracles? The distinct between only love or fear. It is about how you raise your own vibration

195. Barbara talks about the negativity bias, how people will always have a tendency to focus on the negative. The brain works like velcro on negativity and like teflon on the positive - and Daniel Cornerman goes on to talk about collective beliefs.

196. Simplicity is at the core

197. Al is about gratitude and appreciation and there is a difference: Gratitude is about having overcome something - appreciation is a higher level word, it is loving what is. It is about being and that openness you feel where there is space and you feel timeless

198. The reason why Al is so good is because it is an interruption in the heart, feelings are allowed in Al, it is powerful, people learn more from the positive way, because there is time to connect

199. The power of attention - this is where the power is

200. Organically grown means the undoing of limiting beliefs

201. Beliefs of shortage or lack - it's got to be flawed

202. There is only a reflection of ourselves out there

203. $50 \%$ of staff is chasing their tails, they say I'm working too much, the dynamics are not good, I need more time - then they do spiritual studies, retreats and physical exercises

204. I say to myself: I'm always expanding and my own beliefs frees my tensions around.. and then the topic

205. When talking about this organic growth I can see that in my own life, I have not had big obstacles with manifesting my dreams. I have a high self-worth and clear idea of visions but also the ability to carry them out

206. It is about flowing with the stream, going with what happens

207. Relationships are what drives me, and bringing people together

208. A thread is fun, and fun is following the flow, fun and flow are closely tied. It can be real hard work to have fun and difficult to let it unfold and challenging to follow your heart. It takes perseverance

209. Be clear about your beliefs - what you think is important

210. It is a struggle to be Al every day, living $A l$ is challenging

211. There is a difference between knowing and being - you need to feel what you are intuitively drawn to from your higher self-- it is required. The best in every situation

212. All aspects are invited in - space to voice concerns, fears, negative feelings, on the way to appreciate - this is wholeness tell it like it is! There is an acceptance of flaws

213. The initial Al interview is about questions and stories, personal questions - stories full of meaning

214. Move from the head to the heart, connect with yourself and the other person

215. My daughter lives in the city where great Al people meet, and it felt like synchronicity because an important Al practitioner became my friend and also lives there

216. Without connection you can't affect change

217. Growing organically is due to high point moments - it is amazing, I do not have an explanation, I do not believe in a higher power 
218. I have always had an intuitive quality to see beyond and see the strengths, I have been admired for this. I love deep connection and the kind of persons that I wanted to hang out with was intuitive.

219. It just all fell into place. Like there was something greater. This was due to skills like: seizing the moment, finishing up, carry through, being well organized, write well, thinking boldly and going after the dreams

220. I have been successful in a systematic way, but the miracle is to be embraced. The opportunity is one thing and to dream it, it is another thing to do it

221. Sometimes I think who am I to be telling others? - but for me it is the simple life

222. Strengths they can rely on

223. For me simplicity and synchronicity are close - things were meant to be, when I found David, we did the development projects, and I have been doing leadership programs and came from a deficit-based way

224. Organic growth is a deep feeling from the beginning and on and on again, it is a mind body connection which is also clear in $\mathrm{Al}$, in the roots

225. My journey began with the relationship to my mom, she made me do mirror exercises - it sound very simple, like I am a happy girl, but it worked

226. I made a journal about future hopes and I wanted to broadcast the benefit in Al. Stories became a global force of power and technology made synergy

227. Watch out for what you wish - it may very well come true

228. Right now, I am in the middle of a small hope, a world inquiry that has a synchronist history - I asked a question to a friend of mine about impact and we were like "how can we not have done this yet?" It was so obvious

229. We cast our eyes and our hearts into the future, it is about awareness and attention

230. Synchronicity is a thread of $\mathrm{Al}$, there is research on the emergent principle - it is about noticing and connection. What you believe is important - it is a connection to the universe, to the whole

231. This is what I have been looking for all my life

232. As I understand synchronicity, it is good things happening simultaneously

233. What we went through those seven years was a living laboratory. A lot of experiments in leadership, organization excellence, consulting teams, management

234. There were some of us who were so interested that they said, can we have a course and then Anne and Walt organized, I guess, one of the very first Al courses in Europe in 1995

235. And when this lady talked about strength-based change and, I guess, even though I don't quite remember our conversation or talk, but it had to do with building from a basis of trust and respect, I thought that was, I guess, as a human being that is very important to me

236. I know I was attracted. I found Walt Hopkins' course at that time very interesting and that was in the beginning of the 80 s, to look at negotiation, not from win-lose perspective, but from a win-win perspective and really, if you were to take an attitude of trust, what a big difference that made

237. And when they said, well let's organize a course, I immediately said yes, that is something that appeals to me very much

238. I guess a deep respectful attention to one another and looking of life from a perspective of "let's see if we can create win-win situations" was something that was, and that is, very important

239. I have been to various courses and I think the most important, the ones that made the biggest impact was the first one with Jane and Barbara, that was an eye opener

240. That was a conference where David was, and that was an interesting conference because Al didn't work very successfully there, I mean, we were all, I guess practicing and looking for it and it was not a tremendous success then

241. A terrific course with people from South Africa, people from India, from Latin America, and that was really, that was a fantastic course, simply a fantastic course, fantastic experience

242. Well I guess it is the connection with people and with people like Sallie Lee and Tish and a few others - Ada Jo and Ron Fry the connections are still there - it is, I guess in the end, Al is, you could say, a way of being, that's a least my view

243. Al is also a methodology of course, but it is also very much a way of being and you connect to the people you find are on some sort of the same path, the same struggle, the same search and so that course was a fantastic experience, because of those people

244. I do remember a few things and a few topics but what I remember most is the people

245. I experiment, I would say, quite a bit in trying to see what happens if you - if you take a real appreciative stance, if you put the trust in people, if you believe that what is there is right, if you can look at that from a perspective whereby you judge as little as possible, we all have our beliefs and our own realities, really try to open up

246. And sometimes I experiment by just using the principles and not talking about the 4Ds and see what happens if we take that attitude, this appreciative attitude so to speak

247. I experiment with new additions e.g. as long as it is in the line, with the Al where he says, we are mysteries to be embraced

248. I think the most important thing I think I carry with me is the fact that I when I see a group of people, when I work with them, regardless of whom, I make a very serious effort and these days that is becoming easier, I think, I make a very serious effort see the potential and the possibilities in the people 
249. I've come to believe that we all have to learn our things and that basically no one gets up in the morning with a notion that he or she is going to hurt somebody else. that may have developed in a course of a life is most unfortunate and sad, and, but normally I believe that we really are seeking the best for ourselves and for other

250. So that potential and those possibilities, that is what I bring, that's what I bring to my intervention and my engagement

251. I am very much, I would say, addicted to people, cause I feel that I'm traveling more-or-less path similar path with

252. And I know that I really can learn a lot from conversations I have with others

253. I was fortunate to be invited to become part of a group with whom they tried to lift Al up in the world, so this is sometimes called the founders group, it's the group that organized the first conference. So she invited me to join that group and I found the learning fascinating, it was like we struggled to find the purpose and principles around Al

254. So, what is it to be such a group, and that's been, that was a real struggle, and therefore very strong learning

255. It's not only a relational concept, but if you are traveling with people and you're doing something that you're passionate, both feel passionate about even if you have different views, it is wonderful to see what learning takes place

256. What physical meetings do to me is that you can exchange information and knowledge and probably experiences where I find it, that if I want to really connect to the whole, almost literally to the whole person, I have to see them

257. And then you can sort of slow down and there is place for wisdom and thinking of the whole and being of the whole and that's why physical meetings are very important

258. I guess to me it's important that it's not I mean just once, but that there is almost some sort of regularity in that so that you see each other regular. And regular maybe once every two years or like that, but that's okay

259. Online conversations are important too, because even though there is only a picture, but I can see and I can feel you now

260. Somebody doesn't become important because he wrote an article, he wrote a paper, somebody becomes important to me, only after I have had the experience of meeting them

261. I can acknowledge that, that person may be important to the community, but he may not be an important person to me as I have not had the chance to meet him and connect with that person - let's say as a whole person

262. So he is only important from, let's say a knowledge perspective, not from an experienced or wisdom or even a spiritual perspective. Then I really need to meet somebody

263. The world is so full of things, at least that (...) filled with things that we need to do, and everything is speeding up and so the amount of mail and the amount of content almost seem to explode

264. It might be very good if you connect to so and so or give them a call that might help you on your next step in growth regarding $\mathrm{Al}$

265. Everyday look at something in your world, from let's say a challenging social constructionist perspective, so something which you, I mean it could be as basic as looking at the traffic and everybody hurry and driving on the right

266. I can only do that by being in balance

267. I need time to rest

268. I believe most thrive by being in flow and balance between actions and rest

269. I need time to adjust and to play

270. Maybe balance is just something we chase the whole time

271. The opposite is an mechanistic way of growing, where the process are controlled and forced

272. Follow what excited you

273. I was leaning into the flow

274. To be in balance I need to have my own energy channel free so I can hear my intuition and follow those instructions

275. I like to keep it simple so I have three simple questions that everybody can understand in my processes

it was just like there were very few obstacles and things seemed to fell into place

276. I live my life out of synchronicity, I approach life like that and see the results all the time

277. I am fortunate but to be able to be fortunate I am open to the flow and I say yes when somebody asks

278. Al heals naturally because it invites in a curiosity and a presence and a deep listening in the relation that heals

279. The most important thing for me is the undoing of my beliefs.

280. I do not think about healing all the time, I only take responsibility for healing certain patterns when they bubble up in my consciousness, when they are ready

281. Soul as the first condensed form of energy

282. It is very important to trust the process

283. Trust that it is always the right people who are in the room

284. By this time in my life, I had a strong belief that "life would provide"

285. It is important for my employees to feel accepted

286. I say to myself: Everything is going to be alright, it is natural to feel that way, you did the best you could

287. I teach my customers to be kinder towards themselves

288. The book emerged out of situations happening in my life

289. You can only have eye for what is emerging if you have presence, time, relax, no stress, patience, flow - if you are in the moment, if you look for it --if your mind is set on it

290. The more I listened, the more I was able to hear the others perspective and therefore went into dialogue

291. We don't really have the full understanding of what it is and then we call it energy 
292. There were an initial resonance

293. Humans are the connection between heaven and Earth, but only if the energy can flow freely the people were energized every time

294. It feels light to come into a business and give them some energy and inspiration

295. We are led into the noises and pressures of this world, because that is the strongest energy and the strongest energy always win

296. Then do more and more of what excites you

297. I feel most resistant towards my own growth when I try to force something that may be premature or if the pace is too high, then I need to slow down

298. You need to respond to feelings - to understand that we are not separate from nature

299. They need to do it in the whole setting, so that everyone knows what is going on and can learn from that

300. The whole that sums up the whole of a single human person is a very fine instrument in tuning in into vibrations

301. Interconnectedness is the most key factor in the work with Al

302. Connections is what everybody is looking for, but they get distracted by focusing on the problem

303. In every situation you can basically choose to feel love or fear

304. The most important thing is to keep yourself happy and safe (...) to keep your own energy field clear so that you are the best possible tool for the world and your surroundings

305. It is powerful, very simple, everyone can do it and the power lies in the questions, it is almost magical

306. Everyone has the ability to some kind of source that are both without you and within you - and from that point - there is an ability to create miracles

307. It needs to have some aspects of humor and fun in it

308. I sometimes feel doubt about my own creative abilities but then I remind myself that to make mistakes is a part of creativity

309. I try to have a high energy level

310. We just kept on doing more of the stuff they were excited about and less about the stuff they were not excited about

311. You can use anything to change belief.

312. There are two buttons that you can choose, either press the red button or press the green button

313. I try to do that with education, with what we learn, about the leaves, with the words that we use, so I really try to become very aware and very courteous of what it is that we do and I DO

314. I do it because it keeps me open - whenever I do an intervention or have an intervention and may even be an intervention with myself. To be open to whatever is there. Not to be locked in - this is because it is like this

315. So it's traffic, maybe it's relationships, maybe it's education, maybe it's your own, how do you put the dishes always in the same spot, small and big stuff but yeah, yeah, just one example a day

316. Every day take, take the time and the silence to I would say realize the importance of the relations you have

317. So, I started a long time ago, already even before I started to know Al my practice and my exercises by doing yoga and the my meditation and I guess the most important piece is the meditation

318. That meditation is always around the people that have brought meaning and sometimes it may be sad or angry meaning always brought meaning to my life and helped me become who I am and I need, you need moments of silence for that

319. All will benefit from reflecting on the importance of the relations that you have and what they have brought you and thanking them for that and -as said- that may be good or bad and then - take the silence, take the moment and do that in silence

320. I need this type of spiritual practice to, this discipline to keep this open mind, but what I do believe, so and I don't know other people may use or need different things, but what is key is that you do things in life, that really help you to keep an open mind

321. And for the miracle that the other person is

322. The practice of meditation and silence has been very, very helpful, because in the business world, I mean, I would have been diving into providence law statements and balance sheets and all the things that need to be done and to me, it has been helpful, so I can sort of step back and, and be in the silence

323. That's also one of the reasons why I motorcycle, so there is no disturbance by phone, I do not get tempted to call and just by myself in the moment, trying to drive safely and in joy

324. What makes you a better Al practitioner is when you not only use the stuff but also believe in it

325. The open mind is so essential because if you do not at least have a sense of how important the other is and you can only really see the other and yourself by the way, if you have an open mind from all the things that we have constructed.

326. So if I can really look at you or your friends or my children or my friends or my world around me from - I would say - from a perspective that it is a miracle, that it's here a miracle with a purpose,

327. If I can only say have that open mind and do whatever that miracle might be and whatever that purpose might be, that's the only way for me to really connect to somebody else

328. If I start with a question, I start to put on all sorts of things in there, like good which is a construct, like bad which is a construct, but if I just say wow, this is a question and it's a question that's being asked and let me answer it as sincerest as can be, so sincere in my words that means some sort or form of purity, so from within and I can only do that best when I have 
an open mind, not locked in from the perspective that you may have the wrong believe or you may do things that I do not approval or whatever

329. I think it is to be more connected, that would be my dream

330. In one of my communities they talk about putting CCTV, for security. But when they say, having conversations with six neighbors is what make me feel safe

331. But it is not really something you recognize very often, and then they try all sorts of ways and getting that need meet, without really challenge it. I think that everyone wants to be connected to and listen to

332. Being seen at the human being, who they are

333. They were all very passionate and always challenging the counsel, criticizing it. And we went in and asked them to talk to each other. And they were all so delighted because until then all their energy has been focused on the counsel. They hardly knew anything about what each other was doing.

334. I heard a story from someone who is mentoring somebody, she felt like the gap between them were quite big, and they ended up doing a session together about values. And in both discussing what their values were, they connected.

335. That was a micro-moment of connecting....

336. I came to think today in session, the underlying assumption of research is, I do not have information and I need to get. He was questing fundamentally reality. He was saying if you go along with social constructivism, then everyone's reality is different. So whose reality are we talking about? ...So I come to think of research unless it is appreciative research, it is formed on deficits...so we don't really know how appreciative research look like, do we?

337. Wow, it opens my eyes

338. But you are good enough already...Knowing that you are good enough

339. It is really hard to use it in my private life, I am only human after all, but we use it when we supervise caregivers, because we enter their private home and there is no use in just telling all the mistakes - we need to look at the good stuff

340. Al needs to be combined with something else, we cannot just talk about the good stuff. We need to be able to give clear feedback also and talk about what does not work

341. Before this interview I did not want to re-read about Al because then, you know, you might as well just look it up in a book, but now I want to read my notes again. It may be that I could become a little better in using $\mathrm{Al}$

342. When we become honest and vulnerable, we let go of our defense mechanisms, and then we connect

343. It is the same in a group, you feel you are an individual and then something happens and then you feel like a unity - like one

344. If you can connect in a group then you can connect with larger groups like the society, but we have a separation culture in our country and we want to change the way we are present with each other

345. We take all the stigmatized groups - they find out about their own self-worth, this lets them leave their offer position and that raised their worth

346. I do not use AI directly, I am not good with boxes, I use it intuitively - to find out what is working, that is my philosophy

347. Of course, you need to look at the problems as well, I work a lot with the participants to be active themselves during the sessions

348. If I should do AI, I would grab the 4D model, but there are loads of other models and I am best at creating my own. The model needs to support the output we want, that is the most important, but you need to listen to the group - it is more important to do what makes sense

349. Al is one of the things I am mostly inspired by - after four hours of working with the association for depression I ask a lifegiving question - that is typically what I would come up with

350. We create a space, a meeting, safety where there is no wrong or right and this creates connections. It is meaningful to me to create a space where people can be themselves and evolve

351. There are way too few spaces for people to be themselves and unfold. it is the most beautiful thing to see how people fold themselves out and heal

352. You need to have a more nuanced understanding of the process. Al is great, but it is a gateway into people and the things I want to do with them

353. There was this book and when my friend read it he said, this book is describing how you do things - we always started with the positive in the meeting with the kids and the adults

354. In our country we have a great tradition for influence on our own job and this sort of openness makes us more productive

355. I get energized when I go to meetings or conferences but in between the energy is very low

356. I have worked like this my whole life... When I think about things, I turn to academic communities...It (Al and strength-based) opened up things that was hard to talk about 
357. Strength-based is not another checklist; it is a way of being in the world

358. I see more the relational between the importance of the other. I have always had that. But now I have a community that this is important too, therefore my ability to do that has been enriched.

359. That is very powerful... So that is what makes community so important... I practice situated in life all my wisdom come from living, this moment and the next moment...

360. Just the fact that communities do exist make a difference, let's look on individuals like ourselves...It is not the community that will make the different

361. The community is a platform so to speak, it is an arena, to action in a sudden way... and then people have the opportunity to take action, from that platform

362. I think it is the positivity that works, we had a hundred hour long learning program for all the managers in the department

363. All of the fun stuff can drown in all the serious things we need to address

364. We still use the tools, the positive schemes, the metaphors, the structures, the names

365. You can see it as integrated in our praxis

366. If we hire a person who is not steeped in the appreciative approach, we need to be close to him or her

367. The appreciative approach is a culture now and it is a political decision now and has been for years

368. I speak with my employees every third month in order to support their development processes

369. If we have a staff meeting and talk about negative sides of a case, I can invite them to look for star moments in the next week - this is to turn the perspective, to have something else in focus

370. I am always curious and want to learn more and now we are working on a new project and I get very excited very easy

371. I used Ken Gergen's theory I am going to take this seriously, but there is part of this story I am not going to buy into... Okay I am going to do this, I am in an Al bootcamp, and I am going to be a ninja

372. I am very proud I am a part of that, it is a nice feeling...We did it together...I know now that I am on my best when we work together, I am not good on my own...

373. We are going to do it for the first time. My job and your job is to create a space, a safe space, it is okay to fail here...I am very conscious about that... we most play to win, that is your birthright...our highest self...

374. I would absolutely flip if an American president would mention Al...I would like to see the power of a national leader talk about Al...

375. Someone with influence mentioning $\mathrm{Al}$ and how they used it Al, I would love it...a part of pop culture, I mean even the Kardashians

376. I have a boss who is very appreciating and wants everything to work this way, because this is where you get your support

377. Professional developments are so key, recently we took a course on movement because that was really needed for my employees

378. I am getting better in acknowledging others - earlier on I could think great things about the employees but now I say it out loud

379. If something is not working, then we get help from qualified supervisors

380. Trust is very important, and is built because we know each other privately as well

381. As a manager you need to be able to fire a person and to know how to do it in the best way

382. There is a positive intention in everything

383. Professional love basically means that you treat the kid in a different way which causes the self-worth to raise

384. I have been inspired by positive psychology since the $90 \mathrm{~s}$

385. When it works it creates a calm atmosphere and a feeling of success for everyone

386. In the beginning we thought that appreciation is THE way to approach human development but after a while we learned that of course there needs to be space left for trials and mistakes

387. New learning creates new people, it takes courage to learn, to implement new knowledge

388. You know Obama talks about the obesity of hope

389. Cooperation and trust is a better business model

390. The energy is totally out after a conference and there is an emptiness

391. In this project it became a full-scale test lounge

392. Open space and emotional intelligence is some of the things very important in my opinion

393. I live Al, I never heard of it before. We are now having a good time and we get great results in the project

394. It was so exciting to exceed our own expectations, it was crazy

395. At that moment we just said - let us go do it now 
396. It is very simple, we just did the dream. With trial and error and one guy said It swept away all my methods

397. We kept dropping the exercise that they did not get excited about and did more of the fun stuff

398. This just wasn't about me

399. It just blows my mind that it is so simple, it can be really spiritual but it is really just about doing it

400. Our whole Western culture is founded in problem solving, but we can get out of that, that critical thinking

401. Everyone can do it - it is powerful, it is magic, and so simple

402. Humor is a great thing and I felt a lightness after that

403. Our son was sick, and we found a doctor who was outside the box, a creative doctor and he got healed by being in nature - in the natural world

404. It was mind blowing and a life change, I fell in love and started a family - like quantum change? It was like that

405. All I needed was to trust in the process, it is a question about faith and attitude

406. The whole of life is learning and you can't remember who you were

407. My own competencies reached farther than I thought

408. When you have kids you learn, we are only amateurs, we need to have the courage to be able to mirror ourselves and belief that we can make it even better - to know more

409. There are a lot of approaches and none are wrong

410. Challenge instead of just confirming because this leads to not-knowing

411. It is crucial to stay humble when you are working with human beings

412. Humor is a key ingredient

413. It is a question about being curious with each other's practical approaches, to become a better version of yourself and everyone has positive intentions

414. There needs to be the possibility to ventilate and to recognize that as an adult you can feel powerless and there needs to be a space where you can pause, acknowledge one's own limits

415. You are allowed to try out, and you can fail and that is okay

416. There needs to be a pedagogical backdoor, a possibility for you to withdrawn and regain strengths and your emotional state

417. There is always another story you can tell in a situation

418. We get influenced by what is happening in the news - you cannot miss the news, e.g. Trump, terror, refuges, environment worries - I say get rid of the noise

419. I spent eleven days in a silent retreat, just emptying the mind, it was very refreshing and I was surprised that the world just continued

420. I work with questions like tell me the best story of yourself, tell me the story in the purest firm - getting into the core and you cannot get there with all the noise

421. Everything is faster and faster - what used to be three days training is now a half day training, our world is going faster and faster, numbers of emails, Facebook, Linkedin

422. I saw a line on Linkedin saying "I have coached 2000 people" - yes but how was the quality of that?

423. We are creating a world of fastness

424. No, it is wise to take the time to converse, take the time, slow down - an organic pace

425. A manager's finest task today is to get the employees to slow down

426. You used to be adult when you were thirty - today you are eighteen and adult

427. Things have their own pace, trees grow in a certain pace, you cannot push

428. Staying with the right pace, it is a challenge

429. Organic growth is the pace of human development - to have space, to be in flow

430. I need balance, I need to be aware of my own ability - to honor my pauses, sometimes I walk

431. It is the awareness - to take time for yourself, for family and friends - it is dynamic elements and you need to be able to understand the dynamics

432. It is a choice and it is to take responsibility for your own life

433. Take us back to the origin of who we are

434. We are energy - we have taken a certain shape and form

435. Hopeful energy - your energy and thoughts will live on

436. Humans have eternal structure

437. Balance is a feeling, it is a notion, but you never reach it 
438. The outside world will always and constantly pressure and keeps going - it is easy to go where there is most pressure, because the strongest energy always wins

439. But thinking about this pace, I find healing to be a way out, to take care of what's happening in my life

440. The is a constant need for balance

441. Tension is the opposite of play

442. It is creating the space for rest and setting the right priorities

443. We need to deconstruct to know what is a body and what is a soul

444. Humans are the energy channel between the Earth and heaven - between the sky and the planet. We are where the energy flows through

445. Energy is so exciting and to learn about that and reflect on how it affects my life, like wavelengths and light and when it is something we do not know what is, we call it energy

446. Back when big bang happened there was nothing.. no time, no space

447. What is the soul of the appreciative leader?

448. I meditate to become empty

449. there are a growing number of emails

450. It is about balance. to function well, slow down, I love dancing

451. Dancing is all about timing - you cannot dance faster than the music

452. The speed of nature is organic, you need to be able to listen to the music to follow it, pick the apple when it is right

453. The rhythm is crucial

454. Humans, we are connections, between heaven and Earth - we are the pipeline that needs to be clear in order for the streaming to happen

455. We are part of the whole system

456. If only the head works, the brain, the neo-cortex and the rest does not work - that is no good

457. The chakras need to be in line, that is old ancient wisdom - the energy points of the body, in our system

458. We need to be aligned to be in flow

459. To be in flow is to be happy, excited, feel joy

460. To listen and to embrace the context

461. In dancing it depends on which type of dance, if we use that metaphor, move with the music and the floor, e.g. tango

462. In Al stories the eyes lit up

463. You can feel that in the whole system from the toes to your mouth

464. In Buddhism you would say step away from anger and longing

465. Organic processes are about finding joy in meetings with another soul

466. Dance - starts and endings

467. Al is about how and what type of stories we feel and share

468. Being is about flow - to what extend we are following

469. Awe capable of being ourselves in our purest form like a young child?

470. Not to lose the ability to be who we really are

471. the appreciative way - the society

472. To be the best version of yourself, listening deep within, speaking from within, with freedom, with courage

473. Listening to the whole inner system, honoring that with respect for the other

474. People being kind loving, have authenticity, purity

475. Being $\mathrm{Al}$ - the meaning of the principles, living them - like saints - being it for real

476. To really feel, sensing the feelings

477. Healing can be simple or complex - a wound will heal naturally

478. There can be different healing - healing in the energetic field

479. Healing has to take place because we are off balance

480. To be grateful is a sort of healing

481. In 2009 I needed to see the doctor and get medicine and he said, let us look at your life and your habits, like coffee, outside pressure, too much licorice, diet habits, what makes your life stressful - we talked about play

482. I guess I am sensitive

483. I now play every day, I have a mini train from my childhood, it helps me to be playing and present

484. That play is a sort of healing 
485. To allow the child to be there

486. The healing is in listening to myself - it is me

487. You have to be able to listen to yourself

488. Trust is to be with what there is

489. Keep your mirror as clean as possible

490. My voice heals

491. Endings are an illusion

492. The energy we put into things - it is like we think we can push

493. If we appreciate e.g. this table but without identifying with it

494. Flow happens if we do not attach to things - just flow with it

495. We did our project and it helped bringing people together, they were connecting, and building skills

496. We all wanted to learn more about Al and strength-based management, we had high curiosity and high energy

497. Fireworks were part of that $-\mathrm{Al}$ as a coaching approach towards people outside the labor market - to find their strengths and follow their dreams

498. It sparked an interest, we wanted to develop our own, we did not want to copy

499. We applied for the EU funding and got a big funding

500. 5000 people were involved, it was spreading - together we are able to make a big shift, a movement

501. I want you to be in this conversation with you and your high heels! When you know you can create the worlds together, don't create awkward situations

502. Spirit is not the language we use - it is about the tribe - speak the language of the client

503. Establish interpersonal connectedness - goes together with the outcome

504. Understanding your life history and the present place in time and one's own strengths and how you want to make a difference

505. There was gratitude to be able to do these kinds of projects - because this is just the coolest thing you can use your time on

506. It is about letting go and then trust emergence --because it pops up again

507. How does this resonate with your own life?

508. It was like playing with good friends, like the inner circle - a gift --giving form to what was important in my life

509. The intention never was to keep going, it just happened

510. We decided to close down, but it re-birthed

511. How do you connect different people in a mutual desired vision?

512. We were wondering if we could make this sustainable

513. The feelings in the room were wonder, surprise, involvement, hope, being touched by many people and rapid connections and these connections are possible because of this process

514. How can you scale up that what is emerging - and when scaling up - what does the world need?

515. In the process we find each other, ask what is good for the world and the questions that matter for the participants and society

516. The approach of making the world a better place

517. We wanted to help them see, feel, experience that they are not alone in this search for a better world

518. It is about meeting people and very quickly feel close connection and share desires and aspirations

519. The speed of the connectedness within this group was amazing

520. Connection on a deeper level, understanding each other

521. Not only to get to know the story but also the soul, the spirit

522. Empowerment and feeling wow we are capable of doing things we thought were impossible, it is like magic

523. They are connected on longings - in Al they find a language, a perspective and later on methodology

524. The energy is important, not only talk about the "outside" projects but also the insides - the values, the beliefs, a deeper interhuman connectedness

525. Wanting to show up deep in conversations and relations - invitations to the other to show up deep

526. A reality to explore and inquire into

527. We do not used the language of spirit - I would say interconnectedness

528. Stories are so important in life, it is through stories we understand ourselves, we share vows and how we bring about change, when people tell their story they change immediately

529. We are powerful, together we can do more

530. Empowering is when they realize they have something they did not know

531. Most NGOs still focus on problems, with sophisticated tools 
532. Why are Al people still a minority? Why don't Al people lead the world? It is a product of negative thinking. Al is just too easy, I guess

533. The problem, the blame, because our whole culture are so rooted in problem solving --we learn it in school

534. The positive opposite - when nobody looked at the things that did succeed

535. Positive attitude - a unique force that can solve big problems

536. I guess I have been really fortunate in my life, it is only a question about realizing it and notice it as amazing things, as for example we have a summer house

537. It is key to not take it lightly, be grateful for it everyday

538. The process of life just unfolds if you follow, with ease it is organic

539. You can't emotionally prepare for somebody you love dying

540. We buried the cat and embraced the feelings, listening, and it was okay to be sad, we tried to contain the feelings, it was easier when sharing

541. It is about allow the other - an Al practitioner would enhance it in the other, make them shine and raise

542. An avenue to grow in your way and to spark something in each other to way stuff

543. Tis like an Al life - finding the best lifegiving forces, dream stages, being with people

544. It is about personal things, there is a huge energy, strong, easy, effective, makes others shine

545. The attention is there, and the intention is crystal clear - it is purposeful and effortless

546. It takes patience, listening, articulating words really, talking and pause - and just being

547. Organic growth is growing within and growing without - affecting yourself and others - like melting, joining together, being true

548. Carrying out a feeling of being true, of reacting honestly, really being true - like with kids, and your own children, meeting them, cherishing and appreciating each other

549. Having joyful experiences, learning about stuff, respecting each other, having fun, times of sparking

550. This is like art processes, organic design, follow the flow, join it in, make it flow - it grows out of something and into something

551. It is expanding and adding bubbles

552. that true connection to other people that is organic, that is love - and wanting to spend time together

553. Love is interconnection, it can be overwhelming, but it is joy with each other, the easy way, like kindness, compassion, honoring the other

554. It seems easy for love - my upbringing really made me feel safe, I am grateful I had an embracing family, it was a gift, now I pass it on - these things should not be taken for granted

555. Through joining a continual path, flow and ease happened, switch other to epic moments

556. There are things we can't avoid - listen to them, not fix them - flow can be hard to see

557. Look more carefully for flow - it is hard to stay at easy throughout so take a pause, what will help, having a take out

558. At least when you grow there will be challenges and obstacles - I have had challenging relationships in my family, I have been giving in on myself, trying to be more flexible

559. Lighten it up, loosen up - allowing it to go in another way - not directing it

560. Not controlling, but giving to it - let it happen, listen to it

561. I am intuitive and sometimes I may not feel confident or feel I have the right ability when creating I can be stuck in fear like I am not good enough - and stuck in that realm and that does not help the flow, so instead I allow that to happen and invite it in - it occurs to me that I think I want the outcome to look good when I really seeks a rich and enjoyable process

562. Sometimes we have to realize that we are different and let go of control - and take a loving approach because goodness is wanted and by allowing a different way it may become richer - it depends on openness and closeness

563. It is important to keep working toward that mindshift

564. Guidelines could be: let go of a relation that do not give energy

565. It is about being aware, being attuned, being awaked with the surroundings, with feelings and allowing mistakes, explore without fear

566. It is non-forcing and realizing how it is going anyway, observing it

567. You can learn it. You can learn to keep working towards that mindshift, with pause and patience

568. You need to soften up and move energy toward it - kids come to it easily

569. Situations can either help it or hurt it - organic growth. Hurtful times can still be organic and help us grow - it depends on how we look back at it and how we move on

570. Parents can have a negative effect on us - we need to focus on what is important and let go of the relation if it is not a match

571. Everyone organically grows in their own path... it is about timing and connection 
572. We often have a dialogue about the employees' development and talk about their strengths and what they think can help them and they have mentoring on positive communication

573. Al has had most impact on me on a personal level

574. Fun, positive emotions, the art of the question, and the we-feeling, the belonging

575. But it is a question about readiness, depending on which of these countries are ready to get involved in initiatives like this

576. There is a kind of urgency to this and to that global consciousness

577. Luck is something we create - there is no such thing as synchronicity but we can feel like it because we are ignorant to the laws of the universe

578. It may seem magical but this is really intended, because we create our own experiences

579. It is about who you are and what you want - you need to take a decision, then act and then you can see the result

580. You have to get out of the comfort zone and that always makes me tired but I allow myself to get feedback and then adjust till I understand the new system

581. I am basically a perfectionist and an aesthetics

582. It is all about adjustment, to make adjustments when we have feedback

583. What do I want to create? I want to play, to have a good time, honor and fulfill my longings, I want to travel, to have somebody to clean my house, I want to surround myself with beautiful stuff

584. I dream about taking money out of the equation, having this huge bank and to be able to hold that freedom and joy that comes from no worries

585. It is mostly women I work with and there is a difference between a forced way of developing and a more organic way - in the forced they feel wrong, they expose the joy and the meaning with their life

586. to grow is never the purpose - happiness is the purpose of life... for all I think

587. If they degenerate they have the focus in the wrong place - it is always supposed to be fun and enjoyable

588. Research is bullshit - it is just something that we have created in this world

589. Everything that do not nourish us - is a great reminder to heal - that is smart

590. The transformation happens in the cells of the body - that is healing

591. Nourishment is so important - to take positive choices, it is juicy, that helps me to growth, it is building up

592. trust is crucial --I have always been selfconfident, but we need to believe in ourselves and believe in the universe

593. If you are away from your passion and your essence it creates mistrust, fear, impatience and resistance - many have that when they turn forty, a crisis, loss of hope

594. Contrasts are happening and then you lose faith in that everything is good and alright

595. It is like an ecosystem, a synergy

596. Intuition is the language of the soul - you get input from your feelings

597. You need to know yourself, your intuitive messages and then it depends on you, if you take action or not

598. there are the consciousness and then the sub consciousness - if something pops up and it hinders your being and your action and you feel like soothes the pain then you may be ready to heal

599. It is not nourishing to have a low consciousness - we need to take $100 \%$ responsibility and not be a victim

600. Our actions have consequences and if we act from a high frequency of energy, our actions are aligned with happiness

601 . We are made up of our physical part, then the mental brain, thinking, ego part and then the consciousness - the spiritual awareness - but if all says what I think is true, then we have war. if everyone could accept that others have other truths there are no real reasons for war besides our ego and low consciousness

602 . When you are happy you grow automatically - growing is a side-effect to happiness

603. It is about flow and taking choices that nourishes you and then there are new inputs which creates new growth

604. Happiness is the language of the soul

605. The opposite of this kind of growing is forcing - but here you lean in. into wholeness, healing and trust

606. Humans get born perfect and whole but then we become externally controlled, learning from our parents not to listen to our inner voice

607. Trauma puts traces in the heart, but these can be healed 


\subsection{Thirty-six competencies of Al practitioners}

The following list of thirty-six competencies sorted into four main code categories was found as a result of Newhard's doctoral dissertation study (Newhard, 2010, p. 180-212).

1. Personal competencies

- Open mind;

- Critical-thinking lifelong learner, driven by curiosity;

- Courageous and willing to take risks to varying degrees;

- Comfortable with ambiguity;

- Hopeful and optimistic, seeks the light;

- Self-aware and self-confident;

- Dynamic leadership balanced with the reflective thoughtfulness, humility and no ego;

- Innovative and creative;

- Quick and good at improvising;

- High ideals comprised of integrity, authenticity, sincerity and honesty;

- Strategic thinker with a thorough, organized follow-through;

- Appropriate sense of humor or playful, joyful and exuberant.

2. Interpersonal competencies

- Appreciative listening;

- Great teacher;

- Instills trust;

- Treasures others;

- Needs to be helpful;

- Collaborative, creates community, connections and inclusivity;

- Holds others accountable;

- Gives away the show;

- Affirming, great mentor and confidence-inspiring coach.

3. Business acumen

- Facilitation skills;

- Appreciative listening and reframing;

- Asking meaningful questions;

- Effective synthesizer of large amounts of information;

- Firm grasp of traditional OD models, process and history;

- Results driven to achieve client's goal and to demonstrate the success of Al;

- Good at designing initiatives;

- Experienced consultant grounded in theory and practice;

- Identifies client's core values, industry, and culture and speak their language. 
4. Subject matter expertise (appreciative inquiry)

- Innate or adopted resonance with Al;

- Being/living Al;

- Comprehensive belief in $\mathrm{Al}$;

- Teaches, studies and understands theory, philosophy and history of Al;

- Commitment to advancing Al scholarship, practice and use;

- Strengths-focused/ "the positive core". 


\subsection{Evaluative reflections on the use of the method}

The following text will serve as a comment on the author's experiences while learning and using grounded theory. I used grounded theory in my Masters' thesis in a less rigorous fashion. I attended a seminar with Glaser, which helped by pointing out that I had not gone into the field with questions that were open enough. Looking back at the process, my participation in the field from 2013-2016 was open-minded, but when I continued interviewing in the spring of 2017, I could have been more open to what was on the participants' minds. When I do a research project from a grounded theory approach again, I will probably choose a population I did not know beforehand, and I will be sure to enter the field with open questions like "What's up?"

\section{The resonance of the core category}

After the core category of "organic growth" emerged, every interviewee was presented with the concept. It resonated for everyone and many found it to be "common sense". One analysis workshop participant said, "Well, organic growth, is that your concept - or did some scientific author create that?" Glaser says that if the created grounded theory is strong, it resonates within the main population and it feels like common sense to them (Glaser 1978, 1998).

\section{What is grounded theory from a wider perspective?}

It is about seeing what a group of people are full of, are aware of, what is important to them as the main subject in their everyday work-life, and then coming back with new words and language addressing these subjects in a coherent and meaningful way. In comparing this to a micro-system level, I was thinking about different kinds of coaching, mentoring, guidance, therapy or psychological conversations. The single person has a voice to speak about what is in their heart, to describe what is important to them. And then, in dialogue with a partner, this theme develops, with new words, language, insights and hopefully resonates better or enters the person's being, right down to a cellular level.

Grounded theory can, in this perspective, be seen as a sort of "helping" method. Earlier on I would have seen that as faux pas, that science was not about helping, but about showing correctly what is. That is still an important task in areas studying the physical world.

\section{Was this study co-creative?}

This study could have been created through even more co-creating with the group and invited practitioners to engage in several of the research phases, for example to write narratives to use in the analysis, to help co-create a shared vision, to decide how to create data, to help analyze data to a greater extent or to write some of the parts up together. I did try to let the practitioners speak about what was on their mind and to let the research study be about that instead of my own primary curiosities. Further questions could be asked: Did I act as a social change agent? Did the study create social change?

Cooperrider and Srivastva (1987) argue that one should not underestimate the power of a good theory, which leaves me with the hope that the theory of organic growth resonates within the 
population and has the possibility of creating social change by constructing the possibility of becoming more balanced and organic instead of forced and stressful.

\section{Whose voices are missing?}

Some of the voices absent from this study are the people around the Al practitioners, like family, friends, colleagues and customers, as well as managers, employees and students. In the most critical perspective, these interviewees could say to me that they work and live from a relational orientation, are very authentic, have a high integrity, a high trust in other people and in the world and still be very egoistic and ego-driven in their lives - something we might have heard if people around them had been interviewed. Having attended conferences and courses in the field of appreciative inquiry since 2008 , I have found that interviews match the observations. It would have strengthened the inquiry to give voice to some of the people close to the Al practitioners, though.

\section{On biases in Western social science}

WEIRD is a name used for the biased samples that often characterize Western social research studies and it stands for Western, educated, industrialized, rich and democratic samples.

Running through the details of the interviewees, it is clear that this is present in this set of data, and that voices outside this category are limited. Inviting a greater number of people outside these categories may have created enriched perspectives.

\section{The criteria of utility}

One criterion for this approach to research is utility: "If research cannot prove what is universally true, of what use is it? The constructionist claims that the utility of research is in the array of action potentials it creates in conjunction with the reflexive critique into which it invites participants" (McNamee, 2010, p. 12).

In relation to the grounded theory community, I have tried to create a grounded theory that meets Glaser's four criteria and focused this study on the practitioner's main concern as is prescribed in grounded theory.

In regard to the Al community I have tried to meet the "criteria" of being open and daring to ask generative questions and to create a theory that I found matched the interviewees' interests and reflections and growth processes in the best way possible - a theory suggesting social change for the future.

In relation to the social constructionist community, I have tried to ask critical questions throughout the study of different constructions and discourses that seemed to be taken for granted. I have both tried to stay true to the principles of social constructionism and reflective pragmatism, but also to challenge the assumptions within this realm as well as add my own comments to this metatheory. As well, I have tried to invite participants into the research to give them a voice and I have reserved space in the dissertation for my own voice to enter the dialogue and let my values and thoughts be visible instead of tacit, so that the reader has the possibility of going into dialogue with those perspectives. 


\section{Anonymizing interviewees}

One interviewee decided to make a podcast episode out of an interview, and that represented a potential problem because anonymity for the interviewees was a key principle for the study. One point of view can be that I should have held firm in that position and said no to the suggestion of creating a podcast episode. There are some comments to consider in that case. One is that by studying Al practitioners as a population, I learned how important authenticity, transparency and honesty are for them, as well as wholeness and alignment. The primary argument for anonymizing interviewees is that one can never know what will happen with the statements and information over time when it is published publicly. This practitioner trusted that no one would do any harm with the statements. Instead, this practitioner and others showed that they trusted further use of the work and that they knew that opinions, circumstances, populations and people could and will change. They were not afraid of giving voice to a statement that might change in the future.

A second point in that case might be that the topic they speak about is perhaps private - personal growth - but they do not speak from a position tied to their ego. They often speak in positive or constructive language, where they do not harm themselves or the other. One interviewee did want to ensure anonymity, and that helped keep to the decision about anonymizing all of the voices.

A third comment is to point to the fact that the interviewee chose to create a podcast and therefore reveal her role in this sample. That might not be a fair argument because traditionally the researcher could not let the interviewee decide that for themselves - the researcher was supposed to take full responsibility for taking care of her interviewees and therefore protect them by hiding their identity. This population is operating from another consciousness arena and therefore it would not be a sign to them of empowerment or equality, if I had said no to that idea. It might have signaled a position of researcher-as-expert or as an individual with superior knowledge instead of trusting that she had the power and responsibility to take actions that nourished her on an informed basis. This is an important discussion around traditional academic values and new arenas of consciousness that can make way for new ways of approaching future studies.

A fourth comment is about the broadcasting, spreading and use of the reflections from this study as well as the interactive element characterizing this study. If I listen to the podcast I can hear my own thought process around the notion of relational and human energy and, after the interview, the interviewee found four or five interesting articles around that subject that I could use in my research. That is a brilliant example of very concrete co-creation and it provides a direct look into the conversation and shared construction on the next important concept and how to define it. This can serve as an example of how many of the subcategories emerged and were unfolded in the interviews and therefore it provides an open insight into a key part of the research process. Readers within Al communities will often know the practitioner, which may not be the case for readers outside. A final comment is that in my next research project I will probably invite people into open interviews and create podcast episodes out of all of the interviews, as in McQuaid's (2019) PhD research project, in order to make the data production even more open and the conversations available to everyone. I find that approach belongs to future-forming research.

The people representing this population are not only themselves eager to be authentic but also expect those who they meet to be as well. Reviewing a note I took, it says: "It is like they will not 
settle with anything less than people being real and being honest. It is like they are the future interviewees. They require to be met with appreciative question and authenticity and a researcher that has her values up front and that they expect the research to co-create the future. They are not interested in participating in research if it does not have these ingredients." They find that no meeting is neutral and that it always affects them and therefore expect an interview that lifts up their vibration.

\section{Autobiography}

Why was autobiography not chosen as a method? Many of the points made in the "researcher's voice," I guess, could be seen as an autobiographical approach. The answer to that is simple. I wanted to create new theory. I find theory-building uplifting, important, lifegiving, crucial for the population and fun to work with. Could grounded theory and autobiography have been combined? Probably. But I wanted to keep it as simple as possible and I wanted to put all the effort into grounded theory. I wanted to go deep, to understand in-depth and to follow a systematic approach to a wide extend.

\section{The researcher's voice sections}

The researcher's voice sections were put in to meet the invitation from Gergen to "put the researcher's values in front" (Gergen, 2015). In the theory-building approach of grounded theory the researcher herself becomes an instrument. And one way to gain knowledge about how this "instrument" works is to open the machine room, to know what she thinks during the process and of the process. That way the reader might better understand how the interaction between the voices in the data and the researcher's voice has resulted in the specific theory being laid out. It was made to create transparency, honesty, clarity and insight into sometimes chaotic thought processes.

A critical comment towards the researcher's voice section is that is has no methodological basis, apart from Gergen's suggestion to put the researcher's values up front. Taking, for example, an autobiographical approach towards this might have ensured a ground and a frame for this perspective. 


\subsection{What has the researcher learned?}

The researcher has learned many important things, including the following reflections:

- The researcher has learned a great deal about communities of practices, appreciative inquiry and some things about quantum physics.

- She has gained experience in the use of grounded theory.

- She has learned what it is like to work alone, and she finds it absurd to create a research project in a relational theoretical field and then be alone most of the time.

- She has learned that she is a highly sensitive researcher with the benefits and challenges this brings to a project, and that instead of disregarding her sensitivity towards emotions and atmosphere, she can use that skill actively to be guided by.

- She has learned how much control and predictability still rules academia and how important it is to be able to communicate in the correct and clear manner in order to be heard and accepted into academia.

Consider some of the major criteria of excellence in scholarly writing, called verbal economy, logical coherence, clarity, dispassionate demeanor, comprehensiveness, and certainty. Such criteria can all be derived from a modernist construction of ideal reasoning. This tradition places a heavy burden on the individual scholar. To step outside the accepted practices of writing is to risk being labeled a second-rate mind. (Gergen, 2009, p. 331)

- The quote above precisely articulates how the researcher felt.

- She has learned that she is able to live with a great deal of uncertainty and confusion and still be disciplined enough to carry on the work. In relation to that, she has learned that she has perseverance and is able to endure challenging periods when working towards a higher purpose is part of her essence.

- The researcher has tried to work organically and to follow the theory herself by taking breaks, following flow, trusting to a great degree, practicing a mothering voice towards herself and being aware of energy in and around her. This has resulted in a lower tolerance towards negative emotions and thought patterns (Divine Intolerance, Kelly, 2018), which means that she has often focused on being in flow before going back to write or edit, when she experienced emotions out of flow. 


\subsection{Critical perspectives}

The following section is devoted to the unfolding of critical perspectives of the scientific area of positive change to which Al belongs. The purpose of this appendix is to ensure the possibility of seeing Al through an alternative lens and it invites voices of reflection and clarification on the field of positive change. Starting with an introduction to the concept of critique, the section goes on to present critique on positive change chosen as the object of this study, with a specific focus on $\mathrm{Al}$, and includes related comments on different types of critique.

\subsubsection{The concept of critique}

Critique has been theoretically treated by the "Frankfurt School", which was founded by Horkheimer, Adorno and Marcuse, as their shared work gained the status of being one coherent theoretical movement, publishing the journal Zeitschrift für Sozialforschung (Horkheimer (Ed.), 1932-1941). Today there are many critical theories, not limited to the Frankfurt School (Willig, 2007 , p. 7) and the main shared focus of these theories is to give proper critique to modern societies and to discuss whether, how and under which conditions critique is possible. The Frankfurt School was founded in the mid-war years in Europe in the University of Frankfurt am Main and the researchers shared the common critique that theories about societies did not adequately succeed in describing societies in the climate of a world war. Horkheimer defines a critical theory as a theory seeking to "liberate human beings from the circumstances that enslave them" (Horkheimer, 1982, p. 244).

Critical theory is also a key foundation in the development of the meta-theoretical approach of social constructionism, as mentioned in Chapter 8.3. The next section will look at how a new concept or theory might be criticized and shaped through the first years after emergence, which can be relevant for the new concepts presented in this study.

\subsubsection{The validity police}

In a keynote at the Canadian positive psychology conference in 2016, a professor at University of Michigan, Kim S. Cameron, addressed several forms of critique of positive psychology. With inspiration from the article "Umbrella Advocates Versus Validity Police: A Life-Cycle Model" (Hirsch and Levin, 1999), he described seven steps of a journey which a new concept or a framework can go through, when it is introduced;

1. A new framework or perspective is introduced, e.g. "a focus on the positive".

2. The new perspective resonates broadly because it sheds lights upon important issues not previously addressed.

3. The "validity police" challenge the new perspective and its validity.

4. Critique emerges, usually focusing on specific research findings and concepts, and distinctive aspects of the new perspective.

5. Some aspects do not stand up in the face of close scrutiny and fall away.

6. Sometimes the whole perspective or framework is abandoned and collapses.

7. If the perspective stands, it becomes stronger and has the possibility of becoming more institutionalized and expanding in impact and influence. 
This overview provides an understanding for the development of a scientific field that is common for development in all scientific fields, where a theory or a concept goes through certain phases in order to be recognized. Comparing the field of Al that was originally born in the discipline of organizational development, this research field is younger than most social sciences. As for positive psychology, it is said to have started in 1998 by the speech of Martin Seligman, but psychology as a modern research field began in 1890 with William James' definition. Both Al and other fields of positive change are in that sense young. And Al was not received without critique in the first years.

\subsubsection{Critique of the field of positive change}

As in every other scientific field, the field of positive change has been criticized from different positions and the theories have been questioned. It is important for this presentation to show the awareness of the voices critical of the field of positive change in order to present a nuanced look at the field. Before presenting the details, a quote from Theodore Roosevelt (Brown, 2015) follows:

It is not the critic who counts; not the man who points out how the strong man stumbles, or where the doer of deeds could have done them better. The credit belongs to the man who is actually in the arena, whose face is marred by dust and sweat and blood; who strives valiantly; who errs, who comes short again and again, because there is no effort without error and shortcoming; but who does actually strive to do the deeds; who knows great enthusiasms, the great devotions; who spends himself in a worthy cause; who at the best knows in the end the triumph of high achievement, and who at the worst, if he fails, at least fails while daring greatly. (Speech by Roosevelt in Paris, April 23, 1910)

In agreement with this, a critique needs to be respectful, constructive, open and relevant to the case, not personal. In an ideal world, constructive critique creates developments to make fields unfold in enriched ways. In the following is listed a review of the critical stances within the fields of positive change represented here. It is crucial that the field of positive change is being criticized and challenged because it means that the subject is being taken seriously and conversations are being held.

\subsubsection{Different types of critique}

It is important to know a bit more about what kind of critique we are talking about to gain an understanding of where the critique is coming from, what the motivation is for the critical voices, which part of the voices is important and qualified to be taken into account, and which to leave out. Danish PhD researcher and positive psychologist Ebbe Lavendt distinguishes three elements; 1. critiques that hit the target of the subject in question and those that do not hit the target, 2. critiques that hit the target of a topic of previous research and 3. critiques that hit the target on an important issue relevant to that currently being addressed. The following is inspired by Lavendt's thoughts about critique created within the field of positive psychology (Lecture by PhD researcher Ebbe Lavendt, Århus University, October 2012). The points relevant for Al are: 


\subsubsection{Critiques that miss the target}

- Confusion regarding areas of research: In the case of a critique that has not hit the target, Lavendt points to shadings within the understanding of the different theoretical approaches. There is often a blend between the different approaches to positive change, where people seem to mix up positive psychology, positive thinking, appreciative inquiry, positive organizational development, strengths-based approaches and others related to this field. The critique needs to be specific, the person analyzing the feedback needs to be aware of the distinctions between the fields, their histories and their research approaches as well as their basic assumptions.

- Concept inflation: Popular ideas from research are often used in many different settings and can undergo a process where the concept is overused. It can lose meaning because too many use it in different settings, which means it no longer has a shared understanding, as for example the concepts of coaching and innovation. In Denmark these terms have been widely used in research, applied practices, media and common language, and therefore have lost meaning. But to criticize a theory because a term used within it has experienced inflation would also be to miss the target if that is the only negative argument.

- Misuse: Lavendt emphasizes the fact that every theory and method can be misused and that it is the users' responsibility to use it correctly, to get the right training and carry out an ethical and morally respectful practice. If a theory or method is misused, there is not necessarily something wrong with the theory or method. That being said, he points to the fact that some theories or methods are more easily misused (he gives the example of the work of Niels Bohr that was used to create the first atomic bomb). Lavendt makes it clear that the researcher or originator has an ethical co-responsibility to ensure that the methods are practiced in useful ways.

- Dogma: A dogma is a form of knowledge that is claimed to be real without arguing or providing evidence. Lavendt emphasizes the clear contrast from a dogma to science, characterized by arguments, explanations and evidence for the proof of a certain belief or phenomenon. He points to the fact that several positive-change approaches are practiced in dogmatic ways and are therefore not connected to science. In positive psychology, Seligman calls this "blinded by ideology". If studying the scientific field of Al, one finds a wealth of arguments, case stories, research studies and evidence documenting processes and results (e.g. Baker \& Wright, 2005; Barros \& Cooperrider, 2000; Bushe, 2001; Cooperrider, 2017; Ludema \& Barrett, 2008). If people pull out the 4D model to use without knowing the basic assumptions of $\mathrm{Al}$, it can end up looking dogmatic in a practical setting. But that does not mean that the evidence for the method does not exist.

- Misunderstandings: Some critiques are created on the basis of misunderstandings, e.g. that theories about positive change are superficial and that you just have to think positively. Reading scientific articles about positive change, it is clear that this is a scientific area like every other and that the science is not superficial; it is always trying to dig deeper (Fredrickson et. al., 2000; Dweck, 2010; Seligman and Csikszentmihalyi, 2000). 
- Ignorance: Sometimes a critique is put forward without the author knowing about the field in depth. He or she might be ignorant within the specific theories about methods, models, measuring possibilities, quantitative and qualitative approaches, and how scientific results are discussed and used in societies. This can make the critique unqualified.

- Untrained experts: Within the field of positive change, people sometimes put themselves forward in the media as an "expert" in the field without having training or education or experience in that field. This can give a wrong impression to the public, and a new, unqualified critique can be born.

- Undocumented critique: Sometimes a critique has very little documentation, being based on a single case or on allegations. Lavendt points to the fact that the critique might very well be sound, though not well documented yet.

- Non-constructive: Some critiques point out what is missing and what is not working without presenting new ideas, methods, enriching perspectives or invitations to dialogue.

These are all positions of critique that Lavendt (2012) finds miss the target and therefore the author invites a focus on other types of critique that are better qualified. The following section will go deeper into the second critique, a critique that is used to hit a target on a subject, in order to present how the field of appreciative inquiry has developed and has handled the critique of elements that might have been relevant in the early days, not developed yet at that time, or not communicated clearly enough.

\subsubsection{Critique hitting the target earlier on}

- A unilateral focus on the positive: Jan Reed (Reed, 2007) states in general terms, that:

Al has been accused of being naive and idealistic in the way that it concentrates on positive experiences, which some may feel paints an unduly sanitized picture of human life. Moreover, Al has been accused of focusing on positive aspects to the extent that it can ignore or suppress accounts of negative experience. (Reed, 2007, p.39)

Reed refers to two voices responding to this critique, one is McNamee who states that "problems and weaknesses are often much easier to address when evaluation takes an appreciative stance" (McNamee, 2003, p.37). This points to the perspective that it might be easier to embrace and give voice to difficulties when the structures and atmosphere are inspired by appreciative approaches. The other voice is represented by the staff of Mountbatten Ward when using appreciative inquiry in the National Health Service in England (Baker \& Wright, 2005, p.42). They found that the organization was going through a period of change where the problems - and the solutions - were expected to come from individuals and they describe how Al overcame that tension and led to a high level of participation. Reed also states: 
The experiences of using $\mathrm{Al}$ in a number of studies suggests that interviews are negotiated not imposed, and that if people want to talk about problems, they will. Sometimes this happens because the idea of $\mathrm{Al}$ is so new to people who have lived in a culture of fault finding that it takes time for them to switch from a defensive way of responding to one that explores strengths. (Reed, 2007, p.38)

Shaw (2008) operated with a "trash can" phase in his development of Al, where the participants in Al processes had the chance to give voice to elements that did not work prior to entering a strengths-based process (Lecture by professor and Al practitioner Jody Shaw, Roskilde University, 2008). That phase invited in the voices of people who had had very bad experiences. They felt appreciated and listened to, and he found them to be more open towards creating a better future after that.

Another voice worth mentioning is the work by Barrett and Cooperrider (1990) where they tested their appreciative framework with a leading staff group from a hotel who had severe communication problems and conflicts. Having heard a little bit about their problems, Barrett and Cooperrider decided to ban the staff from speaking about their problems and after doing that for some months, as well as working with a generative metaphor and together visiting a hotel that worked very successfully, they managed to turn the atmosphere around. This points to the fact that there are good experiences from practical settings, both through inviting in the negative voices and the opposite, consciously leaving them out and replacing them with something more life-giving. Many Al practitioners would say that focusing solely on the positive is a question of perspective. And one perspective can always be exchanged for another, or it would have been called a "truth".

- Lack of rigor and transparency: One concern raised about appreciative inquiry is presented by Rogers and Fraser (2003, p. 81) who say that if $\mathrm{Al}$ is celebrated as being more effective than other change methods, then it might affect Al negatively because it might cause Al to develop without enough rigor and transparency. That is one of the reasons why a thorough section on critique is provided here, to ensure that different voices and experiences with $\mathrm{Al}$ are put forward to invite a transparent evaluation of the method. That being said, I want to remind the reader of the role of $\mathrm{Al}$ in this study: it was not the research method and not the core research object, but the defining characteristics of what is common for the practitioners in the community of practice in question.

All methods and approaches can be misunderstood and misused. But Al is perhaps more likely to be both misunderstood and misused; misunderstood because it represents a way of looking at the world that is contradictory to common Western culture and language around "problems" and therefore might require a special openness and readiness to be able to hear and fully understand the approach. And misused because of the many caring aspects of the process and "good" values, like deep listening, equal rights to contribute, being heard - which can make it easier to use for manipulation.

- Documentation: Another critique comes from Lavendt (2012), who shares the viewpoint that $\mathrm{Al}$ has gained widespread popularity but claims that the research on $\mathrm{Al}$ has not been 
able to follow through and therefore much of what is called appreciative inquiry is not fully documented. This experience was shared by Bushe when reviewing Al publications about results, and he pointed out that not much had been published in scientific journals about the results of Al processes at that time (Bushe \& Kassam, 2007). It has been twelve years since the study was published in 2007 and further attempts to document Al have been carried out, both through the work on generativity by Bushe (Bushe, 2013) as well as recent work on positive emotions by Fredrickson (Fredrickson, 2009, 2013) because theories on positive emotions tend to document what happens in Al processes. A quick search on "appreciative inquiry" on Google Scholar (January $6^{\text {th }}, 2019$ ) shows that there are 99,100 entries, which both contain scientific papers specifically working with AI and papers and books referring to the work.

- Evaluation and self-reflection: In their article "Critical evaluation of appreciative inquiry" (2006) Grant and Humphries argue that it is valuable to criticize Al in order to gain a more self-reflective approach and, in doing such an evaluation, borrow perspectives from critical theory. When mentioning critical theory, they point to the Frankfurt School and its main figures, Horkheimer, Adorno, Fromm, Marcuse and Habermas (see the beginning of this chapter), but define their use of critical theory in a broader sense as "a process aiming to produce a particular kind of knowledge that seeks to realize an emancipatory interest, specifically through critique of consciousness and ideology" (Carr, 2000 in Grant and Humphries, 2006, p. 406) and therefore includes works of French philosophers Derrida, Foucault and Lyotard.

Grant and Humphries point to the value in looking at Al and critical theory as a paradox and emphasize the strengths in a paradox: "The energy generated working with/through the paradox may manifest alternative insights that one would not have reached by ignoring the paradox or even working with just one dimension of it" (Grant \& Humphries, 2006, p. 407). They go on to discuss the idea that even though Al and critical theory seem to be opposite viewpoints because one focuses on the positive and the other pays attention to the negative, they share a common research objective about change and emancipation. Another common element is the epistemological base in social constructionism and language as a key to creating change - in the one area by breaking up language and discourses to give space for new voices to be heard and create new language, and the other to try to move beyond the common discourse and assumption of "problems-to-besolved".

The intention of the authors is to "bridge the apparent paradox" and create a shared process of Al they call Critical Appreciative Processes. They propose that some of Habermas' ideas are beneficial to Al, one being the communicative action, the other being Habermas' proposal of the ideal lifeworld: the state of equal, free, undistorted communication. They point to the fact that there is a connection to the dream phase of the 4D cycle. The third point mentioned is that Habermas' understanding of the ideal goes hand-in-hand with the understanding of the ideal in Al (Cooperrider \& Whitney, 2011). "Ideal" is understood to be inspirational, not something that is expected to be carried out fully in reality. The authors conclude that it is important to evaluate appreciative inquiry 
critically and that critical theory can serve as a strong perspective in that work once they have dusted off the key association regarding negativity and found some of the resources and common objectives.

This section has focused on 1: points of critique related to positive psychology and Al being relevant earlier but not at present, and 2: points of critique missing the target. The last part of this section on critique will focus on number 3 : points of critique still relevant today.

\subsubsection{Points of critique relevant today}

Some points of critique are crucial, especially if we take a common, Western, capitalistic approach to happiness and wellbeing. To let the individual bear the sole responsibility for his or her own wellbeing while creating workplaces with high demands are some of the factors that may cause the numbers of dysfunctional stress or burnout to rise (Willig, 2016).

An example of this "push for better and more" in the present research is the emergence of the core category, organic growth. When the core category of organic growth emerged and began to saturate there was discussion about the term and some questions were asked of the researcher in order to ignite the imagination further, for example: What are the exceptional enablers of organic growth for Al practitioners? What are organic growth-promoting experiences? What are the most powerful growth moments of your life?

After a while it became clear that these questions were related to basic assumptions of a capitalist society chasing the bigger, better and more. In this case, it would be the chasing of more organic growth. This was a paradox because the center of the meaning of organic growth is that growth happens organically, which is at a pace and in a manner that are balanced and natural: inspired by nature, not forced.

In her article "Back to Basics: A Critique of the Strengths Perspective in Social Work" (2011), Gray discusses how the strength perspective has a link to neo-liberalism, which has been criticized because it retains a strong focus on the individual and autonomous self. Kristjánson (2007) notes that there is not much evidence showing that "high self-esteem on its own produces better, more stable human beings, or that it prevents social problems. It promotes self-understanding, selfcontrol, and self-interest while contemporary multiculturalism suggests the need for a much larger common core of non-individualistic values" (Gray, 2011, p. 8). Gray raises a critical voice towards the use of the concept of individualization and Kristjánson emphasizes that there is no clear research proving that this tendency to cultivate the individual creates better human beings. In the discussion section of this thesis, a new concept of the individual was introduced called "viveunia". Introducing the term of viveunia in Chapter 7.7. shows an understanding beyond the fear of "selfinterest, self-understanding and self-control" in a way that lacks the multicultural values because for viveunia, the fears of the ego are tamed, and wholeness and purpose are common understandings which make it easier and "unavoidable" - in a positive sense - to collaborate.

In almost the opposite view, Gray introduces another perspective when she points to an uncritical adoption of community development theory. What Gray (2011) argues is that the strength 
perspective "has taken an overly optimistic view of communities as forces for good" and has forgotten the fact the communities can lead to exclusion and marginalization of some groups and voices. This critique points to the fact that it is crucial to take power structures in relationships seriously and to remember that not everyone comes from a position of freedom of speech because of inequalities such as gender, race, poverty, education, internet access etc. in the world we live in.

Following the points made by Gray, I noticed how Gray describes her critique with phrases like "statements on spirituality" as involving "honoring and getting in touch with the health and wisdom within" and states that claims that health realizations that "builds up from within rather than being imposed from without come dangerously close to neoliberal individualism" (Gray, 2011, p. 9). When researchers use a vocabulary as strong as "come dangerously close", I become curious about the researcher's values. Inspired by Gergen (2015), I would guess that Gray's intention is almost aligned with the intention of strengths-based researchers: to help and empower other people. Gray and Gergen do not share approaches: Gray's approach is mainly critical, whereas Gergen's is future forming. As much as I respect sharing critical reflections and creating space for them, my own values as a researcher are that I believe in ongoing dialogue, finding shared values and learning from each other when having opposing viewpoints. 